\title{
Politik, Religion und Markt: Die Rückkehr der Religion als Anfrage an den politisch- philosophischen Diskurs der Moderne
}

Wilhelm Guggenberger, Dietmar Regensburger, Kristina Stöckl (Hg.)

Edition Weltordnung - Religion - Gewalt 4 



\section{SERIES}

\section{Edition Weltordnung - Religion - Gewalt}

Editor-in-Chief: Wolfgang Palaver

Editorial Board:

Andreas Exenberger, Wilhelm Guggenberger, Johann Holzner, Brigitte Mazohl, Dietmar Regensburger, Alan Scott, Roman Siebenrock, Kristina Stöckl, Claudia von Werlhof

Band 4

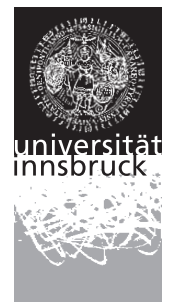


Gedruckt mit Unterstützung

der Österreichischen Forschungsgemeinschaft.

(C) innsbruck university press, 2009

Universität Innsbruck, Vizerektorat für Forschung

1. Auflage

Alle Rechte vorbehalten.

Umschlaggestaltung: Alexander Eberharter

Satz: Joseph Wang

Herstellung: Fred Steiner, Rinn

www.uibk.ac.at/iup

ISBN 978-3-902719-14-0 


\section{Politik, Religion, Markt:}

Die Rückkehr der Religion als Anfrage an den politisch-philosophischen Diskurs der Moderne

Wilhelm Guggenberger, Dietmar Regensburger,

Kristina Stöckl (Hg.)

Edition Weltordnung - Religion - Gewalt 4 



\section{Inhaltsverzeichnis}

7 Einleitung

Wilhelm Guggenberger, Dietmar Regensburger, Kristina Stöckl

\section{Historische und philosophische Grundlegungen}

19 Eurozentristischer Säkularismus und die Herausforderung der Globalisierung

José Casanova

41 Religion(en) zwischen Antimodernismus und Aggiornamento. Fundamentaltheologische Prolegomena zu ihrer „Rückkehr““ Gerhard Larcher

61 Habermas, Ratzinger und die postsäkulare Gesellschaft Walter Reese-Schäfer 


\section{Systematische Perspektiven}

89 Wiederverzauberung der Welt oder Wiederkehr des Verdrängten? Post-positivistische Perspektiven auf Religion

Frank Adloff

115 Erlebnis, Tradition, Institution: Die drei Dimensionen der Rückkehr der Religion

Kristina Stöckl

133 Offene Gesellschaft und geschlossene Gemeinschaft. Zur Kritik der kommunitaristischen Revitalisierung der Gemeinschaften Harald Stelzer

157 Gemeinschaft nach der Gemeinschaft Evert van der Zweerde

\section{Konkrete Problemfelder}

187 Die politische Diskussion um eine „Leitkultur“ als Kritik an Moderne und Säkularisierung Emil Brix

197 Freier Markt statt freie Bürger. Über die Tendenzen einer transzendenzvergessenen Gesellschaft zum Wirtschaftsliberalismus Wilhelm Guggenberger

223 Über Verwurzelung: Aktuelles ökonomisches Denken und Adam Smith Andreas Exenberger

245 Kontinuitäten und Wandel politischer Religion. Vom Kommunismus zum Politischen Islam Harald Wydra 


\section{Einleitung}

Wilhelm Guggenberger, Dietmar Regensburger, Kristina Stöckl

Dieser Band präsentiert die Ergebnisse der Fachtagung Politik, Religion, Market: Die Rückkehr der Religion als Anfrage an den politischphilosophischen Diskurs der Moderne, die vom 5. bis 7. Juni 2008 an der Universität Innsbruck stattgefunden hat. Veranstaltet wurde die Konferenz von der Arbeitsgemeinschaft Politik - Religion - Gewalt der Österreichischen Forschungsgemeinschaft und von der Innsbrucker Forschungsplattform Weltordnung - Religion - Gewalt. Die Fachtagung war bereits die dritte Veranstaltung in einer laufenden Folge von Aktivitäten, deren Ziel die interdisziplinäre Diskussion und kritische Befragung verschiedener Rahmentheorien zum Verhältnis von Politik, Religion und Gewalt vor dem Hintergrund konkreter politischer und sozialer Fragen des weltanschaulich und religiös pluralen Zusammenlebens in Europa ist. Im Jahr 2006 ging es um die Darstellung und Verarbeitung von Politik, Religion und Gewalt im Film, 2007 um das Verhältnis von Monotheismus und Gewalt in der Geschichte des Christentums und des Islam und deren jeweils spezifisches Verhältnis zur Moderne. Die Ergebnisse dieser beiden Tagungen sind bereits in Buchform zugänglich, ${ }^{1}$ und der vorliegende Band fügt dieser Serie einen weiteren Baustein hinzu. 
Im Rahmen der Fachtagung Politik, Religion, Markt diskutierten Theologen, Philosophen, Politik- und Sozialwissenschaftler über die Frage, in welchem Maße, auf welche Art und Weise und mit welchen Konsequenzen das Thema Religion in politisch-philosophische und sozialwissenschaftliche Diskussionen der Gegenwart Einzug hält. Liberale, die Tradition der Aufklärung fortsetzende soziale und politische Theorien sind bisher davon ausgegangen, dass mit fortschreitender Modernisierung der Gesellschaft eine Privatisierung oder gar ein Verschwinden von Religion einhergeht. ${ }^{2}$ Gesellschaftspolitische Entwicklungen der Gegenwart, nicht zuletzt das verstärkte Auftreten religiöser Fundamentalismen, werfen jedoch die Frage auf, ob diese Säkularisierungsthese wirklich stichhaltig ist und ob sie als konzeptuelles Instrumentarium für den Umgang mit Religion in demokratischen Gesellschaften ausreicht. ${ }^{3}$ Die Frage, der in der Fachtagung nachgegangen werden sollte, lautete: Wie reagiert der zeitgenössische politisch-philosophische Diskurs, insbesondere im Spannungsfeld zwischen liberalen und kommunitaristischen Positionen, auf die Rückkehr der Religion und welche Ansätze zum gesellschaftspolitischen Umgang mit Religion kommen darin zum Tragen? Ein besonderes Anliegen war es, eine konzeptuelle und wissenschaftstheoretisch präzise Verortung von Schlüsselbegriffen und -autoren vorzunehmen, und daneben auch praktische Fragen aufzugreifen, die sich auf die politischen und sozialen Herausforderungen einer pluralistischen Gesellschaft beziehen. Besonders bedeutsam für die Auseinandersetzung zwischen unterschiedlichen Gesellschaftsmodellen erschien das Feld der Ökonomie, deren maßgeblicher Anteil an der konkreten Ausformung der derzeit bestehenden Weltordnung wohl unbestritten ist. Im vorliegenden Band sind die Beiträge zu dieser Diskussion in überarbeiteter Fassung versammelt. Der Charakter eines Gedankenaustausches ist auch in der schriftlichen Fassung der Vorträge großteils erhalten geblieben, wie die Bezugnahme der Beiträge aufeinander und die Komplementarität bzw. Gegensätzlichkeit der vorgebrachten Argumente beweisen.

Im Titel dieser Aufsatzsammlung - Die Rückkehr der Religion als Anfrage an den politisch-philosophischen Diskurs der Moderne - stecken zwei Vorannahmen. Die erste Vorannahme besagt, dass Religion ,zurück 
kehrt", dass sie Sichtbarkeit und Relevanz in solchen Bereichen des gesellschaftlichen Zusammenlebens erhält, aus denen sie zuvor verschwunden war. Gemeint sind damit in erster Linie die Politik und das öffentliche Leben, Religion als Thema und Gegenstand der Auseinandersetzung in juristischen Diskursen, Moraldebatten und in Kunst und Kultur. ${ }^{4}$ Daneben gilt aber auch die soziologische und anthropologische Beobachtung, dass religiöse Orientierungen mit zunehmender Modernisierung von Gesellschaften keineswegs zum Verschwinden verurteilt sind. Europa, das vielfach als Modell für die Privatisierung von Religion und graduelle Abnahme von Religiosität gesehen wurde, gilt heute eher als Sonderfall denn als die Regel. ${ }^{5}$ Die Rede von einer „Rückkehr der Religion“ mag aus dieser Perspektive zwar empirisch wie theoretisch gut abgesichert erscheinen, keineswegs geklärt aber ist, was damit genau bezeichnet ist: die erstarkende Präsenz und Relevanz von institutionalisierten Religionen, die Intensivierung von individueller Glaubenssuche, eine anwachsende Bandbreite an esoterischen Heilsangeboten? Die Beiträge in diesem Band setzen sich mit dieser Frage auseinander und versuchen, das Schlagwort der „Rückkehr von Religion“ auf differenzierte Art und Weise mit Inhalten zu füllen.

Die zweite Vorannahme im Titel besteht darin, dass der politisch-philosophische Diskurs der Moderne einen unabhängigen Reflexionsraum darstellt, innerhalb dessen die Religion zur Anfrage werden kann. Was genau ist damit gemeint? Das Ziel der politischen Philosophie liegt in der Formulierung und Begründung von einer guten gesellschaftlichen Ordnung. Modern wird sie in dem Moment, in dem sie sich aus vermeintlich vor-modernen religiösen und traditionellen Bezügen löst, die ihren Inhalt bestimmen könnten. Ideengeschichtlich wird der Zeitpunkt dieser Loslösung in der Regel ins 17. bis 18. Jahrhundert verlegt, festgemacht an Schlüsselfiguren wie Thomas Hobbes oder an Schlüsselereignissen wie der Französischen Revolution. ${ }^{6}$ Als politisches Wesensmerkmal der Moderne gilt fortan, dass Autorität und Ordnung sich nicht mehr auf göttlichen Willen berufen können, dass politische und religiöse Institutionen voneinander unterschieden und Religion und Politik als getrennte Bereiche menschlicher Aktivität und Kreativität gedacht werden. Religiöse 
Glaubensüberzeugungen können im Rahmen der politischen Philosophie zum Gegenstand der Betrachtung, aber nie zum alleinig bestimmenden Inhalt werden. Der politisch-philosophische Diskurs der Moderne gilt als säkularer Diskurs. Die Existenz eines solchen säkularen, unabhängigen Bereichs menschlicher Reflexion über politische Ordnung, auf den die Religion gleichsam zutritt und für den sie zur Anfrage wird, wird in den Beiträgen in diesem Sammelband freilich verschiedentlich in Frage gestellt. Insbesondere die erste Gruppe von Aufsätzen entwirft ein differenzierteres Bild vom politisch-philosophischen Diskurs der Moderne und stellt seine Säkularität einerseits und seine Post-Säkularität andererseits zur Diskussion. Gleichzeitig hat die Annahme der Existenz eines unabhängigen Reflexionsraums über Religion und Politik eine heuristische Funktion. Sie erlaubt es Autoren nämlich, systematische Überlegungen zur theoretischen und methodologischen Auseinandersetzung mit Religion anzustellen. Die zweite Gruppe von Aufsätzen in diesem Band hat daher zum Ziel, einen Überblick über die Bandbreite der Auseinandersetzung mit Religion im sozialphilosophischen und politischen Diskurs zu geben, ohne dabei die Grenze zwischen wissenschaftlicher und philosophischer Betrachtung und religiöser Anfrage grundsätzlich in Frage zu stellen. Jedoch spätestens dann, wenn konkrete gesellschaftliche Phänomene ins Zentrum der Betrachtung rücken, verschwimmt diese Grenze. Gemeinschaft, Ökonomie und Terrorismus sind drei Bereiche, in denen Religion einerseits zur Anfrage an vorherrschende säkulare Diskurse, andererseits aber auch in gesellschaftlichen Prozessen konkret wirksam wird.

Zur ersten Gruppe von Arbeiten, in denen die Definition des politisch-philosophischen Diskurses als ,säkular" kritisch diskutiert wird, gehören die Beiträge von José Casanova, Gerhard Larcher und Walter Reese-Schäfer. In seinem Beitrag stellt Casanova das Thema der Tagung in einen globalen Rahmen. Die Säkularisierung ist, das streicht Casanova hervor, ein westliches Phänomen und die Geburt des säkularen Europa aus der Erfahrung der Religionskriege eher Mythos denn Realität. Die Religionskriege hätten in Wahrheit nämlich weniger zu gegenseitiger Toleranz, als vielmehr zu territorialer Einhegung und gegenseitiger Abgrenzung von Religionen geführt. Der richtige Umgang mit religiösem Pluralismus ist aus Casanovas Perspektive keine Frage, die Europa bereits geklärt hat und als „Säkularität“ dem Rest der Welt modellhaft vorführen kann, sondern viel- 
mehr eine höchst aktuelle Herausforderung für die europäischen Gesellschaften.

Larcher geht in seinem Beitrag der Frage nach, wie eine authentische Rückkehr von Religion in unserer Gegenwart - im Gegensatz zu einer lediglich oberflächlichen, auf Esoterik und religiöse Derivate beschränkten Rückkehr einerseits, und zu einer fundamentalistischen, antimodernen und exklusivistischen Rückkehr andererseits - aussehen könnte. Bei den von ihm angeführten Kriterien, die er für eine authentische und mithin wünschenswerte Rückkehr von Religion in einen säkularen gesellschaftlichen Kontext festlegt, sticht das Kriterium eines „eschatologischen Vorbehalts“ besonders ins Auge. In diesem Kriterium steckt der Schlüssel für ein positives Pluralismusverständnis sowohl seitens der Religionen, die sich in einem „Wettstreit der Liebe“ miteinander befinden, wie auch seitens säkularer sozialphilosophischer und politischer Debatten, in welchen um ein nicht rein additives und relativistisches Verständnis von Pluralismus und Multikulturalismus gerungen wird.

Eben diese sozialphilosophischen und politischen Debatten sind Gegenstand des Beitrags von Reese-Schäfer, der anhand der Auseinandersetzung zwischen Jürgen Habermas und dem damaligen Kardinal Joseph Ratzinger aus dem Jahr 2004 auslotet, wie weit die Annäherung zwischen nicht-religiösen und religiösen Überzeugungen in einer post-säkularen Gesellschaft gehen kann. Der „,komplementäre Lernprozess", der Habermas vorschwebt, anerkennt das sinnstiftende Wertereservoir der Religionen, auf das Demokratien für ihren inneren Zusammenhalt angewiesen sind, setzt gleichzeitig aber eine Rückkehr der Religion unter genau jenen Kriterien voraus, die im Beitrag von Larcher genannt werden. Allerdings führt ReeseSchäfer ins Feld, dass die Rückkehr der Religion aus europäischer Sicht zu einem nicht geringen Anteil der Einwanderung von Menschen aus anderen Kulturkreisen geschuldet ist, für die Religion im Einwanderungsland zu einer wichtigen Quelle von Identität wird. Inwiefern vor dem Hintergrund dieser Entwicklung das Modell des katholischen Antimodernismus bzw. eines Aggiornamento beispielhaft für andere Religion werden kann, ist eine Frage, die bei der Lektüre dieser beiden und anderer Beiträge in dem Band mitschwingt. ${ }^{7}$ 
Systematische und methodologische Fragen stehen im Mittelpunkt der zweiten Gruppe von Beiträgen. In ihnen geht es um die Konturen und die innere Struktur des politisch-philosophische Diskurses der Moderne als Reflexionsraum über Religion. Während es in den Aufsätzen von Frank Adloff und Kristina Stöckl um die Frage geht, welche Folgen die Rückkehr der Religion für Wissenschaftstheorie und disziplinäre Grenzziehungen in den Sozial- und Geisteswissenschaften hat, steht in den Beiträgen von Harald Stelzer und Evert van der Zweerde der Kommunitarismus als konkretes Beispiel einer religiösen Anfrage an den politisch-philosophischen Diskurs der Moderne zur Diskussion.

Adloff richtet in seinem Aufsatz einen kritischen Blick auf die Soziologie als Disziplin und fragt, was ihr Beitrag zu einem besseren Verständnis des Verhältnisses von Religion und Säkularität sein kann. Die Aufgabe der Sozialwissenschaften liegt seiner Ansicht nach darin, den Stellenwert der Religion als das Abgespaltene und Verdrängte der Moderne zu erkennen und die Interaktion zwischen religiöser Dynamik und säkularistischer Lebensform als Charakteristikum moderner Gesellschaften vorurteilsfrei zu untersuchen. Gerade solche Vorurteilsfreiheit lasse die Sozialwissenschaft, die gleichzeitig als Träger und Produkt des Säkularitätsparadigmas auftritt, jedoch häufig vermissen. In dieselbe Kerbe schlägt Stöckl mit ihrem Beitrag. Ausgehend von einer Analyse der unterschiedlichen Formen der Rückkehr des Religiösen - sie unterscheidet zwischen Erfahrung, (intellektueller) Tradition und Institution - argumentiert sie, dass Interdisziplinarität und Methodenpluralismus notwendige Bedingungen für die wissenschaftliche Auseinandersetzung mit Religion darstellen.

Um ein konkretes Beispiel politiktheoretischer Grenzziehung zwischen säkularem Diskurs und religiöser Einmischung geht es in der Diskussion des Kommunitarismus bei Stelzer und Van der Zweerde. Für Stelzer stellen die religiösen Motive in der kommunitaristischen Kritik am säkularen und liberalen Mainstream unzulässige Interventionen dar. Eine auf kommunitaristischen Argumenten aufbauende Öffnung des politisch-philosophischen Diskurses hin zur Religion hält Stelzer für unvereinbar mit einer modernen liberalen Gesellschaftskonzeption. Während er also kategorisch verneint, dass Religion eine Anfrage an den politisch-philosophischen Diskurs der Moderne sein kann oder sollte, argumentiert Van der Zweerde unter Rückgriff auf Motive der russischen Religionsphilosophie genau umgekehrt. Er ist der Ansicht, dass sich die sozialphilosophi- 
sche Diskussion der Realität religiöser und gemeinschaftlicher Erfahrungen nicht verschließen könne. Van der Zweerde entwickelt in seinem Beitrag die Ansätze für eine differenzierte Ontologie und Terminologie des Wir, die möglichen unterschiedlichen Erfahrungen von Gemeinschaft, Gesellschaft und Politik Rechnung tragen und somit verhindern sollen, dass der politisch-philosophische Diskurs der Moderne auf eine säkulare, objektivierende Perspektive festgelegt wird.

Im dritten Abschnitt kommen konkrete Problemfelder zur Sprache, in denen Religion als intervenierendes Element in gesellschaftlichen Prozessen Beachtung erfährt. Dies ist einmal der gesamte Bereich von kultureller Identität und gesellschaftlicher Integration. Emil Brix erläutert in seinem Beitrag zur „Leitkultur“-Debatte, dass Religion in einer multikulturellen Gesellschaft zu einem Konfliktfaktor werden kann. Eine friedliche Bewältigung solcher Konflikte erfordert eine Stärkung der republikanischen Prinzipien liberaler Gesellschaften, nicht aber eine kulturelle oder gar religiöse Homogenisierung. Dies konkretisiert Brix anhand der gegenwärtigen Situation der europäischen Union, die an einem Mangel identitätsstiftender, gemeinsamer Überzeugungen zu leiden scheint, woraus mitunter die Forderung nach einer Re-theologisierung der Politik entsteht. Eine solche Forderung wird zurück gewiesen, ohne aber zu leugnen, dass religiöse und daraus erwachsende ethische Impulse ein wesentliches Moment der europäischen Entwicklung auf zivilgesellschaftlicher Ebene darstellen können.

Andreas Exenberger und Wilhelm Guggenberger setzen sich mit der ökonomischen Dimension der Moderne auseinander. Beide gehen dabei von Adam Smith aus, dem Klassiker moderner Volkswirtschaftslehre, der als Moralphilosoph gleichzeitig auch Repräsentant der Schottischen Aufklärung war. Während Exenberger für eine differenzierte und umfassende Rezeption Smiths plädiert, um so einem vollständigen Verlust der politischen Ökonomie und der Kapitulation vor einem regellosen Wirtschaftsliberalismus zu entgehen, sieht Guggenberger bereits im Werk des Autors selbst eine Tendenz zur Marktautonomie grundgelegt, die der politischen Verantwortung mehr und mehr Handlungsraum zu entziehen droht. Das spannungsreiche Dreieck Politik, Wirtschaft, Religion wird von Exenberger mehr im Hinblick auf das wechselseitige Verhältnis der beiden ersten Komponenten beleuchtet, wobei er aufzeigt, dass Smith kaum 
als Gewährsmann einer Ökonomie betrachtet werden kann, die völlig losgelöst von einer wirkmächtigen Gemeinwohlorientierung agiert. Guggenberger plädiert in seinem Beitrag dafür, die Rolle religiöser Transzendenzorientierung im Hinblick auf eine - dem politischem Willen unterworfene - Zügelung der Marktkräfte zu beachten. Eine Ausblendung dieser Dimension aus dem philosophischethischen Diskurs konstatiert er sowohl bei Adam Smith, als auch bei David Hume.

Harald Wydra analysiert in seinem Aufsatz den Beitrag der Religion zu den neuen Konflikten des 21. Jahrhunderts. Mit Verweis auf historische Parallelen zwischen politischem Islam und bolschewistischem Terror relativiert er einige gängige Argumente über den $\mathrm{Zu}-$ sammenhang zwischen religiösem Fundamentalismus und terroristischer Gewalt. Unter Rückgriff auf die mimetische Theorie René Girards argumentiert Wydra, dass terroristische Gewalt als Säkularisierung von archaischen religiösen Opferriten verstanden werden kann, und Religion als friedensstiftende - weil den Opfermechanismus durchbrechende - Ressource in den Hintergrund gedrängt wird.

Die Beiträge in diesem Band geben einen Überblick über zentrale Problemstellungen in der Auseinandersetzung mit dem Verhältnis von Religion und Sozialwissenschaften einerseits, und den spannungsreichen Beziehungen zwischen Religion, Politik, Wirtschaft und struktureller wie offener Gewalt andererseits. Sie vermitteln einen Einstieg in die sozialwissenschaftlichen, philosophischen und theologischen Debatten zu diesem Thema und führen in die philosophische und sozialwissenschaftliche Hintergrundliteratur ein. Daneben zielen fast alle Beiträge auf eine Vertiefung und Differenzierung der Problematik unter Berücksichtigung aktueller gesellschaftspolitischer Herausforderungen. Die Aufsatzsammlung empfiehlt sich aus diesem Grund als Einführung für Studierende in gleichem Maße wie für ein interessiertes Fachpublikum. Die Herausgeber danken an dieser Stelle der Österreichischen Forschungsgemeinschaft für ihre Unterstützung der Tagung und Drucklegung dieses Sammelbandes und Herrn Joseph Wang für Satz und Layout des Manuskripts. 


\section{Literatur}

Berger, Peter L. (1999): „The Desecularization of the World. A Global Overview", in: Ders., Hg.: The Desecularization of the World: Resurgent Religion and World Politics. Washington, D.C.: Ethics and Public Policy Center.

Berger, Peter L. (2008): „Secularization falsified”, in: First Things (February), 23-27.

Bruce, Steve/Wallis, Roy (1992): „Secularization. The Orthodox Model”, in: Bruche, Steve, Hg.: Religion and Modernization. Oxford: Clarendon Press.

Casanova, José (1994): Public religions in the modern world. Chicago: University of Chicago Press.

Casanova, José (2006): „Aggiornamenti? Katholische und muslimische Politik im Vergleich“, in: Leviathan 34 (3), 305-320.

Eder, Klaus (2002): „Europäische Säkularisierung. Ein Sonderweg in die postsäkulare Gesellschaft?" in: Berliner Journal für Soztologie 12, 331-344.

Lilla, Mark (2007): The Stillborn God. Religion, Politics and the Modern West. New York: Vintage Books.

Palaver, Wolfgang/Siebenrock, Roman/Regensburger, Dietmar, Hg. (2008): Westliche Moderne, Christentum und Islam. Gewalt als Anfrage an monotheistische Religionen. Innsbruck: Innsbruck University Press.

Regenburger, Dietmar/Larcher, Gerhard, Hg. (2008): Paradise Now!? Politik - Religion - Gewalt im Spiegel des Films. Marburg: Schüren. 



\section{Historische und}

philosophische Grundlegungen 



\section{Eurozentristischer Säkularismus und die Herausforderung der Globalisierung}

José Casanova

Der Ausgangspunkt einer jeden Diskussion über das Säkulare, Säkularisierung oder Säkularismus sollte die Einsicht sein, dass alle diese Konzepte von einer westlich-christlichen theologischen und rechtlich-kanonischen Kategorie hergeleitet werden, nämlich der des saeculum, die als solche nicht nur in den anderen Weltreligionen keine Entsprechung hat, sondern nicht einmal im byzantinischen Christentum. Als eine Weltanschauung oder Ideologie kann der Säkularismus dann als „eurozentristisch“ definiert werden, wenn er seine eigene partikulare Genealogie im geschichtlichen Prozess der Säkularisierung des westlichen Christentums ignoriert und sich als das reife teleologische Ergebnis eines universalen Prozesses menschlicher Entwicklung von religiösem Glauben zu säkularem Unglauben darstellt. Paradoxerweise ist es nicht das reflexive Bewusstsein der eigenen europäischen und christlichen Wurzeln, welches den Säkularismus eurozentristisch macht, sondern die Annahme, dass eine auf Europa beschränkte, eigenständige geschichtliche Entwicklung paradigmatisch, universal und somit von normativer Gültigkeit sein kann.

Mein Vortrag ist in drei Abschnitte aufgeteilt. Im ersten Teil werde ich eine sehr schematische Rekonstruktion des komplexen Prozesses der westlichen christlichen Säkularisierung aus der vergleichenden Perspektive der achsenzeitlichen Revolutionen anbieten. Der zweite Teil präsentiert einen kurzen Abriss der zwei Hauptformen des Sä- 
kularismus, nämlich des politischen Säkularismus und des historischphilosophischen Säkularismus, und analysiert die Art und Weise, wie diese nicht nur im sozialwissenschaftlichen Diskurs, sondern auch in aktuellen öffentlichen Debatten im Westen, vor allem in Europa, in Erscheinung treten. Der letzte Abschnitt wird auf einige der Herausforderungen hinweisen, welche die gegenwärtigen Prozesse der Globalisierung für unser eurozentristisches Verständnis von säkularer Moderne aufwerfen.

\section{Westliche christliche Säkularisierung}

Der Prozess der Säkularisierung in all seinen mannigfachen Dimensionen lässt sich nur hermeneutisch verstehen, und zwar als eine bestimmte historische Dynamik, die im Westen zuerst im Kontext des mittelalterlichen lateinischen Christentums entsteht und sich dann gegen dieses wendet, und nicht als ein universaler Prozess menschlicher Entwicklung von „Glauben“ zu „Unglauben“ oder von ,primitiver“ Religion zu rationalem Wissen, wobei diese letztere, säkularistisch selbst-reflexive Konzeptualisierung auf die Religionskritik der Aufklärung zurückgeht. Die partikularen historischen Dynamiken des modernen Säkularisierungsprozesses sind ja sowohl hergeleitet wie auch bestimmt von der einzigartigen dichotomen Klassifikation der Wirklichkeit in Religion und saeculum, welche im mittelalterlichen Christentum institutionalisiert wurde.

Aus der vergleichenden Perspektive der achsenzeitlichen Revolutionen erscheint der Prozess der westlichen Säkularisierung als eine Radikalisierung jenes großen Verlustes der Eingebettetheit des Individuums in den heiligen Kosmos und in die Gesellschaft, der mit den achsenzeitlichen Revolutionen in Gang gekommen ist. Im Kontext einer generellen Theorie ,religiöser“ Evolution könnte man diesen Prozess als eine Neubestimmung der Grenzen zwischen dem Heiligen und Profanen, der Transzendenz und Immanenz, dem Religiösen und Säkularen auffassen. Viel zu häufig tendieren wir dazu, diese dichotomen Paare - heilig/profan, transzendent/immanent, religiös/säkular - als Synonyme zu sehen. Dabei sollte es offensichtlich sein, dass diese drei dichotomischen Klassifizierungsschemata sich nicht nahtlos ineinanderfügen. In den vorachsenzeitlichen Gesellschaften ist das Heilige tendenziell immanent, in einigen Achsenzivilisationen ist die Transzendenz nicht unbedingt religiös konnotiert, und im modernen säkularen Zeitalter können 
Bereiche der säkularen Wirklichkeit (die Nation, Staatsbürgerschaft, das Individuum, unabdingbare Rechte auf Leben und Freiheit) offensichtlich den Status der Heiligkeit erlangen.

Was die achsenzeitlichen Revolutionen auszeichnet, ist die Einführung eines neuen Klassifikationsschemas aufgrund des Aufkommens der Transzendenz, einer Ordnung, eines Prinzips oder eines Seins jenseits der weltlichen Realität, das nunmehr als transzendentes Prinzip zur Bewertung, zur Regulierung und möglicherweise zur Veränderung dieser weltlichen Realität dienen kann. Im Fall von radikalem Monotheismus kann religiöse Transzendenz zu einer DeSakralisierung der gesamten immanenten Wirklichkeit führen. Wie aber der Fall der platonischen Welt der Ideen oder der konfuzianischen Neuformulierung des chinesischen Tao zeigt, muss Transzendenz nicht notgedrungen religiös sein, noch muss alles „Religiö$\mathrm{se}^{\text {" }}$ transzendent werden.

Aus dieser Perspektive stellt die Dichotomie von religiös und säkular eine bestimmte mittelalterlich-christliche Version der generellen achsenzeitlichen Dichotomie zwischen transzendenten und immanenten Wirklichkeitsordnungen dar. Einzigartig für das mittelalterliche lateinische Christentum ist allerdings die Institutionalisierung eines ekklesiastisch-sakramentalen Systems der Mediation zwischen der transzendenten Civitas Dei und der immanenten Civitas bominis, nämlich der Kirche. Die Kirche kann die Funktion der Mediation deshalb übernehmen, weil sie beiden Wirklichkeiten angehört. Der moderne westliche Prozess der Säkularisierung ist eine spezifische geschichtliche Dynamik, die nur als Antwort und Reaktion auf ebendieses mittelalterliche lateinisch-christliche System der Klassifikation der Wirklichkeit in eine ,geistige“ und temporäre bzw. in eine religiöse und säkulare Wirklichkeit Sinn macht.

In seinem jüngsten Werk, A Secular Age, hat Charles Taylor deutlich gezeigt, dass der geschichtliche Verlauf der modernen Säkularisierung als ein Prozess interner säkularer Reform im lateinischen Christentum beginnt, als ein Versuch, das Zeitliche zu vergeistigen und das religiöse Leben der Vollendung aus den Klöstern hinaus und in das saeculum hinein zu tragen, als ein - im wahrsten Sinne des Wortes Versuch, das Religiöse zu säkularisieren. Der Prozess der Vergeistigung der zeitlich-säkularen Wirklichkeit bringt eine Verinnerlichung von Religion und damit eine gewisse Entritualisierung, DeSakralisierung oder Entzauberung von Religion mit sich, was sich im 
besonderen Fall des Christentums in Form einer De-Sakramentalisierung und Entkirchlichung von Religion auswirkt. Die wiederholten Anläufe zu einer christlichen Reform des saeculum begannen mit den päpstlichen Revolutionen und setzten sich mit dem Aufkommen von Bettelorden und Wanderpredigern fort, deren Ziel die Christianisierung der wachsenden mittelalterlichen Dörfer und Städte war.

Bereits während des Mittelalters entstanden eine ganze Reihe von fundamentalistischen mönchischen Bewegungen sowie sektiererischen Gruppierungen und gnostisch-heterodoxen Bewegungen, die den Dualismus zwischen immanenter und transzendenter Wirklichkeit zu überwinden versuchten, entweder durch die Ausweitung des Lebens in christlicher Vollkommenheit über die Klöster hinaus oder durch eine radikale Transformation des saeculum nach christlichen transzendenten Prinzipien. Wenn auch mit vielen Variationen, so stellen doch diese beiden Strategien die zwei grundsätzlichen Wege zur Säkularisierung dar, beispielhaft verkörpert durch die Protestantische Revolution und die Französische Revolution, und erreichen in unserem säkularen Zeitalter ihren Höhepunkt. Auf unterschiedliche Art und Weise führen beide Wege eine Überwindung des mittelalterlichen katholischen Dualismus durch eine positive Affirmation und Neubewertung des saeculum herbei, d.h. des säkularen Zeitalters und der säkularen Welt, und sie verleihen dem saeculum dadurch quasiheilige Bedeutung als Ort des menschlichen Gedeihens.

Der protestantische Weg, der seine paradigmatische Manifestation im angelsächsischen calvinistischen Kulturbereich erfährt, insbesondere in den Vereinigten Staaten, ist dadurch gekennzeichnet, dass die Grenze zwischen dem Religiösen und dem Säkularen verschwimmt und die beiden Bereiche ineinander fließen, wodurch das Religiöse in einem gewissen Sinne säkular und das Säkulare religiös wird. Daneben nimmt er auch die Form einer radikalen DeSakramentalisierung an, die in dem Ansinnen fanatischer Sekten, kirchliche Institutionen zu demontieren und die ecclesia, die Gemeinde, in eine rein säkulare Vereinigung von sichtbaren „Heiligen“ zu verwandeln, ihre extreme Ausprägung findet.

Der französisch-lateinische katholische Weg hingegen manifestiert sich als Laifizierung und zeichnet sich durch eine bürgerlichkirchliche und laizistisch-klerikale antagonistische Dynamik aus. Im Gegensatz zum protestantischen Weg wird hier die Grenze zwischen dem Religiösen und dem Säkularen streng aufrecht erhalten, aber sie 
wird mit dem Ziel an den Rand gedrängt, alles Religiöse einzuhegen, $\mathrm{zu}$ privatisieren und zu marginalisieren und ihm keinerlei sichtbare Präsenz im säkularen öffentlichen Bereich zu gönnen. Als die Klöster im Zuge der Französischen Revolution und der darauffolgenden liberalen Revolutionen säkularisiert werden, liegt der Sinn und Zweck des Einreißens der Klostermauern nicht darin, das religiöse Leben näher an die säkulare Welt zu bringen, wie das bei der Protestantischen Revolution der Fall war, sondern vielmehr darin, diese religiösen Orte zu laifizieren, sie ihres religiösen Inhalts zu entleeren und die religiösen Bewohner, die Mönche und Nonnen, zu Laien und Bürgern zu machen und sie in die säkulare Welt hineinzuzwingen.

Dieser alternative Weg zur säkularen Moderne überwindet den Dualismus und die Spannung zwischen dem saeculum und der transzendenten Ordnung auf der Basis einer Naturalisierung der transzendenten Prinzipien und Normen, er beseitigt jegliche übernatürliche oder „religiöse“ Referenz und übersetzt die transzendente Vision in immanente Projekte zur radikalen Veränderung der Welt. Dies wird der Weg sein, den ein Großteil Kontinentaleuropas im Rahmen der Aufklärung, der Französischen Revolution und der liberalen und proletarischen Revolutionen einschlägt.

Im lateinisch-katholischen Kulturbereich, und bis zu einem gewissen Grad in ganz Europa, kommt es zu einem Zusammenprall zwischen Religion und den ausdifferenzierten säkularen Bereichen, d.h. zwischen dem katholischen Christentum und den modernen Naturwissenschaften, dem modernen Kapitalismus und dem modernen Staat. Als ein Ergebnis dieser anhaltenden Auseinandersetzungen fand die Religionskritik der Aufklärung breiten Zuspruch; die säkularistische Genealogie der Moderne wurde als eine triumphierende Emanzipation der Vernunft, Freiheit und des weltlichen Strebens gegenüber den Einschränkungen der Religion dargestellt; und praktisch jede ,progressive“ soziale Bewegung in Europa von Zeiten der Französischen Revolution bis in die Gegenwart berief sich auf den Säkularismus und trug häufig eine anti-religiöse Haltung zur Schau. In den säkularistischen Selbstdarstellungen, die den Hintergrund für Theorien der funktionalen Ausdifferenzierung und Säkularisierung bilden, wird dieser Prozess als Emanzipation und Expansion der säkularen Sphäre auf Kosten der eingehegten, reduzierten und selbst neu ausdifferenzierten religiösen Sphäre präsentiert. 
Im anglo-protestantischen Kulturbereich hingegen, und vor allem in den Vereinigten Staaten, kam es zu einem unterschwelligen Einverständnis zwischen Religion und ausdifferenzierten säkularen Bereichen. Es gibt kaum historische Belege für eine Spannung zwischen amerikanischem Protestantismus und Kapitalismus und, bis zur Darwinkrise am Ende des neunzehnten Jahrhunderts, ebenso wenige Anzeichen für eine Auseinandersetzung zwischen Naturwissenschaften und Religion in Amerika. Die amerikanische Aufklärung hatte kaum eine anti-religiöse Komponente. Sogar die „Trennung von Kirche und Staat", die zweifach in den Bestimmungen des First Amendment verfassungsmäßig festgeschrieben ist, hatte einerseits zum Zweck, die „freie Religionsausübung“ von staatlicher Einmischung zu schützen, und andererseits den föderalen Staat vor religiösen Verstrickungen $\mathrm{zu}$ bewahren. Zumindest bis vor kurzem konnte man in Amerika kaum eine progressive soziale Bewegung finden, die sich auf säkularistische Werte berufen hätte. In den Vereinigten Staaten wurde der Triumph des Säkularen von der Religion eher befördert, als dass er auf ihre Kosten erfolgt wäre, und die Grenze zwischen den beiden Bereichen erweist sich als derart verschwommen, dass zumindest nach europäischen kirchlichen Maßstäben nicht deutlich ist, wo Religion beginnt und wo das Säkulare endet.

Mit Charles Taylor könnte man sagen, dass unser „säkulares Zeitalter" durch die strukturelle Wechselwirkung von ausdifferenzierten kosmischen, sozialen und moralischen Ordnungen mit einem sich selbst genügenden immanenten Rahmen gekennzeichnet ist, innerhalb dessen wir zu leben gezwungen sind, sei es auf säkulare oder auf religiöse Art. Unsere kosmische Ordnung ist konfiguriert als ein entzaubertes, unpersönliches, gewaltiges, unfassbares, und trotzdem wissenschaftlich erforsch- und erklärbares Universum, das auf paradoxe Art und Weise offen für alle möglichen moralischen Sinndeutungen ist. Es kann in uns die Gotteserfahrung eines mysterium tremendum und fascinosum auslösen, und genauso die mystische Empfindung von tiefer Einheit zwischen unserer inneren und der äußeren Natur.

Unsere gesellschaftliche Ordnung verstehen wir als eine selbst gesetzte und sozial konstruierte, unpersönliche und instrumentell vernünftige Ordnung, deren Zweck es ist, Individuen bei der Erfüllung ihrer Bedürfnisse und Ziele wechselseitige Vorteile zu sichern. Im Zuge dieses Prozesses erschaffen die individuellen Akteure kol- 
lektiv neue, spezifisch moderne Formen der Sozietät, von denen die Marktwirtschaft, der auf einem staatsbürgerlichen Verständnis beruhende demokratische Staat und die Öffentlichkeit - alle drei zeichnen sich durch das Prinzip des unmittelbaren, direkten und gleichberechtigten Zugangs aus - wohl die herausragendsten sind.

Unsere moralische Ordnung baut auf dem Bild des abgefederten Selbst auf, eines unbeteiligten und disziplinierten rationalen Akteurs, der für äußerliche Einflüsse undurchlässig ist und seine inneren Leidenschaften und Wünsche unter Kontrolle hat. Gesteuert wird dieser Akteur entweder von utilitaristischen Berechnungen zur Erreichung von individuellem Glück oder von universalistischen Maximen, die ihn zu guten Taten bewegen und befähigen, und zwar nicht nur auf der Basis vernünftiger unparteiischer Betrachtung, sondern kraft der Entdeckung von menschlicher Würde, Mitgefühl und Solidarität.

Alle drei Ordnungen, die kosmische, die soziale und die moralische, werden als rein immanente säkulare Ordnungen aufgefasst, frei von Transzendenz. Sie funktionieren etsi Deus non daretur. Es ist diese phänomenologische Erfahrung, welche, laut Taylor, unser Zeitalter als ein paradigmatisch säkulares ausmacht, unabhängig vom Ausmaß, in welchem die in diesem Zeitalter lebenden Menschen noch an religiösen oder theistischen Glaubensüberzeugungen festhalten mögen. $\mathrm{Zu}$ dieser phänomenologischen Erfahrung gehört darüber hinaus ein modernes „Phasendenken“, übernommen von der Aufklärung, welche die anthropozentrische Wende in den Voraussetzungen des Glaubens als einen Prozess der Reifung und des Wachstums interpretiert, als ein „Erwachsenwerden“ und als progressive Emanzipation. Moderner Unglaube ist nicht einfach ein Zustand der Abwesenheit von Glauben, noch der Gleichgültigkeit. Er ist ein historischer Zustand, der die Vergangenheitsform fordert, „ein Zustand des ,Überwunden-Habens' der Irrationalität von Glauben“"1.

Es ist diese phänomenologische Erfahrung, welche das Fundament des Säkularismus als moderne Ideologie ausmacht. Dieses historische Bewusstsein verwandelt allein die Idee, man könnte in einen bereits überwundenen Zustand zurückkehren, in eine undenkbare intellektuelle Regression. Es ist, in Taylors Worten, „der Sperr- 
hebel am Ende der anthropozentrischen Wende“ ${ }^{2}$. Aus diesem Grund sind alle analytischen und phänomenologischen Darstellungen der Moderne unvermeidlich auch große Narrationen, immer eingebettet in die eine oder andere Genealogie.

Aber die grundsätzliche und immer noch ungelöste Frage in den Säkularisierungs-Debatten der Gegenwart lautet, was die strukturelle Bedeutung von Säkularisierung als historischer Transformationsprozess der westeuropäischen Gesellschaften mit der weiter gefassten Bedeutung des Begriffs zu tun hat, nämlich mit der Abnahme von religiösen Überzeugungen und Praktiken bei den Menschen, die in diesem immanenten Rahmen im säkularen Zeitalter leben. Dass die Abnahme von religiösen Überzeugungen und Praktiken eine relativ junge Bedeutung des Begriffs Säkularisierung darstellt, wird durch die Tatsache verdeutlicht, dass sie bisher in keinem einzigen Wörterbuch einer modernen europäischen Sprache zu finden ist. Und trotzdem ist dies heutzutage die in der Allgemeinheit in allen europäischen Gesellschaften meistverbreitete Verwendung des Begriffs Säkularisierung.

Für mich ist die soziologisch interessanteste Tatsache nicht der progressive religiöse Niedergang innerhalb der europäischen Bevölkerung, sondern dass dieser Niedergang durch die Brille des Säkularisierungsparadigmas interpretiert und daher von einem säkularistischen Selbstverständnis begleitet wird, welches den Niedergang als „normal“ und „fortschrittlich“ ansieht, d.h. als quasi-normative Konsequenz des „modernen“ und ,aufgeklärten“ europäischen Daseins. In diesem Sinne hat die Säkularisierungsthese in Europa den Charakter einer sich selbst erfüllenden Prophezeiung angenommen. Das wird auf anekdotische Art und Weise in dem Moment offensichtlich, wenn man die Antworten auf Umfragen zu Religiosität in Europa und in den Vereinigten Staaten vergleicht.

Wir wissen, dass in den Vereinigten Staaten die Befragten dazu tendieren, die Interviewer anzulügen, sie übertreiben die Häufigkeit, mit der sie beten oder religiösen Feiern beiwohnen. Es ist offensichtlich, dass Amerikaner der Auffassung sind, sie sollten religiös sein, und sie fühlen sich ein wenig schuldig, dass sie nicht so religiös sind, wie sie eigentlich sein sollten. Es steht außer Zweifel, dass Amerika- 
ner sehr „,modern“ sein möchten und sich auch so bezeichnen, allerdings identifizieren sie ihre Modernität eher mit Religion als mit Säkularität. Europäer hingegen nehmen es als gegeben hin, dass Modern-Sein gleichbedeutend ist mit Säkular-Sein. Diese beiden so unterschiedlichen phänomenologischen Erfahrungen über den Atlantik hinweg spiegeln nicht nur die zwei oben beschriebenen unterschiedlichen Muster der Säkularisierung wider, sie wirken vielmehr wie sich selbst erfüllende Prophezeiungen, die zum Fortbestehen der zwei unterschiedlichen europäischen und amerikanischen Muster beitragen.

\section{Historisch-philosophischer und politischer Säkularismus}

Das Phasendenken, wonach man die Irrationalität von religiösem Glauben in einem fortschrittlichen Prozess menschlicher Entwicklung überwunden hat, stellt das phänomenologische Fundament des historisch-philosophischen Säkularismus dar. Heutzutage wird dieser Säkularismus gewöhnlich nicht mehr in die Form jener explizit säkularistischen Geschichtsphilosophien gebracht, wie sie für die Aufklärung im achtzehnten und für den Positivismus im neunzehnten Jahrhundert typisch waren, auch wenn wir gegenwärtig die Rückkehr von einer ziemlich aggressiven und militanten Form des Säkularismus in den Werken von u.a. Richard Dawkins und Christopher Hitchens beobachten können. Aber als eine unhinterfragte Annahme, als eine Art des Ungedachten durchdringt der Säkularismus das moderne europäische Bewusstsein.

Analytisch muss man selbstverständlich zwischen einem historisch-philosophischen und einem politischen Säkularismus unterscheiden. Man kann im Prinzip ein politischer Säkularist sein, ohne irgendwelche der anti-religiösen Annahmen des historischphilosophischen Säkularismus zu teilen. Allerdings sind die beiden Grundannahmen des Säkularismus, dass Religion als vor-rationale Form des Glaubens von rationalem Wissen abzulösen ist und dass sie intolerant, konfliktträchtig und daher für demokratische Politik gefährlich ist, fest mit dem europäischen Säkularismus verwoben, sowohl im akademischen wie auch im öffentlichen Diskurs.

Die säkulare Natur des modernen europäischen Staats und der säkulare Charakter der europäischen Demokratie dienen als Gründungsmythen für die gegenwärtige europäische Identität. Es gibt eine weit verbreitete säkulare europäische Narration, normalerweise 
in Form einer genealogischen Erklärung und normativen Rechtfertigung für den säkularen Charakter der europäischen Demokratie, welche die folgende schematische Struktur hat: Im mittelalterlichen Europa herrschte einmal, so wie es für vor-moderne Gesellschaften üblich ist, eine Verschmelzung von Religion und Politik. Aber diese Verschmelzung führte unter den neuen Bedingungen von religiösen Unterschieden, extremem Sektierertum und Konflikten, wie sie die protestantische Reformation herbeiführte, zu den gehässigen, brutalen und lang andauernden Religionskriegen der frühen Neuzeit, welche die europäischen Gesellschaften in den Ruin trieben. Die Säkularisierung des Staats war die glückliche Antwort auf diese katastrophale Erfahrung. Die Aufklärung erledigte den Rest. Moderne Europäer haben gelernt, Religion, Politik und Wissenschaft zu trennen. Sie haben - und das ist am allerwichtigsten - gelernt, religiöse Leidenschaften und störenden, obskurantistischen Fanatismus zu zähmen, indem sie die Religion in eine geschützte private Sphäre verbannt haben, während sie eine offene, liberale, säkulare Öffentlichkeit geschaffen haben, in der Meinungsfreiheit und öffentliche Vernunft herrschen. Dies sind die bewährten säkularen Fundamente, auf denen Demokratie wächst und gedeiht. Wie die tragischen Beispiele gewalttätiger religiöser Konflikte rund um die Welt zeigen, muss die unvorteilhafte De-Privatisierung von Religion und ihre Rückkehr in die Öffentlichkeit sehr sorgfältig gehandhabt werden, wenn diese empfindlichen Fundamente nicht untergraben werden sollen.

Ich nenne dies einen Gründungsmythos, weil er die geschichtlichen Entwicklungen in Europa nur sehr ungenau wiedergibt und nicht einmal eine akkurate Beschreibung für die real existierenden Demokratien in Europa heute ist. Die Religionskriege der frühen Neuzeit mündeten nicht, zumindest nicht unmittelbar, im säkularen Staat, sondern im konfessionellen Staat. Das Prinzip cuius regio eius religio, das im Frieden von Augsburg zum ersten Mal festgelegt wurde, ist nicht das Gestaltungsprinzip des modernen, säkularen, demokratischen Staats, sondern des modernen, konfessionellen und absolutistischen Territorialstaats. Nirgendwo in Europa haben religiöse Konflikte zur Säkularisierung geführt, sondern im Gegenteil zur Konfessionalisierung des Staats und zur Territorialisierung von Religionen und Völkern. Obendrein war dieses frühmoderne duale Muster von Konfessionalisierung und Territorialisierung bereits vor den Religi- 
onskriegen gut etabliert, sogar noch vor der protestantischen Reformation.

Der spanische katholische Staat unter den katholischen Königen kann als erstes paradigmatisches Modell für eine staatliche Konfessionalisierung und religiöse Territorialisierung gelten. Die Vertreibung spanischer Juden und Muslime, die sich weigerten zum Katholizismus zu konvertieren, ist die logische Konsequenz einer solchen Staatsgründungsdynamik. In dieser Hinsicht stehen ethno-religiöse Säuberungen am Ursprung des frühmodernen europäischen Staats. Aus dieser Perspektive sollten die sogenannten „Religionskriege“ zutreffender als Kriege der frühen europäischen Staatenbildung bezeichnet werden. Religiösen Minderheiten, die sich auf dem falschen konfessionellen Territorium wiederfanden, wurde keine säkulare Toleranz gewährt, geschweige denn Religionsfreiheit, sondern lediglich die „Freiheit“ zu emigrieren.

Die Säkularisierung des europäischen Staats sollte, wenn überhaupt, erst viel später eintreten und nicht notgedrungen immer zu einer Demokratisierung beitragen, wie die säkularistischen Regime sowjetischen Zuschnitts deutlich vor Augen führen. Und doch, ungeachtet seiner augenscheinlichen historischen Ungenauigkeit wird die übliche europäische Säkularisierungsnarration nicht nur häufig von europäischen Eliten wiederholt, sie scheint sich auch in der kollektiven Erinnerung gewöhnlicher Menschen in den meisten europäischen Gesellschaften festgesetzt zu haben.

Es ist in der Tat erstaunlich zu beobachten, wie weit verbreitet in Europa die Ansicht ist, dass Religion intolerant ist und Konflikte schürt. Laut der von ISSP durchgeführten Meinungsumfrage von 1998 ist die überwiegende Mehrheit der Europäer - praktisch mehr als zwei Drittel der Bevölkerung in jedem westeuropäischen Staat der Ansicht, Religion sei ,intolerant“. ${ }^{3}$ Da Menschen selten bereit sind, die eigene Intoleranz anzuerkennen, kann man davon ausgehen, dass die Europäer an die Religion von anderen denken, wenn sie eine solche Meinung äußern, oder aber eine selektive Erinnerung an ihre eigene, vergangene Religion zum Ausdruck bringen, die sie als zum Glück überwunden betrachten. Noch aussagekräftiger ist die Tatsache, dass die Mehrheit der Bevölkerung eines jeden westeuropäi- 
schen Landes, mit der bemerkenswerten Ausnahme von Norwegen und Schweden, der Ansicht ist, dass „Religion Konflikte schürt“.

Es ist ganz offensichtlich, dass eine solche weitverbreitete negative Meinung über Religion unmöglich empirisch in der kollektiven geschichtlichen Erfahrung der europäischen Gesellschaften im zwanzigsten Jahrhundert begründet sein kann, noch in den konkreten persönlichen Erfahrungen der meisten Europäer. Sie kann allerdings plausibel als eine säkulare Konstruktion erklärt werden, die die Funktion hat, moderne säkulare Europäer auf positive Art und Weise von einem religiösen Anderen abzugrenzen, sei es von den vormodernen religiösen Europäern oder von den zeitgenössischen religiösen Nicht-Europäern, insbesondere von den Muslimen. Ganz und gar erstaunlich ist die Sichtweise von der abstrakt verstandenen Religion als primäre Quelle für gewalttätige Konflikte in Anbetracht der eigentlichen geschichtlichen Erfahrung der meisten europäischen Gesellschaften im zwanzigsten Jahrhundert. „Das europäische kurze Jahrhundert", von 1914 bis 1989, um Eric Hobsbawms zutreffende Charakterisierung zu verwenden, war in der Tat eines der gewalttätigsten, blutigsten und völkermörderischsten Jahrhunderte der Menschheitsgeschichte. Aber von keinem einzigen dieser Massaker könnte man sagen, es sei durch religiösen Fanatismus oder Intoleranz verursacht worden. Alle waren vielmehr die Ausgeburt moderner säkularer Ideologien.

Aber die Europäer der Gegenwart ziehen es offensichtlich vor, die frischen und unbequemen Erinnerungen an säkulare ideologische Kämpfe selektiv zu vergessen und stattdessen die seit langem vergessenen Erinnerungen an die Religionskriege hervorzuholen, um sich auf diese Art und Weise die religiösen Konflikte, die sie weltweit um sich greifen sehen und die sie zunehmend bedrohen, zu erklären. Anstatt den gemeinsamen strukturellen Kontext von moderner Staatenbildung, zwischenstaatlichen geopolitischen Konflikten, modernem Nationalismus und politischer Mobilisierung von ethnischkulturellen und religiösen Identitäten - alles Prozesse, die für die moderne europäische Geschichte zentral sind und die durch die europäische koloniale Ausdehnung globalisiert wurden - zu sehen, ziehen es die Europäer vor, diese Konflikte der Religion zuzuschreiben, d.h. dem religiösen Fundamentalismus oder eben jenem Fanatismus und eben jener Intoleranz, die der vor-modernen Religion anhaften, ein Relikt aus grauer Vorzeit, welches die säkularen und aufgeklärten Europäer zum Glück hinter sich gelassen haben. Man könnte 
vermuten, dass die Funktion einer solchen selektiven Erinnerung darin liegt, den Eindruck der fortschreitenden Erfolge der westlichen säkularen Moderne zu wahren und eine sich selbst bestätigende Rechtfertigung für die säkulare Trennung von Religion und Politik zu liefern, die so zur Grundbedingung für liberale Demokratie, globalen Frieden und die Wahrung einer individuellen und privatisierten Religionsfreiheit wird.

Aber wie säkular sind die Staaten Europas? Wie hoch und wie solide sind die „Trennmauern“ zwischen den nationalen Staaten und den nationalen Kirchen und zwischen Religion und Politik in Europa? Bis zu welchem Punkt soll man den unwidersprochenen Erfolg der westeuropäischen Demokratien nach dem Zweiten Weltkrieg dem Triumph der Säkularisierung über die Religion zuschreiben? Frankreich ist der einzige westeuropäische Staat, der offiziell und selbstbewusst säkular ist, d.h. es definiert sich selbst und seine Demokratie durch das Prinzip der laïcité. Im Gegensatz dazu gibt es eine Reihe von europäischen Staaten mit einer langen demokratischen Tradition, die Staatskirchen aufrecht erhalten haben. Dies sind England und Schottland innerhalb des Vereinigten Königreichs und alle nordischen lutherischen Staaten: Dänemark, Norwegen, Island, Finnland und, bis zum Jahr 2000, Schweden. Unter den neueren Demokratien verfügt Griechenland mit der griechisch-orthodoxen Kirche über eine Staatskirche. Mit der Ausnahme der katholischen Kirche, die eine Stellung als Staatskirche in allen jüngeren Übergängen zur Demokratie (nach 1974) in Südeuropa (Portugal, Spanien) und Osteuropa (Polen, Ungarn, Tschechische Republik, Slowakei, Slowenien, Kroatien) gescheut hat, stellt also jeder andere Zweig des Christentums (Anglikanisch, Presbyterianisch, Lutherisch, Orthodox) irgendwo in Europa eine staatlich eingerichtete Kirche, augenscheinlich ohne die Demokratien in diesen Ländern zu gefährden. Da es andererseits viele historische Beispiele für säkulare und undemokratische Staaten in Europa gibt - die Regime sowjetischen Zuschnitts sind deutliche Beispiele - kann man mit einiger Sicherheit zu der Schlussfolgerung gelangen, dass eine strenge Trennung von Kirche und Staat weder eine ausreichende noch eine notwendige Bedingung für Demokratie darstellt.

Man könnte geradezu die Behauptung aufstellen, dass von den beiden Bestimmungen im First Amendment der Verfassung der Vereinigten Staaten die „freie Religionsausübung“ die eigentliche notwen- 
dige Bedingung für Demokratie darstellt, und nicht „keine Einrichtung“. Ohne Religionsfreiheit gibt es keine Demokratie. „Freie Religionsausübung" ist ein normatives demokratisches Prinzip. Das Prinzip der „Nicht-Einrichtung“ hingegen ist vertretbar und notwendig nur als ein Mittel zur Sicherstellung freier Ausübung und gleicher Rechte. Die De-Etablierung wird in einer Demokratie nur dann politisch notwendig, wenn eine etablierte Religion ein Monopol über staatliches Territorium beansprucht, freie Religionsausübung verhindert und die gleichen Rechte aller Bürger untergräbt. Dies war für die katholische Kirche der Fall, ehe sie das Prinzip der Religionsfreibeit offiziell als unabdingbares individuelles Recht anerkannte. Mit anderen Worten, säkularistische Prinzipien können auf der Basis instrumenteller Überlegungen verteidigt werden, als Mittel zum Zweck der Wahrung des Rechts auf freie Religionsausübung, aber nicht als intrinsisch liberale und demokratische Prinzipien an sich.

Alfred Stepan hat darauf hingewiesen, dass die wichtigsten empirischen analytischen Demokratietheorien, von Robert Dahl bis Juan Linz, Säkularismus oder eine strenge Trennung von Religion und Staat nicht als institutionelle Voraussetzung für Demokratie verstehen, anders als die bekannten liberalen normativen Theorien wie jene von John Rawls oder Bruce Ackerman. Als eine Alternative zu säkularistischen Prinzipien oder Normen schlägt Stepan das Modell der „gegenseitigen Tolerierung“ vor; dieses beschreibt er als „die kleinstmöglichen Handlungseinschränkungen, die politischen Institutionen gegenüber religiösen Instanzen und religiösen Individuen und Gruppen gegenüber politischen Institutionen auferlegt werden. “4 Innerhalb dieses Rahmens gegenseitiger Autonomie, so Stepans Schluss, „kann es eine außerordentlich große Bandbreite von konkreten Religion-Staat-Beziehungen in politischen Systemen geben, die unsere Minimaldefinition von Demokratie erfüllen."

Dies ist, empirisch gesehen, genau der Fall in Europa. Zwischen den zwei Extremen französischer laïité und nordischem lutherischem Staatskirchentum gibt es eine breite Palette von verschiedenen Staats-Kirchen-Beziehungen im Bereich der Bildung, der Medien, des Gesundheits- und Sozialwesens usw., die sehr unsäkulare Verschränkungen darstellen, zum Beispiel die Konkordanzformel 
der Versäulung in den Niederlanden oder die Anerkennung von protestantischer und katholischer Kirche in Deutschland als Körperschaften öffentlichen Rechts. ${ }^{6}$ Man könnte dem natürlich entgegen halten, dass die europäischen Gesellschaften de facto so säkularisiert sind und dass das, was von Religion noch übrig ist, so moderat geworden ist, dass sowohl die Einrichtung von Kirchen in der Verfassung als auch verschiedene Formen der Verschränkungen zwischen Kirche und Staat harmlos, wenn nicht sogar völlig irrelevant geworden sind. Man sollte sich aber erinnern, dass die drastische Säkularisierung des Großteils der westeuropäischen Gesellschaften nach der Konsolidierung von demokratischen Strukturen stattgefunden hat, nicht davor, und dass es daher nicht folgerichtig wäre, wenn man neben der Säkularisierung von Staat und Politik auch die Säkularisierung der Gesellschaft als eine Bedingung für Demokratie darstellen würde.

In Wirklichkeit sind zu dem einen oder anderen Zeitpunkt in fast allen kontinentaleuropäischen Gesellschaften konfessionelle religiöse Parteien entstanden, die eine entscheidende Rolle in der Demokratisierung dieser Gesellschaften gespielt haben. Sogar diejenigen konfessionellen Parteien, die ursprünglich als anti-liberale und zumindest ideologisch anti-demokratische Parteien gegründet wurden, wie dies bei den meisten katholischen Parteien im neunzehnten Jahrhundert der Fall war, spielten letztendlich eine wichtige Rolle in der Demokratisierung ihrer Gesellschaften. Dies ist das Paradox der Christdemokratie, das Stathis Kalyvas meisterhaft analysiert hat. ${ }^{7}$

\section{Die Herausforderung der Globalisierung für ein eurozentrisches Verständnis der säkularen Moderne}

Die soziologische Säkularisierungstheorie neigt dazu, Muster der Säkularisierung vermittels unterschiedlicher Grade der Modernisie-

6 John Madeley (2007) hat ein dreiteiliges Modell zur Analyse von Kirche-StaatsBeziehungen entwickelt, welches er als das TAO für das europäische Management und die Regulation von Religion-Staats-Beziehungen bezeichnet: $\mathrm{T}$ steht für treasure (finanzielle und eigentumsrechtliche Verbindungen), A steht für authority (die Ausübung staatlicher Befehlsgewalt), und $\mathrm{O}$ für organization (die wirkungsvolle Intervention staatlicher Institutionen im religiösen Bereich). Laut seiner Analyse erzielen alle europäischen Staaten eine positive Punktezahl in zumindest einem dieser Bereiche, die meisten in zwei von ihnen, und über ein Drittel (16 von 45 Staaten) schneidet in allen Bereichen positiv ab.

7 Siehe Kalyvas (1996). 
rung zu erklären, gerade so, als ob Säkularisierung notwendigerweise auf Modernisierung folgt, in dem Sinne, dass Modernisierung selbst die Ursache oder der Auslöser für Säkularisierung ist. Je moderner eine Gesellschaft, so die Annahme, desto säkularer sollte sie sein. Eine solche Annahme, die alleine schon in Hinblick auf die Variationen innerhalb Europas problematisch ist, wird noch unhaltbarer, wenn man eine globale vergleichende Perspektive einnimmt. Bis vor kurzem ging man in den meisten Diskussionen über Säkularisierung davon aus, dass europäische religiöse Entwicklungen typisch oder paradigmatisch modern sind, wohingegen das Fortdauern von Religion im modernen Amerika dem amerikanischen Sonderweg zugerechnet wurde. Man ging davon aus, dass Europa säkular sei, weil es modern war. Amerika war die Ausnahme, die die europäische Regel bestätigte. Der schrittweise Niedergang der Religion wurde so sehr als normaler Prozess moderner Entwicklung angesehen, dass es die amerikanische Abweichung von der europäischen Norm war, für die eine Erklärung gefunden werden musste.

Die grundlegende Frage lautet allerdings, ob die Säkularisierung in ihrem hergeleiteten Sinn - nämlich als Niedergang religiöser Überzeugungen und Praktiken, welcher paradigmatisch in der europäischen Form der Entkirchlichung, d.h. dem Ende von Zugehörigkeit zu einer christlichen Kirche und von Ausübung kirchlicher Religiosität, zum Ausdruck kommt - überhaupt wahrscheinlich ist, ohne zuerst die geschichtliche Erfahrung von Säkularisierung in ihrer ursprünglichen strukturellen Bedeutung gemacht zu haben, und zwar im Sinne der Transformation der christlichen Kirchen vom System des mittelalterlichen Christentums über die Reformation und Gegenreformation und die Territorialisierung und Konfessionalisierung der absolutistischen Staatskirchen bis hin zur Säkularisierung des Staats. Ohne die phänomenologische Erfahrung des Phasendenkens, wie es zu den Stadien der europäischen historischen Säkularisierung gehört, könnten Modernisierungsprozesse an anderen Orten möglicherweise nicht dieselben säkularisierenden Auswirkungen haben wie in Europa.

Dies ist die grundlegende Lektion des amerikanischen Sonderwegs. Besonders relevant ist $\mathrm{zu}$ allererst die historische Tatsache, dass die Bevölkerung der Vereinigten Staaten weder verfassungsmäBig eingerichtete kirchliche Institutionen noch das, was Taylor die paleo-Durkheim'schen Glaubensbedingungen des alten europäischen ancient regime genannt hat, überwinden musste. 
Genauso wichtig ist, zweitens, die Tatsache, dass die Vereinigten Staaten schon als brandneue, moderne und säkulare Republik zur Welt kamen und dass ihre Gründung mit dem neo-Durkheim'schen „Zeitalter der Mobilisierung“ zusammenfällt, welches besagt, dass religiöse und politische Mobilisierungen in der christlichen säkularen Republik simultan und gleichursprünglich ablaufen. Aus diesem Grund fehlt in der amerikanischen Aufklärung und in der Praxis der amerikanischen Zivilreligion jene Art von antichristlichem Geist, der Taylors genealogische Darstellung des exklusiven Humanismus durchzieht. Mit anderen Worten, ein antichristlicher oder antireligiöser säkularer Geist ist unwahrscheinlich, wenn die eigentliche Christianisierung des amerikanischen Volkes das historische Ergebnis der religiös-politischen Mobilisierung war, die mit den great awakenings und der sozio-historischen Transformation der amerikanischen Demokratie einherging.

Schlussendlich ist der Wendepunkt in der radikalen Säkularisierung der europäischen Gesellschaften zweifelsohne mit dem ,Zeitalter der Authentizität" verbunden. Dieser phänomenologische Zustand hat viel mit der romantischen Reaktion zu tun, die uns Taylor in seinen Arbeiten so konsequent zu erhellen vermocht hat und die mit den gegenkulturellen Bewegungen und den Jugendrebellionen der 1960er in der gesamten nordatlantischen Welt demokratisiert wurde. Für die Vereinigten Staaten, allerdings, könnte man sagen, dass, zumindest im Bereich des Religiösen, das Zeitalter der Authentizität bereits mit dem second great awakening gegeben und operativ war, mit Sicherheit im sogenannten Burned Over District im Staat New York mit seinen unzähligen utopischen Gemeinden und seinen in alle Richtungen wirkenden radikalen spirituellen Experimenten, den Jon Butler passend und eindrucksvoll als „das spirituelle Treibhaus Amerikas vor den Weltkriegen" beschrieben hat.

Was wäre, wenn man das Blatt der europäischen Theorien über den amerikanischen Sonderfall wenden und den geschichtlichen Prozess der Säkularisierung des lateinischen Christentums als die einzig wahre Ausnahme betrachten würde, als eine Entwicklung, deren Wiederholung mit derselben Abfolge von Phasen in einem anderen Teil der Welt unwahrscheinlich ist. Das heißt nicht, dass man die Theorien eines europäischen Exzeptionalismus akzeptieren muss, wie sie zuletzt unter anderem von Peter Berger in die Debatte eingebracht worden sind. Diese gehen davon aus, dass Säkularität ein einzigarti- 
ges europäisches Phänomen darstellt, das im Rest der Welt außerhalb der verwestlichten Eliten unbekannt ist, sodass der weltweite Zustand eher als eine De-Säkularisierung der Welt und als Rückkehr des Religiösen zu bezeichnen ist. Es gibt, zum Beispiel, eine ganze Reihe von Hinweisen auf Säkularität in der japanischen oder der chinesischen Kultur. Was diesen jedoch fehlt, ist genau jenes Denken in Phasen, und man könnte sich fragen, ob ohne ein solches der immanente Rahmen der säkularen modernen Ordnung dieselbe phänomenologische Wirkung auf die Bedingungen für Glauben und Unglauben in nicht-westlichen Gesellschaften haben kann? Wenn ein solches Denken in Phasen fehlt, kann das säkularistische Selbstverständnis der westeuropäischen Moderne dann denselben Effekt auch in nicht-westlichen Gesellschaften haben? Oder wird es nicht eher als das erkannt werden, was es offensichtlich auch ist, nämlich ein besonderer westchristlicher Prozess der Säkularisierung, der in nicht-christlichen Gesellschaften, die keine vergleichbare geschichtliche Entwicklung durchlaufen haben, sondern ganz im Gegenteil mit der westlichen säkularen Moderne seit der ersten Erfahrung mit dem europäischen Kolonialismus stets als das Andere konfrontiert waren, nicht dieselbe Wirkkraft entfaltet?

Wir werden uns erst jetzt immer stärker bewusst, dass der partikulare geschichtliche Prozess der westchristlichen Säkularisierung durch den ebenso partikularen geschichtlichen Prozess der europäischen kolonialen Ausbreitung globalisiert wurde. Die Folge war, dass der immanente Rahmen auf eine gewisse Weise global wurde. Dies trifft zumindest auf zentrale Aspekte der kosmischen Ordnung zu, innerhalb derer Wissenschaft und Technologie eine Globalisierung erfahren haben, auf zentrale Aspekte der Institutionalisierung von sozialer Ordnung in Staat, Markt und Öffentlichkeit, und auf gewisse Aspekte der moralischen Ordnung durch die Globalisierung der individuellen Menschenrechte. Aber der Prozess der europäischen kolonialen Ausbreitung traf auf post-achsenzeitliche Zivilisationen mit ganz anderen sozialen Vorstellungsbildern, die oft eigene etablierte Reformmodelle in Übereinstimmung mit ihren eigenen achsenzeitlichen und zivilisatorischen Prinzipien und Normen hatten.

Der säkulare immanente Rahmen der Moderne ist in der Tat global geworden. Von statten gegangen ist diese Entwicklung als ein interaktives dynamisches Ineinandergreifen, Umwandeln und Umgestalten von vorhandenen nicht-westlichen zivilisatorischen Mustern und sozialen Vorstellungsbildern im Austausch mit den moder- 
nen und säkularen westlichen. Obendrein, auf dieselbe Art und Weise wie ,unser“ modernes säkulares Zeitalter grundsätzlich und unvermeidbar post-christlich ist, so ist es wahrscheinlich, dass die entstehenden multiplen Modernen in den verschiedenen post-achsenzeitlichen zivilisatorischen Bereichen post-hinduistisch oder postkonfuzianisch oder post-muslimisch sein werden, d.h. dass auch sie eine moderne Umgestaltung und Umwandlung von bereits bestehenden zivilisatorischen Mustern und sozialen Vorstellungsbildern sein werden.

Wenn die Globalisierung eine gewisse Dezentralisierung, Provinzialisierung und Historisierung von Europa und der europäischen säkularen Moderne mit sich bringt, sogar in Bezug auf den unterschiedlichen Verlauf der amerikanischen Moderne innerhalb ein und desselben säkularen Rahmens, dann ist es unwahrscheinlich, dass „unser" säkulares Zeitalter einfach das gemeinsame globale säkulare Zeitalter der gesamten Menschheit werden wird, oder dass „unser" säkulares Zeitalter von dem Prozess der Globalisierung und von dem Aufeinandertreffen mit verschiedenen Ausprägungen einer aufstrebenden nicht-westlichen und in gewisser Hinsicht nichtsäkularen Moderne völlig unberührt bleiben wird. Ohne irgendwelche Prognosen aufstellen zu wollen, so sind doch einige Muster in unserer globalen Gegenwart bereits erkennbar.

Eine wahrscheinliche Auswirkung ist die weitere Verbreitung dessen, was Taylor als den Nova- und Supernova-Effekt des Zeitalters der Erfahrung bezeichnet hat, und zwar, dass alle Religionen dieser Welt, ob alt oder neu, ob vor-achsenzeitlich, achsenzeitlich oder nach-achsenzeitlich, für eine individuelle Aneignung zu jedem beliebigen Zeitpunkt und an jedem beliebigen Ort offen werden und sich damit die Möglichkeiten zu Bekehrung und $\mathrm{zu}$ individueller Suche nach der Transzendenz vervielfachen.

Die wichtigere Frage ist jedoch, ob das mittlerweile klar erkennbare Entstehen von multiplen und erfolgreichen nicht-westlichen Modernen (über den Sonderfall Japan hinaus), signalisiert durch das Aufstreben Chinas und Indiens als globale wirtschaftliche, politische und soziokulturelle Kräfte, das Phasendenken der westlichen säkularen Moderne zumindest erschüttern wird können. Wir wissen nicht, ob diese Entwicklung mit der Entstehung eines globalen post-säkularen Zeitalters einhergehen wird, in welchem die Besonderheit und der Ausnahmecharakter der westlichen säkularen Moderne verstärkt 
sichtbar werden wird. Aber es ist wahrscheinlich, dass sie die Europäer dazu zwingen wird, zum ersten Mal ihre post-christliche Säkularität reflexiv wahrzunehmen. Wahrscheinlich wird ein solcher Prozess mit einer reflexiven Bestätigung und Neuformulierung der europäischen christlichen und säkularen Identität einhergehen, wie die eher feindliche Aufnahme des Islam in Europa bereits jetzt zeigt. Es mag ein wenig verfrüht sein von einem post-säkularen Europa zu sprechen. Aber wenn in den nicht-westlichen Zivilisationen neue Formen von post-hinduistischen, post-buddhistischen, postkonfuzianischen oder post-muslimischen Formen von Transzendenz generell und global verfügbar werden, dann werden wir nicht umhin kommen von einer globalen post-säkularen Ära zu sprechen. Dieses neue globale Zeitalter wird wahrscheinlich von einer weitgehenden Auflösung von territorialen zivilisatorischen Grenzen gekennzeichnet sein sowie von der Ausbreitung dessen, was man als globalen Denominationalismus bezeichnen könnte.

Bis vor kurzem hatte die zivilisatorische oikumenè aller Weltreligionen deutliche territoriale Abgrenzungen. Diese Grenzen waren einerseits vorgegeben durch die Weltregime, in welche diese Religionen zivilisatorisch und somit territorial eingebettet waren, und andererseits durch die geographische Begrenztheit der vorhandenen Kommunikationsmittel. Der Bischof von Rom mag bereits von jeher behauptet haben, er spreche zu urbi et orbi, zur Stadt und zur Welt. Wirklich zur Realität geworden ist dies erst im zwanzigsten Jahrhundert. Was das eigentlich Neue an dieser gegenwärtigen globalen Situation ausmacht, ist die Tatsache, dass alle Weltreligionen erstmals wirklich als de-territorialisierte global vorgestellte Gemeinschaften wiederhergestellt werden können, losgelöst von ihrer zivilisatorischen Umgebung, in die sie traditionell eingebettet waren. In Anlehnung an Arjun Appadurais Begriff der „Modernity at large“ könnte man sagen, dass die Weltreligionen durch die Verbindung zwischen elektronischen Massenmedien und Massenmigration, als deterritorialisierte globale Religionen ,auf freiem Fuß“ oder als globale ummas neu konstituiert werden.

Diese Ausbreitung von de-territorialisierten, transnationalen, global vorgestellten Gemeinschaften, die die sogenannten alten Weltreligionen ebenso umfasst wie die vielen neuen Formen von hybriden globalisierten Religionen, z.B. die Bahai, Anhänger der Moon-Sekte, Hare Krishna, afro-amerikanische Religionen, Falun Gong u.a., nenne ich den heraufziehenden globalen Denominationa- 
lismus. Selbstverständlich konkurrieren diese Gemeinschaften mit anderen Formen von säkularen vorgestellten Gemeinschaften oder ummas. Aber alle diese transnationalen, vorgestellten religiösen Gemeinschaften stellen eine fundamentale Herausforderung für unsere Theorien der säkularen Moderne dar, für unsere Theorien der internationalen Beziehungen, die immer noch auf den Voraussetzungen des internationalen Systems nach Westfalen aufbauen, und für unsere säkularen und kosmopolitischen Theorien der Globalisierung.

(Aus dem Englischen von Kristina Stöckl)

\section{Literatur}

Greeley, Andrew M. (2003): Religion in Europe at the End of the Second Millennium. New Brunswick, N.J.: Transaction Books.

Kalyvas, Stathis (1996): The Rise of Christian Democracy. Ithaca, N.Y.: Cornell University Press.

Madeley, John T. S. (2007): Unequally Yoked: the Antinomies of Church-State Separation in Europe and the USA, Vortrag beim Jahrestreffen der Vereinigung Amerikanischer Politikwissenschafter, Chicago, 30.08.02.09.2007.

Stepan, Alfred (2001): Arguing Comparative Politics. Oxford: Oxford University Press.

Taylor, Charles (2007): A Secular Age. Harvard: Harvard University Press. 



\section{Religion(en) zwischen Antimodernismus und Aggiornamento. Fundamentaltheologische Prolegomena zu ihrer „Rückkehr“}

Gerhard Larcher

Nach den religionssoziologischen, -philosophischen und -politologischen Überlegungen soll es hier um ein paar zeitdiagnostische, historische und systematische Reflexionen aus fundamentaltheologischer Sicht gehen. Man könnte diese mit der bewusst paradoxen Untertitelformulierung „Fundamentaltheologische Prolegomena zu ihrer (der Religion(en), ,Rückkehr"“ in loser Anlehnung an Kant genauer noch umschreiben als: „kritische fundamentaltheologische Prolegomena zur Beurteilung einer jeden sogenannten ,Rückkehr' von Religion, welche als erwünschte soll gelten können."

Dabei ist nach der Erörterung der Frage, ob es diese vielbeschworene „Rückkehr der Religion(en)“ überhaupt gibt (1. Schritt), als historische Voraussetzung für die rechte Platzierung einer dafür evtl. vorzusehenden Kriteriologie schon auf zwei exemplarische Eckdaten aus der Kirchengeschichte des 20. Jahrhunderts hinzuweisen (2. Schritt), welche für die ungeheuere Spannweite des Verhältnisses von Religion zur Moderne stehen: nämlich auf die, besonders den Katholizismus in der Moderne über lange Zeit prägende Phase eines Antimodernismus sowie auf den Paradigmenwechsel gegenüber der Moderne mit dem II. Vatikanischen Konzil, welche Wende als Herausforderung im Zeitalter der Globalisierung auch für andere Religionen polarisierend stehen mag. Mit diesen beiden, historischen 
Zäsuren des 20. Jahrhunderts kommen auch schon sachliche Kriterien für jede Religion ins Spiel (zuvörderst natürlich für das Christentum, prinzipiell aber zumindest auch für die anderen monotheistischen Weltreligionen), welche in der postmodernen bzw. fundamentalismusgefährdeten Gegenwart mit authentischer Geltung wiederzukehren beanspruchen dürfen (3. Schritt).

Obwohl sich also mein fundamentaltheologischer Beitrag eher im Systematisch-Grundsätzlichen halten wird, werde ich dennoch immer noch im Banne des 100. Gedenkjahres der hochpolitischen Modernismus-Verurteilung von 1907 und im 50. Gedenkjahres der Ankündigung des II. Vatikanischen Konzils im Jahr $1959^{1}$ - einige historische Bezüge vornehmen. Diese gelten natürlich primär der neueren Katholizismusgeschichte, sind aber m.E. prinzipiell auch modellhaft relevant z.B. für den Protestantismus, der seinen (partiellen) Antimodernismus erst seit dem 1. Weltkrieg entdeckt hatte und für den Islam, insofern er sich gegenwärtig in europäischen Gesellschaften verstärkt ausbreitet und in einer globalisierten, postkolonialen Welt angesichts der Herausforderungen der realisierten Moderne sich anders als militant wird positionieren müssen.

\section{Rückkehr der Religion(en)?}

Weil das gängige Stichwort von der „Rückkehr der Religionen“ sehr ambivalent verstanden werden kann: einmal im Sinne eines Wiedererstarkens traditionaler, institutionalisierter Religionssysteme, zum anderen im Sinne einer Erneuerung individueller wie kollektiver, spirituell-religiöser Stimmungslagen, muss uns im Folgenden die Frage beschäftigen: Was ist sein Bedeutungsgehalt und was ist die „metaphysische Situation“ der Zeit heute, in welcher solche Prozesse der Rückkehr oder Wiederkehr der Religion(en) behauptet werden können?

1 Zum Zeitpunkt der Abfassung dieses Beitrages war nicht abzusehen, dass der 50 . Jahrestag der ersten Konzilsankündigung am 25. Jänner 2009 in der medialen Öffentlichkeit aufgrund der heftigen Diskussionen rund um die Aufhebung der Exkommunikation der Piusbruderschaft fast gänzlich untergehen würde; Anm. d. Hg. 


\subsection{Aktuelle thematische Aspekte}

Ich wiederhole hier ein paar Phänomene, die in anderen Beiträgen schon angeklungen sind. Ich denke, angesichts der gegenwärtigen weltanschaulichen Gemengelage würden sich die alten Religionskritiker heute die Augen reiben: ein Boom von Wellness, Spiritualität und Esoterik schwappt übers Land; Religion ist bype in Film und Neuen Medien, von Harry Potter bis zum Herr der Ringe; ferner gibt es eine muntere kulturelle Bricolage christlicher Festinhalte, von Halloween bis zu einem unspezifischen Christmasgedusel. Doch abgesehen von diesen ökonomisch breitgetretenen Travestien religiöser Elemente würden unsere Religionskritiker auch seriöse Anzeichen einer Reestimierung religiöser Traditionen bzw. des Phänomens Religion als solchem sehen können: so gibt es z.B. im Bereich der neuen Medien mit der Problematik virtueller Realität den Entwurf einer, auch theologisch relevanten, Parallelwelt (cf. „second life"), die als Herausforderung kritisch zu untersuchen ist. Auch im Umfeld des Dialogs mit den Naturwissenschaften kommt es aus manchen Lagern zu einem neuen, freilich oft fundamentalistisch klingenden metaphysischen Ton. Man denke nur an die Intelligent Design-Debatte. Vor allem aber lassen die offenkundigen gesellschaftspolitischen Aporien der realisierten Moderne heute wieder Dimensionen vernehmbar erscheinen, die lange Zeit wie verdrängt oder vergessen schienen. Der Kollaps totalitärer Systeme, aber auch die generelle Erosion des Politischen, der sogenannte „clash of civilisations“, der weltweite Terrorismus, die (mediale) Präsenz der Weltreligionen, die Debatten um Menschenrechte, um eine Europäische Verfassung, um ethische Grundwerte (z.B. zur Kontrolle der Biogenetik) etc., alle diese Phänomene schärfen erneut die Aufmerksamkeit für nicht verfügbare, aber notwendige Ressourcen von Ethos und sinnbestimmter Menschlichkeit. Nachdem Geschichte sich nicht im Sinne Francis Fukujamas unter dem Vorzeichen von universalem Markt und westlich-formaler Demokratie hat entsorgen lassen, generieren jene Grundlagenprobleme vermehrt Momente von Nachdenklichkeit, z.B. im Sinne des vielzitierten Böckenförde-Paradoxons, dass „der freiheitlich säkularisierte Staat (...) von Voraussetzungen (lebt), die er selbst nicht garantieren kann". ${ }^{2}$ Auch wird z.B. zur Frage einer gesamteuropäischen Verfassungspräambel ein „Gottesbezug“ disku- 
tiert, zumindest als ideelle Eingrenzung von Staat und Gesellschaft als Vorbeuge gegen jeden potentiellen Totalitarismus (Habermas). Ist es möglich, dass die Religionen zwischen Individualmoral, objektiver Rechtsordnung und universalem Weltethos sinnstiftend vermitteln?

Die globale „Weltzivilisation“ erfährt ferner überwältigende Irritationen durch außergewöhnliche Naturkatastrophen, welche das Bewusstsein um die Grenzen technischer Beherrschbarkeit der Natur, um die Ungesichertheit des Daseins und um das Leben als zerbrechliche Gabe herausfordern. Menschliche Allmachtsphantasien scheinen erschüttert, ethisch globale Solidarität gefordert, die Theodizeefrage gestellt (welche ja einen Adressaten der Klage braucht). Die Flutkatastrophen des Tsunamijahres und jene in Burma sowie das Erdbeben in China wühlen auf ihre Weise ähnlich intensiv auf wie auf gesellschaftspolitischer Ebene der symbolisch gewordene 11. September; ganz zu schweigen vom immer noch unfassbaren $\mathrm{Zu}$ sammenbruch des Kommunismus/der Berliner Mauer von 1989. Es war wie der unerwartete Vorübergang einer unbegreiflichen Macht vom Rücken her.

Ist also Gott oder was immer man dafür gehalten hat, vielleicht doch nicht ganz ,tot“ oder zumindest in seinen religiösen Simulakren wieder auflebend? Der eindimensionale Geschichtsfahrplan der Religionskritik scheint jedenfalls nicht mehr gültig zu sein. Vielleicht wird gegenwärtig die nach wie vor wirksame „untergründige Struktur des Glaubens“3 - als Frage ,wie können wir der Welt, die wir nicht verstehen, vertrauen?" (R. Safranski) - wieder bewusster; eine Frage, die allein zu stellen, von Friedrich Nietzsche über Carl Schmitt bis hin zu Jacques Lacan als verkappte theologische Prägung unserer Kultur diagnostiziert wurde.

Um es hier schon anzumerken: trotz analoger (Ausgangs)Bedingungen in einer globalisierten Welt gilt es bezüglich der Ansage einer „Rückkehr“ des Religiösen, gar der Religion, vorsichtig zu sein und zu differenzieren, je nachdem, ob hier von Europa oder dem Rest der Welt die Rede ist. Wird z.B. Europa hinreichend als religiöskonfessionell vielgestaltiger und unterschiedlich dichter Kontinent gesehen? Spricht man vom Zustand der institutionell verfassten Religionsgemeinschaften oder von Religion/Religiosität als allgemei- 
nem, zivilreligiösem Kulturphänomen, von dem sich ein explizites monotheistisches Gottesbekenntnis noch einmal unterscheidet? Geht es um reale Bewusstseinslagen breiter Bevölkerungsschichten oder um vorauseilende Vermutungen einzelner Zeitdiagnostiker, die sich möglicherweise am tatsächlichen Tiefenbewusstsein der Menschen vorbei artikulieren? Nicht erst beim Flug der Eule der Minerva post festum zu analysieren, sondern oft allzu kühn im Voraus Bescheid wissen zu wollen, scheint ihr Problem zu sein. Vielleicht ist ja Europa weder jemals ganz so säkularisiert gewesen, wie es nach außen schien, noch heute so sehr von einer Wiedergeburt des Religiösen ergriffen, wie das gegenwärtig von manchen vermutet wird. Und wenn schon, so bleibt weiterhin die Frage, ob es sich bei den neuen Anzeichen von Religion/Religiosität nicht teilweise nur um eine breite Palette bunter Dekonstruktionsphänomene des überlieferten biblisch christlichen Monotheismus handelt - im Sinne synkretistischer Mutationen, fundamentalistischer Metamorphosen oder schlicht privater, esoterisch okkulter Anmutungen, ohne Garantie einer sinnvollen neuen Rekonfiguration von Religion? Zumindest eine Ambivalenz des behaupteten modernen Religionsrevivals muss an dieser Stelle schon konstatiert werden dürfen.

Und überhaupt - ist hier zu fragen -, nährt sich das gegenwärtige Interesse an Religion aus einem authentischen Tiefenbedürfnis an geistiger Orientierung, das auch um einen weitreichenden Zusammenhang von europäischer Freiheitsgeschichte und Religion weiß, oder bezieht es seinen „Kick“ nur aus der Lust am Sensationellen oder der Wiederentdeckung des schon fast exotisch fremd Gewordenen? Allenfalls könnte man von einer gewissen, unspezifischen Renaissance des Religiösen insofern sprechen, als sich vor dem Hintergrund einer globalen ästhetischen Unterströmung Selbstkorrekturphänomene der realisierten Moderne als Immanenzprojekt zeigen. Oft spielen hier vor allem die oben genannten ethischen Ressourcenfragen und ökologischen Umdenkprozesse eine Rolle; sehr wesentlich aber - so meine These - dürften es auch die Künste sein, die im Sinne eines radikal erweiterten Verständnisses ihrer selbst - eine neue öffentliche Nachdenklichkeit induzieren und indizieren, häufig die Stelle der Religionen einnehmend, aber ohne das Pathos einer Kunstreligion des 19. Jahrhunderts. Immerhin könnten ihre zahlreichen spirituellen Impulse dafür stehen, dass de facto wieder mehr geglaubt wird, als man an der Oberfläche der theoretischen Vernunft einzugestehen bereit ist. Auch innerhalb der christlichen Religion 
selbst ergeben sich besonders über die Künste als verdrängte Dimensionen einer verinstitutionalisierten oder kopflastig gewordenen Konfessionalität Chancen für eine konstruktive Erneuerung des Religiösen durch Poesie, Symbole, Bilder... Im Spiegel also der Künste sowie ethischer und kulturpolitischer Grundsatzfragen zeigt sich - nicht nur bei den intellektuellen „Konvertiten“ von Habermas über Zizek bis Vattimo - ein gewisser aktueller Sinnorientierungsbedarf, welchen man als neu bezeichnen könnte, der aber noch nicht unbedingt eine Wieder- bzw. Rückkehr von Religion im vollen, institutionellen Sinne ausmacht, sondern allenfalls Voraussetzungen dafür schafft.

Evident ist schließlich sicherlich eine Revitalisierung des Religiösen als seine Repolitisierung. Die USA repräsentieren dies auf ihre bekannte, missionarisch hegemoniale Weise, bei großem Einfluss der protestantischen Freikirchen bzw. der sogenannten ,moral majority“ auf die republikanische Politik. Vor allem aber große Teile der islamischen Welt - nicht nur der Iran - repolitisieren Religion auf eine radikal militant entgegengesetzte Weise, die im Konzept des djihad potentiell bereitliegt. Die Europäer dazwischen reagieren meist nur zögerlich in diesem Kultur-Machtkampf und verweigern sich einer religiös (apokalyptisch) dramatisierenden Bewertung der weltpolitischen Lage. Sie, die in Sachen Religion in der Regel eher zu genierlicher kultureller Kindesweglegung tendierten, sehen sich nun durch die islamistischen Herausforderungen von außen und innen, ob sie es wollen oder nicht, doch genötigt, sich der Gretchenfrage nach ihrem Verhältnis zur Religion zu stellen. „Multikulti“ ohne näheres Wissen über das provozierende Gegenüber und ohne eine Haltung gegenüber den eigenen, wenn auch meist verdrängten oder ignorierten, religiös-kulturellen Herkünften, funktioniert nicht mehr.

\subsection{Fama einer Rückkehr der Religionen:}

Kein fait accompli, sondern eine (mehr oder weniger gut fundierte) Vermutung

Das Stichwort einer sogenannten Rückkehr oder Wiederkehr der Religionen bezeichnet also noch kein fait accompli, sondern erst eine Vermutung in starker Behauptungsform (mehr als Hoffnung oder mehr als Befürchtung artikuliert); diese mag sich z.T. aus Außenfaktoren nähren, wie z.B. dem Faktum „Migration“, vor allem muslimischer Migranten, der generellen Radikalisierung des Islam bzw. der verstärkten medialen Präsenz von Weltreligionen (Papstreisen, Katholikentage, Dalai-Lama Auftritte, etc). Auf alle Fälle widerspricht 
aber jene Behauptung den Grundannahmen des modernen, politisch-philosophischen Diskurses über Religion, sodass angesichts unterschiedlicher Symptome einer neuen Öffentlichkeit derselben einige Fragen zu stellen sind: Handelt es sich nach der Erfahrung des "Todes Gottes“ bzw. des gottebenbildlichen Menschen (Nietzsche/Foucault) um eine genuine Wiederkehr der Religionen in ihrer Substanz, sozusagen aus ihren eigenen spirituellen, regenerativen Kräften, z.B. mit dem ganzen Gewicht der Gottesproblematik? Oder legt sich dieser Eindruck neuer Religionspräsenz nur ex negativo, aufgrund gewisser Grenzerfahrungen und Selbstkorrekturen der Moderne nahe, welche neben ökologischen Aufbrüchen, alternativen Lebensformen, esoterischen Tendenzen auch neuen, religiös spirituellen Orientierungsbemühungen erst wieder Raum geben? Handelt es sich dabei zu einem nicht geringen Anteil nicht eher nur um eine „Rückkehr“ im Modus von Derivaten authentischer Religion als Esoterik, Okkultismus, Rock und Pop-Kultur etc.? Oder ist vielleicht das, was wie ein genuines Wiederaufleben von Religion aussieht, gar ein Stück weit nur ein sich Aufbäumen fundamentalistischer Rechthaberei angesichts der Unübersichtlichkeit der Verhältnisse und möglicherweise nur aus Unsicherheit entstanden, wie mit dem Islam umzugehen sei.

Kommt es also zu jener Diagnose von einer Wiederkehr hauptsächlich nur, weil es eben - vor allem aufgrund von Migration in den letzten Jahrzehnten - die neue Herausforderung des Islam gibt, der ziemlich vital expandierend sich kaum um die westlichen, säkularen, pluralistischen und laizistischen Befindlichkeiten kümmert und einfach versucht, z.B. durch faktische, kulturell-religiöse Parallelgesellschaften sich in der westlichen Säkularität einzunisten und diese wo es geht - strategisch zu unterminieren, z.B. Elemente der Scharia in das Rechtssystem einzuschleusen, etwa durch die erwartete Duldung von Zwangsehe, Polygamie, Erbrecht, Burka im Gerichtssaal etc.? Sodass es dann da und dort, wenn der säkulare Verfassungsstaat fallweise nachgibt, allmählich zu dem Eindruck einer unkontrollierbaren, potentiell gefährlichen Desäkularisierung unter Einschluss religiöser Sonderwelten, also zu einer problematischen Wiederkehr von Religion kommen kann?

Im Zusammenhang solcher Ereignisse geschieht es dann auch, dass Religionen jene große öffentliche Aufmerksamkeit gewinnen, welche durch mediale Rückkoppelungseffekte erst dazu führt, dass sich der Eindruck einer insgesamt postsäkularen Gesellschaft heute 
verstärkt einstellt. Möglicherweise ist aber die darin wieder deutlicher wahrnehmbare Religionsfassade vielleicht nur eine gigantische virtuelle Realität, letztlich eine strategische Fiktion, Ausdruck eines kulturpolitischen Machtkampfes bzw. eines irrationalen Selbstbehauptungswillens.

\section{Religion(en) im 20. Jahrhundert zwischen Antimodernismus und Aggiornamento}

Zur besseren Beurteilung der Tragweite jener Behauptung einer angeblichen Rückkehr der Religion unter den Bedingungen der aktuellen Moderne, wollen wir nun in einem zweiten Schritt unsere Gegenwartsanalysen modellhaft auf das Christentum, und zwar auf die katholische Modernismuskrise (inkl. deren Verurteilung) vor ca. 100 Jahren bzw. auf das kritische Ja zur Moderne im II. Vatikanischen Konzil vor fast 50 Jahren beziehen, um daraus dann Kriterien für eine authentische Rückkehr von Religion zu gewinnen. Ging es doch beide Male um einen, wenn auch unterschiedlichen Versuch, Wiederkehr von Religion im 20. Jahrhundert im Sinne ihrer Reform und Erneuerung zu ermöglichen.

In einem epochalen Übergangsprozess zwischen Antimodernismus und Aggiornamento haben hier Hauptakteure der Modernismuskrise wie Maurice Blondel, Friedrich von Hügel, George Tyrrell, Edouard Le Roy u.a. einerseits sowie Pioniere und Berater des Konzils wie Henri De Lubac, Karl Rahner, Hans Küng, Joseph Ratzinger andererseits theologische Standards gesetzt, die es verbieten, eine sogenannte Wiederkehr von Religion überstürzt und unkritisch zu feiern, ohne dass man deren Status bzw. ihre Inhalte im Verhältnis zur Moderne geklärt hätte; wir wollen dies exemplarisch anhand des angesprochenen Spannungsbogens in der Katholischen Kirche des 20. Jahrhunderts versuchen und dies modellhaft als eine prinzipielle Herausforderung auch für die anderen Konfessionen bzw. monotheistischen Weltreligionen unter den Bedingungen der realisierten Moderne ansehen.

\subsection{Modernismusstreit exemplarisch: Maurice Blondels Intervention}

Unter den gewichtigen religionsphilosophischen, apologetischen und hermeneutischen Interventionen während der Krise will ich exemplarisch auf Blondels Zwischenrufe zur sozialen Frage in Frankreich zu Beginn des 20. Jahrhunderts in seinen pseudonym ("Testis“) 
verfassten Schriften zu den sogenannten Semaines Sociales de Bordeaux ${ }^{4}$ hinweisen, worin er die Tragweite einer rechten Verhältnisbestimmung von Vernunft und Glaube auch im öffentlich politischen Raum am Beispiel seiner Kritik des sogenannten „Monophorismus" (d.h. der Action Francaise und ihres Führers Charles Maurras mit dessen Bewunderung für die „physique sociale“ A. Comtes) darlegen wollte. Papst Pius X. Enzyklika Pascendi Dominici Gregis (1907) im Hintergrund war noch - wie wir heute durch neuere Vatikanische Archivforschungen wissen - ganz und gar von der Option für ein integralistisches, ständisch autoritäres und vorrevolutionäres Gesellschaftsmodell, mit der Kirche als ordnender „societas perfecta" geprägt. Dies ist im Horizont des restaurativen Kurses der Kirche im 19. Jahrhundert als Reaktion auf die Französische Revolution insgesamt zu sehen. Man erwartete im Grunde eine Wiederkehr von Religion nach dem liberalistischen Abfall der Reformation, der Aufklärung, der Französischen Revolution unter restaurativem, gegenmodernem Vorzeichen, wobei dieser Antimodernismus selbst schon „die Krise einer abgeschlossenen Welt“ war. ${ }^{5}$

Gegen ein derartiges Gesellschaftsmodell mit einem entsprechend eng geführten, extrinsezistischen Religionsbegriff hat Blondel von seiner Philosophie der ,action“ her argumentiert und auch über die Nouvelle Theologie, besonders über De Lubac (Catholicisme. Les aspects sociaux du dogme $\left.e^{(}\right)$, mit seinen Vorschlägen auf das Vatikanum II, und dessen Pastoralkonstitution Gaudium et Spes voraus- und weitergewirkt.

Blondel hatte schon in seiner Methodenschrift Lettre von 1896 vorausschauend optimistisch von einer ,gegenseitige[n] Erneuerung der philosophischen und religiösen Perspektiven durch den bis ins letzte konsequenten Vollzug des modernen Denkens“" gesprochen. ${ }^{7}$ Keine traditionalistischen Nostalgien oder nur ängstliche Zugeständnisse bzw. Kompromisse gegenüber der Moderne klingen hier an. Die Moderne muss wirklich kritisch zu sich kommen, nicht bloß eine positivistische oder monistische Abspiegelung der alten Metaphysik sein. Nach Blondel ist es also geboten, die konsequente denkerische und kulturelle Herausforderung der Moderne kritisch aus-

4 Vgl. Blondel (1910); zum zeitgeschichtlichen Hintergrund siehe Sutton (1994).

5 Vgl. Sander (2009).

6 De Lubac (1970).

7 Blondel (1974), 159-212. 
zuloten und im Blick auf eine eventuelle geistige Renaissance anzunehmen. ${ }^{8}$ Er formuliert damit Bedingungen bzw. Mindestniveaus, welche auch Religionen einzuhalten haben, wenn sie diesen Namen verdienen. Es ging ihm vor allem um die politischen Implikationen seiner Immanenzmethode, die er religionsphilosophisch seit seinem Hauptwerk L'Action' von 1893 bzw. der Lettre von 1896 entfaltet hatte. Blondel schließt in diese seine Sicht der Herausforderungen der Moderne ein prinzipielles Anerkennen des liberalen Verfassungsstaates ein; und religionsphilosophisch ersteht im konsequenten Ausloten der Praxis, der Willensdynamik autonomer Subjekte, ihrer Bedürfnisse und Aporien eine glaubwürdige Hypothese des Übernatürlichen als Tradition, d.h. als einander anerkennende Hingabe in Liebe. Damit ginge es von Blondels Hauptschriften her um eine transzendentalphänomenologische „Überwindung“ des extrinsezistischen Autoritarismus bzw. eines „postmodernen“ ästhetisierenden Relativismus - zweier möglicher Spielarten wiederkehrender Religiosität.

Mit Blondel wäre also auf katholischer Seite der entzweiten Situation (aufgrund einer extrinsezistischen, positivistisch missverstandenen Neuscholastik) - ähnlich wie protestantischerseits 100 Jahre früher zur Zeit des jungen Hegel mit jener abstrakten Entzweiung der bürgerlichen Gesellschaft - als entscheidendes Kriterium ein christologisches entgegenzusetzen; dieses dient sowohl zum Verständnis der kenotischen Ferne Gottes in der Moderne (welche in der Nachfolge des leidenden Christus anzunehmen und zu ertragen ist) als auch als grundsätzliches Angebot versöhnter gesellschaftlicher Interaktion im Horizont einer Christozentrik. Dies wäre zugleich die inhaltliche Norm, um die sich die Phänomene einer rückkehrenden Religion zu polarisieren hätten.

Blondel denkt ähnlich wie Hegel Neuzeit und Moderne als Prozesse im Fortschritt des Bewusstseins der Freiheit, durch Prozesse christologisch fundierter Anerkennung hindurch. ${ }^{10}$ Gott ist es, der in Jesus Christus durch dessen traditio-Hingabe, durch seinen gebrochenen Leib in eucharistischer memoria und Praxis die Zeit der Geschichte je neu eröffnen, und damit auch Religion je neu aufleben

8 Vgl. Larcher (1999), besonders $60 \mathrm{ff.} \mathrm{und} 71 \mathrm{ff.}$.

9 Blondel (1965).

10 In Erinnerung an gute Gespräche mit dem Autor verweise ich auf Appel (2008), bes. IX. Epilog. 
lassen kann. Blondels „panchristisme“, und „charitisme“ sind in der liebenden Anerkennungsbewegung der Menschen füreinander verknüpft, was einen ebenso spekulativen wie liturgischen und praktischen Prozess einschließt. Damit sind entscheidende Kriterien zur Kritik einer modernen, sozialen und politischen Funktionalisierung von Religion, wie sie Blondel etwa bei Mauras und der Action Française konkret vor Augen hatte und wie sie heute wieder von fundamentalistischen Kreisen (nicht nur in den USA) im Sinne einer Restauration von Religion als gesellschaftlichem Ordnungssystem verfochten werden, vorbereitet.

\subsection{Vatikanisches Konzil}

Die Christozentrik Blondels in ihrer praktischen und heilsgeschichtlichen Tragweite wurde zu einem der Evidenzpunkte des Konzils, nicht nur, aber vor allem greifbar in dessen Pastoralkonstitution Gaudium et Spes im berühmten Kapitel 22. Zugleich verschrieb sich die Katholische Kirche einem „Aufbruch von oben“ hin zu einer kritischen Anerkennung der Moderne und einer Hermeneutik des „Aggiornamento“ ihrer Botschaft im Lichte der „Zeichen der Zeit" in einem selbstkritischen Bewusstsein um ihren mehrfachen Antimodernismus im 19. und 20. Jahrhundert. Man muss von diesem konziliaren Aufbruch her froh sein, dass sich heute christliche Kirchen und Theologien auch an der Basis der ganzen Komplexität der Moderne bewusst zu werden beginnen und sich in konkrete pastorale, politische und kulturelle Auseinandersetzungen mit dieser begeben. Dabei war das Konzil nicht die utopische Erfüllung modernistischer Aspirationen, auch kein vorweggenommener Postmodernismus, es war ein wirklicher Paradigmenwechsel über Fortschrittsmodernismus und postmodernen Relativismus hinaus im Sinne eines vorbehaltlosen, nicht exkludierenden Angebotes der Liebe Gottes. ${ }^{11}$

Als solcher Paradigmenwechsel stellt das II. Vatikanum jedenfalls den Hintergrund für die abschließende Kriteriologie dieses Beitrages. Denn die Rede von einer tatsächlichen oder vermeintlichen Wiederkehr der Religion ist im Sinne des II. Vatikanums daraufhin zu überprüfen, ob diese nicht erreichte Niveaus, etwa in der Hochschätzung des personalen Selbstvollzugs des Menschen, seiner

11 Der Sache nach findet sich dieser Gedanke bei Hans-Joachim Sander, vgl. Sander (2009). 
„actuosa participatio“ (Sacrosanctum Concilium) und des relativen Eigenwerts der Welt möglicherweise unterbietet; ähnlich wie heute, z.B. bei einem beliebten Revival der Nazarenerkunst, Religion wieder eher supranaturalistisch und konfessionalistisch ausdifferenziert und stilistisch segmenthaft etikettiert wird (vgl. auch die Vorlieben für tridentinische Liturgie). Die Problematik der Nazarener bzw. ihrer Epigonen als religiös stilbildend bestand ja darin, dass sie im Zeitalter der technischen Reproduzierbarkeit und der missionarischkolonialen Expansion fast monopolartig das 19. und 20. Jahrhundert bestimmten und dies im Sinne einer klischeehaften, religiöskonfessionalistischen Sonderwelt bis hinein in Bildtypen der Popund Trivialkultur (vgl. noch den Erfolg von Franco Zefirellis JESUS VON NAZARETH oder Mel Gibsons THE PASSION OF THE CHRIST) besetzten, die man so leicht nicht wieder los wird.

Für die Religion(en) unter den Bedingungen der (Post)Moderne - konkret bei uns für das Christentum im Dialog mit den anderen Religionen - dürfte es aber für eine öffentliche Wiederkehr entscheidend sein, dass sie ,welthaltig“ und d.h. umfassend plural kulturfähig werden können, so wie in den Zeiten ihrer großen Schlüsselepochen; und dass sie nicht an die „Fleischtöpfe“ und Sicherheiten eines integralistischen, konfessionellen Kulturmilieus mit den entsprechenden symbolischen Artikulationen zurück wollen. Das gilt auch für die ganze Problematik einer neuen Rede von sakraler bzw. gar christlicher Kunst, die vielleicht weniger in einer didaktisierenden, realistischen Mimesis ehrwürdiger Traditionen besteht, sondern in einem offenen Dialog zwischen der ikonographischen Überlieferung und den aktuellen Spiegelungen religiöser Topoi ${ }^{12}$ in zeitgenössischer autonomer Kunst, wie z.B. in deren Erfahrungsfeldern Mystik, Gedächtnis, Körper. ${ }^{13}$

\section{Kriteriologie für jede Religion, von der in Zukunft eine „Rückkehr“" nicht nur behauptet, sondern auch dringend erhofft werden kann.}

Indem wir nunmehr versuchen, vor dem Hintergrund der Blondelschen Modernismusintervention und der Weichenstellung des II. 
Vatikanums in loser Systematik eine fundamentaltheologische Kriteriologie für jede potentielle Wiederkehr von Religion bzw. für jede geistliche Bewegung, die als Religion sinnvoll auftreten könnte, zu erarbeiten, muss vor allem von Folgendem die Rede sein:

\subsection{Kriterium der „Globalisierungsfähigkeit“}

Ein Kriterium von besonderer Aktualität liegt - trotz aller Schlagseiten - im Horizont der aktuellen Globalisierung, sozusagen als einem providentiellen Parameter der universalen Heilsökonomie Gottes. Die Väter des II. Vatikanischen Konzils haben mit ihrem Ansatz in den 60er Jahren mehr Recht gehabt, als sie es damals übersehen konnten, wenn sie von dem immer engeren Zusammenwachsen des Menschengeschlechtes sprachen (Lumen Gentium, Nostra Aetate, Gaudium et Spes) und ein pastorales Nichtausschließungsprinzip vertraten. Auch ermöglicht die Chance der Globalisierung, die Vielfalt der Religionen verstärkt wahrzunehmen und diese im Rahmen einer alle gemeinsam berührenden Weltzivilisation füreinander zu öffnen.

Theologisch kann also wohl durch die Globalisierung - ungeachtet aller Probleme dieses Sachverhaltes - ein wachsendes Bewusstsein um die Einheit des Menschengeschlechtes (cf. Lumen Gentium 1) und der Verantwortung der Religionen, zumal der monotheistischen Universalreligionen, füreinander, vielleicht sogar ein gesunder Wettbewerb untereinander im Prozess der Einigung des Menschengeschlechtes entstehen - im Blick auf gemeinsame Aufgaben (Stichwort „Weltethos“; Überwindung eines potentiellen „clash of civilizations“; Ehrfurcht vor dem Heiligen) gegenüber der durch eben diese Globalisierung gefährdeten Welt. Zumal die Religion der Inkarnation des Logos und der universalen Geistausgießung müsste dem Tonfall neu sich artikulierender Religiosität nachgehen und sich auch kritisch mit dem Verfehlen bzw. Falsch-Verstehen von Globalisierung auseinandersetzen. Denn obwohl diese aus der Fernwirkung des Christentums entstand (cf. „Katholizität“ der Kirche) und eine Chance von universaler Nähe und Gleichzeitigkeit der Religionen zueinander bedeutet, birgt sie, durch den neuen ökonomischen Heilsraum des Marktes und der Zivilreligion der Medien auch die Gefahr von verschleiernden quasireligiösen Ersatztotalitäten in sich bzw. von diffusen religiösen Synkretismen. 


\subsection{Kriterium der Anerkennung von Grundsätzen europäischer Freibeitsgeschichte}

Ein potentielles, gesellschaftlich kulturelles Wiederbedeutsamwerden der Religionen wird vor allem nicht an der Anerkennung von Grundsätzen der europäischen Freiheitsgeschichte, wie Anerkennung des (unideologischen) Liberalismus, vorbei erfolgen können. Denn die Kirchen und Religionen selbst leben von den Freiheitsräumen eines politischen und gesellschaftlichen Liberalismus auch dort, wo sie ihn kritisieren. Das Böckenförde-Paradoxon gilt nicht nur in Bezug auf die Gesellschaft bzw. den modernen Verfassungsstaat, sondern auch im Blick auf die Kirchen und Religionen, die ihrerseits von modernen Freiheitsspielregelräumen leben, die sie in Anspruch nehmen, aber selbst nicht sicherstellen könnten.

Dennoch oder gerade deswegen muss vor allem das Christentum auch dazu stehen, was es an Prozessen und Inhalten der Aufklärung mit hervorgebracht hat im Bereich der Menschenrechte und -pflichten, der Würde des Menschen, seiner Innerlichkeit und Autonomie der kritischen Vernunft - auch mit den Aspekten von Pluralismus und Relativismus. Aber auch jede andere Religion, der heute machtvoll (wieder) aufzutreten ermöglicht wird, hat diese Grundwerte anzuerkennen und zu schützen. Diese dürfen nicht zugunsten heteronomer, autoritativer Fremdbestimmung verspielt werden. Das Kriterium schlägt auch da, wo binnenchristlich wiederkehrende religiöse Tendenzen einem Freiheits- bzw. kritische VernunftDefätismus im Sinne einer völligen Aporetisierung der neuzeitlichen Vernunft das Wort reden wollten, etwa mit der Alternative eines „Wissens aus der Taufe“. ${ }^{14}$

\subsection{Kriterium der Respektierung von Säkularität}

Vielfach neigt man gegenwärtig in manchen Kirchen bzw. Religionen auch dazu, Säkularisierung als etwas eher schlechthin zu Bekämpfendes und möglichst zu Revozierendes anzusehen und - falls gesellschaftspolitisch bzw. kulturpolitisch nicht möglich - dann zumindest durch die Betonung klerikaler Gegenwelten zu kompensieren. Es ist von potentiell ,rückkehrenden“ Religionen also - ungeachtet der Engführungen europäisch laizistischer Säkularisierungsteleologie - prinzipiell ein Mindestmaß an theologischer Anerken- 
nung solcher Säkularität zu verlangen. ${ }^{15}$ Und man muss dieses Kriterium betonen angesichts jenes Gejammers über Säkularisierung, welche man pauschal als Glaubensabfall mit immer radikalerer Zuspitzung versteht und dabei nicht die historischen staatskirchenrechtlichen Errungenschaften im Säkularisierungsprozess sowie die kulturellen Chancen der Neukonfigurierung von in der säkularen kulturellen Öffentlichkeit frei sich bewegenden, dekonstruierten christlichen Überlieferungselementen sieht.

Darf schließlich theologisch nicht auch gedacht werden, dass die moderne Säkularität als Kontext der Religionen in der Heilsökonomie Gottes vorgesehen ist und nicht nur schieren Abfall verkörpert? Zur Prüfung und Läuterung der Religionen nach oft furchtbaren Religionskriegen und integralistischen Sackgassen, zur Beförderung der Freiheit des Glaubens erschien eine solche geschichtliche Phase als notwendig. Vattimo (wie vor ihm schon Bonhoeffer und Hegel) betont das sogar theologisch von der Kenosis her und Habermas sieht darin eine legitime geschichtstheoretische Kategorie, die freilich einen „uneinholbaren Rest“, der nicht säkularisierbar sei, offen lasse (,,so etwa die Hoffnung auf Ressurektion“ der Opfer der Geschichte... ).

Und ein gedeihliches, wachsendes Zueinander der Religionen in einem globalen Weltkontext scheint auch eine Anerkenntnis von Säkularität (die ja im Positiven wie im Negativen durchaus auch religionsgeneriert ist) einzuschließen und damit eine nur scheinbar sich relativierende Pluralität zu befördern.

Damit ist jedenfalls für jede Rückkehrbehauptung eine Dimension der Relativierung von religiösen Absolutheitsansprüchen gegeben. Und irgendwie werden sich alle Religionen, ob sie es wollen oder nicht, in dem Maße als die globale Welt zum gemeinsamen Lebenskontext wird, damit arrangieren müssen. Sie tun das ja auch de facto schon mit der Annahme der Moderne zumindest via Technik. Das muss aber von allen Religionen auch in der Sache anerkannt werden und bedeutet für sie natürlich eine gewisse Selbsteinschränkung (Pluralismus, Gewaltenteilung), aber ebenso die Chance zur stärkeren Hervorkehrung des je Eigenen bei gleichzeitiger Gesprächsfähigkeit auch mit Atheisten und Nichtglaubenden und der

15 Vgl. das Vatikanum II mit seiner Anerkennung der Autonomie der weltlichen Sachbereiche (Gaudium et Spes 36). 
gegenseitigen Durchdringung der von Huntington irrtümlich als geschlossen angesehenen Kulturkreise. Als heilsgeschichtliche Entdeckung bleibt jedenfalls: Religion ist mehr, wenn sie nicht integralistisch alles ist/sein muss. Das ist im Zeitalter eines grassierenden Fundamentalismus zu betonen.

\subsection{Kriterium eines „Antiintegralismus“}

Aus dem vorhergehenden folgt ferner, dass ein integralistisches Verhältnis von Religion und Politik, d.h. ohne klare Unterscheidung und kontrollierte Zuständigkeiten, im Ernst nicht mehr in Frage kommen kann, wenngleich so manche dies heute vielleicht wieder so wollten. Man denke nur an verschiedene römische europapolitische Interventionen oder an den vatikanischen Druck auf die italienische Innenpolitik; auch sollten römische Initiativen, wie die Seligsprechungen hunderter spanischer Martyrer aus der Bürgerkriegszeit, Einfluss auf die spanische Wahl ausüben; in Polen wird über Radio Maria Politik gemacht; und die Intelligent Design-Debatte wurde nicht zufällig von den USA her jetzt bei uns lanciert; die Verurteilung der Befreiungstheologie in der Person von Jon Sobrino ist ebenfalls signifikant.

Besonders auch im Blick auf freikirchliche Fundamentalisten in den USA und Lateinamerika, und natürlich auch im Blick auf gewisse islamische Gemeinden bzw. Vereinigungen in Westeuropa, die in ihren Paragesellschaften vielfach fundamentalistischer leben möchten als in ihren muslimisch geprägten Herkunftsländern möglich (von den islamistischen Terroristen ganz zu schweigen), gibt es da recht irritierende Signale.

\subsection{Kriterium der Kulturfähigkeit}

Eine weitere kriteriologische Anfrage an eine zurückkehrende Religion wäre, wie kulturfähig diese denn sei? Strahlt sie nur die große Selbstbehauptung ihres Eigensinns aus oder ist sie fähig, ihre neue Positionalität in offene und (selbst)kritische kulturelle Auseinandersetzungen einzubringen, v.a. angesichts der Disseminationen des Christlichen in die Kultur der Neuzeit. Ein stärkeres Selbstbewusstwerden der christlichen Traditionen (nicht nur in Europa) ist also sicher prinzipiell sinnvoll (vgl. den Kommunitarismus), sollte aber von Christen doch zugleich um einer Transgressivität und Dialogfähigkeit willen in heutige Kultur und Kunst hinein angestrebt werden; 
es dürfte keine traditionalistische oder bloß historistisch museale Konsolidierungsstrategie für sich damit verbunden sein. In unserer Gegenwart fundamentalistischer Kurzschlüsse sollten die christlichen Kirchen nicht einfach das nach Wolfgang Schöne seit der Moderne entzogene Gottesbild selbstmächtig als wiedergefunden behaupten oder die nach Hans Sedlmayr verlorene Mitte krampfhaft wiederbesetzen wollen, sondern sich vorsichtig in einem Dialog dafür bereiten, aus der Pflege des Überlieferten und der Zumutung des experimentell Neuen die wahrhaft sakrale Kunst wiedergeschenkt zu bekommen (Arnulf Rainer).

\subsection{Kriterium der Anerkenntnis eines eschatologischen Vorbehalts}

Mit der zuvor angesprochenen, prinzipiellen Selbsteinschränkung „wiederkehrender“ Religionen ist auch eine eschatologische „Relativierung" der Religionen theologisch sinnvoll einzuschärfen, ohne in Aporien pluralistischer Religionstheologie zu verfallen. Gibt es denn menschheitsgeschichtlich nicht epochale Erfahrungen, die uns davor zurückschrecken lassen sollten, Gott heilsökonomisch allzu eilfertig über die Schulter schauen zu wollen; Erfahrungen der Distanzierung und Irritation (vor allem angesichts des Theodizeeproblems), die gedacht werden können müssen, z.B. als Gottes Wartenkönnen in der Kraft seines Geistes (Verweyen)? Bezüglich providentieller Absichten in größeren Geschichtszusammenhängen sollten wir uns vielleicht darauf bescheiden, dass Gott Spielräume der Freiheit für seine Heilsökonomie aufreißt, sich jedoch trotz der Inkarnation seine definitive Manifestation am Ende der Zeiten vorbehält. Gott will eben in der Zeit die Vielfalt der Spiegelungen und Brechungen seiner Heilsökonomie, und die Vielfalt der Inkulturationen seines Heilswillens, will den Wettstreit der Liebe (s. Lessings Nathan), die Begegnung und den Dialog; für welche es geschichtlich voranschreitend eine immer dringlichere Zeit gibt.

Das alles ist nicht inklusivistisch vereinnahmend gedacht, aber auch nicht resignativ pluralistisch. Es geht heilsökonomisch offenkundig nicht darum, dass alle Menschen durch unsere Missionsanstrengungen explizit Christen werden. Vielmehr soll wohl das Zeugnis vom Heil und vom Heiligen vielfältig, also z.B. monotheistischprophetisch, heilsgeschichtlich oder eher asiatisch, weisheitlichpneumatisch erklingen, je nach den kulturellen Möglichkeiten, und sich fortschreitend gegenseitig induzieren. Dies bedeutet, heute im Horizont der Globalisierung als wechselseitiger Herausforderung 
und Anregung voneinander zu lernen bzw. im Spiegel der anderen das jeweils vielleicht verborgene Eigene freizulegen und es unter Einschluss des Anderen weiterzudenken.

\section{Schlussbemerkung: Dialektik von kritischer Vernunft und Glaube}

Wir sind schließlich der Überzeugung, dass eine Wiederkehr von Religionen weder als „naturwüchsiges“ metaphysisches Ereignis noch bloß als Konterstrategie herbeigesehnt oder gar instrumentalisiert werden darf, sondern nur als ein Prozess erwünscht sein kann, der vernünftigen Kriterien unterworfen ist und der eine kreative Neukonfigurierung der Überlieferung auf die heilsgeschichtliche Zukunft hin einschließt.

Wenn das Goya-Wort zutrifft, dass der Schlaf der Vernunft Ungeheuer gebiert, dann in Sachen Politik und Religion, Vernunft und Glaube. Es ist deshalb die Grundspannung von selbstkritischer Vernunft und selbstkritischem Glauben an alle neuen oder wiederkommenden Ansprüche von Religionen anzulegen. Eine solche Dialektik von Vernunft und Glaube käme z.B. in einer „Zustimmung im Widerspruch" zum Zeitkontext der Moderne zum Ausdruck; etwa dadurch, dass die neuen sozialen und ökonomischen Tendenzen einem Lackmustest im Lichte der anspruchsvollen religiösen Inhalte der eigenen christlichen Überlieferung unterzogen werden.

So z.B. konkret im Blick auf die Logik des Tauschmarktes im Widerspruch zum christologisch begründeten Charitismus eines Blondel, worin das praktische Schlüsselkonzept liebender traditio bzw. Anerkennung entfaltet wird. Kirchen und Religionsgemeinschaften können mit solcher Anknüpfung im Widerspruch in plurale und säkulare Bewusstseinshorizonte hinein glaubwürdige, normative Einreden anbringen. Sie können aber eine solche prophetisch kritische Vernunftstimme nur erheben, wenn sie nicht von außen her abstrakt reden. Diese Grundhaltung hätte sich auch auszuwirken auf eine kritische, zeitdiagnostische Sicht der Moderne insgesamt, wobei zu entscheiden wäre, ob Kirche eher polemisch das apokalyptische Register bedienen oder, sich selbst involvierend, betroffen und konkret kritisch sprechen soll.

So etwa wie das Kardinal Joseph Ratzinger und Jürgen Habermas an der Bayerischen Akademie getan haben, wenn sie Vernunft 
und Glaube ,in einem universalen Prozess der Reinigung und des komplementären Lernens aneinander verwiesen" sehen. ${ }^{16}$ Mit dem Stichwort von der Wiederkehr ist also nicht einfach eine naturwüchsige Rückkehr der Religionen gemeint, sondern wird eine Wiederkehr in Verwandlung, im Neukonfigurieren religiöser Überlieferungen aus der Kraft des Geistes in die Gegenwart und Zukunft unserer Zeit hinein erhofft. Solche „Rückkehr“ darf nichts archaisch Zwanghaftes an sich haben, sondern muss notwendig durchsäuert sein von Wirkkriterien des Heiligen Geistes - der Toleranz bzw. der ökumenischen Offenheit in der Achtung des Heiligen sowie des Respekts vor der modernen Säkularität und der universalen menschlichen Solidarität

\section{Literatur}

Appel, Kurt (2008): Zeit und Gott. Mythos und Logos der Zeit im Anschluss an Hegel und Schelling. Paderborn: Schöningh.

Blondel, Maurice (1910): La semaine sociale de Bordeaux et le monophorisme. Paris 1910.

Blondel, Maurice (1965): Die Aktion. Versuch einer Kritik des Lebens und einer Wissenschaft der Praktik. Freiburg i.Br.: Alber.

Blondel, Maurice (1974): Zur Methode der Religionsphilosophie. Mit einer Einleitung von Hansjürgen Verweyen. Einsiedeln: Johannes Verlag.

Böckenförde, Ernst-Wolfgang (1976): Staat, Gesellschaft, Freiheit. Frankfurt a.M.: Suhrkamp.

De Lubac, Henri (1970): Glauben aus der Liebe. Mit einer Einleitung von Hans Urs von Balthasar. Einsiedeln: Johannes Verlag.

Grenier, Catherine (2003): L'art contemporain est-il chrétien? Nimes: Chambon.

Kölbl, Alois/Larcher, Gerhard/Rauchenberger, Johannes, Hg. (1997): Katalog zur Ausstellung, ENTGEGEN. ReligionGedächtnisKörper in Gegenwartskunst'. Ostfildern-Ruit: Cantz.

Larcher, Gerhard (1999): „Zwischen Tradition und Modernität - Maurice Blondels Impulse für Kirche, Theologie und Gesellschaft im 20. Jahrhundert", in: Autiero, Antonio/Menke, Karl-Heinz, Hg.: Brückenbauer zwischen Kirche und Gesellschaft - A. Rosmini, J. H. Newman, M. Blondel und R. Guardini. Münster: Lit, 59-75.

Müller, Klaus (2007): „Balancen philosophischer Topographie. Jürgen Habermas über Vernunft und Glaube“, in: Langthaler, Rudolf/Nagl- 
Docekal, Herta, Hg.: Glauben und Wissen. Ein Symposium mit Jürgen Habermas. Wien: Oldenbourg, 216-237.

Sander, Hans-Joachim (2009): „Von der Modernismus- zur Postmodernismus-Krise“, in: R. Bucher, Ch. Heil, G. Larcher, M. Sohn-Kronthaler, Hg.: Methodenvielfalt und Kirchlichkeit der Theologie. Der Modernismusstreit 100 Jahre danach. Innsbruck: Tyrolia, Druck in Vorbereitung.

Sutton, Michael (1994): Charles Maurras et les Catholiques Francais. 1890 1914. Nationalisme et Positivisme. Paris: Beauchesne.

Zizek, Slavoj (2001): Die gnadenlose Liebe. Frankfurt a.M.: Suhrkamp. 


\title{
Habermas, Ratzinger und die postsäkulare Gesellschaft
}

\author{
Walter Reese-Schäfer
}

\section{Einleitung}

Als Habermas im Jahre 2001 bei der Verleihung des Friedenspreises des deutschen Buchhandels seine Rede „Glauben und Wissen“ hielt, wurde für eine breite Öffentlichkeit sichtbar, wie intensiv er sich für Fragen der Religion interessierte. Es wäre jedoch ein Irrtum zu meinen, es handele sich um das späterwachte Interesse eines Siebzigjährigen. Denn schon seit seiner Assistentenzeit am Lehrstuhl von Theodor W. Adorno hat er bemerkenswerte Aufsätze über den messianischen Glutkern des Denkens der Frankfurter Schule veröffentlicht, so in seiner Auseinandersetzung mit der Aktualität Walter Benjamins im Jahre 1972 oder seiner Würdigung Gershom Sholems unter dem Titel „Die verkleidete Tora“ von 1978. ${ }^{1}$ Johann Baptist Metz ist über Jahre hinweg ein wichtiger Gesprächspartner für $\mathrm{Ha}$ bermas gewesen, was dieser in seinem Aufsatz „Israel oder Athen? Johann Baptist Metz zur Einheit in der multikulturellen Vielfalt" offengelegt hat. ${ }^{2}$ Daher hatte ich in meiner Darstellung der Theorie von Habermas auch ein Kapitel mit dem Titel „Eine habermasianische Theologie?" aufgenommen und bei ihm eine Art nachreligiöse Soziotheologie verbunden mit einer Konzeption der 
Versprachlichung des Sakralen und Ansätzen zu einer ekstatischen Sprachverwendung ausgemacht. ${ }^{3}$ Aber auch die theologische Rezeption der Philosophie von Habermas ist umfassend dokumentiert. ${ }^{4}$

Habermas hat den Begriff der Kommunikation nicht nur in das Zentrum seines Denkens gestellt, er hat dieses auch im permanenten Diskurs mit anderen Positionen entwickelt. So war es ein naheliegender Schritt der Münchner katholischen Akademie und der dortigen Jesuitenhochschule, am 19. Januar 2004 ein Gespräch zwischen Jürgen Habermas und dem damaligen Kardinal Joseph Ratzinger als dem bedeutendsten Theologen der katholischen Kirche zu arrangieren. Dort wurden keine diplomatischen Floskeln ausgetauscht, sondern es wurden auf höchstem intellektuellem Niveau einige Grundprobleme im Verhältnis von Politik und Religion verhandelt. Hier trafen sich als gleichrangige Gesprächspartner der agnostische, nachmetaphysische Philosoph des Projekts der Moderne und der Theologe des Primats der Vernunft. ${ }^{5}$

\section{Die Friedenspreisrede „Glauben und Wissen“}

Am Ursprung dieses Treffens stand der Habermas-Vortrag aus dem Jahre 2001. Die Überschrift lautete „Glauben und Wissen“, das wirkliche Thema war aber nicht so weit gefasst, sondern es ging um den politischen Umgang mit religiösen Denk- und Verhaltensweisen sowie religiösen Gruppen in einer angeblich säkularisierten, aber, wie Habermas in der Rede fünfmal betonte, in Wirklichkeit postsäkularen Gesellschaft. Spannungen zwischen Religion und organisierter Wissenschaft waren seit langem zu konstatieren gewesen, besonders in der Frage der Gentechnik. Jedoch sei diese Spannung, merkte Habermas in seiner Diagnose des Anschlags vom 11. September 2001 an, nun auf ganz andere Weise explodiert. Habermas vermerkte in den ersten Reden von Präsident Bush nach dem Attentat einen alttestamentarischen Klang der Vergeltung und stellte fest, dass sich die Synagogen, Kirchen und Moscheen wieder gefüllt hätten, so als

3 Reese-Schäfer (2001a), 157-163.

4 Arens (1989).

5 Zur Theologie des Logosprimats vgl. Benedikt XVI (2006) und Ratzinger (2005a), bes. 112-130. Positiv kommentierend Gesine Schwan: Mut zur Weite der Vernunft. Braucht Wissenschaft Religion? In: Benedikt XVI (2006), 33-76. 
sei hierdurch eine der religiösen Saiten der Gesellschaft wieder in Schwingungen versetzt worden.

Habermas betont, wie die meisten Zeitdiagnostiker, dass religiöser Fundamentalismus ein ausschließlich modernes Phänomen sei, nämlich eine Reaktion auf den Zerfall traditionaler Lebensformen, eine Modernisierungsreaktion also, die selber durchaus auf moderne Mittel zurückgreift. Hierbei ist anzumerken, dass die politischen Ideengeschichtler seit langem erkannt haben, dass auch der Konservatismus und das reaktionäre Denken Reaktionsphänomene auf die europäischen Revolutionen, besonders auf die französische Revolution, gewesen sind, denn eine Tradition, die mit sich einig ist, wird gelebt und bedarf keiner besonderen Denkanstrengungen.

Die Idee der Säkularisierung, die Habermas unumwunden mit der Säkularisation gleichsetzt, von der wir im Geschichtsunterricht gelernt hatten, sie sei die Auflösung und Übertragung von Kirchengütern an die weltlichen Fürsten bzw. den Staat gewesen, enthielt einen geschichtsphilosophischen Zug. Der Prozess der Verdrängung der Kirchen und der Religion aus der nunmehr aufgeklärten modernen Alltagswelt beschleunige sich mehr und mehr bis hin zu einem vollends säkularen Zustand, in dem Religiosität allenfalls noch in Nischen überlebe. Nun hat sich aber gezeigt, dass religiöse Gemeinschaften in einem säkularen Umfeld fortbestehen, dass sie, sozialwissenschaftlich gesprochen, eine hartnäckige Persistenz aufweisen. Es kommen sogar neue hinzu, die auch auf staatliche Anerkennung in Deutschland zielen, wie sich gerade wieder bei der Gründung des „Koordinierungsrats der Muslime“ (Ende März 2007) gezeigt hat. Sie werden darüber hinaus noch vom Staat ermuntert, da dieser nach verbindlichen Ansprechpartnern sucht, die auch bereit sind, sich dem Primat des Staates und der Zivilität zu unterwerfen. Das Gründungsdokument des islamischen Koordinierungsrats bekennt sich ausdrücklich zur freiheitlich demokratischen Grundordnung und erklärt erst anschließend, dass Koran und Sunna des Propheten Mohammed die Grundlage für die Arbeit dieses Rates seien. Hierbei ist allerdings zu bemerken, dass mittlerweile auch das Bundesinnenministerium nicht mehr daran glaubt, dass sich der Koordinierungsrat als Ansprechpartner und Hauptrepräsentant des Islam in Deutschland eignen wird. Das Bekenntnis zur freiheitlichdemokratischen Grundordnung gehört zur rhetorischen Pflicht- 
übung der Verbände, dennoch üben Milli Görüş und teilweise auch die Muslimbrüder einen dominierenden Einfluss aus. ${ }^{6}$

Aus der Sicht des liberalen Staatsdenkens erwirbt eine Religionsgemeinschaft auf diese Weise das Prädikat „vernünftig“, wie Habermas mit einer gewissen Distanz von dieser Position referiert. Aus eigener Einsicht sollen die Religionsgemeinschaften ,auf eine gewaltsame Durchsetzung ihrer Glaubenswahrheiten und auf den militanten Gewissenszwang gegen die eigenen Mitglieder, erst recht auf eine Manipulation zu Selbstmordattentaten Verzicht leisten. "7 Die in der säkularen Welt überlebenden bzw. neu sich einleben wollenden Religionen müssen nämlich drei Grunderfahrungen verarbeiten: 1. sie müssen die kognitiv dissonante Begegnung mit anderen Konfessionen und anderen Religionen verarbeiten, 2. sie müssen sich auf die Autorität von Wissenschaften einstellen, die das gesellschaftliche Monopol an Weltwissen innehaben, und 3. sie müssen sich auf die Prämissen des demokratischen Verfassungsstaates einlassen, die sich aus seiner profanen, nicht religiösen Moral begründen. ${ }^{8}$

Hier zeigt sich das aus religiöser Sicht anstößige Faktum des weltanschaulichen Pluralismus, das verarbeitet werden muss, ohne in der Manier von Konfessions- und Religionskriegen das soziale Band des politischen Gemeinwesens zu zerreißen. Und an diesem Punkt bringt Habermas einen neuen und von vielen als überraschend empfundenen Ton in die Debatte, weil er hier ein wenig von der klassischen Lehre des politischen Liberalismus abweicht.

Der klassische Liberalismus hatte nämlich die fortschreitende Verlagerung des Religiösen in die Privatsphäre und damit dessen Entpolitisierung postuliert, ganz im Sinne der Säkularisierungsthese. Und dies im doppelten Sinne: als faktischer Prozess, aber auch als Forderung an die Religiosität, sich aus der Politik herauszuhalten. Der moderne Liberalismus von Rawls und anderen, den Habermas hier übernimmt und zuspitzt, ist dagegen postsäkular. Das heißt in

6 Der Koordinierungsrat der Muslime in Deutschland (KRM) ist der Spitzenverband der vier größten islamischen Organisationen in Deutschland. Er wurde am 11. April 2007 vom Zentralrat der Muslime in Deutschland (ZMD), der Türkisch-Islamischen Union der Anstalt für Religion (DİTIB), dem Islamrat für die Bundesrepublik Deutschland (IRD) und dem Verband der Islamischen Kulturzentren (VIKZ) gegründet.

7 Habermas (2001), 14. Er bezieht sich hier auf Rawls (1998), 132-141 und Forst (2000), 144-161.

8 Habermas (2001), 14. 
diesem Zusammenhang: Der Staat soll selbstverständlich ein weltanschaulich neutraler und in diesem Sinne säkularer Staat bleiben, seine Aufgabe wird aber anders verstanden. Da er für alle Bürger da ist, auch für die religiösen, bedeutet Neutralität nunmehr auch, dass er nicht ohne weiteres die Partei des Säkularismus ergreifen darf, sondern zur gleichmäßigen Distanz von starken Traditionen und weltanschaulichen Inhalten genötigt ist. Er darf sich also auch nicht ohne weiteres auf die Seite von naturwissenschaftlichen Moralansprüchen oder Ideologien stellen. An dieser Stelle geht Habermas von einer Theorie des Staates zu einer Theorie der Zivilgesellschaft über, oder fast schon hegelianisch, zu einer Theorie der pluralisierten Vernunft des Staatsbürgerpublikums: diese folge einer Dynamik der Säkularisierung nur insofern, als sie osmotisch nach beiden Seiten hin geöffnet bleibe - weil natürlich im zivilgesellschaftlichen Diskurs jede Meinung sich Gehör verschaffen kann, ohne deshalb schon politisch-staatliches Handeln zu beeinflussen oder gar zu steuern.

Da Habermas ein Theoretiker nicht so sehr des Staates als vielmehr der Zivilgesellschaft ist, hat er es an diesem Punkt etwas einfacher in der Argumentation, denn die Zivilgesellschaft ist anders als der liberale Staat nicht der weltanschaulichen Neutralität verpflichtet. „Die Zivilgesellschaft setzt sich aus jenen mehr oder weniger spontan entstandenen Vereinigungen, Organisationen und Bewegungen zusammen, welche die Resonanz, die die gesellschaftlichen Problemlagen in den privaten Lebensbereichen finden, aufnehmen, kondensieren und lautverstärkend an die politische Öffentlichkeit weiterleiten." ${ }^{\text {"Sie }}$ übt Einfluss aus auf eine in öffentlichen Debatten, also im Kontroversstil, sich herausbildende öffentliche Meinung, ohne jedoch direkten Zugang zu den organisatorischen Herrschaftsstrukturen zu gewinnen.

Allerdings ist in der Zivilgesellschaft nicht jede beliebige exzentrische religiöse Positionierung akzeptabel. Vielmehr kann sie sich ohne eine gewisse Öffnung und Offenheit für wissenschaftliche Argumentationen und Forschungsergebnisse nicht weiterentwickeln: „Natürlich muss sich der Commonsense, der sich über die Welt viele Illusionen macht, von den Wissenschaften vorbehaltlos aufklären lassen." 10 Sie unterliegt also einer Selbstbegrenzung. ${ }^{11}$ Auch ihr 
Selbstverständnis entwickelt sich mit der Entwicklung der naturwissenschaftlichen Episteme: „Wenn wir über die Welt, und über uns als Wesen in der Welt, etwas Neues lernen, verändert sich der Inhalt unseres Selbstverständnisses."12 Allerdings zieht er eine philosophische Grenze dieser Veränderung. Sobald es nicht mehr um naturwissenschaftliche Erklärung, sondern um Rechtfertigung moralischen Handelns geht, werden die Wissenschaften unzuständig. Das gilt selbst für die Hirnforschung mit ihrer Naturalisierung des Geistes, wie Habermas mit einem sprachtheoretischen Argument zu belegen versucht: das Sprachspiel der Rechtfertigung lässt sich nicht auf die bloße Beschreibung reduzieren, denn die Notwendigkeit, andere Gründe für das Handeln anzugeben, erschließt sich nicht aus der Außenperspektive und der objektivierenden Beschreibung, sondern nur aus der Perspektive des Beteiligten. Oder kurz: Gründe sind keine Ursachen. Das Sprachspiel der Begründung im moralischen Diskurs unterscheidet sich grundsätzlich von der wissenschaftlichen Ursachenanalyse im kognitiven Diskurs. „Der szientistische Glaube an eine Wissenschaft, die eines Tages das personale Selbstverständnis durch eine objektivierende Selbstbeschreibung nicht nur ergänzt, sondern ablöst, ist nicht Wissenschaft, sondern schlechte Philosophie. Auch dem wissenschaftlich aufgeklärten Commonsense wird es keine Wissenschaft abnehmen, beispielsweise zu beurteilen, wie wir unter molekularbiologischen Beschreibungen, die gentechnische Eingriffe möglich machen, mit vorpersonalem menschlichem Leben umgehen sollen." $" 13$

An diesem Punkt liegt zweifellos ein möglicher Einfallspunkt christlicher Argumente gegen die Genforschung und Gentechnologie. Und nun, an dieser Stelle, betont Habermas, dass der Commonsense, als dessen zivilgesellschaftliches Sprachrohr er selbst sich offenbar versteht, sowohl gegenüber der Wissenschaft als auch gegenüber der religiösen Überlieferung einen Eigensinn bewahrt.

Denn der demokratisch aufgeklärte Commonsense, also $\mathrm{Ha}$ bermas, stellt auch in Richtung der Religion die Frage, ob sie denn Gründe angeben könne, „die nicht nur für Angehörige einer Glaubensgemeinschaft akzeptabel sind." 14 Das führt bei den Gläubigen dann zu dem Argwohn, „dass die abendländische Säkularisierung 
eine Einbahnstraße sein könne, die die Religion am Rande liegen lässt."15 Hier kommt Habermas auf eine Kehrseite der Säkularisierung, nämlich auf die ungleichen Folgelasten, die die Befriedung des weltanschaulichen Pluralismus für die Religion und die nichtreligiösen Menschen hatte. „Bisher mutet ja der liberale Staat nur den Gläubigen unter seinen Bürgern zu, ihre Identität gleichsam in öffentliche und private Anteile aufzuspalten. Sie sind es, die ihre religiösen Überzeugungen in eine säkulare Sprache übersetzen müssen, bevor ihre Argumente Aussicht haben, die Zustimmung von Mehrheiten zu finden." 16 Wenn es z.B. um eine Eizelle außerhalb des Mutterleibs geht, muss der Versuch unternommen werden, die theologische These von der Gottesebenbildlichkeit des Menschen in die säkulare Sprache des Grundgesetzes zu übersetzen. Würden ausschließlich säkulare Argumente gelten, würde das einen unfairen Ausschluss der Religion aus der Öffentlichkeit bedeuten. Die säkulare Gesellschaft selbst würde sich darüber hinaus von wichtigen Ressourcen der Sinnstiftung abschneiden. Um dem vorzubeugen, müsste ,sich auch die säkulare Seite einen Sinn für die Artikulationskraft religiöser Sprachen“" bewahren. ${ }^{17}$ Das ist der meines Erachtens entscheidende Schritt von Habermas in das Reich des Postsäkularen. Die Öffentlichkeit ist ja ein plurales Gebilde. Wenn sich Menschen in ihren Glaubensüberzeugungen verletzt fühlen, dürften säkulare Mehrheiten keine Beschlüsse fassen, sondern sollten das als Einspruch mit aufschiebendem Veto betrachten. ${ }^{18}$ Habermas hat dies vor dem Streit um die dänischen Mohammed-Karikaturen geschrieben. Es scheint mir aber offensichtlich, dass eine nicht auf rationale Fundierung angewiesene religiöse Empörungsrede jederzeit den eigenen Irrationalismus oder die eigene Aufgeregtheit im politischen Spiel instrumentell einsetzen kann. Ein derart weitgefasster, postsäkularer Liberalismus hätte dem nichts weiter entgegenzusetzen als die geduldige Prüfung der Gründe. Habermas fällt an dieser Stelle hinter Einsichten einer wehrhaften Demokratie zurück, die in der Auseinandersetzung mit den Totalitarismen des 20. Jahrhunderts gewonnen worden sind. ${ }^{19}$ 
Immerhin, Habermas hatte wohl an etwas anderes als an die künstliche Empörung religiöser Aktivisten gedacht. Als Beispiel nennt er Kants kategorisches Sollen, welches zugleich eine säkularisierende und rettende Dekonstruktion von Glaubenswahrheiten gewesen sei. Kants Autonomievorstellung zerstörte das traditionelle Modell der Gotteskindschaft. Oder in den Worten von Kant selbst: „Die Moral, so fern sie auf dem Begriffe des Menschen als eines freien, eben darum auch sich selbst durch seine Vernunft an unbedingte Gesetze bindenden Wesens, gegründet ist, bedarf weder der Idee eines andern Wesens über ihm, um seine Pflicht zu erkennen, noch einer andern Triebfeder als des Gesetzes selbst." 20 Als zweites Beispiel nennt Habermas einen Gedanken Adornos aus Vernunft und Offenbarung: „Nichts an theologischem Gehalt wird unverwandelt fortbestehen; ein jeglicher wird der Probe sich stellen müssen, ins Säkulare, Profane einzuwandern. "21 Als negatives Gegenbeispiel, in dem die Andacht zum Andenken mutiert, nennt er den Posthumanismus seines Erzfeindes Heidegger. Die Rückkehr zu den archaischen Anfängen vor Sokrates und vor Christus ist für ihn die „Stunde des religiösen Kitsches. “22

Die Entzauberung, die ja immer mit Säkularisierungsprozessen einhergeht, erscheint ihm unvermeidlich. Sie habe ja im Grunde auch schon durch die Weltreligionen selbst begonnen, die die Magie entzaubert, den Mythos überwunden, das Opfer sublimiert und das Geheimnis gelüftet hätten. Das Geschichtsmodell von Habermas geht hier ganz deutlich von einem Dreistufenmodell Mythos - Religion - Philosophie aus. „Die postsäkulare Gesellschaft setzt die Arbeit, die die Religion am Mythos vollbracht hat, an der Religion selbst fort. "23 Allerdings erfolgt die Entzauberung nicht mehr in der hybriden Absicht der feindlichen Übernahme, worauf einst die politischen Religionen des Totalitarismus abzielten, sondern mit dem Ziel, dem Schwinden von Sinnressourcen entgegenzuwirken, und zwar im Modus der rettenden Formulierungen bzw. der Übersetzung. Diesen Gedanken wendet Habermas dann zu einer Schlussformel, betreffend die Unverfügbarkeit der genetischen Disposition: „Nun man muss nicht an die theologischen Prämissen glauben, um die 
Konsequenz zu verstehen“, wenn die im Begriff des „Schöpfers“ angenommene Differenz verschwände und nunmehr ein anderer Mensch über die genetische Ausstattung nach eigenem Belieben entscheidet. Denn es würde die Freiheit unter Ebenbürtigen zerstört, wenn ,ein Mensch nach eigenen Präferenzen in die Zufallskombination von elterlichen Chromosomensätzen eingreifen würde, ohne dafür einen Konsens mit dem betroffenen Anderen wenigstens kontrafaktisch unterstellen zu dürfen." ${ }^{\text {"24 }}$

\section{Vorpolitische Grundlagen des demokratischen Rechtsstaats}

In der direkten Begegnung mit Kardinal Ratzinger, also in seinem Münchner Vortrag von 2004 hat Habermas das Thema der postsäkularen Gesellschaft erneut aufgegriffen, diesmal verbunden mit dem oft zitieren Böckenförde-Paradoxon aus den sechziger Jahren, demzufolge der freiheitliche, säkularisierte Staat von normativen Voraussetzungen zehre, die er selbst nicht garantieren könne. ${ }^{25} \mathrm{Da}$ hinter steht die Vermutung, dass er ein kaltes Projekt sei, das selber nicht die kommunikative Intensität erbringen könne, die zur Bildung tiefgreifender ethischer Verbindlichkeiten erforderlich sei. Der moderne Staat müsse daher auf ethische Überlieferungen traditionaler, vor allem religiöser Art zurückgreifen, denen er aber durch das weltanschauliche Neutralitätsgebot ständig zugleich den Boden entzieht. Wenn Pluralismus ein bloßer modus vivendi ist, dann können die Quellen einer Solidarität der Staatsbürger nicht mehr reproduziert werden. Die Säkularisierung entgleist, weil ihre gesellschaftlichen Quellen versiegen.

Habermas selbst übernimmt diese Gedanken nur mit einer gewissen Zurückhaltung: diese Diagnose sei zwar nicht von der Hand zu weisen, die Gebildeten unter den Verteidigern der Religion könnten daraus aber kaum einen besonderen argumentativen Gewinn ziehen. Er empfiehlt stattdessen, ganz im Sinne der schon in der Friedenspreisrede vorgetragenen Argumentation, einen doppelten, nämlich beidseitigen Lernprozess, in dem die Traditionen der Aufklärung (ganz im Sinne der selbstreflexiven Aufklärungskritik Hork- 
heimers und Adornos) und die religiösen Lehren sich zur Selbstreflexion auf ihre jeweiligen Grenzen nötigen.

Habermas verteidigt den politischen Liberalismus, wie er selbst sagt, in der Form eines Kantischen Republikanismus. Im Gegensatz zum Böckenförde-Paradoxon gibt er eine radikal andere Antwort auf die Frage, wie sich die staatsbürgerliche Solidarität reproduziert: nämlich selbstgenügsam, aus den kognitiven Beständen eines nicht nur von religiösen, sondern auch von metaphysischen Überlieferungen unabhängigen Argumentationshaushaltes. Ein Zweifel allerdings bleibt in der Frage der motivationalen Grundlagen. Bekanntlich gibt es fünf Probleme einer gegenwärtigen politischen Ethik, nämlich das Begründungsproblem, das Applikationsproblem, das Motivationsproblem, das Institutionenproblem und das Ausdifferenzierungsund Reintegrationsproblem. ${ }^{26}$ Während die Frage der Institutionalisierung, wenn wir einmal von der Notwendigkeit einer adaptiven Föderalismusreform absehen, einigermaßen überzeugend gelöst zu sein scheint, das Begründungsproblem in erträglicher Weise pragmatisch heruntertransformiert werden kann, das Applikationsproblem mit zunehmender Erfahrung demokratischer Systeme im Sinne gegenseitiger Lernprozesse z.B. in dem nie abzuschließenden Feld der Korruptionsbekämpfung doch immer wieder ganz erfrischende neue Lösungen findet, sind das Ausdifferenzierungs- und Reintegrationsproblem und vor allem das Motivationsproblem die schwierigsten Felder einer gegenwärtigen Ethiktheorie.

Denn das erste Problem ist in seiner Dimension bislang kaum verstanden worden, das zweite gewinnt zunehmend an Bedeutung, weil unter den Prämissen einer rationalen Entscheidungstheorie und einer zunehmenden Durchökonomisierung gerade auch des Alltagslebens und der Entscheidungsstrukturen des Einzelnen die Frage, warum man eigentlich moralisch sein solle und nicht vielmehr das Eigeninteresse in den Vordergrund stellen müsse, warum man besondere Opfer für moralisches Verhalten zu erbringen habe, immer schwieriger $\mathrm{zu}$ beantworten ist. Es war immer klar, dass eigenes moralisches Verhalten mit der Inkaufnahme von Nachteilen verbunden ist - andernfalls wäre der Sinn des Moralischen nicht erkennbar. Wäre es vorteilhafter als anderes Verhalten, dann bräuchte man 
keine Moral. Die Parole „Der Ehrliche ist der Dumme“ gibt das gängige Bewusstsein einigermaßen treffend wieder.

Es sind also die Motive. Die Bürger ,sollen ihre Kommunikations- und Teilnahmerechte aktiv, und zwar nicht nur im wohlverstandenen eigenen Interesse, sondern auch gemeinwohlorientiert wahrnehmen. Das verlangt einen kostspieligeren Motivationsaufwand, der legal nicht erzwungen werden kann." 27 Allerdings muss man dazu nicht notwendigerweise auf das religiöse Erbe zurückgreifen. Habermas meint, gut republikanisch (deshalb der Rückbezug auf den liberalen Republikanismus), dass die gemeinsam ausgeübte kommunikative Praxis des demokratischen Prozesses selbst das einigende Band und das motivationale Element darstellen müsste. In die Sprache der Religion übersetzt hieße das ja wohl: der Vollzug des demokratischen und kommunikativen Ritus soll auch die Motivation zur aktiven Beteiligung schaffen. Niedrige Wahlbeteiligung wäre dann so etwas wie geringer Zulauf zum Gottesdienst. Rousseau hatte geradezu eine demokratische Zivilreligion postuliert, mit wenigen einfachen, aber verbindlichen Dogmen, und war überzeugt, dass der demokratische Staat zusammenbrechen müsse, wenn der Bürger nicht ständig freudig zu den Versammlungen eile. Diese Assoziation versucht Habermas zu vermeiden, indem er seinen Republikanismus statt an Rousseau lieber an Immanuel Kant bindet, also an einen stärker individualistischen, antitotalitären Liberalismus, während man Rousseaus Demokratiekonzept - ob nun zu Recht oder zu Unrecht - eine totalitäre Basisorientierung nachsagt.

Zwar wird niemand bereit sein, „für Nizza zu sterben“, aber das ist eben kein Argument gegen eine gemeinsame europäische Verfassung. Ein ziviltheologisches Grundelement sieht Habermas in den politisch-ethischen Diskursen über den Holocaust und andere im Namen der eigenen Regierung begangene Massenverbrechen: die Gedächtnispolitik zeigt, wie sich nicht zuletzt auch außerhalb Deutschlands ,verfassungspatriotische Bindungen im Medium der Politik selbst bilden und erneuern können“". ${ }^{28}$ Verfassungspatriotismus heißt bei ihm entgegen einem weit verbreiteten reduktiven Missverständnis keineswegs nur eine Bindung an abstrakte Prinzipien, sondern an den konkreten Kontext der eigenen Geschichte 
und insbesondere der herausragenden Ereignisse, die zu beklagen oder zu feiern sind. Habermas gesteht zu, die weltweite Übereinstimmung in der moralischen Empörung über massive Menschenrechtsverletzungen würde allein ,nur für die hauchdünne Integration der Bürger einer politisch verfassten Weltgesellschaft genügen (wenn es sie denn eines Tages geben sollte)",29 meint aber, dass das dichtere Geflecht kultureller Wertorientierungen in einer Region, z.B. in der europäischen Gesellschaft, durchaus eine größere Verbindlichkeit gewinnen kann.

Die säkulare Modernisierung allerdings kann „entgleisen“, wenn dieses gemeinsame Staatsbürgerbewusstsein nicht entsteht, und so etwas stattfindet wie ,die Verwandlung der Bürger wohlhabender und friedlicher liberaler Gesellschaften in vereinzelte, selbstinteressiert handelnde Monaden, die ihre subjektiven Rechte nur noch wie Waffen gegeneinander richten. "30 Das ist die Gefahr, die ja auch von Kommunitariern wie Amitai Etzioni ${ }^{31}$ und Mary Ann Glendon (Rights Talk) ${ }^{32}$ sehr präzise herausgearbeitet worden ist. Wie Habermas arbeiten sie an der Rekonstruktion des gemeinsamen, sozialethisch-kulturellen Bandes von Gesellschaften, auf die sie angewiesen sind. Rechte allein können auch trennend und isolierend wirken. Darüber hinaus gilt: Wenn Märkte, die ja nicht wie staatliche Verwaltungen demokratisiert werden können, zunehmend Steuerungsfunktionen übernehmen, wenn also bisher normativ oder durch vorpolitische Kommunikation integrierte Bereiche nunmehr marktmäßig integriert werden, die öffentlichen Legitimationszwänge damit schrumpfen, dann kann das zur Entmutigung und zum Funktionsverlust demokratischer Meinungs- und Willensbildung führen. Wenn immer mehr Entscheidungsprozesse auf supranationalen Ebenen stattfinden und dort auch eher von ökonomischen statt von politischen Instanzen (Weltwährungsfonds, Welthandelsorganisation) getroffen werden, dann kann das eben auch den staatsbürgerlichen Privatismus und die Entfremdung vom politischen Prozess verstärken. 


\section{Säkularisierung als europäischer Sonderweg}

Die Säkularisierungsdiskussion kulminiert in der sogenannten Teheraner Frage, die ein dortiger Kollege an Habermas gerichtet hat: Sei nicht möglicherweise der europäische Säkularisierungsprozess im weltweiten Maßstab gesehen ein Sonderweg gewesen, der nunmehr einer Korrektur bedürfe? ${ }^{33}$ Seine Antwort darauf ist leider einigermaßen oberflächlich ausgefallen, denn er fühlte sich dadurch erinnert an die Stimmungslage der Weimarer Republik, an Carl Schmitt, Martin Heidegger oder Leo Strauß. Zu solchen Argumenten, die ja einen denunziatorischen Zug haben und statt einer inhaltlichen Aussage im Grunde nur mit einem Etikettenaufkleben, einem „labeling" arbeiten, greift Habermas in seinen schwächsten Momenten recht gern.

Es ist bemerkenswert, dass in jenem Münchner Gespräch an genau diesem Punkt Joseph Ratzinger eingehakt hat, der empfahl, diese Frage doch deutlich ernster zu nehmen. In interessanter Weise hat er - in der mündlichen Kommunikation - den Namen von Leo Strauss, der bei Habermas ohnehin nicht ganz in diese Reihe gepasst hatte, missverstanden. Ratzinger bemerkt, dass man von der faktischen Nichtuniversalität der beiden großen Kulturen des Westens, nämlich der Kultur des christlichen Glaubens und derjenigen der säkularen Rationalität, ausgehen müsse, so sehr diese weltweit und in allen übrigen Kulturen starke Prägungswirkungen entfaltet hätten. „Insofern scheint mir die Frage des Teheraner Kollegen, die Jürgen Habermas erwähnt hat, doch von einigem Gewicht zu sein, die Frage nämlich, ob nicht aus kulturvergleichender und religionssoziologischer Sicht die europäische Säkularisierung ein Sonderweg sei, der der Korrektur bedürfe. Ich würde diese Frage nicht unbedingt, jedenfalls nicht notwendig, auf die Stimmungslage von Carl Schmitt, Martin Heidegger und Levi Strauss, sozusagen einer rationalitätsmüden europäischen Situation, reduzieren. "34 Claude Levi-Strauss war ja der Prophet der Interkulturalität und des kulturellen Relativismus und ist bis heute eine Art Ikone vernunftkritischer Diskurse. Genaugenommen ist das Missverständnis ein besseres Verständnis dessen, was Habermas meinte, mit der hinzugefügten Diagnose der Rationalitätsmüdigkeit, was aus der Sicht Ratzingers mit seiner starken Ver- 
nunftorientierung nicht nur im Sinne einer rationalen Theologie, sondern vor allem seiner auch politisch gemeinten Einbettung des Glaubens in einen rationalen Weltzusammenhang unter Führung des Rationalitätspostulats ein entscheidender und schwerwiegender Vorwurf ist.

Habermas hat allerdings, neben der denunziatorischen, doch noch zwei weitere Antworten auf die Teheraner Frage: einmal schlägt er vor, auf eine vernunftkritische Dramatisierung zu verzichten und es schlicht als eine offene empirische Frage anzusehen, ob die ambivalente Moderne sich alleine aus säkularen Kräften einer kommunikativen Vernunft stabilisieren kann. Und zweitens kann man die Rede von der postsäkularen Gesellschaft auch so interpretieren, dass sie eine Art konservativ gewordenes Bewusstsein im Verfassungsstaat nahe legt, konservativ insofern, als sie einen schonenden Umgang mit den kulturellen Quellen und den normativen Ressourcen der sozialen Integration empfiehlt. ${ }^{35}$ An dieser Stelle verwendet Habermas - so weit ich sehen kann, zum ersten Mal in seinem Werk - das Wort „konservativ“ unpolemisch und beinahe wertfrei, weil er in dieser schonenden Haltung dem Herkommen gegenüber einen religiös unverfänglichen Sinn sieht, den man dem Böckenförde-Paradoxon geben könnte. Mit dem Begriff „postsäkular" verbindet Habermas nunmehr die normative Einsicht, dass der Umgang von ungläubigen mit gläubigen Bürgern einen komplementären Lernprozess darstellen kann, in dem beide Seiten sich gegenseitig ernst nehmen. Dazu gehört durchaus auch ein Blick in uralte Traditionen, z.B. auf die gegenseitige Durchdringung von Christentum und griechischer Metaphysik im Hellenismus, durch die eine Art rationale Übersetzung der Gottesebenbildlichkeit des Menschen in die gleiche und unbedingt $\mathrm{zu}$ achtende Menschenwürde zustande gekommen sei. Dies ist ein Modell für die rettenden Übersetzungen, an die Habermas im Geiste Walter Benjamins denkt, und die den Sinn haben, den Gehalt biblischer bzw. religiöser Begriffe einem generellen Publikum von Andersgläubigen und Ungläubigen verständlich und zugänglich zu machen.

Es ist vielleicht sinnvoll, diese Überlegungen noch einmal auf die politikwissenschaftliche Grundbegrifflichkeit zurückzubeziehen. Wir kennen drei typisierte gesellschaftliche Integrationsmedien, näm- 
lich den koerziven Typus, das ist die in der politischen Sphäre verkörperte staatliche bzw. administrative Macht, den utilitären Typus, der sich in den Märkten manifestiert, und den normativen Typus, der sich in den Werten, dem Ethos und dem verständigungsorientierten Sprachgebrauch zeigt. ${ }^{36}$ Das Problem, das Habermas bewegt, besteht nun darin, dass zwischen diesen drei Sphären eine zunehmende Unausgewogenheit sich einstellt: der koerzive Typus verliert an Bindungskraft, wenn er nicht wertmäßig legitimiert ist, der utilitäre Typus vergrößert seinen Einflussbereich, tendiert aber dazu, durch den Konkurrenzprozess und die Orientierung nicht am Gemeinwohl, sondern am Eigennutz sozial sprengend zu wirken, und der normative Typus verliert seine traditionale Basis, während er im Neuaufbau zu abstrakt und zu wenig motivational ansprechend wird. Hier setzt Habermas' neuer Konservativismus einer Schonung der normativ-integrativen Diskursressourcen ein.

Es ist daher keineswegs verwunderlich, dass Joseph Ratzinger im Anschluss an Habermas' Vortrag sofort erklärt hat: „Hinsichtlich der praktischen Konsequenzen befinde ich mich in weitgehender Übereinstimmung mit dem, was Jürgen Habermas über eine postsäkulare Gesellschaft, über die Lernbereitschaft und die Selbstbegrenzung nach beiden Seiten hin ausgeführt hat." 37 Die theoretischen und theologischen Unterschiede spart er an dieser Stelle aus: da es sich um eine Begegnung in der Welt der praktischen Philosophie und Politik handelt, können sie in der Tat zurückstehen. Ich werde aber darauf zurückkommen.

Um noch einmal zu verdeutlichen, was Habermas mit dem Begriff Postsäkularität meint, und worin er über viele religionssoziologische Überlegungen, die diesen Begriff ebenfalls verwenden, deutlich hinausgeht: es geht keineswegs nur um die faktische Konstatierung, dass die Religionen überlebt hätten, und auch nicht bloß um eine Anerkennung der sozialfunktionalen Integrationsleistung von Religion und Kirche, sondern um das normative Postulat, wie gläubige und ungläubige Bürger miteinander umzugehen hätten. Hier stützt Habermas sich weitgehend auf den politischen Liberalismus, wie er im Spätwerk von John Rawls entwickelt wird. Die weltanschauliche Neutralität des modernen politischen Systems (als Politikwissen- 
schaftler halte ich den an dieser Stelle meist eingesetzten Staatsbegriff für zu eng und auch ein wenig zu autoritär) stellt gewiss keine Symmetrie zwischen Gläubigen und Ungläubigen her - das zeigt sich schon an den mehr oder weniger liberalen Abtreibungsregelungen. Zweifellos wird den Gläubigen mehr zugemutet. Aber auch auf der Seite der Ungläubigen oder der Säkularisten wird „die Einübung in einen selbstreflexiven Umgang mit den Grenzen der Aufklärung erwartet" ${ }^{\text {"38 }}$, nämlich die Akzeptanz, dass es bei einem dauerhaften, vernünftigen Dissens bleiben kann. Entscheidend ist an dieser Stelle das Wort „vernünftig“. Rawls hatte von den Bürden der Vernunft, the burdens of reason, gesprochen, die darin bestehen, dass aus verschiedenen Gründen, zu denen die Unvollständigkeit der Information, weite Ermessensspielräume und die nie wirklich auszuräumende Unschärfe der Begrifflichkeit gehören, im politischen Raum ein begründeter und nicht auflösbarer Dissens bestehen bleiben kann, dass also nicht alle politischen Probleme rational vollständig auflösbar sind. ${ }^{39}$

Habermas weitet diesen Gedanken auf die postsäkulare Gesellschaft aus: „Die Erwartung einer fortdauernden Nicht-Übereinstimmung von Glauben und Wissen verdient nämlich nur dann das Prädikat ,vernünftig ${ }^{6}$, wenn religiösen Überzeugungen auch aus der Sicht des säkularen Wissens ein epistemischer Status zugestanden wird, der nicht schlechthin irrational ist. " ${ }^{" 40}$ Und er folgert, dass naturwissenschaftliche Weltbilder deshalb keineswegs von vornherein in der Öffentlichkeit den Vorrang vor religiösen oder anderen konkurrierenden weltanschaulichen Auffassungen genießen dürfen. Er geht sogar noch weiter, wobei ich gerne einmal mit ihm diskutieren möchte, was das für den Schulunterricht, also die in den USA und auch von der vormaligen hessischen Schulministerin diskutierte Frage darwinsche Evolutionslehre versus Schöpfungsgeschichte oder „,intelligent design“ bedeutet: „Die weltanschauliche Neutralität der Staatsgewalt, die gleiche ethische Freiheiten für jeden Bürger garantiert, ist unvereinbar mit der politischen Verallgemeinerung einer säkularistischen Weltsicht. " ${ }^{11}$ Habermas würde vermutlich antworten, dass das Fach Biologie ja an die wissenschaftliche Fachdisziplin 
gebunden sei und auch bleiben solle, der politische Diskurs aber jeden Beitrag zulasse.

Joseph Ratzinger hat in seinem Antwortvortrag auf Habermas den Punkt der Selbstreflexion der wissenschaftlichen Kultur noch präziser und schärfer bezeichnet als jener: zwar kann die Wissenschaft ein soziales Ethos, insbesondere eine Art Weltethos, wie Hans Küng es sich vorstellt, nicht hervorbringen. Ihre Selbstreflexion aber sollte sich darauf richten, ihre Verallgemeinerungen, ihre voreiligen Schlussfolgerungen oder Scheingewissheiten kritisch zu durchleuchten, um unterscheiden zu können, was wirklich wissenschaftlich erhärtetes Ergebnis und was nichtwissenschaftliches Element ist, das mit diesem sich unzulässig vermengt hat. So ist es möglich, „den Blick auf das Ganze, auf die weiteren Dimensionen der Wirklichkeit des Menschen offen zu halten, von dem sich in der Wissenschaft immer nur Teilaspekte zeigen können." ${ }^{\text {44 }}$

\section{Rückkehr der Religionen?}

Nach diesen Überlegungen zur politischen Seite der Konzeption eines säkularen politischen Systems möchte ich jetzt einen Blick auf die empirische, die religionssoziologische Diskussion der Säkularisierungsfragen werfen, um die Unterschiede zum normativen Ansatz von Habermas herauszuarbeiten: Welche realen Indizien sprechen eigentlich dafür, den Begriff einer postsäkularen Gesellschaft zu verwenden? Wenn man von einer Rückkehr der Religionen spricht, was ist genau damit gemeint? Ist nicht der Rückgang der Kirchgängerzahlen, der Kirchensteuerzahler weiterhin ein deutliches Indiz für die Säkularisierung unserer Gesellschaft? Ist nicht auch Joseph Ratzingers etwas überraschender und aus seinem Munde gewichtiger Hinweis, dass die christliche Kultur im Westen gegenüber der naturwissenschaftlich-säkularen in die Minderheitsposition geraten sei, ebenfalls ein Indiz dafür? Denn in den gängigen relativistischen interkulturellen Diskursen wird dem europäischen Abendland doch gerade dessen christliche Dominanz kritisch vorgehalten - wobei ich die argumentative und psychologische Komfortabilität der Selbstzuschreibung einer Minderheitsposition selbstverständlich sofort einräumen will. 
Neuerdings wird in der Religionssoziologie gelegentlich ein eurozentrischer Provinzialismus konstatiert: die Säkularisierung sei ein europäischer Sonderweg, der nicht einmal für den Westen insgesamt gelte, denn in den USA halte sich weiterhin ein hohes Maß an religiösem Bewusstsein. Für die übrigen Kontinente gelte das ohnehin, insbesondere natürlich in der islamischen Welt.

Martin Riesebrodt hat argumentiert, dass die beiden Prozesse der Säkularisierung und der globalen Revitalisierung von Religionen nicht nur empirisch stattgefunden haben, sondern empirisch aufeinander bezogen sind. ${ }^{43}$ Es haben sich neue Dimensionen von Ungewissheit, Machtlosigkeit und Orientierungslosigkeit aufgetan, in die religiöse Deutungsangebote eindringen können. Verunsicherte Bewusstseinsformen, ein Scheitern an der Modernisierung kann durchaus, wie vielfach in der islamischen Welt zu beobachten, zu einer Reislamisierung führen. Sayyid Qutb, der Chefideologe der Muslimbruderschaft in Ägypten, hat sich bei einem Studienaufenthalt in den USA 1948/50 radikalisiert, und seinen Weg haben seitdem viele Studenten aus islamischen Ländern nachvollzogen. Aus der Muslimbruderschaft ist auch die HAMAS, arabisch für Eifer, hervorgegangen. Es geht dabei nicht zuletzt um Geschlechterbeziehungen und Sexualmoral, konkreter gesprochen um die „Repatriarchalisierung der Geschlechterbeziehungen". 44

In den USA ist die Religiosität nach allen Umfragen weiterhin deutlich intensiver geblieben als in Europa. Für dieses in der Sicht vieler Sozialwissenschaftler erstaunliche und erklärungsbedürftige Phänomen wird eine Reihe von Erklärungen angeboten:

1. Die Religionsfreiheit in den USA habe zu einem freien religiösen Markt geführt, auf dem die unterschiedlichen Religionen wie auch andere Waren konkurrieren mussten. Das persönliche Engagement, ja auch das Charisma der Prediger und die hohe Professionalität des Marketings seien die Erklärung dafür, warum die Religionszugehörigkeit noch so stark verbreitet sei (Angebotstheorien).

2. Dieses Modell hat ein älteres Erklärungsmodell abgelöst, das sich etwa bei Tocqueville findet: das Moment der Freiwilligkeit sei für den einzelnen sehr viel ansprechender und überzeugen- 
der als die europäische Situation, in der man in eine Art Staatskirche hineingeboren wird (liberale Theorie).

3. Max Weber hatte in seiner Studie über die protestantischen Sekten zudem auf den Aspekt der Absicherung und Stärkung des sozialen Status wie auch der Kreditwürdigkeit hingewiesen (Netzwerktheorie).

4. Die neueste und stärkste Erklärung ist der Verweis auf die Korrespondenz von Einwanderung und Religiosität. In der neuen Welt angekommen, fanden die Einwanderer vor allem die Kirchen, die sich um sie kümmerten, wo man ihnen Vertrauen und Zuwendung entgegenbrachte. Dabei können politische und ökonomische Motive durchaus die genuin religiösen überlagert haben. In einem Auswandererkontinent wie Europa vollzog sich dagegen die Säkularisierung (Immigrationsthese). ${ }^{45}$

Dieser letzte Punkt ist hochinteressant. Nach Hartmut Lehmann sollen um 1800 die religiösen Bindungen in den USA sehr viel geringer gewesen sein. Nur etwa 10\% der Bevölkerung sollen einer offiziellen Kirche angehört haben. Als im Laufe des 19. Jahrhunderts die Einwandererwelle anschwoll, ergab sich damit auch eine religiöse Welle. „Erst im 19. Jahrhundert entstand das ,christliche Amerika"“.46 Mark Twain hat das Auftreten der Erweckungsprediger z.B. in Huckleberry Finn sehr anschaulich satirisch geschildert. Es fand eine beinahe militärisch geplante Massenmissionierung statt. Nach dem Ersten Weltkrieg wurden strikte Einwanderungsquoten eingeführt. Seitdem vollzog sich in den USA wie überall ein Säkularisierungsprozess. Ab ca. 1960 wurden die Tore für die Einwanderung wieder geöffnet. Damit korrespondiert ein erneuter Rereligiösierungsprozess. Seit Jimmy Carter hat sich bislang jeder US-Präsident als Born-Again Christian bezeichnet. Der letzte Präsident, der in seiner Zeit im Weißen Haus nicht demonstrativ in die Kirche gegangen ist, war Ronald Reagan.

Die Rede von der postsäkularen Gesellschaft korreliert also mit Einwanderungswellen. Das ist vermutlich auch in Europa der Fall, wo eine Islamisierung muslimischer Immigranten stattfindet, offenbar auch solcher, die in ihren Heimatländern eher laue Gläubige 
gewesen waren. Nach der amerikanischen Erfahrung überrascht das nicht. Man könnte nun natürlich fragen, ob die Islamisierung in Europa nicht auch zu einer christlichen Gegenreaktion, zu einer stärkeren Rückbesinnung auf die eigenen Wurzeln und die eigene Zugehörigkeit geführt hat oder führen könnte. Bislang sind dafür keine Anzeichen erkennbar. Nachdem sich zunächst die protestantischen Milieus säkularisiert hatten, ist nun auch die katholische Welt erfasst. Im Herbst 2002 haben sich nur noch 19\% von 2700 befragten Katholiken als gläubig und mit ihrer Kirche eng verbunden bezeichnet. Von einer kritischen Verbindung sprachen weitere 35\%. Bei den jüngeren, unter 30, waren nur noch 7\% kirchennah. Inzwischen schlägt das schon auf die theologischen Fakultäten sogar in Bayern durch. Das gilt längst für ganz Europa, also auch für Italien, Spanien und sogar Irland, wo man das nie für möglich gehalten hätte. Die Säkularisierung ist ein gesamteuropäischer Prozess, der daher auch - nebenbei gesagt - auf eine durchaus gemeinsame europäische Kultur schließen lässt.

Hartmut Lehmann, der Göttinger Historiker, vermutet, der Grundfehler habe dort gelegen, wo es in Europa seit dem 18. Jahrhundert nicht gelungen sei, authentische Religiosität mit sozialem Fortschritt sowie dem wissenschaftlichen, ökonomischen und technischen Fortschritt zu verbinden. In Lateinamerika oder Afrika sei das in gewisser Weise anders, daher sei das Christentum dort stärker, und auch die traditionale japanische Religiosität habe sich immer mit dem Fortschritt verbinden lassen. ${ }^{47}$ Ich halte das für spekulativ, weil die Modernisierung des Katholizismus etwa mit dem 2. Vatikanischen Konzil hier ja auch keine Wende gebracht hat.

Möglicherweise ist ja eine Interpretation des radikalen Islamismus zutreffend, dass dieser zum Untergang verurteilt sei und nur eine Art letzte Abwehrreaktion junger Männer gegen den Modernisierungsprozess und die Gleichberechtigung der Geschlechter darstelle, der spätestens dann abebben werde, wenn der massive Geburtenüberschuss und insbesondere der Überschuss junger Männer in den nahöstlichen Ländern überwunden sei. ${ }^{48}$ Eine ähnliche generationelle Deutung hatte Samuel Huntington in seinem „Clash of Civilizations“ der ersten, stark kulturalistischen Erklärung nachgeschoben. 
Wenn Europa zunehmend zum Einwanderungskontinent wird, dann wird es einerseits Prozesse der Islamisierung erleben, andererseits aber auch zum Schauplatz der Missionsanstrengungen der verschiedensten außereuropäischen Religionen werden. Hinzu können jederzeit Krisenmomente kommen, die ebenfalls zur Revitalisierung religiöser Orientierungen beitragen können.

\section{Dennoch: Es bleiben zwei unterschiedliche Vernunftbegriffe}

Es gilt also, deutlich die religionssoziologische These von der postsäkularen Gesellschaft und die theologisch-politikwissenschaftliche Verwendung desselben Begriffs durch Habermas und Ratzinger zu unterscheiden. Bei Habermas und John Rawls handelt es sich um Reflexionsprozesse des politischen Liberalismus, ein wie hohes Maß an Verzicht auf eigene Grundüberzeugungen religiösen Menschen und Gruppen in einer im Prinzip säkularen Gesellschaft zugemutet werden kann. Sie plädieren für einen größeren Respekt vor religiösen Überzeugungen, allerdings nur insoweit, als sich diese in rationale, säkulare Argumentationsformen übersetzen lassen. Religiöse Empörung wird als Intuition wahrgenommen, argumentativ allerdings erst dann respektiert, wenn sie auch ein rationales Argument anführen kann, das für jedermann akzeptabel ist. Zum modernen Liberalismus fügt Habermas aus dem geschichtsphilosophischen Erbe der Frankfurter Schule die Idee der rettenden Kritik hinzu: „Der Glaube behält für das Wissen etwas Opakes, das weder verleugnet noch bloß hingenommen werden darf. Darin spiegelt sich das Unabgeschlossene der Auseinandersetzung einer selbstkritischen und lernbereiten Vernunft mit der Gegenwart religiöser Überzeugungen. Diese Auseinandersetzung kann das Bewußtsein der postsäkularen Gesellschaft für das Unabgegoltene in den religiösen Menschheitsüberlieferungen schärfen."

Bei Joseph Ratzinger liegt, vom gegensätzlichen Ausgangspunkt her, ein komplementäres Bewusstsein vor. In einer im Prinzip säkularen Gesellschaft verstehen sich die Christen als Minderheit, die ihrerseits den Anspruch erheben, Vernunft und Glauben vereinbaren zu können, und in einer weltlichen Gesellschaft mit Vernunftargumenten überzeugen zu können. Das macht das überzeugende 
intellektuelle Profil dieses Papstes aus und ist auch der Grund dafür, weshalb die Begegnung mit Habermas zu einer so weitgehenden Übereinstimmung führen konnte. Denn es ist keine Selbstverständlichkeit, dass ein als konservativ geltender Theologe und Habermas, für den schon die leichte Andeutung, ein Argument enthalte konservative Züge, bislang ein vernichtendes Werturteil darstellte, in zentralen Punkten eine so weitgehende Übereinstimmung herstellen konnten, die offensichtlich von radikal unterschiedlichen Ausgangspunkten herrührte und die ebenso offensichtlich nicht bloß auf einem freundlichen Formelkompromiss basierte, sondern der Argumentation in der Sache selbst geschuldet war.

Eine Übereinstimmung in bestimmten praktischen Fragen ist aber keineswegs auf eine grundlegende Übereinstimmung in der Begrifflichkeit angewiesen. Hier geht es vor allem um den für Habermas wie für den heutigen Papst zentralen Begriff der Vernunft. In seiner Regensburger Rede hat er vom Logos, der ja Wort und Vernunft zugleich bedeutet, einen weiten Vernunftbegriff entwickelt. Dieser zielt auf eine harmonische Verbindung von Vernunft und Glauben, von antiker Philosophie und christlicher Innovation. Diese Verbindung habe sich seit Duns Scotus, also seit 1300 gelockert, die Reformatoren und Pascal hätten sie zerstört, Kant habe schließlich die Trennung auf die Spitze getrieben. Der Vernunftbegriff des Papstes hat also einen klassischen, modernitätskritischen Zug. Die Ausgangsbestimmung in der Regensburger Vorlesung besteht in einer praktischen Unterscheidung: der Glaube an einen vernünftigen Gott wird sich friedlich, durch Argumente verbreiten. Gewalttätiges Handeln dagegen wäre vernunftwidrig und damit auch gegen das Wesen Gottes gerichtet.

In seiner Reaktion auf die Regensburger Vorlesung „Glauben und Vernunft" aus dem Jahre 2006 besteht Habermas darauf, dass Benedikt die Wende zu einem modernen säkularen Vernunftbegriff nicht mitvollzogen habe und damit letztlich einer vor dem heutigen naturwissenschaftlichen Denken verharrenden, christlich-hellenischen Vernunft verpflichtet geblieben sei. Die drei von Benedikt kritisierten Enthellenisierungsschübe des Nominalismus, der kritischen kantischen Philosophie und des Historismus hätten eben auch positive Züge innerhalb des Projekts Moderne: der erstere haben den Weg zu den modernen Naturwissenschaften geöffnet, Kants Kritizismus sei die Bedingung der Möglichkeit von Autonomie, Rechtsstaat und Demokratie, und der Historismus schütze vor der 
Überverallgemeinerung kontextunabhängiger Urteile. ${ }^{50}$ Die Modernitätskritik ist für Habermas also immer noch die Differenzlinie.

Die entscheidende Differenz zu Benedikt scheint aus der Sicht von Ricken und Habermas selbst in der entschlossenen Verteidigungsrede von Habermas für das „Projekt der Moderne“ zu liegen, auch wenn dieses durch eine Selbstkritikbereitschaft der modernen Vernunft und das Selbstverständnis der Postsäkularität aufgebrochen ist. Diese Selbstkritikbereitschaft ist gerade in der kritischen Philosophie Immanuel Kants verankert, so dass von dieser Seite die Einreihung Kants in die moderne Trennungsgeschichte nicht akzeptiert wird. In diesem Sinne definiert Habermas sein Verständnis von postsäkularer Säkularisierung noch einmal neu als Transformationsprozess, der den Strom der Tradition nicht etwa ausfiltert und ausscheidet, sondern vielmehr produktiv umwandelt. ${ }^{51}$ Und das hat mit dem von ihm kritisierten „herablassenden Wohlwollen einer säkularisierten Obrigkeit" gegenüber diskriminierten Minderheiten nichts $\mathrm{zu}$ tun. ${ }^{52}$

Allerdings hat Benedikt in Regensburg ausdrücklich erklärt, die „Selbstkritik der modernen Vernunft schließt ganz und gar nicht die Auffassung ein, man müsse nun wieder hinter die Aufklärung zurückgehen und die Einsichten der Moderne verabschieden. “53 Er erklärt den Willen „zum Gehorsam gegenüber der Wahrheit“54 als wesentlich christlich, vertritt aber einen insofern postpositivistischen Vernunftbegriff, als er ihre Beschränkung auf das im Experiment Falsifizierbare überwinden und damit ihre ganze Weite wiedergewinnen will, weil dann auch wieder im universitären und wissenschaftlichen Kontext die Frage nach der Vernunft des Glaubens gestellt werden kann. Seine Modernitätskritik zielt demnach vor allem in zwei Richtungen: gegen ein zu enges positivistisches Vernunftkonzept und gegen einen modernen Relativismus, der die Frage nach der Wahrheit nicht mehr zu stellen in der Lage ist. ${ }^{55}$

50 Habermas (2008), 35. Ähnlich pointiert Ricken (2008).

51 Habermas (2008), 29-30. Er spricht metaphorisch von der Säkularisierung als Transformator, nicht als Filter.

52 Habermas (2005b), 125.

53 Benedikt XVI (2006), 29.

54 Benedikt XVI (2006).

55 Dies vor allem in seinen Schriften zur Enzyklika „Fides et Ratio“ in: Ratzinger (2005a), 148-169. 
Der nachmetaphysische Vernunftbegriff von Habermas ist ebenso hochkomplex wie mehrschichtig und bis heute in der theologischen Diskussion, soweit ich sehen kann, kaum nachvollzogen worden. ${ }^{56}$ In Analogie zu den drei Kritiken Kants tritt bei Habermas neben die kognitive und die praktische Seite der Rationalität ihre ästhetisch-expressive Funktion. Bei dieser Dreispaltung der Rationalität bleibt er aber nicht stehen, denn in der kommunikativen Rationalität, also im „Wort“, können diese drei Schichten integriert werden, jedenfalls sofern von gelingender Kommunikativität die Rede sein kann. ${ }^{57}$ In seinem Aufsatz „Die Einheit der Vernunft in der Vielfalt ihrer Stimmen" hatte er 1988 entwickelt, wie in der Sprache sowie der Nichthintergehbarkeit einer symmetrischen Perspektivenstruktur, wie sie in jeder Gesprächssituation angelegt ist, letztlich doch eine schwache, transitorische Einheit der Vernunft ausgemacht werden kann. Was übrig bleibt, sind begründende Redeformen, die keinen Exklusivitätsanspruch mehr erheben: Solange die kommunikative Vernunft ,im Medium begründender Rede für das, was Religion sagen kann, keine besseren Worte findet, wird sie sogar mit dieser, ohne sie zu stützen oder zu bekämpfen, enthaltsam koexistieren." 58 Denn die großen Gesten radikaler Weltveränderung (das „ganz Andere“ von Herbert Marcuse) oder Weltverneinung (Adornos These, das Ganze sei das Unwahre) früherer Formen der kritischen Theorie hat Habermas beiseitegeschoben zugunsten seiner Konzeption umfassender Dialogizität.

\section{Literatur}

Adorno, Theodor W. (1969): Stichworte. Frankfurt am Main: Suhrkamp. Arens, Edmund, Hg. (1989): Habermas und die Theologie. Beiträge zur theologischen Rezeption, Diskussion und Kritik der Theorie kommunikativen Handelns. Düsseldorf: Patmos.

Benedikt XVI (2006): Glaube und Vernunft. Die Regensburger Vorlesung. Kommentiert von Gesine Schwan, Adel Theodor Khoury, Karl Kardinal Lehmann. Freiburg/Basel/Wien: Herder.

Berger, Peter L., Hg. (1999): The Desecularization of the World. Resurgent Religion and World Politics, Washington: Ethics and Public Policy Center. 
Böckenförde, Ernst Wolfgang (1991): „Die Entstehung des Staates als Vorgang der Säkularisation (1967)“, in: Böckenförde Ernst Wolfgang:

Recht, Staat, Freiheit, Frankfurt am Main: Suhrkamp, 92-114.

Forst, Rainer (2000): Toleran₹: Philosophische Grundlagen und gesellschaftliche Praxis einer umstrittenen Tugend. Frankfurt am Main: Campus.

Glendon, Mary Ann (1991): Rights Talk. The Impoverishment of Political Discourse. New York: Free Press.

Habermas, Jürgen (1972): „Bewußtmachende und rettende Kritik - die Aktualität Walter Benjamins", in: Unseld, Siegfried, Hg.: Zur Aktualität Walter Benjamins. Frankfurt am Main: Suhrkamp, 173-224.

Habermas, Jürgen (1981): Philosophisch-politische Profile. Erweiterte Ausgabe. Frankfurt am Main: Suhrkamp.

Habermas, Jürgen (1988): „Die Einheit der Vernunft in der Vielfalt ihrer Stimmen“, in: Habermas, Jürgen: Nachmetaphysisches Denken. Philosophische Aufsätze. Frankfurt am Main: Suhrkamp, 153-186.

Habermas, Jürgen (1992): Faktizität und Geltung. Beiträge zur Diskurstheorie des Rechts und des demokratischen Rechtsstaats. Frankfurt am Main: Suhrkamp.

Habermas, Jürgen (1997): „Israel oder Athen: Wem gehört die anamnetische Vernunft? Johann Baptist Metz zur Einheit in der multikulturellen Vielfalt", in: Habermas, Jürgen: Vom sinnlichen Eindruck zum symbolischen Ausdruck, Philosophische Essays. Frankfurt am Main: Suhrkamp, 98111.

Habermas, Jürgen (2001): Glauben und Wissen. Friedenspreis des deutschen Buchhandels 2001. Frankfurt am Main: Suhrkamp.

Habermas, Jürgen (2005a): Vorpolitische Grundlagen des demokratischen Rechtsstaates, in: Habermas, Jürgen/Ratzinger Joseph: Dialektik der Säkularisierung. Über Vernunft und Religion. Freiburg: Herder, 18-37.

Habermas, Jürgen (2005b): Zwischen Naturalismus und Religion. Philosophische Aufsätze. Frankfurt am Main: Suhrkamp.

Habermas, Jürgen (2008): „Ein Bewußtsein von dem, was fehlt“, in: Reder, Michael/Schmidt Josef, Hg.: Ein Bewnßtsein von dem, was fehlt. Eine Diskussion mit Jürgen Habermas, Frankfurt am Main: Suhrkamp, 26-36.

Heinsohn, Gunnar ('2006): Söhne und Weltmacht. Terror im Aufstieg und Fall der Nationen. Zürich: Orell Füssli. 2003 ist das Ersterscheinungsdatum und insofern maßgeblich, wie bei Kant, der sein Buch ja auch nicht 2003 geschrieben hat

Höhn, Hans-Joachim (2007): Postsäkular. Gesellschaft im Umbruch - Religion im $W$ andel. Paderborn u.a: Schönigh.

Horster, Detlef (2006): Jürgen Habermas und der Papst. Glauben und Vernunft, Gerechtigkeit und Nächstenliebe im säkeularen Staat. Bielefeld: transcript.

Huntington, Samuel (1996): The Clash of Civilizations. New York: Touchstone.

Joas, Hans/ Wiegandt Klaus, Hg. (2007): Säkularisierung und die Weltreligionen. Frankfurt am Main: Fischer. 
86 Habermas, Ratzinger und die postsäkulare Gesellschaft

Kant, Immanuel (2003): Die Religion innerbalb der Grenzen der bloßen Vernunft, Hg. Bettina Stangneth. Hamburg: Meiner.

Langenthaler, Rudold/Nagl-Docekal Herta (2007): Glauben und Wissen. Ein Symposium mit Jürgen Habermas. Wien: Oldenbourg.

Lehmann, Hartmut (2004): Säkularisierung. Der europäische Sonderweg in Sachen Religion. Göttingen: Wallstein.

Norris, Pippa/Inglehart, Ronald (2004): Sacred and Secular. Religion and Politics Worldwide. Cambridge: Cambridge University Press.

Ratzinger, Joseph (2005a): Glaube - Wabrbeit - Toleran₹: Das Christentum und die Weltreligionen. Freiburg u.a.: Herder.

Ratzinger, Joseph (2005b): „Was die Welt zusammenhält. Vorpolitische moralische Grundlagen eines freiheitlichen Staates“, in Habermas, Jürgen/Joseph Ratzinger: Dialektik der Säkularisierung. Über Vernunft und Religion. Freiburg: Herder, 39-60.

Rawls, John (1998): Politischer Liberalismus. Frankfurt am Main: Suhrkamp.

Reder, Michael/Schmidt, Josef, Hg. (2008): Ein Bewußtsein von dem, was fehlt. Eine Diskussion mit Jürgen Habermas. Frankfurt am Main: Suhrkamp.

Reese-Schäfer, Walter (32001a): Jürgen Habermas. Frankfurt/New York: campus.

Reese-Schäfer, Walter (2001b): Amitai Etzioni zur Einführung. Hamburg: Junius Verlag.

Reese-Schäfer, Walter (2007a): Grenzgötter der Moral. Der neuere europäischamerikanische Diskurs zur politischen Ethik. Frankfurt am Main: Humanities Online.

Reese-Schäfer, Walter (2007b): „Sicherheit, Freiheit, Terrorismus“, in: Zeitschrift für Menschenrechte/Journal for Human Rights, 1 (1), 37-51.

Ricken, Friedo (2008): „Nachmetaphysische Vernunft und Religion“, in: Reder, Michael/Schmidt, Josef, Hg.: Ein Bewußtsein von dem, was fehlt. Eine Diskussion mit Jürgen Habermas. Frankfurt am Main: Suhrkamp, 6978.

Riesebrodt, Martin (2000): Die Rückkehr der Religionen. Fundamentalismus und der „Kampf der Kulturen“. München: Beck. 


\section{Systematische Perspektiven}





\section{Wiederverzauberung der Welt oder Wiederkehr des Verdrängten? Post-positivistische Perspektiven auf Religion}

Frank Adloff

In seinem Vortrag Wissenschaft als Beruf aus dem Jahr 1919 spricht Max Weber bekanntlich mehrfach von der „Entzauberung der Welt“. Diese beruht auf dem Wissen oder Glauben, dass man die Welt durch Berechnen beherrschen könne. ${ }^{1}$ Die Entzauberung, Rationalisierung und Intellektualisierung der Welt dränge zugleich letzte Werte aus dem öffentlichen Bereich in die private Sphäre mystischer Erfahrung oder in die Brüderlichkeit unmittelbarer Beziehungen von Einzelnen. ${ }^{2}$ Dies ist eine der klassischen Beschreibungen der Säkularisierung moderner Gesellschaften: Differenzierung und Privatisierung von Religion sind ihr Ergebnis. Im Folgenden soll ein kritischer Blick auf die Soziologie als Disziplin gerichtet und gefragt werden, was ihr Beitrag zum Verständnis des Verhältnisses von Religion und Säkularität ist. Es wird sich zeigen, dass leider wenig von dieser Seite in den letzten Jahren beigetragen wurde, vielmehr müsste es darum gehen, an vielen Stellen historisch-reflexive sowie theoretische Neujustierungen vorzunehmen und vor allem eine größere Konzeptabstinenz an den Tag zu legen. 
90 Wiederverzauberung der Welt oder Wiederkehr des Verdrängten?

\section{Säkularisierung und Modernisierung}

Für Max Weber und Emile Durkheim, die beiden zentralen Gründer der Soziologie, stand die Religionssoziologie noch im Zentrum ihrer soziologischen Arbeit und war ein integraler Bestandteil ihrer Gesellschaftstheorie. Die dort vorfindbaren Säkularisierungstheorien sind bei beiden Autoren eng verknüpft mit ihrer Differenzierungstheorie. Säkularisierung ist bei ihnen Prämisse und Resultat von sozialen Differenzierungsprozessen, und beide gingen von einem zunehmenden Bedeutungsverlust der institutionalisierten Religion in der modernen Gesellschaft aus. Wie wenig haltbar diese Perspektive schon damals war, zeigen neuere (weltgeschichtliche) Untersuchungen zum 19. Jahrhundert, das gerade durch die Ausbreitung und Konsolidierung der großen Weltreligionen gekennzeichnet ist ${ }^{3}$ - für Deutschland spricht Olaf Blaschke gar von einem zweiten konfessionellen Zeitalter. $^{4}$

Nichts desto trotz: Lange Zeit gab der westeuropäische Fall das Modell für die These vom Bedeutungsverlust der Religion ab. Und tatsächlich lässt sich Säkularisierung hier auch nicht leugnen - insbesondere nicht im Zuge der dramatischen Entkirchlichungsprozesse seit den 1960er Jahren. ${ }^{5}$ Entwicklungen insbesondere in den USA, wo man mitnichten von einem rapiden Bedeutungsverlust der Religion sprechen kann, galten als Sonderfall. Aus einer internationalen Perspektive betrachtet zeigt sich allerdings seit einigen Jahren deutlich, dass eher der starke Rückgang an Religiosität in Westeuropa erklärungsbedürftig ist. Empirisch ist also die These eines universalen Trends in Richtung eines Verschwindens der Religion in modernen Gesellschaften definitiv nicht haltbar. In den letzten Jahrzehnten wurden denn auch zunehmend Zweifel gegenüber dieser Sichtweise formuliert, sodass man heute kaum noch von einer klar definierten und einhellig vertretenen Säkularisierungsannahme ausgehen kann. ${ }^{6}$

Für den hier interessierenden eher politischen Kontext ist José Casanovas Studie Public Religions in the Modern $\mathrm{W}_{\text {orld }}{ }^{7}$ von besonderer Bedeutung. Denn in den 1980er Jahren wurde mit der Entprivatisierung der Religion beispielsweise in den USA deutlich, dass Differen-

3 Vgl. Bayly (2006), $400 f f$.

4 Blaschke (2002).

5 Vgl. McLeod (2006).

6 Vgl. Herbert (2003), $29 \mathrm{ff}$.

7 Vgl. Casanova (1994). 
zierungsprozesse und der Verlust gesellschaftlicher Regulierungsfunktionen nicht zu einer Privatisierung der Religion führen müssen und dass Kirchen weltweit in die Arena der Zivilgesellschaft als öffentliche Religionen eintraten.

Doch bis zur breiteren Durchsetzung dieser Einsicht war es ein langer, steiniger Weg. Denn bald schon nach Weber und Durkheim wurde Religion in der allgemeinen Sozialtheorie und der Makrosoziologie marginalisiert, sie wurde beiseite geschoben und verdrängt. In den 1950er und 60er Jahren war sie zwar noch integrierter Bestandteil der klassischen Modernisierungstheorie, und Autoren wie Parsons, Eisenstadt, Bellah und Lipset befassten sich mit ihr. Doch wurde Religion hier schon in ein Entwicklungsraster eingetragen: Modernisierung und traditionale Religiosität standen sich diametral gegenüber. Religiöse Werte galt es vielmehr zu abstrahieren und zu generalisieren, um mit ihrer Hilfe gesellschaftsintegrierende Kräfte zu entfalten.

Der Modernisierungstheorie - so weit gefächert die Forschungsperspektiven ihrer Vertreter auch waren - liegen einige gemeinsame theoretische Annahmen zugrunde: ${ }^{8}$

- Modernisierung beginnt in Europa mit der industriellen Revolution und erreicht von dort die ganze Welt.

- Modernisierung wird zwar als globales Phänomen verstanden, doch werden Gesellschaften separat analysiert und als geschlossene und abgegrenzte Entitäten begriffen.

- Bei der Transition von traditionalen zu modernen Gesellschaften wird eine scharfe Antithese zwischen beiden Seiten unterstellt.

- Traditionale Gesellschaften sind von partikularistischen und funktional diffusen Einstellungen gekennzeichnet und die dort vorfindbaren Religionen sind als quasi prä-rational aufzufassen.

- Im Gegensatz dazu sind moderne Gesellschaften säkular, universell und leistungsbezogen orientiert.

- Modernisierung ist ein endogener gesellschaftlicher Prozess; exogene Einflüsse und Verflechtungen wie Kolonialismus und Imperialismus werden nicht thematisiert.

- Der Übergang in die Moderne ist überall linear und uniform. 
92 Wiederverzauberung der Welt oder Wiederkehr des Verdrängten?

Viele der Grundannahmen wurden schon im Verlauf der 1960er Jahre heftig kritisiert, und schließlich gab man das Modernisierungskonzept im Zuge mikrosoziologischer und neo-marxistischer Kritiken auch auf. ${ }^{9}$ Insbesondere die Ethnozentrik der Modernisierungstheorie und ihre Endogenitätsannahme wurden attackiert. Dies hat jedoch nicht verhindert, dass modernisierungstheoretische Annahmen in den frühen 1990 er Jahren wieder auftauchten ${ }^{10}$ und sich auch heute gewandelt in Globalisierungs-, Weltkultur- und Weltsystemtheorien wieder finden - doch dazu weiter unten mehr.

Die in den USA der 1970er Jahre aus der Kritik an der Ahistorizität des Strukturfunktionalismus hervorgegangene Historische Soziologie schloss Religion dagegen komplett aus ihren Analysen aus: Die marxistisch inspirierten Arbeiten von Charles Tilly, Barrington Moore, Immanuel Wallerstein oder Theda Skocpol ${ }^{11}$ konnten Religion nicht theoretisch integrieren. Insgesamt bleiben „ideelle Faktoren" hier eher außen vor. Obwohl die Historische Soziologie angetreten war, eher Kontingenzen als evolutionäre Gesellschaftsentwicklungen zu betrachten, war sie in diesem Falle nicht gewappnet, der modernistischen Falle zu entgehen: Von Comte und Saint-Simon über Weber und Durkheim bis zur Modernisierungstheorie und dem Neo-Marxismus sah man Religion und Moderne als Antagonisten an. ${ }^{12}$ In Europa war die Lage nicht besser, eher im Gegenteil: Die sozialtheoretischen Entwürfe von Habermas, Luhmann, Bourdieu oder Giddens lagen im modernisierungs- und säkularisierungstheoretischen Mainstream und historisch-konkreteren Analysen von Gesellschaft oder Religion widmeten sie sich nicht. Auch hier herrschten hauptsächlich lineare Entwicklungskonzepte vor.

Zunächst erfasste die amerikanische Soziologie seit den 1980er Jahren ein Revival der Religionssoziologie, hauptsächlich durch äuBere Umstände wie dem fundamentalistischen Protestantismus motiviert. Dies führte zu einer sehr umfangreichen Debatte um den Status der Säkularisierungstheorie. Zwei Lager dominieren bis dato das Feld: Es stehen sich Verteidiger der klassischen Säkularisierungs- 
theorie ${ }^{13}$ und Verfechter der so genannten angebotsorientierten Religionssoziologie ${ }^{14}$ gegenüber.

Von der klassischen Säkularisierungstheorie wird der Säkularisierungsprozess sehr unterschiedlich definiert: Aber alle Varianten „have tended to see its causes in strikingly similar terms - namely, as an inevitable and irreversible result of ,modernization' in all its guises (industrialization, urbanization, rationalization etc.) “. ${ }^{15}$ Es wird eine singuläre Verlaufsform Richtung Modernität und damit verbunden Richtung Säkularisierung unterstellt. Für unterschiedliche Pfade, Brüche, Umschwünge und vor allem Kontingenzen wird kein Raum gelassen.

Von der Rational Choice beziehungsweise angebotsorientierten Religionssoziologie wird dem gegenüber unterstellt, dass freie Religionsmärkte wie in den USA religiöse Vitalität hervorbringen, während religiöse Monopole wie in Europa Religiosität untergraben. ${ }^{16}$ Angenommen wird dabei psychologisch oder quasi anthropologisch, dass die individuelle „Nachfrage“ nach Religion immer und überall identisch ist. Abgesehen davon, dass der Zusammenhang zwischen religiösem Pluralismus und religiöser Vitalität nur zum Teil nachgewiesen werden konnte, ${ }^{17}$ steht die Theorie in ihren Grundannahmen auf tönernen Füßen. Unterschiedliche Qualitäten (und nicht nur Quantitäten) von Religiosität spielen in dem Modell keine Rolle, und auch hier wird ahistorisch argumentiert: Eine zeit- und raumunspezifische generelle Theorie religiösen Wandels wird nämlich avisiert.

Weitet man die Perspektive und blickt insgesamt auf das Feld der gegenwärtigen Makrosoziologie dominieren globale Perspektiven die Szenerie: etwa im Sinne von Luhmanns Weltsystemtheorie ${ }^{18}$, Globalisierungstheorien, Becks und Giddens' Theorie eines reflexiven Kosmopolitismus ${ }^{19}$ oder von John Meyers Weltkulturansatz. ${ }^{20}$ Diese Schriften erwecken den Eindruck, dass neben der globalen Ausbreitung von Märkten und Nationalstaaten nun die globale Ausbreitung der Zivilgesellschaft ihren Siegeszug antritt - als Komple-

13 Bruce (1996).

14 Stark/Iannaccone (1994).

15 Gorski (2005), 170.

16 Iannaccone et al. (1997).

17 Vgl. Chaves/Gorski (2001).

18 Luhmann (1975).

19 Beck/Sznaider (2006).

20 Meyer (2005). 
94 Wiederverzauberung der Welt oder Wiederkehr des Verdrängten?

mentär zu Staat und Markt. In diesem Zusammenhang ist es sinnvoll, kurz auf die Arbeiten des Neo-Institutionalisten John W. Meyer einzugehen, der zusammen mit einigen Koautoren in den vergangenen 25 Jahren ein groß angelegtes Projekt, den ,world polity“- oder Weltkulturansatz verfolgt hat, dessen theoretische Überlegungen im Wechselspiel mit empirischen Untersuchungen entwickelt wurden. Dabei geht es Meyer um die Kennzeichnung einer breiten kulturellen Ordnung, die man im Anschluss an Max Weber als den okzidentalen Rationalismus bezeichnen könnte, und die global diffundiert. Es sind vor allem drei Strukturformen, die sich in den letzten Jahrzehnten über den Globus ausgedehnt haben: Nationalstaaten, formale Organisationen und das handelnde, rationale und autonome Individuum.

Dieses global sich ausbreitende kulturelle System ist seinem Ursprung nach westlich und judeo-christlich; doch die spezifischere Ausarbeitung ist ein Ergebnis des liberalen protestantischangloamerikanischen Modells, das sich in der zweiten Hälfte des 20. Jahrhunderts über die ganze Welt ausgebreitet hat. Der Historiker Bruce Mazlish spricht in diesem Zusammenhang von „Global America“, um die Dominanz der USA in diesem Globalisierungsprojekt $\mathrm{zu}$ verdeutlichen. ${ }^{21}$

Die Existenz und Wirkung globaler Modelle hat Meyer an verschiedenen empirischen Beispielen vorgeführt: an der Verbreitung westlicher Ideen von Bildung als globalem Mythos ${ }^{22}$ oder der des Nationalstaates. So leitet sich für ihn die weltweite Existenz beispielsweise von Nationalstaaten aus globalen Modellen ab: „Globale Modelle definieren und legitimieren die Ziele lokalen Handelns, sie prägen die Strukturen und Programme von Nationalstaaten und anderen nationalen und lokalen Akteuren, und dies in fast allen rationalisierten gesellschaftlichen Bereichen - in Wirtschaft, Politik, Erziehung, Gesundheitswesen, Wissenschaft, ja sogar in Familie und Religion“. ${ }^{23}$ Die kulturelle globale Ebene hat für Meyer unmittelbare kausale Bedeutung, da sie nicht nur weit verbreitet, sondern auch allgemein anerkannt ist. So nähern sich die Nationalstaaten einerseits immer mehr an, andererseits kommt es aber auch ständig zu Entkopplungserscheinungen, da sie sich zwar an der externen Kultur orientieren, diese aber nicht komplett und funktionsfähig importiert 
werden kann. Die globale Kultur wird über einen organisationalen Rahmen der Vereinten Nationen und anderer internationaler Körperschaften transportiert; sie verbreitet sich durch Diffusion und gegenseitiges Kopierverhalten und wird durch eine Vielzahl an NGOs, internationalen Verbänden und sozialen Bewegungen vorangetrieben.

Wolfgang hat gezeigt, dass der Meyer'sche Weltkulturansatz als eine normativistische Radikalisierung von Talcott Parsons' Werk zu verstehen ist. ${ }^{24}$ Es geht um ein allgemeines weltweit durchgesetztes Wertmuster, das westlichen, genauer: protestantischen Ursprungs ist. Lokales wird dadurch als „makrodeterminiert“ aufgefasst. Machtprozesse bleiben in diesem Konzept völlig außen vor, und die empirisch konstatierte Kluft zwischen allgemeinen Wertmustern und konkreten Institutionen auf lokaler und gesellschaftlicher Ebene wird in keiner Weise überbrückt. Eine akteurlose und normativistisch verkürzte top down Theorie hat sich also selbstgewiss an die Stelle der Modernisierungstheorie setzen können. Ähnliche Kritiken könnte man gegenüber Luhmanns Weltgesellschaftsansatz - bei dem es ja nur um die Erreichbarkeit für Kommunikation im Rahmen von funktionaler Differenzierung geht - sowie gegenüber anderen Globalisierungstheorien anmelden. Beck und Giddens wählen beispielsweise die Kategorie der Reflexivität als Grundachse, die den linearen Übergang von der einfachen zur zweiten Moderne und von dort zum Kosmopolitismus und zur Weltrisikogesellschaft markiert.

Im Feld der Makrosoziologie zeigt sich mithin ein erstaunlich dichotomes Verständnis vom „West and the Rest". Alles, was im „Rest" noch anders ist, wird als Mangel, als etwas noch nicht Existentes gedeutet, der dann häufig auch mit Interventionen zu kompensieren sei: durch Demokratisierung, humanitäre oder Entwicklungshilfe. Postkoloniale Theorien kritisieren denn auch dieses asymmetrische Denken als Fortsetzung kolonialen Denkens in Entwicklungsstufen. ${ }^{25}$

Was sich im Feld der Soziologie also zeigt, und was meines Erachtens sicher auch für viele politikwissenschaftliche Analysen gilt, ist die Persistenz eines methodologisch „positivistischen“ Denkens wenn man das Konzept des Positivismus weiter fasst. In seiner ur- 
96 Wiederverzauberung der Welt oder Wiederkehr des Verdrängten?

sprünglichen Form, wie es Comte mit seinem Dreischritt von einem religiösen, zu einem metaphysischen und schließlich positiven Zeitalter darlegte, wird es natürlich nicht mehr vertreten. Und natürlich vollziehen Durkheim und Weber als Gründerväter der Soziologie rund um die vorletzte Jahrhundertwende einen Bruch mit dieser Form des Stadiendenkens, aber wie Gorski betont, keinen radikalen Bruch: „For while Durkheim recognized that religion was grounded in real experiences and Weber emphasized that science could not answer questions of value and meaning, both still assumed, if only tacitly, that the future of religion was either extinction (Durkheim) or drastic decline (Weber). "26

Der dominante methodologische Positivismus in der Makrosoziologie und empirischen Forschung (speziell in den Vereinigten Staaten) beruht auf spezifisch ontologischen und epistemologischen Annahmen und einem szientifisch-naturalistischen Glauben an die Einheit der Natur- und Sozialwissenschaften. In dieser Tradition geht es Carl Gustav Hempel folgend um die Identifikation von generellen Gesetzen des sozialen Lebens, die unabhängig von spezifischen Raum-Zeit-Konstellationen Geltung beanspruchen sollen. ${ }^{27}$

\section{Säkularisierung: ein alternativer Blick}

Mit Philip Gorski ließe sich ein radikalerer Bruch mit der positivistischen Sicht der Dinge fordern: ein Bruch, der anerkennt, dass es keine Stufen historischer Entwicklung gibt und dass die Sozialwissenschaften nicht in der Lage sind, zukünftige Entwicklungen in irgendeinem gehaltvollen Sinne vorherzusagen. ${ }^{28}$ Es ginge also darum, jegliche theoretische Teleologien abzustreifen. Aus dieser Perspektive ist Säkularisierung ein möglicher historischer outcome neben vielen anderen denkbaren. Im Feld historisch-komparativer Forschung müsste es also darum gehen anzuerkennen, dass Säkularisierung einen Pfad neben vielen anderen darstellt und dass sie sich nicht evolutionär entfaltet, sondern gemacht wird, also von Akteuren, beispielsweise politischen Akteuren, bewusst oder unbewusst vorangetrieben wird. Säkularisierung als europäisches Projekt müsste viel stärker als politisches Handeln bestimmter gesellschaftlicher Grup- 
pen rekonstruiert werden, wie insbesondere der Anthropologe Talal Asad herausgearbeitet hat. ${ }^{29}$ Säkularisierung als Projekt säkularistischer Bewegungen ist vielleicht deswegen eins der am schlechtesten untersuchten Forschungsgebiete, da Sozialwissenschaftler weitgehend Teil dieses Projektes waren; sie versuchten ja als Angehörige dieser Bewegung den Nachweis zu führen, dass große soziale Prozesse wie Rationalisierung und Modernisierung zum Bedeutungsverlust der Religion führen. Mit William Isaac Thomas könnte man hierzu anmerken: „If men define a situation as real, it's real in its consequences."

Die wissenschaftliche Säkularisierungsperspektive ist ja gerade keine Sicht, die gleichsam von Verunreinigungen befreit schlichtweg nur neutral wäre, sie verbindet sich mit spezifischen Sichtweisen, Werten, Interessen, Emotionen, Lebensstilen und Institutionen. Säkularität schaffte es historisch, sich als die quasi natürliche Rückzugsposition zu etablieren, die keiner weiteren Rechtfertigung bedarf. Sie kann sich als fortgeschrittene Position darstellen, die vorhergehende Stufen des Denkens hinter sich gelassen hat. Charles Taylor bezeichnet diese Perspektive als eine Art Substraktionstheorie, die davon ausgeht, dass man Illusionen abgestreift hat und auf diese Weise die eigentlich menschliche Natur freilegt. Dem gegenüber stellt Taylor heraus, dass Säkularität ebenfalls eine historisch erfundene und konstruierte Praxis ist. ${ }^{30}$ Er sieht Säkularität als verwoben „with the rise of a society in which for the first time in history a purely self-sufficient humanism came to be a widely available option. I mean by this a humanism accepting no final goals beyond human flourishing, nor any allegiance to anything else beyond this flourishing. Of no previous society was this true“. ${ }^{31}$ Diesen exklusiven Humanismus stellt Taylor als die fundamentale Rahmenbedingung des Lebens in den modernen westlichen Gesellschaften dar, sprich in Europa und Nordamerika, wobei fraglich ist, ob diese Beschreibung für die USA überhaupt zutreffend ist, wie José Casanova kürzlich andeutete. ${ }^{32}$

Will man sich in der Beschäftigung mit den USA auf einen sozialwissenschaftlichen Klassiker verlassen, bietet es sich eher an, Ale- 
98 Wiederverzauberung der Welt oder Wiederkehr des Verdrängten?

xis de Tocqueville als Gewährsmann zu nutzen, da er kein säkularistisches Selbstverständnis hatte und nicht annahm, dass gesellschaftlicher Fortschritt nur mit dem Niedergang der Religion zu erkaufen sei. Sein 1835 erschienenes Werk Über die Demokratie in den $U S A$ gilt als erste tiefschürfende Analyse der amerikanischen Demokratie und ist darin bis heute unübertroffen. Es ging Tocqueville darum zu zeigen, dass die politische Kultur Amerikas von immenser Bedeutung für die Entfaltung und Erhaltung der Demokratie ist. ${ }^{33}$ In den USA ist die Religion - so beobachtet es Tocqueville - eine Symbiose mit der Freiheit eingegangen: Religiöse und republikanische Traditionen der Selbstregierung und Tugendhaftigkeit stehen im Zentrum der amerikanischen Sitten. Im Gegensatz dazu beobachtet der Franzose Tocqueville in seinem Heimatland eine Frontstellung zwischen Aufklärung, Freiheit und Demokratie einerseits und Religion andererseits - also eine für Säkularisierungsprozesse paradigmatische Grundkonstellation. Die politische Freiheit der Amerikaner stellt sich nur über ein gemeinsames öffentliches, durchaus auch religiös geprägtes Leben her. Hier kommt das für die Diskussion der Zivilgesellschaft wohl bekannteste Argument Tocquevilles ins Spiel: Freie Zusammenschlüsse - Assoziationen oder Vereine - sind es, die die Demokratie mit Leben erfüllen und erhalten. Das amerikanische Gemeinwesen ruht auf einer Vielzahl an politischen wie auch an geselligen, unpolitischen Vereinen. Das „Miteinander-Handeln“ scheint dabei entscheidend zu sein: „Nur durch die gegenseitige Wirkung der Menschen aufeinander erneuern sich die Gefühle und die Ideen, weitet sich das Herz und entfaltet sich der Geist des Menschen" ${ }^{34}$ Die Menschen werden also durch den Zusammenschluss, durch die Auseinandersetzung miteinander, aus ihrer Egozentrik gerissen und neue Bande werden zwischen ihnen geknüpft. Und man könnte noch hinzufügen, dass Religion privatistische und autistische Realitäten transzendiert. ${ }^{35}$ Sie integriert die Individuen einerseits in eine intersubjektive und kommunale Welt, gleichzeitig transzendiert Religion durch ihren Verweis auf eine transsoziale Welt jeden Gemeinschaftskult. Das Individuum wird gleichsam von partikularen Bindungen an die Welt befreit. 
Kritiker zeitgenössischer Religiosität wie Robert Bellah bezweifeln, dass diese Transzendierungsleistung auch heute noch vollbracht wird. ${ }^{36}$ Mit den kulturellen Veränderungen der 1960er Jahre, die vor allem eine enorme Verbreitung des so genannten expressiven Individualismus mit sich brachten, hat sich eine individualistische Spiritualität durchgesetzt, die nicht mehr auf einen größeren Zusammenhang verweist. Es geht nun um den authentischen Ausdruck des Selbst; die Zugewandtheit zum eigenen Ich wird zum Massenphänomen. In einem expressivistischen Glaubenssystem besteht keine Notwendigkeit mehr, die Verbindung zum Sakralen in einen größeren Rahmen, sei es die Kirche oder die Gesellschaft, einzufügen.

Eine andere Grundperspektive lässt sich allerdings bei Max Weber rekonstruieren. In der während des Ersten Weltkriegs verfassten berühmten Zwischenbetrachtung geht es Weber bekanntlich um die Bedeutung der Herausbildung von differenzierten Lebensordnungen beziehungsweise Wertsphären für die moderne Gesellschaft. ${ }^{37}$ Die religiöse Sphäre stellt nur noch eine neben anderen dar: Ökonomie, Politik, Ästhetik, Wissenschaft/Intellektualität und Erotik sind die anderen Wertsphären, die sich gegenüber der Religion und ihrer Brüderlichkeitsethik emanzipiert haben. Im Gesellschaftsvergleich ging es Weber darum zu zeigen, wie diese Dynamik vor allem durch die Weltablehnung der Erlösungsreligionen und insbesondere durch das Christentum beziehungsweise den asketischen Protestantismus befördert wurde. Kompromisse zwischen Religion und Welt (Weber spricht von einer organischen Sozialethik) werden ab dem Punkt immer schwieriger, wo der Protestantismus gleichsam hinter den klösterlichen Mauern hervortritt und in die Welt schreitet. Die religiösen Ansprüche gegenüber der Welt verstärken sich auf diese Weise nicht nur, auch die Abwehrreaktionen und Autonomiebemühungen anderer gesellschaftlicher Sphären werden intensiviert. „The result is increasing differentiation among the value-spheres and increasing rationalization within them. Thus, it is, Weber concluded, that the religious rejection of the world culminates in the fragmentation of social life. " ${ }^{38}$ In diesem Sinne stellt der Text dar, wie Religion paradoxerweise selbst als Motor der Säkularisierung zu betrachten ist. 
100 Wiederverzauberung der Welt oder Wiederkehr des Verdrängten?

Eine andere Lesart jedoch würde nahelegen, dass Weber selbst Spuren für die These legte, dass eine Wiederverzauberung der Welt in anderen Wertsphären als der religiösen durchaus denkbar ist. Weber spricht von den innerweltlichen, aber dennoch außeralltäglichen Erlösungsalternativen in der Politik im Rahmen des Nationalismus oder des Kriegs, von der Verschmelzungsmystik im Bereich der Erotik, der Abwehr des rein Instrumentellen und Alltäglichen im Bereich der Ästhetik. In den Bereichen Wissenschaft und Ökonomie sah er keine Erlösungspfade angelegt, doch Weber schrieb den Text ja auch noch vor der Durchsetzung des Massenkonsums als Erlösungsideologie des 20. und 21. Jahrhunderts. Wenn man Webers Programm ernst nimmt, auch eine historische Soziologie der Herausbildung des modernen Subjekts zu betreiben, stellt sich natürlich die Frage, was im Verlauf des 20. Jahrhunderts aus der asketischprotestantischen Persönlichkeit geworden ist. Die fragmentierte konsumistische Persönlichkeit richtet ihr Leben wahrscheinlich weniger auf außerweltliche Erlösung aus als auf weltliche Erfahrungen „kleiner Transzendenzen“. Die Entzauberung der Welt in einigen gesellschaftlichen Sphären bringt also durchaus den Möglichkeitsraum für eine Wiederverzauberung der Welt in anderen Bereichen mit sich - Weber spricht dabei dezidiert von den innerweltlichen Konkurrenzen zur außerweltlichen Erlösungsreligion. ${ }^{39}$

Aber auch die Brüderlichkeitsethik selbst ist im Verlauf des 20. Jahrhunderts nicht, wie Weber glaubte, an ihr Ende gekommen. Robert Bellah stellt heraus, dass Weber solche religiösen und politischen Führungsfiguren wie Martin Luther King oder Gandhi nicht mehr erwartete oder für möglich hielt; ${ }^{40}$ auch der Wohlfahrtsstaat mit den dort eingelassenen Solidaritätspotentialen ist als eine institutionalisierte Variante der Brüderlichkeitsethik zu betrachten. Gleiches gilt für die unzähligen zivilgesellschaftlichen Assoziationen, die sich dezidiert einer Differenz zwischen Binnen- und Außenmoral entziehen möchten.

Zivilgesellschaftliche Selbstorganisation, philanthropisches Geben und globale Solidarbeziehungen lassen sich als geleistete Hilfe ohne Erwartung einer bestimmten Erwiderung und mit der Absicht, eine soziale Beziehung aufzubauen, auffassen - und dies ist etwas

40 Bellah (1999). 
fundamental anderes als ein ökonomischer Tausch, der der Logik des do ut des (,,ich gebe dir, damit du mir auch etwas gibst") folgt. Der französische Soziologe Alain Caillé entfaltet die These, dass mit dem Übergang zur modernen Gesellschaft Gaben und daran geknüpfte (reziproke) Beziehungen nicht obsolet werden, sondern im Gegenteil in einigen sozialen Bereichen eine Radikalisierung und (im Weberschen Sinne) Rationalisierung erfahren haben. ${ }^{41}$ Gerade mit der reformatorischen Gnadentheologie setzt sich eine Radikalisierung und Rationalisierung der Vorstellungen vom Geben durch, also mit der Idee, dass wir radikal auf Gottes Gnade als einer Gabe angewiesen sind, diese aber weder erarbeiten noch erwidern können. Während in vielen sozialen Sphären eine Tendenz zu ausgeglichener Reziprozität (Tausch) Einzug gehalten hat, universalisiert sich idealtypisch die vom jüdisch-christlichen Denken geprägte karitative Gabe im Übergang zur Moderne, radikalisiert sich und wird ,introvertiert". Benjamin Nelson spricht in diesem Zusammenhang davon, dass sich eine universalistische Nächstenbeziehung durchsetzt, in der alle Menschen Brüder sind, indem sie zugleich „Andere“ sind. Nelson bringt den Übergang so auf den Punkt: „from tribal brotherhood to universal otherhood“. 42 Universalisierte Gaben richten sich nicht mehr nur an soziale Gruppen, die einem nahe stehen, sondern auch an Fremde. Die radikalisierte Gabe erwartet keine Erwiderung mehr, und die introvertierte Gabe setzt sich ab vom theatralisch inszenierten, für alle sichtbaren Geben. Man müsste also der Frage nachgehen, wo, wann und unter welchen Umständen diese Brüderlichkeitsethik institutionell auch und gerade unter modernen Bedingungen Fuß fassen konnte.

Dass es uns heute möglich sein sollte, Religion in ihrer Vielfältigkeit, in ihren Schattierungen und Verschränkungen mit anderen Phänomenen besser wahrzunehmen, also das Verdrängte wieder bewusstseinsfähig werden zu lassen, liegt in verschiedenen Umständen begründet: in der Skepsis gegenüber modernistischen Entwürfen inner- und außerhalb der Wissenschaft, die sicherlich mit postmodernen und multikulturalistischen Gegenentwürfen verknüpft ist, sowie mit dem „cultural turn“ in den Geistes- und Sozialwissenschaften. Und natürlich sind zeitgenössische religiöse Bewegungen 
102 Wiederverzauberung der Welt oder Wiederkehr des Verdrängten?

zu nennen, die an vielen Orten der Welt zu beobachten sind. Wichtig ist bei all diesen Neuorientierungen, eurozentrische Vorannahmen weitestgehend einzuklammern.

Der Begriff Säkularisierung hat ja beispielsweise seinen Ursprung im europäischen Konzept der Säkularisation, also in der Überführung kirchlicher Güter in weltliche. Auch Säkularisierung, ein relativ junger Begriff, geht von einem Spannungsverhältnis zwischen dem Weltlichen und Profanen zum Sakralen und Transzendenten aus. Streng genommen ist der Begriff Säkularisierung also nur in Kontexten brauchbar, die von der Dualität des Heiligen und Profanen und zugleich von der zwischen Religion und Welt ausgehen diese Annahme machte bekanntlich Durkheim, ${ }^{43}$ doch ist diese Perspektive bezogen auf den Konfuzianismus oder Taoismus sicher nicht haltbar. Säkularisierung als Konzept macht zunächst nur vor dem Hintergrund des lateinischen Christentums Sinn, weil dort die Klassifikation von zeitlicher und göttlicher Ordnung, von religiös und weltlich überhaupt erst eingeführt wurde. Westliche Gesellschaften kennen nicht nur diese Dichotomie, sondern auch vielfältige sprachliche Distanzierungsstrategien vom Bereich des Religiösen (Profanisierung, Entkirchlichung, Verweltlichung, Antiklerikalismus, Transzendenzverlust, Entweihung usw. usf.) - Distanzierungen, die es in anderen Weltreligionen sicher so nicht gibt. ${ }^{44}$

Was bedeutet dies nun alles für den politischen Bereich, für die Frage nach dem Verhältnis von Religion und Politik und für die Konstitution von Zivilgesellschaft, also dem öffentlichen Bereich neben Markt und Staat? Hier ist nochmals José Casanovas Studie Public Religions in the Modern World zu erwähnen. In den 1980er Jahren wurde mit der Entprivatisierung der Religion beispielsweise in den USA ja deutlich, dass Differenzierungsprozesse und der Verlust gesellschaftlicher Regulierungsfunktionen nicht zu einer Privatisierung der Religion führen müssen und dass Kirchen weltweit in die Arena der Zivilgesellschaft als öffentliche Religionen eintraten. Casanova schlägt vor, die allgemeine Säkularisierungstheorie in drei separate Thesen zu unterteilen: in die These des religiösen Rückgangs, die Privatisierungsthese und in die Differenzierungsthese. ${ }^{45}$ Die These vom religiösen Rückgang beziehungsweise vom Ver-

43 Durkheim (1981).

44 Lehmann (2004), 29-30.

45 Casanova (1994), $19 \mathrm{ff}$. 
schwinden der Religion ist wie oben erläutert empirisch unhaltbar und wird in dieser Form auch kaum noch vertreten. Die These der Privatisierung von Religion beinhaltet zwei Subthesen: Säkularisierung bedeutet hier, dass religiöser Glaube subjektiv und privat wird. Zum zweiten ist die institutionalisierte Religion als Konsequenz der funktionalen Differenzierung entpolitisiert, und die Suche nach subjektivem Sinn ist aus dieser Perspektive eine persönliche Angelegenheit. ${ }^{46}$ Die Privatisierung der Religion ist zwar eine historische Entwicklung in bestimmten Gesellschaften, aber kein universaler Trend, so Casanova. Die von ihm beschriebenen öffentlichen Religionen in Spanien, Polen, Brasilien und den USA verweisen darauf, dass Privatisierung nicht die einzige Entwicklungsoption von Religion in modernen Gesellschaften ist. Die Differenzierungsthese schließlich behauptet die Ausdifferenzierung verschiedener gesellschaftlicher Sphären: Staat, Wirtschaft, Recht und Wissenschaft emanzipieren sich von der Religion und bilden eine spezifische Eigenlogik heraus. Gleichzeitig entsteht eine eigene religiöse Sphäre in der Gesellschaft beruhend auf dem Prinzip religiöser Freiheit. Die Säkularisierung im Sinne einer Differenzierung gesellschaftlicher Sphären wurde im Westen vor allem von vier Prozessen getragen: von der protestantischen Reformation, der Formation des modernen Staats, der Entwicklung des kapitalistischen Wirtschaftssystems und der Herausbildung der modernen Wissenschaft. ${ }^{47}$ Die Dynamik dieses Differenzierungsprozesses verlief in allen Gesellschaften sehr verschieden, sodass sich daraus verschiedene Muster der Säkularisierung und von Staat-Kirche-Arrangements ergeben. ${ }^{48}$

Dieser Lesart der Säkularisierungsthese - der Differenzierungsthese - stimmt Casanova weitgehend zu: Säkularisierung als Differenzierung ist für Casanova der valide Kern der Säkularisierungsthese. ${ }^{49}$ Ein struktureller Trend moderner Gesellschaften sei die Trennung der säkularen Sphären von religiösen Institutionen und Normen. Doch auch dies ist als empirische wie theoretische These meines Erachtens äußerst zweifelhaft - und Casanova hat vor kurzem selbst begonnen, diese These zu relativieren. ${ }^{50}$ Allzu schnell ergibt 
104 Wiederverzauberung der Welt oder Wiederkehr des Verdrängten?

sich daraus nämlich wiederum eine Analogie zu angeblichen sozialen Evolutionsprozessen, die sich gleichsam nur noch entfalten müssen. Eine Theorie moderner Gesellschaften, die die Kontingenz historischer Entwicklungen ernst nimmt, sollte sich prinzipiell skeptisch gegenüber der Behauptung evolutionärer Prozesse zeigen, die angeblich eine bestimmte Richtung einschlagen und sich quasi von allein, hinter dem Rücken der Akteure, vollziehen. ${ }^{51}$ Vielmehr verbirgt sich offenbar hinter der behaupteten Validität der Differenzierungsthese eine normative Forderung, nämlich dass die religiöse von anderen gesellschaftlichen Sphären getrennt sein sollte. Als normative Forderung nach Religionsfreiheit lässt sich meiner Meinung nach die Differenzierungsthese tatsächlich diskutieren, nicht aber als evolutionäre Entwicklungsthese.

Das Prinzip der religiösen Toleranz - und weniger das Prinzip der Trennung von Politik und Religion - erfordert, dass kein religiöses Programm in ein Gesetz gegossen werden sollte. Michael Walzer betont, dass es richtiger wäre, nicht mehr von der Trennung von Politik und Religion zu sprechen, sondern von der Trennung von Religion und Staatsmacht. ${ }^{52}$ Er folgert, dass der Religion nicht prinzipiell der Zugang zur Politik versperrt sein sollte, sondern nur der Zugang zur Ausübung von religiösem Zwang. Nimmt man diesen normativ qualifizierten Begriff von religiöser Toleranz ernst und wendet ihn auf demokratietheoretische Fragen an, muss gegenüber Religionsgemeinschaften die Forderung formuliert werden, dass sie das religiöse Monopol aufgeben und die Gewissens- und Religionsfreiheit anerkennen. Rechtlich umgesetzt müsste sich dieses Gebot in Form von Vereinigungs- und Meinungsfreiheit niederschlagen.

Für den momentan viel diskutierten Islam würde dies auch bedeuten, dass das Recht auf Apostasie gewährt werden müsste. Doch ist diese Form von religiöser Toleranz auch im Westen noch nicht lange zur Selbstverständlichkeit geworden. Die katholische Kirche hat eine positive Wende eigentlich erst in den 1960er Jahren mit dem II. Vatikanischen Konzil vollzogen und die Gewissensfreiheit des Einzelnen sowie die formale Trennung von Staat und Kirche anerkannt. ${ }^{53}$ Christen haben längst nicht zu jeder Zeit intern Toleranz

51 Vgl. Knöbl (2007).

52 Walzer (1998), 304.

53 Dennoch war die Praxis der Katholiken etwa im Deutschen Reich, wo sie eine angefeindete Minderheit gegenüber der protestantisch-preußischen Mehrheit darstellten, 
gegenüber abweichenden Meinungen, Werten und religiösen Überzeugungen oder extern gegenüber anderen Religionsgemeinschaften gezeigt - und das Zeitalter der (ersten) Konfessionalisierung ist schwerlich mit dem Konzept der Trennung von Staat und Kirche zu beschreiben.

\section{Islam und Zivilgesellschaft}

Unter civil society, also Zivil- oder Bürgergesellschaft, wird in der Regel ein gesellschaftlicher Raum, nämlich die plurale Gesamtheit der öffentlichen Assoziationen, Vereinigungen und Zusammenkünfte verstanden, die auf dem freiwilligen Zusammenhandeln der Bürger und Bürgerinnen beruhen. Vereine, Verbände und soziale Bewegungen sind dabei typische Organisationsformen. Diese Vereinigungen sind weitgehend unabhängig von einem staatlichen Apparat und in der Regel auch nicht wirtschaftlichen Profitinteressen verbunden, das heißt, idealtypisch bilden sie eine Sphäre aus, die nicht staatlich ist und nicht auf reinen Marktprinzipien beruht. Die meisten Autoren, die sich mit Zivilgesellschaft beschäftigen, grenzen diesen Raum darüber hinaus von der Privatsphäre, zum Beispiel von der Familie, ab und betonen, dass zur Zivilgesellschaft Öffentlichkeit gehört. In amerikanischen Debatten werden Religion und Zivilgesellschaft in der Regel nicht dichotom konzeptionalisiert, sondern positiv aufeinander bezogen. Aus dem europäischen Zivilgesellschaftsdiskurs wurden in den letzten Jahren hingegen religiöse Akteure weitgehend ausgeschlossen. Religion wird dabei nicht als zivilgesellschaftliche Ressource thematisiert, sondern klassisch-aufklärerisch als bedrohlich für zivilisatorische Standards qualifiziert. ${ }^{54}$

Blickt man auf den Islam, verschärft sich diese Voreinstellung noch: Vielen westlichen Beobachtern gilt es heute als ausgemacht, dass der Islam sich vom Christentum in einigen Dimensionen fundamental unterscheidet. Mohammed, der Begründer des Islam gründete zugleich seinen eigenen Staat und sein eigenes Reich, also keine

trotz ihres Ultramontanismus viel „zivilgesellschaftlicher“ als es das normative Ordnungsmodell erwarten lassen würde: Nicht-staatliches, gewaltfreies und gemeinwohlorientiertes Handeln fand in den katholischen Assoziationen natürlich statt. „Für viele Mitglieder katholischer Organisationen“, schreibt Manuel Borutta, „war Religion Bedingung und Movens zivilgesellschaftlichen Handelns“. Borutta (2005), 33.

54 Vgl. Borutta (2005); Adloff (2005). 
106 Wiederverzauberung der Welt oder Wiederkehr des Verdrängten?

Kirche, die vom Staat zu unterscheiden wäre. Die westliche christliche Welt sei dagegen von dem Gegensatz von weltlicher und geistlicher Herrschaft - regnum versus sacerdotium - geprägt, so der Islamwissenschaftler Bernhard Lewis. ${ }^{55}$ „Für Christen gab es die Wahl zwischen Gott und Kaiser, und unzählige Generationen von Christen haben mit dieser Frage gerungen. Der Islam kennt eine solche schmerzhafte Wahl nicht. In der universellen islamischen Gemeinschaft der Muslime gibt es keinen Kaiser, denn Gott ist der einzige Souverän und alleinige Ursprung allen Rechts. "56 Schon zur Zeit des Propheten Mohammed hatte die islamische Gesellschaft einen doppelten Charakter: Sie war als Stammesgesellschaft ein politisches Gemeinwesen, aus dem im Laufe der Zeit ein Staat und ein Imperium entstanden. Zugleich war sie eine religiöse Gemeinschaft, gegründet von dem Propheten und regiert von seinen Nachfolgern und Stellvertretern. Diese von Lewis behauptete Einheit von Politik und Religion ist in der westlichen Welt - und interessanterweise auch unter islamistischen Autoren - nahezu zu einem unverrückbaren Axiom geworden. ${ }^{57}$

Der Einklang westlicher und islamistischer Kommentatoren beruht jedoch auf einem essentialistischem Denken und übersieht dabei die Fülle an extrem unterschiedlichen Arrangements zwischen Staat und Religion in der westlichen wie in der islamischen Welt. ${ }^{58}$ Nicht zuletzt beruhen die Staatsmodelle der islamisch geprägten Länder auf einem kolonialem Erbe und dem „Import“ der säkular verfassten modernen Staatlichkeit des Westens, die die politische Ordnung nicht religiös, sondern formal über gesatzte Verfahren begründet. So wurde etwa in Ägypten moderne Staatlichkeit unter Muhammad Ali Pascha (1806-1848) importiert. Auch die Strukturen beispielsweise der islamischen Republik Iran ,orientieren sich klar an den modernen Prinzipien legaler Herrschaft, denen zufolge sich staatliche Macht über selbst gesetzte, formale Verfahren legitimiert" ${ }^{\text {"59 }}$ - Iran ist schließlich vom Regierungssystem her eine Präsidialdemokratie. Das zeitgenössisch formulierte islamistische Ideal einer Einheit von Staat und Religion ist selbst ein Produkt des 20. 
Jahrhunderts und beruht auf der Konfrontation mit westlich inspirierten Modernisierungspolitiken, sei es im Rahmen sozialistischer Gesellschaftsentwürfe, sei es im Rahmen nationalstaatlicher beziehungsweise panarabischer Entwicklungsentwürfe und Gegennarrationen. ${ }^{60}$ Insbesondere für militante Islamisten, die sich beispielsweise auf die Schriften des Ägypters Sayyid Qutb berufen, steht die Bedrohung durch ,verwestlichte“ muslimische Eliten im Vordergrund ihres Kampfes, bei dem das islamische Recht der Scharia zur zentralen Referenz für die Neuerrichtung des Staatswesens erklärt wird. Dabei ist weniger die Verschmelzung oder die Trennung von Staat und Kirche - zumal der Islam ja nicht dem christlichen Kirchenbegriff folgt - das zentrale Thema, sondern das Verhältnis von Scharia, öffentlicher Ordnung und individueller Lebensführung. ${ }^{61}$

Viele der modernen staatlichen Herrschaften im islamischen Raum sind nun seit Jahrzehnten nur noch schwach legitimiert und versuchen sich der legitimatorischen Kraft des Islam zu bedienen, etwa dadurch, dass er zur Staatsreligion erklärt oder indem die traditionelle religiöse Elite kooptiert wurde. Zum anderen bietet die Religion häufig den einzigen relativen Freiraum vor dem staatlichen Zugriff und Herrschaftsanspruch. Dietrich Jung schließt daher: „Der Islam ist beides zugleich: Quelle legitimer staatlicher Herrschaft und Quelle legitimen Widerstands." 62

Auf grundlagen- beziehungsweise sozialtheoretischer Ebene ist hervorzuheben, dass alle drei abrahamitischen Religionen (also das Judentum, das Christentum und der Islam) Gemeinschaftsformen mit einem Anspruch auf Autonomie herausgebildet haben. ${ }^{63}$ Religiöse Vergemeinschaftungen können mit den anderen sozialen Ordnungen und Mächten wie dem Staat, dem Recht oder dem Markt in Spannungsverhältnisse treten. Wird die Autonomie der religiösen Gemeinschaft bedroht, kann dies auch zu einer kriegerischen Solida-

60 Riedel (2003), 21.

61 Krämer (2007), 193.

62 Jung (2002), 36.

63 Man kann z.B. im Islam die fromme Stiftung, den waqf, als eine Körperschaftsform bezeichnen, die durchaus eigene Autonomieansprüche verkörpert und einen eigenständigen Bereich der Öffentlichkeit konstituiert. Kippenberg (2008), 34. Gerade die sporadisch seit dem 19. Jahrhundert immer wieder vorkommenden Verstaatlichungsprozesse von Stiftungen (z.B. in Ägypten, Tunesien, Algerien, Marokko oder auch in Indien) zeigen ja ex negativo deutlich, dass sich der Staat mit wirtschaftlichen, politischen und religiösen Autonomieansprüchen von Stiftungen auseinanderzusetzen hat. Vgl. Hartung (2005). 
108 Wiederverzauberung der Welt oder Wiederkehr des Verdrängten?

ritätsethik der Gläubigen führen, die dem Zweck der (unter Umständen auch gewalttätigen) Verteidigung der eigenen Gemeinschaft dient. ${ }^{64}$ Das Doppelgesicht dieser Vergemeinschaftungen zeigt sich beispielsweise bei militant-politischen und militärischen Organisationen wie der libanesischen Hizbollah oder der palästinensischen $\mathrm{Ha}$ mas, die ihre Basis in der Bevölkerung verbreitern konnten, indem sie soziale Unterstützungsleistungen in großer Breite beziehungsweise auch zielgerichtet den Hinterbliebenen von Märtyrern anbieten. ${ }^{65}$

Wie jüngst José Casanova herausstellte, ähnelt die jetzige Situation des Islam im Verhältnis zum Westen derjenigen des Katholizismus vor dem II. Vatikanischen Konzil, als ihm von protestantischer Seite Rückwärtsgewandtheit, die Ablehnung von Demokratie und Menschenrechten vorgeworfen wurde. ${ }^{66}$ Mit dem Konzil änderte sich die katholische Haltung zu all diesen Fragen schlagartig und die Kirche wurde gar zu einer bedeutenden Verfechterin zivilgesellschaftlicher Anliegen weltweit. Damit will Casanova zeigen, dass die vom Westen propagierte Trennung von Staat und Kirche im Westen selbst auch noch nicht sehr lange von allen Religionsgemeinschaften uneingeschränkt anerkannt wurde und dass das Ringen mit diesem Problem nicht typisch „muslimisch“ sei. Des Weiteren geht es ihm darum, dass Bewusstsein dafür zu schärfen, dass Religionsgemeinschaften sich auch innerhalb relativ kurzer Zeit ideologisch stark wandeln können und dass man ,parallel processes of democratization of Muslim politics throughout the world, thus putting into question the alleged, clash of civilizations' between Islam and the West“"67 finden könne. Noch vor einigen Jahrzehnten hätte Huntingtons These vom „clash of civilizations“ also in der Beschreibung bestehen können, dass der protestantisch-säkulare, aufgeklärte Wes-

64 Kippenberg (2008), 47. So geschehen etwa bei dem ideologischen Übergang zwischen dem sozialen Islam der Muslimbrüder, die der Islamisierung der eigenen Gesellschaft zeitlich und sachlich den Vorrang vor dem bewaffneten Kampf einräumten, und den Verfechtern des Islamischen Jihad, ,die die gegenwärtige Kultur und Gesellschaft ihres Landes für so korrumpiert hielten, dass sie die Möglichkeit einer allmählichen Islamisierung verneinten“ Kippenberg (2008), 124. Unverzügliches, auch kriegerisch-gewalttätiges Handeln sei daher das Gebot der Stunde. Diese in Ägypten zuerst entwickelten Handlungs- und Argumentationsformen fanden über die Beteiligung am Jihad gegen die Sowjetunion in Afghanistan schließlich auch Eingang in das Netzwerk Usama bin Ladens. Kippenberg (2008), 131.

65 Kippenberg (2008), 96.

66 Casanova (2005).

67 Casanova (2005), 90. 
ten mit seinem ,inneren Orient“, nämlich dem Katholizismus, zusammenprallte. Auch das westliche säkulare Selbstbild - und nicht nur das Bild vom „Orient“ 68 - ist essentialistisch konstruiert und realiter von stärkeren Brüchen und Kontingenzen geprägt ${ }^{69}$ als es zeitgenössische Selbstbeschreibungen zulassen: „Every incrimination of Islam as a fundamentalist, antimodern and anti-Western religion could have been directed even more justifiably against Catholicism not so long ago. "70

\section{Schluss}

Haben wir es nun also mit einer Wiederverzauberung der Welt oder einer Rückkehr des Verdrängten zu tun? Mit beidem. Das Potential zur Wiederverzauberung ist auch in der (europäischen) modernen Gesellschaft angelegt, doch vornehmlich muss es Aufgabe des Sozialwissenschaftlers sein, sich der Religion als des Abgespaltenen und Verdrängten der Moderne und der säkularistischen Lebensform bewusst zu werden. Dies bedeutet Abschied zu nehmen von Entwicklungslogiken und allgemeinen Gesetzes- wie Trendaussagen. Vielmehr sind unter den globalen Bedingungen postkoloniale Konstellationen und Verflechtungen ernst zu nehmen. Es gibt weder die eine Moderne, die alle erfasst, noch sollte man von unabhängigen Fällen und Modernen ausgehen. Die multiple modernities ${ }^{71}$ sind vielmehr zugleich verflochtene beziehungsweise entangled modernities ${ }^{72}$. Die heutigen globalen und lokalen Konstellationen sind auch Teil der europäischen Geschichte, insbesondere der Geschichte von Kolonialismus und Imperialismus. Erzählte nationale Geschichten sind zutiefst ineinander verwobene Geschichten, die sich gegenseitig durchdringen und bestimmen. ${ }^{73}$ Das gegenüber dem Westen (auch religiös) Andere sollte meines Erachtens nicht evolutionistisch und hierarchisch behandelt werden und somit als Vorstadium einer westlichen Moderne betrachtet werden.

68 Vgl. Said (2003).

69 Vgl. Randeria (2006).

70 Casanova (2001), 1047.

$71 \mathrm{Vgl}$. Eisenstadt (2002).

72 Vgl. Randeria (2006); Werner/Zimmermann (2002).

73 Vgl. Hobson (2008). 
110 Wiederverzauberung der Welt oder Wiederkehr des Verdrängten?

Wir leben heute alle unter modernen Handlungs- und Ordnungsbedingungen, und Dichotomien von traditional versus modern sind wenig hilfreich beziehungsweise fehlgeleitet. Was die Konstellationen religiöser Vergemeinschaftungen betrifft, sei es in ihrer Verschränkung mit politischen Vergemeinschaftungen, sei es in Abgrenzung hierzu, lässt sich nur bescheiden sagen: Alles ist offen und möglich, nichts ist notwendig. Denn es lassen sich meines Erachtens keine zentralen Transformationsachsen identifizieren und keine grand theory entwickeln, die alle Dynamiken auf den Begriff bringen könnten. Stattdessen sollte der plurale, fragmentierte und historisch kontingente Charakter gegenwärtiger religiöser Dynamiken anerkannt und theoretisch wie empirisch eingefangen werden.

\section{Literatur}

Abbott, Andrew (2004): Methods of Discovery. Heuristics for the Social Sciences. New York: W. W. Norton.

Adloff, Frank (2005): Zivilgesellschaft. Theorie und politische Praxis. Frankfurt/New York: Campus.

Asad, Talal (2003): Formations of the Secular. Christianity, Islam, Modernity. Stanford, Cal.: Stanford Univ. Press.

Bayly, Christopher A. (2006): Die Geburt der modernen Welt. Eine Globalgeschichte 1780-1914. Frankfurt/ New York: Campus.

Beck, Ulrich/Sznaider, Natan (2006): „Unpacking cosmopolitanism for the social sciences: a research agenda", in: The British Journal of Sociology 57 (1), 1-23.

Bellah, Robert (1999): „Max Weber and World-Denying Love: A Look at the Historical Sociology of Religion", in: Journal of the American Academy of Religion 67 (2), 277-304.

Bellah, Robert N. (2002): „Epilogue. Meaning and Modernity: America and the World", in: Madsen, Richard/Sullivan, William M./Swidler, Ann/Tipton, Steven M., Hg.: Meaning and Modernity. Religion, Polity, and Self. Berkeley: University of California Press, 255-276.

Blaschke, Olaf (2002): Konfessionen im Konflikt. Deutschland zwischen 1800 und 1970: ein zweites konfessionelles Zeitalter. Göttingen: Vandenhoeck \& Ruprecht.

Borutta, Manuel (2005): „Religion und Zivilgesellschaft. Zur Theorie und Geschichte ihrer Beziehung", in: Veröffentlichungsreibe der Forschungsgruppe 'Zivilgesellschaft, Citizenship und politische Mobilisierung in Europa', Wissenschaftszentrum Berlin für Sozialforschung: Discussion Paper Nr. SP IV 2005404, online unter: http://skylla.wzb.eu/pdf/2006/iv05-404.pdf (Zugriff am 17.02.2009). 
Bruce, Steve (1996): Religion in the Modern World. Form Cathedrals to Cults. New York: Oxford Univ. Press.

Brugger, Winfried (2007): „Von Feindschaft über Anerkennung zur Identifikation. Staat-Kirche-Modelle und ihr Verhältnis zur Religionsfreiheit", in: Joas, Hans/Wiegandt, Klaus, Hg.: Säkularisierung und die Weltreligionen. Frankfurt a.M.: Fischer, 253-283.

Caillé, Alain (2008): Anthropologie der Gabe. Frankfurt a.M./New York: Campus.

Casanova, José (1994): Public Religions in the Modern World. Chicago: The University of Chicago Press.

Casanova, José (2001): „Civil Society and Religion”, in: Social Research 68 (4), 1041-1050.

Casanova, José (2005): „Catholic and Muslim Politics in Comparative Perspective", in: Taiwan Journal of Democracy 1 (2), 89-108.

Casanova, José (2008a): „Public Religions Revisited”, in: de Vries, Hent, Hg: Religion: Beyond the Concept. New York: Fordham University Press, 101119.

Casanova, José (2008b): „A Secular Age: Dawn or Twilight?” Draft of paper to be presented at the conference Varieties of Secularism, Yale University, 3.-5. April 2008.

Chaves, Mark/Gorski, Philip S. (2001): „Religious Pluralism and Religious Participation", in: Annual Review of Sociology 27, 261-281.

Costa, Sérgio (2007): Vom Nordatlantik zum Black Atlantic. Postkoloniale Konfigurationen und Paradoxien transnationaler Politik. Bielefeld: Transcript.

Durkheim, Emile (1981): Die elementaren Formen des religiösen Lebens. Frankfurt: Suhrkamp.

Eisenstadt, Shmuel N. (2002): „Mirror-Image Modernities: Contrasting Religious Premises of Japanese and U.S. Modernity”, in: Madsen, Richard P./Sullivan, William M./Swidler, Ann/Tipton, Steven M, Hg.: Meaning and Modernity. Berkeley: University of California Press, 56-77.

Gorski, Philip S. (2005): „The Return of the Repressed: Religion and the Political Unconscious of Historical Sociology", in: Adams, Julia/Clemens, Elisabeth S./Orloff Shola, Ann, Hg.: Remaking Modernity. Politics, History and Sociology. Durham/London: Duke University Press, 161-189.

Hartung, Jan-Peter (2005): „Die fromme Stiftung [waqf]: Eine islamische Analogie zur Körperschaft?” in: Kippenberg Hans G./Schuppert Gunnar F., Hg.: Die verrechtlichte Religion: Der Öffentlichkeitsstatus von Religionsgemeinschaften. Tübingen: Mohr Siebeck, 287-314.

Herbert, David (2003): Religion and Civil Society. Rethinking Puclic Religion in the Contemporary World. Aldershot: Ashgate.

Hobson, John M. (2008): „Reorienting Weber? Is a non-Eurocentric Theory of the Rise of the West desirable and possible?" in: Adloff, Frank/Borutta, Manuel, Hg.: Max Weber in the 21st Century: Trans- 
112 Wiederverzauberung der Welt oder Wiederkehr des Verdrängten?

disciplinarity within the Social Sciences. EUI Working Papers, MWP 08/35, 55-72.

Iannaccone, Laurence R./Finke, Roger/Stark, Rodney (1997): „Deregulating Religion: The Economics of Church and State", in: Economic Inquiry $35,350-364$.

Jung, Dietrich (2002): „Religion und Politik in der islamischen Welt”, in: Aus Politik und Zeitgeschichte (42-43), 31-38.

Kippenberg, Hans G. (2008): Gewalt als Gottesdienst. Religionskeriege im Zeitalter der Globalisierung. München: C.H. Beck.

Knöbl, Wolfgang (2001): Spielräume der Modernisierung. Das Ende der Eindeutigkeit. Weilerswist: Velbrück.

Knöbl, Wolfgang (2007): Die Kontingenz der Moderne. Wege in Europa, Asien und Amerika. Frankfurt/New York: Campus.

Krämer, Gudrun (2007): „Zum Verhältnis von Religion, Recht und Politik: Säkularisierung im Islam”, in: Joas, Hans/Wiegandt, Klaus, Hg.: Säkularisierung und die Weltreligionen. Frankfurt a.M.: Fischer, 172-193.

Lehmann, Hartmut (2004): „Säkularisierung. Der europäische Sonderweg in Sachen Religion?” in: Lehmann, Hartmut, Hg.: Säkularisierung. Der europäische Sonderweg in Sachen Religion. Göttingen: Wallstein, 14-35.

Lewis, Bernhard (2003): Die Wut der arabischen Welt. Warum der jabrbundertelange Konflikt zwischen dem Islam und dem Westen weiter eskaliert. Frankfurt/New York: Campus.

Luhmann, Niklas (1975): „Die Weltgesellschaft” in: Luhmann, Niklas: Soziologische Aufklärung 2. Aufsätze zur Theorie der Gesellschaft. Opladen: Westdeutscher Verlag, 51-71.

Mazlish, Bruce (2005): „The Hi-jacking of Global Society? An Essay”, in: Journal of Civil Society 1 (1), 5-17.

Meyer, John W. (2005): Weltkultur. Wie die westlichen Prinæipien die Welt durchdringen. Hg. von Georg Krücken. Frankfurt a.M.: Suhrkamp.

Meyer, John W./Boli, John/Thomas, George M./Ramirez, Franciso O. (2005): „Die Weltgesellschaft und der Nationalstaat”, in: Meyer, John W.: Weltkultur. Wie die westlichen Prinzipien die Welt durchdringen. Hg. von Georg Krücken. Frankfurt a.M.: Suhrkamp, 85-132.

Meyer, John W./Ramirez, Francisco O. (2005): „Die globale Institutionalisierung der Bildung" In: Meyer, John W.: Weltkultur. Wie die westlichen Prinzipien die Welt durchdringen. Hg. von Georg Krücken. Frankfurt a.M.: Suhrkamp, 212-234.

McLeod, Hugh (2006): „Religion in the United States and Europe. The 20th Century”, in: Lehmann, Hartmut, Hg.: Transatlantische Religionsgeschichte, 18. bis 20. Jabrhundert. Göttingen: Wallstein, 131-145.

Nelson, Benjamin (1969): The Idea of Usury. From Tribal Brotherhood to Universal Otherhood. Chicago: University of Chicago Press. 
Randeria, Shalini (2006): „Entangled Histories: Civil Society, Caste Solidarities and Legal Pluralism in Post-colonial India”, in: Keane, John, Hg.: Civil Society. Berlin Perspectives. Oxford: Berghahn, 213-242.

Riedel, Sabine (2003): „Der Islam als Faktor in der internationalen Politik”, in: Aus Politik und Zeitgeschichte (37), 15-24.

Said, Edward W. (2003): Orientalism. London: Penguin.

Schützeichel, Rainer (2004): Historische Soziologie. Bielefeld: transcript.

Steinmetz, George (2005): „The Epistemological Unconscious of U.S. Sociology and the Transition to Post-Fordism: The Case of Historical Sociology", in: Adams, Julia/ Clemens, Elisabeth S./Orloff Shola, Ann, Hg.: Remaking Modernity. Politics, History, and Sociology. Durham/London: Duke University Press, 109-157.

Steinmetz, George (2007): „The Relations Between Sociology and History in the United States: The Current States of Affairs", in: Journal of Historical Sociology 20 (1/2), 1-12.

Stark, Rodney/Iannaccone, Laurence R. (1994): „A Supply-Side Reinterpretation of the ,Secularization' of Europe", in: Journal for the Scientific Study of Religion 33 (3), 230-252.

Taylor, Charles (2007): A Secular Age. Cambridge, Mass.: Harvard Univ. Press.

Tiryakian, Edward A. (1991): „Modernisation: Exhumetur in Pace (Rethinking Macrosociology in the 1990s)", in: International Sociology 6, 165-180. Tocqueville, Alexis de (1985): Über die Demokratie in Amerika. Stuttgart: Reclam.

Walzer, Michael (1998): „Drawing the Line: Religion and Politics”, in: Soziale Welt 49, 295-308.

Weber, Max (2002a): „Wissenschaft als Beruf”, in: Kaesler, Dirk, Hg.: Max Weber - Schriften 1894-1922. Stuttgart: Kröner, 474-511.

Weber, Max (2002b): „Theorie der Stufen und Richtungen religiöser Weltablehnung. Zwischenbetrachtung", in: Kaesler, Dirk, Hg.: Max Weber-Schriften 1894-1922. Stuttgart: Kröner, 609-652.

Werner, Michael/Zimmermann, Bénédicte (2002): „Vergleich, Transfer, Verflechtung. Der Ansatz der Histoire croisée und die Herausforderung des Transnationalen", in: Geschichte und Gesellschaft 28 (4), 607-636. 



\section{Erlebnis, Tradition, Institution: Die drei Dimensionen der Rückkehr der Religion}

Kristina Stöckl

Für lange Zeit sind Vertreter der Säkularisierungsthese davon ausgegangen, dass mit fortschreitender Modernisierung der Gesellschaft eine Privatisierung von Religion einhergeht. Gesellschaftspolitische Entwicklungen der Gegenwart, nicht zuletzt das verstärkte Auftreten religiöser Fundamentalismen, haben diese These jedoch brüchig werden lassen. So brüchig, dass zuletzt ihr prominentester Verfechter, Peter L. Berger, zugeben musste: die Säkularisierungsthese ist falsifiziert worden. ${ }^{1}$ Unter dem Eindruck der „Rückkehr der Religion" steht aber nicht nur die Säkularisierungsthese zur Diskussion, sondern auch die Art und Weise, wie Religion in den säkularen gesellschaftspolitischen Zusammenhang ,zurückkehrt“. Der Begriff „De-

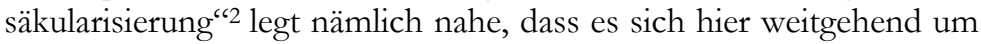
einen Rückfall in vor-moderne Formen der Weltdeutung handelt. Der Mensch, der laut Kant mit der Aufklärung aus seiner selbstverschuldeten Unmündigkeit aufgebrochen ist, fällt gleichsam in einen voraufklärerischen Zustand zurück. Eine solche Sichtweise blendet aber aus, dass Religionen und Religiosität unter Bedingungen der 
Moderne nicht einfach nur „zurückkehren“. Religion erhält vielmehr neue Relevanz in einem Kontext, in dem sie nicht bzw. nicht mehr ein von vorneherein gegebener und unmittelbarer Bestandteil des individuellen und gesellschaftlichen Lebens ist. In diesem Aufsatz möchte ich die Art und Weise, wie Religion unter Bedingungen der Moderne „zurückkehrt“ und innerhalb des politisch-philosophischen Diskurses der Moderne neue Relevanz erhält, anhand der Stichworte Erlebnis, Tradition und Institution beschreiben. Ziel meiner Darstellung ist es, die Vielschichtigkeit der Erscheinungsformen von Religion unter Bedingungen der Moderne ins Bewusstsein zu rufen und davon Schlussfolgerungen für eine interdisziplinäre Auseinandersetzung mit dem Thema Religion abzuleiten.

\section{Die Mittelbarkeit der Religion als Voraussetzung für ihre Rückkehr}

Der Begriff ,post-säkular“ bringt den Umstand, dass Religion unter Bedingungen der Moderne nicht einfach nur „zurückkehrt“, sondern vielmehr in einem Kontext, in dem sie nicht bzw. nicht mehr von vorneherein gegeben und unmittelbar ist, neue Relevanz erhält, sehr viel deutlicher zum Ausdruck als das Schlagwort der Desäkularisierung. Die Präfixe „,de“ und „post“ stehen für unterschiedliche Geometrien der Rückkehr. Das „de“ ist auf der vertikalen Achse angesiedelt, wo es einen Aufstieg und Rückfall in die Ausgangsposition suggeriert, wohingegen das „post“ eine Parabel in vertikaler und horizontaler Dimension beschreibt, deren Ausgangs- und Endpunkt nicht derselbe sind. Postmoderne, Postdemokratie und Postsäkularität sind allesamt reflexive Begriffe. ${ }^{3}$ Sie stehen für die Bewusstwerdung der Geschichtlichkeit und Kontingenz von herrschenden Paradigma und für die gleichzeitige Selbstversicherung des eigenen Standorts und Standpunkts. Agnes Heller spricht in diesem Zusammenhang vom ,,selbstreflexiven Bewusstsein der Moderne“. ${ }^{4}$

Was bedeutet es, wenn die „Rückkehr der Religion“ als Parabel verstanden wird? Es bedeutet, dass Religion nicht mehr unmittelbar gegeben, sondern in ihrer Geschichtlichkeit und Kontingenz offenkundig geworden ist. Es bedeutet aber auch, dass Religion im selbst-

3 Zum Begriff der Postmoderne siehe Lyotard (1999); zum Begriff der Postdemokratie siehe Crouch (2008); zum Begriff der Postsäkularität siehe zuletzt Habermas (2008).

4 Heller (1999), 2. 
reflexiven Prozess der eigenen Standortbestimmung eine Rolle spielt: woher kommen wir, wer sind wir, wohin gehen wir, welche Verantwortung haben wir gegenüber der Welt? ${ }^{5}$ Religion am Ende der Parabel existiert in einem Spannungsfeld von Geschichtlichkeit, Kontingenz und Selbstreflexion. Wie aber begegnet uns letztendlich diese nicht mehr unmittelbar gegebene Religion, wie sollen wir uns ihre „Mittelbarkeit“ vorstellen? Stellt „Mittelbarkeit“ nicht die eigentliche Voraussetzung für eine „Rückkehr“ dar?

In der von Jürgen Habermas geprägten Bezeichnung der ,postsäkularen Gesellschaft" ist der Bedeutungsgehalt der Parabel inbegriffen. Der Begriff „postsäkular“ macht einen Wandel in der Qualität des Verhältnisses von säkularer Gesellschaft und Religion deutlich: die postsäkulare Gesellschaft unterscheidet sich nicht nur von der säkularen Ordnung, in welcher Religion aus dem öffentlichen Raum verbannt ist, sie unterscheidet sich auch von einer vorsäkularen Verfasstheit der Gesellschaft, in welcher der öffentliche Raum mit Religion identisch ist. Darüber hinaus ist bei Habermas auch der Gedanke der „Mittelbarkeit“ von Religion vorhanden, allerdings besteht sie für Habermas weitgehend in Mit-teil-barkeit. Voraussetzung für die Mitteilbarkeit von Religion in der modernen säkularen Gesellschaft sind für Habermas einerseits ein „Formwandel des religiösen Bewusstseins“", im Zuge dessen Religionen auf die Herausforderungen der Moderne antworten, und andererseits eine „selbstreflexive Überwindung“ des säkularistisch verhärteten und exklusiven Selbstverständnisses der Moderne. ${ }^{6}$ Der große Gewinn von Habermas' Formel des „komplementären Lernprozesses“ liegt in der Tatsache, dass er die Bürde der Vermittlung von religiösen Weltanschauungen nicht allein dem religiösen Bürger auferlegt, sondern sie auf religiöse und nicht-religiöse Kommunikationspartner gleichmäBig verteilt.

Noch vor der von Habermas adressierten Frage der Mitteilbarkeit steht für mich allerdings die Frage nach der „Mittelbarkeit“ von Religion, nach ihrer Erscheinungsform in einem modernen Kontext, wo sie nicht mehr unmittelbar gegeben ist. Damit sich die Frage nach der Vermittlung und Mitteilbarkeit überhaupt stellt, muss zuerst die Form ihrer Erscheinung geklärt werden. Mein Anliegen ist 
an dieser Stelle vor allem ein methodisches und theoretisches; es gilt, Überlegungen zur Feststellung der „Mittelbarkeit“ von Religion in Zeiten ihrer Rückkehr anzustellen. Habermas selbst geht dieser Frage nicht nach. Die „,postsäkulare Gesellschaft“ ist für ihn weniger ein historischer oder analytischer, als vielmehr ein politischer Begriff. Sein Anliegen ist es, Gesellschaft, Politik und politische Philosophie für das Phänomen der Religion zu sensibilisieren. Es scheint daher ratsam, sich für die Klärung des Wie der „Rückkehr der Religion" solchen Autoren zuzuwenden, deren Aufmerksamkeit der Erscheinungsform von Religion unter Bedingungen der Moderne gilt.

Zwei zeitgenössische Autoren, die auf die Frage nach der „Mittelbarkeit" von Religion unter Bedingungen der Moderne unterschiedliche, aber komplementäre Antworten gegeben haben, stehen im Mittelpunkt meiner Ausführungen: Charles Taylor und Alasdair MacIntyre. Beide werden gemeinhin als Kommunitaristen bezeichnet (auch wenn MacIntyre diese Definition für sich abgelehnt hat ${ }^{7}$ ), beide sind Kritiker des Liberalismus und des Poststrukturalismus (dem einen werfen sie ein atomistisches Subjektverständnis vor, dem anderen Anti-Humanismus ${ }^{8}$ ). Beide legen Werke vor, in denen die Religion in den politisch-philosophischen Diskurs der Moderne eingeführt wird. Bei beiden ist diese Religion in erster Linie der Katholizismus, und beiden könnte man durchaus eine apologetische Haltung attestieren. Was Taylor und MacIntyre jedoch unterscheidet ist die Art und Weise, wie sie Religion als Element in den politischphilosophischen Diskurs der Moderne einbringen: einmal als Erlebnis, einmal als intellektuelle Tradition.

\section{Erlebnis}

Taylors Anliegen in seinem 2007 erschienen Buch A Secular Age ist die historische Analyse der säkularen Verfasstheit der Moderne. Er geht von der Frage aus, wie es soweit gekommen ist, dass die Religion ihre Funktion als einheits- und sinnstiftendes Element für Individuum und Gesellschaft in der Moderne weitgehend verloren hat. Er unterscheidet eingangs drei Arten und Weisen, den Begriff „ein säkulares Zeitalter“‘ zu verstehen: Säkular ist unser Zeitalter, erstens, 
weil die verschiedenen Bereiche des sozialen Lebens, in denen wir uns bewegen - die Politik, die Wirtschaft, die Kunst und andere kein übergeordnetes Bindeglied mehr aufweisen, welches all diesen Bereichen eine verbindliche Orientierung geben könnte. Säkular ist unser Zeitalter, zweitens, weil immer weniger Menschen Religion aktiv ausüben, zumindest in Europa. Und säkular ist unser Zeitalter, drittens, weil es für den modernen Menschen nicht mehr selbstverständlich ist, gläubig zu sein und der einen oder anderen Religion anzugehören. Wir leben in einer Gesellschaft, in der Religiosität nur eine Option unter vielen ist, um das eigene Leben sinnvoll zu gestalten. ${ }^{9}$ In $A$ Secular Age geht es um diese dritte Definition, um die historische Analyse und die philosophische Bestimmung der „Säkularität 3“.

Taylors Beschreibung ist jedoch keine neutrale. Bereits in der Einleitung macht er deutlich, dass für ihn die Suche des Menschen nach Erfüllung (fullness) eine anthropologische Konstante darstellt. ${ }^{10}$ Er macht auch deutlich, dass Erfüllung aus seiner Sicht letztendlich auf eine Transzendierung des Selbst hinausläuft, wie sie die Religionen vermitteln, und nicht etwa durch innerweltliche Momente der Erfülltheit (zum Beispiel durch Beruf, durch Konsum etc.) ersetzt werden kann. ${ }^{11}$ Wenn nun aber die Sehnsucht nach Erfüllung allen Menschen gemeinsam ist, und wenn Erfüllung etwas mit Transformation des eigenen Selbst zu tun hat, wie kommt es dann, dass Religion - zumindest in Europa, zumindest aus der Sicht der Säkularität 2 - immer weniger Zuspruch findet? Taylor stellt fest, dass in unserer Gegenwart die Möglichkeitsbedingungen für eine Erfahrung von Glauben und Religion (conditions of belief) radikal andere sind als noch vor 500 Jahren, wohingegen die Disposition der Menschen, Erfahrungen von Erfüllung anzustreben, sich nicht verändert hat. Lediglich suchen sie Erfüllung an anderen Orten. In A Secular Age erklärt er auf gut achthundert Seiten, wie es dazu gekommen ist. ${ }^{12}$

Bemerkenswert ist die seiner Erklärung zugrunde liegende Methodologie. Man könnte sie als phänomenologisch bezeichnen. Taylor schreibt, er möchte die Veränderungen der Möglichkeitsbedin- 
gungen von Religion als „lived experience“ beschreiben. ${ }^{13}$ „Lived experience“ ist die englische Übersetzung von Diltheys Begriff „Erlebnis“. Um die Möglichkeitsbedingungen von Glauben in der modernen Gesellschaft umfassend beschreiben zu können, bedarf es einer genauen Erfassung des „,background“ oder des „practical context" ${ }^{\text {"14 }}$ - in der Sprache der Phänomenologie könnte man hier von „Lebenswelt“ sprechen. Taylor möchte also beschreiben, wie sich die Lebenswelt des modernen Menschen so verändert hat, dass Religion als Erlebnis weitgehend kontingent geworden ist.

Geschichte spielt eine wichtige Rolle für Taylor, aber weniger als Historie, als vielmehr als Geschichten über die Veränderung der Lebenswelt des modernen Menschen. Taylor erzählt die Geschichte unseres säkularen Zeitalters in den verschiedenen Kapiteln des Buches auf unterschiedliche Art und Weise. Die Narrative drehen sich um unterschiedliche Zeitachsen. Eine dieser Zeitachsen ist die Zeit der „axial revolutions“. Taylor greift an dieser Stelle die AchsenzeitThese von Karl Jaspers auf, mit welcher dieser den Übergang von archaischen Religionen zu den „höheren“ Formen der Religionen, zu denen auch das Christentum zählt, beschrieben hat. ${ }^{15}$ Eine andere Zeitachse ist der Übergang vom Mittelalter zur Neuzeit, eine weitere das 18. Jahrhundert der Aufklärung und die Geburt des exklusiven Humanismus. Eine jede dieser Geschichten kann man als Erzählung darüber lesen, wie sich die Möglichkeitsbedingungen für Glauben verändern. Retrospektiv und beschränkt auf den Bereich des lateinischen Christentums präsentiert sich diese Entwicklung bei Taylor als eine einzige Bewegung weg von einem ,naiven“ Erleben von Religion hin zu einem „reflexiven“. Gleichzeitig interpretiert Taylor diese Bewegung jedoch nicht mit Sinne einer zunehmenden Emanzipation des Menschen gegenüber allen Formen von verbindlichen Weltdeutungen, sondern vielmehr als Aufstieg einer einzigen rivalisierenden Weltdeutung, nämlich des ,exklusiven Humanismus“. 16

Am Ende seines Werkes fasst Taylor seine Analyse in einem Begriff zusammen: „Reform Master Narrative“. Damit bezeichnet er die Geschichte der christlichen Religion, die selbst die Möglichkeitsbedingungen für den exklusiven Humanismus und damit die Ursa- 
che ihrer eigenen Verdrängung schafft. Taylor spricht in diesem Zusammenhang von einem Wandel von „social imaginaries“, worunter er die Art und Weise versteht, wie Menschen ihre eigene Existenz als Individuen und in Gemeinschaft wahrnehmen und normativ gestalten. ${ }^{17}$ Er weist Schritt für Schritt nach, wie im Verlauf der modernen Entwicklung Naturrecht, Ökonomie und ein moderner Gesellschaftsbegriff religiöse Deutungsweisen von Subjektivität und Gemeinschaftlichkeit ersetzen, ohne dabei der menschlichen Eigenschaft des Strebens nach fullness Abbruch zu tun. Entgegen den säkularen Weltdeutungsangeboten durch das Naturrecht, die moderne Ökonomie oder etwa den Nationalstaat macht Taylor in der christlichen Religion mit ihrer eschatologischen Dimension jedoch die Sicherheit aus, dass ihr ,social imaginary“ nicht in eine totalitäre Weltordnung kippt. ${ }^{18}$

Wenn man am Ende dieser Zusammenfassung von Taylors Argumentation in A Secular Age die Frage stellt, wie Religion unter Bedingungen der Moderne zurückkehrt, so lautet die Antwort, dass das jedem Menschen inhärente „religiöse“ Streben eigentlich nie verschwunden ist. Es hat sich lediglich auf einen weitgehend weltimmanenten Bezugsrahmen reduziert. Im Kontext einer Moderne, die sich ihrer selbst auf selbstreflexive Art und Weise bewusst wird, taucht Religion als ein Element auf, um die oben genannten Fragen - woher kommen wir, wer sind wir, wohin gehen wir, welche Verantwortung haben wir gegenüber der Welt? - zu beantworten. Religion am Ende der Parabel hat für Taylor mit Konversion zu tun, mit Erfahrungen von Selbst-Transzendierung. Die Beispiele, die er anführt, machen deutlich, dass Taylor Konversion nicht als intellektuelles Ereignis auffasst, sondern als Erlebnis. Er spricht in diesem Zusammenhang auch von „epiphanic moments“19 und macht dadurch deutlich, dass die „Mittelbarkeit“ von Religion unter Bedingungen der Moderne nicht in der einen oder anderen konkreten Erscheinungsform oder Institutionalisierung liegt, sondern vielmehr im persönlichen Erleben des Einzelnen. 


\section{Tradition}

Taylor kontrastiert seine Art und Weise, die Geschichte des säkularen Zeitalters zu erzählen, mit einer anderen möglichen Art von Erzählung, und zwar mit ,intellectual deviation stories“, mit Geschichten von intellektuellen Abweichungen. ${ }^{20}$ Eine solche Geschichte intellektueller Abweichung erzählt uns Alasdair MacIntyre in seinen Werken Three rival versions of moral inquiry und Whose justice? Which rationality?, aber wir finden sie in etwas anderer Form auch bei John Milbank. ${ }^{21}$ Vertreter von ,intellectual deviation stories“ gehen davon aus, dass das christliche Denken zu einem gewissen Zeitpunkt am Übergang vom Mittelalter zur Neuzeit den falschen Weg einschlägt und theologisch auf die Bahn eines rationalistischen, mechanistischen und letztendlich immanenten Welt- und Subjektverständnisses gerät.

Der Unterschied zwischen dieser Sichtweise und Taylors „Reform Master Narrative" liegt darin, dass sich MacIntyre in seiner Analyse auf die Welt der Ideen, Taylor hingegen auf die Welt der „social imaginaries“ bezieht. MacIntyre untersucht die kanonischen Werke der christlichen Theologie und Philosophie. Die auf diese Weise beschriebene Gedankenwelt bezeichnet er als ,intellektuelle Tradition“, als ein in sich kohärentes Gebäude aus Ideen und Praktiken. ${ }^{22}$ Eine intellektuelle Tradition ist für MacIntyre eine bestimmte Art und Weise, die Welt zu verstehen und sich zu ihr in Bezug zu setzen, indem man die theoretischen Prämissen und praktischen Umsetzungen, die innerhalb einer Tradition gemeinschaftlich über einen langen Zeitraum gestaltet werden, zu seinen eigenen macht. ${ }^{23}$

MacIntyre ist der Ansicht, dass der intellektuelle Weg der Moderne als fehlgeleitet anzusehen ist. ${ }^{24}$ Die christliche Theologie hat zu Beginn der Neuzeit selbst die intellektuellen Voraussetzungen für ihre Verdrängung geschaffen. Einen Ausweg sieht er darin, dass man zu jenen geistigen und moralischen Grundsätzen zurückfinden sollte, die historisch vor dieser Entwicklung liegen, zu den intellektuellen und spirituellen Ressourcen vor der Abweichung. MacIntyre schlägt vor, an die Theologie eines Thomas von Aquin anzuknüpfen. Dieses

20 Taylor (2007), 774.

21 MacIntyre (1990), MacIntyre (1988), Milbank/Pickstock/Ward (1999).

22 MacIntyre (1990), 65.

23 MacIntyre (1990), 150.

24 MacIntyre (1967). 
Anknüpfen stellt er sich als das bewusste Bekenntnis zu einer intellektuellen Tradition vor, die retrospektiv studiert werden kann und in die man sich folglich ,hineinversetzen“ kann. Die Freiheit des modernen Menschen liegt für MacIntyre darin, dass er eine bestimmte intellektuelle Tradition wählen kann - oder eine andere, oder aber gar keine (was für ihn freilich die schlechteste, weil nihilistische Antwort wäre). Sich eine nicht mehr unmittelbar gegebene Tradition anzueignen und im eigenen Denken und in der eigenen Praxis „mittelbar“ zu machen, bedeutet für MacIntyre, den eigenen Standort in aller Klarheit zu bestimmen.

Religion am Ende der Parabel ist für MacIntyre gebrochene, nicht mehr unmittelbar gegebene Religion. Sie ist, wie auch Taylor in seiner Definition der Säkularität 3 feststellt, eine Option unter vielen anderen, um dem eigenen Leben Sinn zu verleihen. Taylor sagt von sich aus, dass er seine Art und Weise, die Geschichte des säkularen Zeitalters zu erzählen, und jene von MacIntyre für kompatibel hält. Allerdings geht es Vertretern von ,intellectual deviation stories“ um theologische Elitediskurse, deren Entwicklung linear dargestellt wird. Man gehe davon aus, dass sich diese Elitediskurse nach und nach auf andere Lebensbereiche ausdehnen. Taylor hingegen spricht lieber von den Lebensbereichen selbst, innerhalb derer Elitediskurse überhaupt erst möglich werden. ${ }^{25}$ Für Taylor ist die Geschichte des säkularen Zeitalters nicht linear wie bei MacIntyre. Vielmehr könnte man die Bewegung seiner Erzählung als Spirale nachzeichnen. Das Streben des Menschen nach fullness von der Achsenzeit bis zur Moderne geht für Taylor nicht immer in eine Richtung, es kann durchaus gegenläufige Wirkungen haben und Gegenstand unterschiedlicher Deutungen werden, wie die romantische Reaktion auf die Aufklärung deutlich zeigt.

Was bedeuten diese zwei Arten und Weisen, die Geschichte des säkularen Zeitalters zu erzählen, für die eingangs gestellte Frage, wie Religion in den politisch-philosophischen Diskurs der Moderne zurückkehrt? Zuerst die Antwort von MacIntyre, sie ist einfacher: Religion wird als eine intellektuelle Tradition dargestellt, als ein Bündel von Ideen und Praktiken, innerhalb dessen ein Wahrheits- und Gerechtigkeitsanspruch möglich ist. Es sind diese an eine bestimmte Perspektive gebundenen Ansprüche, die in den politisch- 
philosophischen Diskurs der Moderne eingeführt werden - als die eine oder andere Auffassung von Gerechtigkeit. Wer sie vertritt, definiert sich selbst als Angehöriger einer bestimmten geistigen Tradition. Das hat zur Folge, dass Religion in erster Linie ideengeschichtlich erfasst wird. Die Rückkehr der Religion ist für MacIntyre, überspitzt formuliert, die Rückkehr eines vorübergehend aus dem Sichtfeld geratenen Arguments.

Taylors Antwort ist eine andere. Wie führt er Religion in den politisch-philosophischen Diskurs ein? Man könnte sagen: als Phänomen der Lebenswelt, als persönliche Haltung, oder aber als Zeugnis. Wohlgemerkt beruft er sich nicht auf historisch rekonstruierte Traditionslinien, wie MacIntyre. Eher noch beruft er sich auf historisch rekonstruierte Brucblinien und die von ihnen ausgelösten Spannungen. Taylor führt Religion als einen möglichen (und als den für ihn plausibelsten) Weg ein, ein authentisches Leben zu leben. ${ }^{26}$ Die Rückkehr der Religion ist bei Taylor, ebenso überspitzt formuliert wie zuvor, die Rückkehr eines tragfähigen gemeinschaftlichen und moralischen Elements im politischen und gesellschaftlichen $\mathrm{Zu}-$ sammenleben.

\section{Institution}

Die „Mittelbarkeit“ von Religion unter Bedingungen der Moderne stellt sich nach der Lektüre von Taylor und MacIntyre entweder als Erlebnis oder als intellektuelle Tradition dar. Daneben gibt es aber noch eine dritte Dimension, die eigentlich die offensichtlichste ist: Religion als Institution. Katholische, protestantische und orthodoxe Kirchen können ebenso wie die verschiedenen Glaubensrichtungen des Islam und alle anderen Weltreligionen auf jahrhunderte- bzw. jahrtausendelange Kontinuität zurückblicken. Von einer „Rückkehr" kann daher aus dieser Perspektive nicht die Rede sein kann. Gleichzeitig stehen religiöse Institutionen zu Beginn des 21. Jahrhunderts in gewisser Weise jedoch auch am Ende einer Parabel. Sie sind in erster Linie von jenen beiden Entwicklungen betroffen, die Taylor „Säkularität 1 und 2“ nennt: die Ausdifferenzierung der verschiedenen Bereiche des sozialen Lebens, für die Religion kein über- 
geordnetes Bindeglied mehr darstellt, und die Tatsache, dass immer weniger Menschen Religion aktiv ausüben, zumindest in Europa. ${ }^{27}$

Säkularität 1 ist die Feststellung der Tatsache, dass Religion und Politik in der politischen Moderne zu getrennten Bereichen geworden sind. Wie dies ideengeschichtlich vor sich gegangen ist, hat zuletzt Mark Lilla eindrucksvoll beschrieben. ${ }^{28}$ Gleichzeitig steht jedoch außer Zweifel, dass Religion im Rahmen von institutionalisierten Kirche-Staats-Beziehungen und als Bestandteil der Zivilgesellschaft nach wie vor eine öffentliche und auch politische Rolle spielt. ${ }^{29}$ Die „Rückkehr der Religion“ wird aus diesem Blickwinkel insofern zur Anfrage an den politisch-philosophischen Diskurs der Moderne, als dass unter den veränderten Bedingungen der Postsäkularität traditionelle Formen von Kirche-Staats-Verhältnissen in Frage gestellt werden. Die größte Herausforderung stellt, insbesondere in Europa, ein verstärkt sichtbar gewordener religiöser Pluralismus dar, im Rahmen dessen verschiedene Religionen, allen voran der Islam, einen gleichberechtigten Stellenwert in etablierten Kirche-StaatsGefügen einfordern. ${ }^{30}$

Dieser Bereich ist es auch, auf den die Überlegungen von Habermas in erster Linie abzielen, wenn er einmahnt, dass gläubige Menschen in der nach säkularen Prinzipien ausdifferenzierten Gesellschaft keine Nachteile haben dürfen. Darüber hinaus geht es Habermas aber nicht nur um die Tatsache, dass religiöse Menschen ihre Argumente in den politischen Diskurs einbringen können sollen, sondern auch darum, dass eine Gesellschaft, die religiöse Argumente völlig ausklammert, sich unter Umständen von wichtigen Sinnressourcen abschneidet. ${ }^{31}$ Die „Mittelbarkeit“ von Religion hängt für ihn allerdings in erster Linie davon $a b$, in welchem Maß sich eine religiöse Institution mit den „Zumutungen der Moderne“ auseinandergesetzt und arrangiert hat. Im Wesentlichen heißt das, ob eine religiöse Institution bereit ist, wesentliche moderne Errungenschaften wie Religionsfreiheit und Trennung von Kirche und Staat anzuerkennen oder nicht. ${ }^{32}$ Das Phänomen des religiösen Fundamenta-

27 Siehe auch: Taylor (1998).

28 Lilla (2007).

29 Vgl. Casanova (1994), Madeley/Enyedi (2003).

30 Vgl. Bader (2007).

31 Habermas (2005), 137.

32 Vgl. Große Kracht (1997) und den Beitrag von Gerhard Larcher in diesem Band. 
lismus stellt sich aus dieser Perspektive als eine gescheiterte Auseinandersetzung mit der Moderne dar.

Säkularität 2 betrifft die Feststellung, dass immer weniger Menschen Religion aktiv ausüben. Ausgehend vom Beispielfall Europa wird davon ausgegangen, dass die westliche Modernisierung zu einer Abnahme von religiösen Überzeugungen in modernen Gesellschaften führt. Vor allem die Kirchen spüren die Konsequenzen dieser Entwicklung, da immer weniger Menschen am kirchlichen Leben teilnehmen. Für die Religionssoziologie, die sich mit dieser Definition von Säkularität primär auseinandersetzt, wirft der Zustand der Postsäkularität die interessante Frage auf, wie Menschen unter Bedingungen der Moderne religiös sind: ist ihr Glauben mit Kirchen und Gemeinschaften verbunden oder individualisiert, sind religiöse Überzeugungen stabil oder können sie sich mit der Zeit verändern?33

Vor dem Hintergrund solcher Bestandsaufnahmen haben Wissenschaftler in den letzten Jahren verstärkt darauf hingewiesen, dass die Definition von Säkularität als Abnahme von Religiosität im globalen Vergleich nicht stichhaltig ist. ${ }^{34}$ Anstatt die Regel vorzugeben, dass zunehmende Modernisierung eine Abnahme von Religion nach sich zieht, wirkt das europäische Modell auf einmal selbst als „Sonderweg“. Papst Benedikt XVI, damals noch Kardinal, zog im Sinne einer Bestandsaufnahme im Gespräch mit Habermas die Schlussfolgerung von der ,faktischen Nichtuniversalität der beiden großen Kulturen des Westens, der Kultur des christlichen Glaubens wie derjenigen der säkularen Rationalität." 35 Für die institutionalisierte Religion am Ende der Parabel, insbesondere für die katholische, aber, wie das Beispiel unten zeigt, auch für die christlich-orthodoxe Kirche, ist dies ein Zeichen von Stärke: die christlichen Kirche erweist sich als Vertreterin einer Kultur und Weltanschauung, die der Moderne nicht etwa unterlegen, sondern ihr ebenbürtig ist.

Die „Rückkehr der Religion“ als Institution ist streng genommen keine Rückkehr, sondern eine Permanenz unter veränderten Vorzeichen. Sie geht einher mit einer größeren Präsenz von Religion im öffentlichen Raum und zieht neue Debatten über die Grenzziehung zwischen weltanschaulich neutraler Politik und Religion nach sich. Institutionalisierte Religion spielt auch eine Rolle für die beiden

33 Vgl. Hervieu-Léger (2003), Davie (2000).

34 Vgl. Eder (2002) und den Beitrag von José Casanova in diesem Band.

35 Habermas/Ratzinger (2004), 7. 
oben genannten Aspekte - Erlebnis und Tradition - aber sie hebt diese beiden Dimensionen als separate Perspektiven nicht auf, wie das folgende Beispiel zeigen soll.

\section{Beispiel: Dreidimensionale Betrachtung der russischen Orthodoxie}

Warum ist es wichtig, dass diese drei Dimensionen der Anfrage Erlebnis, intellektuelle Tradition, Institution - in der Analyse der Rückkehr der Religion gleichermaßen in Betracht gezogen werden? Als Antwort darauf möchte ich zum Abschluss ein Beispiel skizzieren: die Situation der christlich orthodoxen Religion im postsowjetischen Russland. Hier haben wir es mit einem klaren Fall von Rückkehr von Religion in eine säkulare, vormals sogar atheistisch definierte soziale und politische Ordnung zu tun. Wie stellt sich Religion am Ende der Parabel in diesem Fall dar, welche Formen der „Mittelbarkeit“" nimmt sie ein?

Interessanter Weise geht auch Taylor in A Secular Age auf Russland ein. Er beruft sich auf die Analyse des Religionssoziologen Mikhail Epstein, der im post-sowjetischen Russland eine „minimale Religiosität" heraufziehen sieht, die zwar spirituell, nicht aber institutionell-religiös ist. „Minimal religiöse“ Menschen würden sich als Christen bezeichnen, nicht aber dezidiert als „Orthodoxe“, „Katholiken“ etc., sie würden dadurch zu Trägern einer spontanen und universalen Ökumene. Ihre Erfahrung mit dem Glauben sei nicht institutionell geprägt, weil die religiösen Institutionen im Verlauf der sowjetischen Geschichte weitgehend geschwächt worden seien. ${ }^{36}$ Taylor, so scheint es, liegt diese Vision von Religiosität durchaus nahe. Er nennt sie eine Form von ,religiöser Suche“, die mit dem Niedergang der großen Erzählung von der Säkularisierung, d.h. mit der Erkenntnis, dass Modernisierung eben nicht zu einem Verschwinden von Religion geführt hat, einsetzt. ${ }^{37}$

Wenn man jedoch aus anderer Perspektive auf Religion im post-sowjetischen Russland schaut als das Taylor mit Hilfe von Epstein tut, ergibt sich ein ganz anderes Bild. Im heutigen Russland spielt die orthodoxe Religion als Institution erneut eine wichtige 
Rolle. Das Moskauer Patriarchat als Vertreter der russisch orthodoxen Kirche hat sich im Panorama der russischen Politik und Gesellschaft eine herausragende Stellung zurückerobert, die an vorrevolutionäre und zum Teil sogar zaristische Traditionen anknüpft. Die russisch orthodoxe Kirche hat sich im Verlauf der 1990er Jahre, als das post-sowjetische Russland sich in drei Schritten - 1991, 1993 und 1997 - um eine rechtliche Definition des Verhältnisses zwischen Staat und Religion bemühte, eine privilegierte Position ausgehandelt. Im zuletzt verabschiedeten Religionsgesetz von 1997 wird ihr eine Vorrangstellung als „traditionelle“ Kirche des russischen Volkes eingeräumt, mit restriktiven Auswirkungen auf die Anerkennung von anderen, „ausländischen“ Religionsgemeinschaften. ${ }^{38}$ Für die Ansprüche von „minimaler Religion“, wie bei Epstein, oder von „religiöser Suche“, wie bei Taylor, stellt eine solche Institutionalisierung von Religion in einem Staatswesen eine potenzielle Einschränkung von möglichen religiösen Erfahrungen dar. Allerdings hat der „,minimal religiöse“ Mensch einer solchen Einschränkung wenig entgegen zu setzen; als kirchenferner Gläubiger mag er sie unter Umständen nicht einmal wahrnehmen. Dieses Beispiel macht deutlich, dass die Frage der Religionsfreiheit in unserer postsäkularen Ära keineswegs ein für allemal gelöst ist.

Vor dem Hintergrund der Asymmetrie zwischen minimaler Religiosität und religiöser Institutionalisierung in Russland kommt der dritten Form von „Rückkehr der Religion“ - nämlich der Religion als intellektueller Tradition - eine wichtige Rolle zu. Epsteins Artikel könnte selbst als Beispiel dafür gelesen werden, dass das Streben nach Erlebnis von Religiosität ohne Rückkoppelung an eine intellektuelle Tradition problematisch sein kann. Epstein argumentiert nämlich, dass eine Kausalkette zwischen christlicher negativer Theologie, sowjetischem Atheismus und minimaler Religiosität besteht. Die in der negativen Theologie zentrale Unerfassbarkeit des Göttlichen schlägt, laut Epstein, im Atheismus in die Abwesenheit Gottes um und wird in der minimalen Religiosität zu einer inhaltlich nicht näher bestimmten Affirmation von Transzendenz. Diese Einschätzung ist, wie Jonathan Sutton nachgewiesen hat, theologisch nicht haltbar. ${ }^{39}$ Aus christlich theologischer Perspektive fehlt in Epsteins These 
nämlich die Figur von Jesus Christus, der als Inkarnation des Göttlichen einen Gegenpol zur Negativität der apophatischen Theologie darstellt und diese in Form der Kirche dauerhaft auffängt. Mit anderen Worten, Epsteins Analyse von minimaler Religion mag soziologisch durchaus zutreffend sein, seine theologische Herleitung ist es nicht. Mit diesem fehlenden theologischen Verständnis verkörpert der Autor jedoch eben jenes Problem, das ich oben am Beispiel der Religionsfreiheit in Russland bereits angesprochen habe: zwischen minimaler und institutionalisierter Religion gibt es keine Reibungsfläche mehr. Erstere bietet keinen inhaltlichen Widerstand gegen den theologisch-institutionellen Mainstream, sie weicht gegebenenfalls auf andere Weltanschauungen aus. Aus diesem Grund ist es wichtig, die zweite Dimension der Rückkehr von Religion nicht aus den Augen zu verlieren.

Im heutigen Russland spielt Religion als intellektuelle Tradition erneut eine wichtige Rolle und wird zum Teil auch philosophisch fruchtbar gemacht. Durchaus vergleichbar mit MacIntyres NeoThomismus finden wir neo-patristische Strömungen, die auf der Basis von ideengeschichtlicher und theologischer Analyse wichtige Impulse für die theologischen und philosophischen Diskurse der post-sowjetischen Gegenwart liefern. ${ }^{40}$ Vertreter von derart theologischen und religionsphilosophischen Strömungen nehmen eine kritische Haltung ein: gegenüber der westlichen ,großen Erzählung“" von Aufklärung und Säkularismus, aber auch gegen russischen Nationalismus religiöser Prägung. Die Rückkehr der Religion als intellektuelle Tradition im Sinne MacIntyres kann daher genau jene Reibungsfläche bieten, die zur Klärung des Verhältnisses zwischen minimaler Religion, Kirche und Moderne notwendig ist.

Taylor ist sich potenzieller Spannungen zwischen ,Zentren traditioneller religiöser Autorität“ und verschiedenen „Arten des Suchens" durchaus bewusst. ${ }^{41}$ Die Schlussfolgerung, die daraus zu ziehen ist und die Taylor meines Erachtens nicht deutlich genug herausstreicht, lautet, dass die Rückkehr der Religion in Politik und Gesellschaft unter dem Blickwinkel nur einer der drei Dimensio-

40 Für eine Analyse dieser Diskurse siehe Stoeckl (2008).

41 ,The future of North Atlantic religion depends for one part on the concatenated outcomes of a whole host of such quests; and for another, on the relations, hostile, indifferent, or (hopefully) symbiotic, which will develop between modes of quest and centres of traditional religious authority [...]." Taylor (2007), 532-533. 
nen - nur Erlebnis, nur Institution, nur intellektuelle Tradition nicht $\mathrm{zu}$ fassen ist. Das gilt in besonderer Weise für das postsowjetischen Russland, aber es gilt auch für den Rest der Welt, die gerade ein Wiedererstarken von Religionen erlebt.

\section{Methodologische Schlussfolgerungen}

„Die Rückkehr der Religion als Anfrage an den politischphilosophischen Diskurs der Moderne" lautete der Untertitel der Konferenz, in deren Rahmen der vorliegende Beitrag entstanden ist. Meine scheinbar einfache Frage war, wie Religion denn eigentlich in den politisch-philosophischen Diskurs der Moderne zurückkehrt? In welcher Erscheinungsform wird sie überhaupt zur Anfrage? Mit einem Blick auf die anderen Beiträge in diesem Band wird deutlich, dass diese Frage je nach Erkenntnisinteresse und disziplinärer Verortung unterschiedlich beantwortet werden kann. Aus theologischer Perspektive findet sich eine andere Antwort als aus religionssoziologischer oder aus politisch-philosophischer Sicht. Aus theologischer Perspektive könnte die Rückkehr der Religion eine Besinnung auf die Notwendigkeit von verbindlichen Werten darstellen und entspräche damit einem menschlichen Grundbedürfnis, das sich in der säkularen Welt Bahn bricht - dies ist der Standpunkt, den Wilhelm Guggenberger in diesem Band einnimmt. Aus religionssoziologischer Perspektive mag sie lediglich eine Beobachtung gesellschaftlicher Dynamiken sein, die zu konstatieren sind - eine Haltung, die wir bei José Casanova erkennen können. Von einem politischphilosophischen Standpunkt wiederum wäre mit Religion eine partikulare Quelle von Normativität verbunden, deren Verhältnis zum universalistischen Anspruch der westlichen Moderne sorgfältig geklärt werden muss - dies ist die Perspektive des Beitrags von Walter Reese-Schäfer. Eingedenk dieser drei unterschiedlichen Perspektiven habe ich in meinem Beitrag den Versuch gewagt, einen interdisziplinären Zugang zum Phänomen der Rückkehr der Religion in den politisch-philosophischen Diskurs der Moderne zu skizzieren. Die Analyse von Religion als Erlebnis, wie wir sie bei Taylor angelegt sehen, erfasst die Wissensbereiche der Phänomenologie, Religionssoziologie und Psychologie; die Beschreibung von Religion als intellektuelle Tradition setzt Kenntnisse der Ideengeschichte von Theologie und Philosophie voraus; und für das Studium von Religion als Institution bedarf es eines Hintergrunds in Kirchengeschichte, Theo- 
logie und historischer Institutionssoziologie. Ziel dieser Überlegungen in drei Richtungen war es, die Komplexität des Gegenstandes im Blick zu behalten. Keine grand theory ist dabei herausgekommen - vor der übrigens Frank Adloff am Ende seines Beitrags in diesem Band warnt - sondern ein Ausblick auf Interdisziplinarität und Methodenpluralismus, der dem pluralen, fragmentierten und historisch kontingenten Charakter der Art und Weise, wie Religion zur Anfrage an den politisch-philosophischen Diskurs der Moderne wird, Rechnung trägt.

\section{Literatur}

Bader, Veit (2007): Secularism or Democracy? Associational Governance of Religious Diversity. Amsterdam: Amsterdam University Press.

Behrens, Kathrin (2002): Die Russische Orthodoxe Kirche. Segen für die 'neuen Zaren'? Religion und Politik im postsowjetischen Rußland (1991-2000). Paderborn: Ferdinand Schöningh Verlag.

Berger, Peter L., ed. (1999): The desecularization of the world. Resurgent religion and world politics. Washington DC: Ethics and Public Policy Center.

Berger, Peter L. (2008): „Secularization falsified”, in: First Things (February), 23-27.

Casanova, José (1994): Public religions in the modern world. Chicago: University of Chicago Press.

Crouch, Colin (2008): Postdemokratie. Frankfurt/M.: Suhrkamp.

Davie, Grace (2000): Religion in modern Europe. A memory mutates. Oxford, New York: Oxford University Press.

Eder, Klaus (2002): „Europäische Säkularisierung. Ein Sonderweg in die postsäkulare Gesellschaft?, “in: Berliner Journal für Soziologie 12, 331 344.

Epstein, Mikhail (1999): „Minimal Religion (1982)“, in: Epstein, Mikhail/Genis, Alexander/Vladiv-Glover, Hg.: Russian Postmodernism. New Perspectives on Post-Soviet Culture. New York, Oxford: Berghahn Books, 163-171.

Epstein, Mikhail (1999): „Post-Atheism: From Apophatic Theology to 'Minimal Religion'", in: Epstein, Mikhail/Genis, Alexander/VladivGlover, Hg.: Russian Postmodernism. New Perspectives on PostSoviet Culture. New York, Oxford: Berghahn Books, 345-393.

Große Kracht, Hermann-Josef (1997): Kirche in ziviler Gesellschaft. Studien zur Konfliktgeschichte von katholischer Kirche und demokratischer Öffentlichkeit. Paderborn: Ferdinand Schöningh.

Habermas, Jürgen (2005): Zwischen Naturalismus und Religion. Frankfurt/M.: Suhrkamp. 
Habermas, Jürgen (2008): „Die Dialektik der Säkularisierung“, in: Blätter für deutsche und internationale Politik 4, 33-46.

Habermas, Jürgen, and Joseph Ratzinger (2004): „Vorpolitische moralische Grundlagen eines freiheitlichen Staates", in: zur debatte 34 (1), 1-12.

Heller, Agnes (1999): A Theory of Modernity. Malden (MA): Blackwell.

Hervieu-Léger, Danièle (2003): „Religion und sozialer Zusammenhalt in Europa“, in: Transit 26, 101-119.

Knight, Kelvin, Hg. (1998): The MacIntyre Reader. Cambridge: Polity Press. Lilla, Mark (2007): The Stillborn God. Religion, Politics and the Modern West. New York: Vintage Books.

Lyotard, Jean-François (1999): „The Postmodern Condition“, in: Watters, Malcolm, Hg.: Modernity. Critical concepts, volume IV: After Modernity. London, New York: Routledge, 161-177.

MacIntyre, Alasdair (1967): A Short History of Ethics. London, New York: Routledge.

MacIntyre, Alasdair (1981): After Virtue. A study in Moral Theory. London: Duckworth.

MacIntyre, Alasdair (1988): Whose Justice? Which Rationality? London: Duckworth.

MacIntyre, Alasdair (1990): Three rival versions of moral enquiry. Encyclopaedia, genealogy, and tradition. London: Duckworth.

Madeley, John T. S./ Enyedi, Zsolt, Hg. (2003): Church and State in Contemporary Europe. London: Frank Cass.

Milbank, John/Pickstock, Catherine/Ward, Graham, Hg. (1999): Radical Orthodoxy. London, New York: Routledge.

Stoeckl, Kristina (2008): Community after Totalitarianism. The Russian Orthodox intellectual tradition and the philosophical discourse of political modernity. Berlin, Bruxelles, Wien et. al.: Peter Lang.

Sutton, Jonathan (2006): ,'Minimal Religion' and Mikhail Epstein's Interpretation of Religion in Late-Soviet and Post-Soviet Russia", in: Studies in East European Thought 58, 107-135.

Taylor, Charles (1992): The ethics of authenticity. Cambridge MA: Harvard University Press.

Taylor, Charles (1995): „Cross-Purposes. The Liberal-Communitarian Debate", in: ders. Philosophical Arguments. Cambridge (MA): Harvard University Press, 181-203.

Taylor, Charles (1995): „Lichtung or Lebensform: Parallels between Heidegger and Wittgenstein“, in: Ders.: Philosophical Arguments. Cambridge (MA): Harvard University Press, 61-78.

Taylor, Charles (1998): „Modes of secularism”, in: Bhargava, Rajeev, Hg.: Secularism and its critics. New Delhi: Oxford University Press, 31-53.

Taylor, Charles (2007): A Secular Age. Cambridge, MA: Harvard University Press. 


\section{Offene Gesellschaft und geschlossene Gemeinschaft. Zur Kritik der kommunitaristischen Revitalisierung der Gemeinschaften}

Harald Stelzer

\section{Einleitung}

Während die Religionskritik in den letzten Jahrzehnten im Rahmen der Philosophie zunehmend an Bedeutung verloren hat, erwarten manche unter dem Schlagwort der Entsäkularisierung eine Rückkehr der Religion in den privaten und öffentlichen Bereich. Ohne Zweifel haben sowohl die Radikalisierung fundamentalistischer Strömungen und ihre Instrumentalisierung für machtpolitische, ökonomische und kulturelle Konflikte als auch der feststellbare Zustrom zu manchen religiösen Glaubensgemeinschaften in unterschiedlichen Teilen der Welt die These vom Beginn eines säkularen, post-religiösen Zeitalters als unhaltbar erwiesen. Zwar lässt sich in Bezug auf liberale Gesellschaften nicht von einer ähnlichen Tendenz hin zur Religion ausgehen, jedoch keimt auch hier aufgrund rückläufiger Zahlen von Kirchenaustritten ${ }^{1}$ sowie einer anhaltend steigenden Nachfrage nach

1 So ist die Zahl der jährlichen Kirchenaustritte in Deutschland aus der evangelischen Kirche von 196.602 im Jahr 1997 auf 131.000 im Jahr 2007 zurückgegangen und jene aus der katholischen Kirche im gleichen Zeitraum von 123.013 auf 93.667. Vgl. Statistik (2009). In Österreich ist die Zahl der Kirchenaustritte aus der katholischen Kirche im Jahr 
spiritueller Orientierung die Hoffnung auf ein Wiedererstarken der Religion. Dabei wird in diesem Zusammenhang nicht selten auf die gesellschaftlichen Funktionen der Religion, wie etwa der Stabilisierung von Beziehungen, der Erzeugung von Solidarität, der Vermittlung von Orientierung und Sinn, der Stützung von Werten und Normen, verwiesen. Dies ist nicht nur in sozialkonservativen Kreisen der Fall, sondern auch gemäßigtere Strömungen versuchen sich einzelner Aspekte der Religion zu bedienen, um ihrer eigenen Vorstellung des guten Lebens zum Durchbruch zu verhelfen.

Als Beispiel lässt sich hier der in den 80er Jahren in den Vereinigten Staaten und Kanada in Auseinandersetzung mit dem liberalen Individualismus entstandene Kommunitarismus anführen. ${ }^{2}$ Anders als in vielen liberalen Positionen erscheint die Religion aus kommunitaristischer Perspektive als wichtiger Bestandteil der moralischen Infrastruktur der Gesellschaft. Dieser Bezug auf die religiösen Gemeinschaften ist vor dem Hintergrund des nordamerikanischen Kontextes durchaus verständlich, stellt die biblische Tradition neben der liberalen Tradition und dem Republikanismus doch einen wichtigen Teil des traditionellen Erbes dar. ${ }^{3}$ Auch zeigen Statistiken, dass die Verbreitung und angegebene Bedeutung des Glaubens für die eigene Lebensausrichtung dort um einiges höher ist als in Europa. ${ }^{4}$ Des Weiteren spielen die öffentlichen Kirchen, bestehend aus pluralistisch verfassten Religionsgemeinschaften, eine nicht unbedeutende

2008 im Vergleich zum Vorjahr jedoch um rund 10\% gestiegen (bei einer gleichzeitigen Steigerung der Zahl der Wiedereintritte). Vgl. Der Standard (2009). Die Zahl der Kirchenaustritte 2008 liegt mit 40.595 jedoch deutlich unter jener von 2004, dem Jahr des Skandals um das Priesterseminar in St. Pölten. 2004 waren 51.731 Katholiken und Katholikinnen aus der Kirche ausgetreten, ein Wert, der einen absoluten Negativrekord seit 1945 darstellt.

2 Dieser Bezug auf die Religion findet sich, wie vorausgeschickt werden muss, nicht bei allen kommunitaristischen Autorinnen und Autoren. Dies ist nicht verwunderlich, handelt es sich beim Kommunitarismus doch um keine einheitliche philosophische Strömung. Nur von einer konstruktiven Außenperspektive, wie sie auch im Folgenden eingenommen werden wird, lassen sich die höchst disparaten Ansätze durch die thematische Wahlverwandtschaft unter dem Sammelbegriff des Kommunitarismus zusammenfassen. Den Verbindungspunkt bilden dabei die Kritik am Liberalismus wegen seiner individualistischen Schlagseite sowie die Entgegensetzung einer stärker gemeinschaftsorientierten Moral- und Gesellschaftskonzeption. Vgl. Honneth (1993); Koller (1993), 76; Kallscheuer (1995), 139-40.

3 Der Terminus der biblischen Tradition ist so gewählt, um neben der protestantischen Religion auch die katholischen und jüdischen Einflüsse mitberücksichtigen zu können, und kann als Ausdruck einer Zivilreligion gelten. Vgl. Reese-Schäfer (1994), 83 f.

4 Vgl. Reese-Schäfer (1994), 86 f. 
Rolle in der sozialpolitischen Auseinandersetzung und Praxis in den Vereinigten Staaten. ${ }^{5}$

Es ist jedoch nicht die Präsenz der biblischen Tradition, die, wie zu erwähnen ist, in den letzten Jahrzehnten auch in den USA abgenommen hat, was die Religion für den Kommunitarismus so interessant macht. ${ }^{6}$ Das Interesse erklärt sich vor allem aus dem Gemeinschaftsbezug von religiösen Gruppierungen und ihrer moralischen Ausrichtung an bestimmten gemeinschaftlich geteilten moralischen Normen, Werten und Praktiken. Damit sind religiöse Gemeinschaften aus kommunitaristischer Sicht besser als viele andere in der Lage, die Identität des Individuums auf positive Weise zu prägen. Im Vergleich $\mathrm{zu}$ anderen im Kommunitarismus propagierten Gemeinschaftsformen, wie Gewerkschaften, sozialen Bewegungen, Vereinen, Nachbarschaften, liefern sie eine umfassendere Konzeption des guten Lebens. Sie verbinden nicht nur unterschiedliche Lebensbereich miteinander, sondern stellen auch Modelle für soziale Beziehungen, Symbole für die Wahrnehmung der Gesamtgesellschaft, sowie Vorbilder und Tugenden zur Orientierung des eigenen Lebens bereit. ${ }^{7}$ Zugleich sorgen sie für die Einbettung der Erzählung des Lebens des Individuums in eine Gemeinschaft und Tradition. Weiters stellen religiöse Gemeinschaften eine mögliche Basis für die Partizipation dar. In den religiösen Institutionen können die Menschen in der konkreten gemeinsamen Arbeit Solidarität und Geborgenheit erfahren. Zusätzlich ermöglicht es die große Mitgliederzahl, soziale Bruchlinien in einer ausdifferenzierten Gesellschaft zu überbrücken oder abzumildern. ${ }^{8}$ Die Religion liefert aus kommunitaristischer Perspektive damit vielfältige Ressourcen, um die in liberalen Gesellschaften vorhandenen Probleme wie Egoismus, Isolierung, gesellschaftliche Spaltung sowie Orientierungslosigkeit zu überwinden. Ihr wird aus diesem Grund eine wichtige Funktion für die Revi-

5 Vgl. Kallscheuer (1992), 113 f.

6 So verweist auch der dem Kommunitarismus zugeordnete Christopher Lasch auf die Abnahme der Funktion der biblischen Tradition in den USA und warnt davor die Leistungsfähigkeit und den tatsächlichen Einfluss der Religion zu überschätzen. Vgl. Lasch (1995), 237. Walter Reese-Schäfer wirft Bellah einen unkritischen Schritt von der Diagnose der Missstände in der liberalen Gesellschaft zur Zivilreligion als dem großen Hoffnungsträger vor. Vgl. Reese-Schäfer (1994), 85.

7 Vgl. Bellah et al. (1987), 263.

8 Vgl. Bellah et al. (1987), 228; Bellah et al. (1992), 67. 
talisierung der Gemeinschaften und die Neugestaltung der Gesellschaft zuerkannt. ${ }^{9}$

Abgesehen von den Fragen, ob es im Kommunitarismus nicht zu einer Verklärung religiöser Gemeinschaften kommt, ${ }^{10}$ und ob die Religion überhaupt diese Integrationsfunktion übernehmen kann, die ihr von kommunitaristischer Seite zugeschrieben wird, erscheint schon die Forderung nach einer Revitalisierung der Gemeinschaften in offenen Gesellschaften ein gewisses Gefahrenpotential in sich zu bergen oder zumindest mit erheblichen Problemen belastet zu sein. Damit rückt das kommunitaristische Plädoyer für eine Revitalisierung von Gemeinschaften selbst in den Blickpunkt der Kritik. Dieses soll im Folgenden auf zentrale Grundlagen und Implikationen hin befragt werden, bevor nochmals die Frage nach der Rückkehr der Religion gestellt wird.

\section{Die kommunitaristische Revitalisierung von Gemeinschaften}

Zwar wird im Kommunitarismus an die traditionelle Unterscheidung zwischen Gemeinschaft und Gesellschaft angeschlossen, die schon auf die aufgeklärten Vorreiter der politischen Ökonomie, Soziologie und Anthropologie des achtzehnten und neunzehnten Jahrhunderts zurückgeht und die sich auch noch in der gegenwärtigen Soziologie findet. ${ }^{11}$ Jedoch wird gegenüber einer vom Fortschrittsgedanken getragenen Aufklärungsphilosophie der Wertakzent verschoben. Der Übergang von der Gemeinschaft zur Gesellschaft wird als Verlust aufgefasst, wie dies auch schon bei Ferdinand Tönnies Ende des 19. Jahrhunderts der Fall war. Während die Gemeinschaft von Tönnies als natürliche Form der Assoziation, basierend auf physischer Nähe, einem intimen Verständnis voneinander und traditioneller Bindung beschrieben wird, sind aus seiner Sicht für die Gesellschaft die abstrakten sozialen Beziehungen wie Arbeitsteilung und Güteraustausch kennzeichnend. ${ }^{12}$ Im Gegensatz zur Gemeinschaft beschreibt Tönnies die Gesellschaft als Artefakt, als bloßes Nebeneinander von unabhängigen Individuen, die durch ideelle und mechanische Bin-

10 Vgl. Fach (1992), 46.

11 Vgl. hierzu die zusammenfassende Darstellung bei Riedel (1975), $860 \mathrm{f}$.

12 Vgl. Tönnies (1937), 8 ff. 
dungen verbunden sind. Die Gesellschaft baue auf dem freien Willen und den egoistischen Interessen ihrer Mitglieder auf. Das Tun erfolge nicht aus einem Gefühl der Zusammengehörigkeit heraus, sondern in Hinblick auf eine äquivalente Gegenleistung. Die Gesellschaft sei daher primär ökonomisch begründet, beruhend auf dem Interesse an der Ausdehnung des Austausches von Gütern und Dienstleistungen unter dem Gesichtspunkt der Maximierung des eigenen Gewinns. ${ }^{13}$

Diese wertende Charakterisierung findet sich auch in der kommunitaristischen Kritik an der liberalen Gesellschaft. Diese erscheint wie eine Ansammlung isolierter Individuen, von denen jedes unter minimalen Einschränkungen den eigenen Interessen nachjagt. Durch die Ausklammerung der wichtigen sozialen Bindungen und Verpflichtungen ginge nicht nur eine wesentliche Dimension des moralischen Lebens verloren, sondern auch ein gemeinsames Verständnis dafür, was den anderen Gemeinschaftsmitgliedern geschuldet werde. Das Individuum würde unfähig, Verantwortung zu übernehmen. ${ }^{14}$ In einer auf Leistung, individuelle Nutzenmaximierung, Mobilität und Konfliktbereitschaft ausgerichteten Gesellschaft komme es zu einer radikalen Abnahme der gegenseitigen Verpflichtungen und Solidarität. In ihr herrsche Antagonismus gegenüber Kooperation vor. Die Individuen würden darin gestärkt, ihre eigenen Interessen in den Vordergrund zu stellen und die Freiheit ihrer Wahl einzufordern, ohne Rücksicht auf die Implikationen und Konsequenzen dieser Wahl für die anderen. Die vorhandenen Gemeinschaften würden auf Interessensgemeinschaften reduziert, die keiner anderen Funktion als der Steigerung des individuellen Wohlgefühls dienten, und damit zu bloß temporären Hilfsmitteln der individuellen Bedürfnisbefriedigung. 15

Von kommunitaristischer Seite wird in diesem Zusammenhang die These vertreten, dass die liberale Gesellschaft Gefahr läuft, sich ihrer eigenen moralischen Grundlagen zu entledigen. Immer wieder ist von einer solchen Selbstunterminierung die Rede, sei dies nun in Form der Auflösung der gemeinschaftlichen Basis eines mit Bindungen und Verpflichtungen verbundenen Lebens, der Auflösung der Moral durch das Verschwinden ihres Fundaments in den geteilten 
Gemeinschaftswerten, oder der drohenden Auflösung der Demokratie durch die überhand nehmende Durchsetzung von Individualrechten. Die Basis dieser Auflösungsprozesse bildet aus kommunitaristischer Sicht die sich verstärkende Wechselwirkung zwischen gesellschaftlicher Dynamik und liberaler Theorie, welche sich gegenseitig legitimieren und vorantreiben. Dieser Kreislauf muss gemäß der vorherrschenden Ansicht im Kommunitarismus sowohl auf der theoretischen als auch auf der praktischen Ebene durchbrochen werden. Für die theoretische Ebene bedeutet dies eine philosophisch-anthropologische, moralphilosophische, sozialphilosophische und sozialwissenschaftliche Grundlagenkritik am Liberalismus sowie die Entwicklung einer kommunitaristischen Philosophie, die in der Lage sein soll, die soziale Einbettung und Verankerung des Individuums und die sich daraus ergebenden Konsequenzen in ausreichendem $\mathrm{Maß}$ zu berücksichtigen. Zugleich werden aus diesen theoretischen Überlegungen bestimmte Forderungen für die praktische Ebene abgeleitet, die auf die Reintegration des Individuums durch die Revitalisierung der Gemeinschaften hinauslaufen.

Wie von kommunitaristischer Seite immer wieder versichert wird, geht es nicht um die Wiederbelebung von zu engen, traditionalistischen Gemeinschaften. Vielmehr bräuchte es neue Gemeinschaftsformen, die einerseits dem Menschen genügend Wahlmöglichkeiten ließen und einen Raum für divergente Subgemeinschaften bieten würden und andererseits ermöglichten, gemeinsame Bande aufrechtzuerhalten. ${ }^{16}$ Nicht die Rückkehr zu vergangenen Traditionen rückt im Kommunitarismus in den Vordergrund, sondern die Realisierung des vollen Potentials des Gemeinschaftslebens. ${ }^{17}$ Das kommunitaristische Plädoyer für die Revitalisierung der Gemeinschaften verbindet sich auf diese Weise mit der Forderung einer Transformation von Gemeinschaften, so dass diese näher dem Ideal einer Gemeinschaft im Sinne der attraktivsten Eigenschaften von Gemeinschaften kommen. ${ }^{18}$

Jedoch bleiben die kommunitaristischen Ausführungen in Bezug auf dieses Ideal der Gemeinschaft ebenso wie die Frage nach den Möglichkeiten und Formen der Transformation weitgehend unbestimmt. Es handelt sich beim positiven Gegenbild der Gemein- 
schaft um einen fiktionalen Gegenentwurf, der negativ vom Gemeinschaftsverlust her bestimmt wird. Dem kommunitaristischen Denken liegt dementsprechend ein dreiphasiges Schema zugrunde. Dieses reicht von der Auflösung der traditionellen Gemeinschaften, über die Entwicklung der modernen Gesellschaft bis hin zum Bild einer integrierten Gesellschaft, als Gemeinschaft der Gemeinschaften. ${ }^{19}$ Damit handelt es sich um keine bloß rückwärts gewandte sozialromantische Vorstellung, denn sie verbindet sich mit einer angestrebten Überwindung der gegenwärtigen Verhältnisse. Die Friedlichkeit des Gemeinschaftstraums darf, wie Gérard Raulet betont, nicht über den strukturellen dynamischen Charakter des Gemeinschaftsideologems hinwegtäuschen. ${ }^{20}$ „Das Gemeinschaftspathos ist allzu sehr gegen den ,Untergang' gerichtet, um nur die Sehnsucht nach Geborgenheit auszudrücken. Es hat vielmehr immer mit Aufbruchstimmung zu tun. Die Gemeinschaft ist zugleich Ursprung und Idee, Hoffnung auf die revolutionäre Veränderung des Bestehenden. [...] Es geht um die Wiederherstellung, oder genauer um die Erneuerung des idealisierten ursprünglichen Referenzmodells [...].“21

Die Sehnsucht nach der Gemeinschaft entspringt der Reaktion gegen eine als schlecht empfundene Gegenwart, gegen die sie ausgespielt wird, und stellt einen Indikator für die Krise der modernen Gesellschaft dar. In Analogie zu dem was Hans Albert über die heuristische Funktion von Utopien schreibt, ${ }^{22}$ stellen die Gemeinschaftslehren einen Gradmesser der Unzufriedenheit mit den herrschenden Verhältnissen dar. ${ }^{23}$ Die Attraktivität des Kommunitarismus ergibt sich aus den Nachteilen liberal aufgeklärter Gesellschaften, wie Anonymität, Egoismus, Unruhe, Angst, Stress und Isolation. ${ }^{24}$ Der Ruf nach der Gemeinschaft lässt sich demnach als Antwort auf die menschlichen Bedürfnisse nach Zugehörigkeit, gemeinschaftlicher Identität, Sicherheit, Orientierung, Solidarität, Überschaubarkeit und Konstanz von Sozialbeziehungen verstehen, die in

19 Dieses Schema ist nicht neu, sondern findet sich schon in der amerikanischen Wahrnehmung vor den dreißiger Jahren des 20. Jahrhunderts. Grundlegend hierfür waren die ethischen Ghettos amerikanischer Großstädte, in denen die Zersetzung europäischer Dorfgemeinschaften zu neuen Gemeinschaftsformen geführt hat. Vgl. Joas (1993), 55.

20 Vgl. Raulet (1993), 83.

21 Raulet (1993), 84.

22 Vgl. Albert (1991), 209.

23 Vgl. Rauled (1993), 73.

24 Vgl. Magee (1982), 54. 
modernen Gesellschaftsformen keine zureichende Befriedigung erfahren.

\section{Die Rückkehr zur Gemeinschaft}

Diese Bedürfnisse sind tief in der Psychostruktur des Menschen verankert. Ihre Befriedigung scheint in kleinen, abgeschlossenen Gemeinschaften mit einem geteilten Wertesystem und einer gemeinsamen Weltanschauung unproblematisch. Im cosy social womb dieser Gemeinschaften erfahren die Menschen bei aller Enge und Einschränkung der individuellen Freiheit Geborgenheit, Sinn, Orientierung und Gewissheit. Menschen sind aufgrund ihrer Entwicklungsgeschichte, auf ein Leben in einfachen sozialen Strukturen vordisponiert. 98 Prozent seiner gesamten Entwicklungszeit hat der Mensch in kleinen, abgegrenzten Jäger- und Sammlerverbänden oder wenig komplexen Kleingesellschaften gelebt. Größere menschliche Gesellschaftsformen gibt es erst seit wenigen Jahrtausenden und technisierte Massengesellschaften existieren noch keine 150 Jahre. ${ }^{25}$ Daraus lässt sich eine anthropologische Bedürfnis-Hypothese ableiten, die davon ausgeht, dass das Leben im Schoße einer geschlossenen Gemeinschaft den menschlichen Grundbedürfnissen entspricht, und der Menschen daher aufgrund seiner Bedürfnisstruktur als natürlicher Anhänger geschlossener Gemeinschaften betrachtet werden kann. ${ }^{26}$

Während sich der gesellschaftliche Wandel vergleichsweise rasch vollzieht, verändern sich diese Bedürfnisse der Menschen nicht mit der gleichen Geschwindigkeit. Das heißt die gesellschaftlichen Bedingungen und Lebensweisen unterliegen einem ständigen Wandel, während sich die biologisch-psychologische Struktur des Menschen seit der Entstehung der Hochkulturen nur geringfügig verändert hat. ${ }^{27}$ Dadurch entsteht mit dem Verlassen der geschlossenen Gemeinschaftsformen und deren Entwicklung zu größeren Sozialgebilden in der menschlichen Psychostruktur ein Defizit bei der Befriedigung der oben angeführten Bedürfnisse. ${ }^{28}$ Dieses Defizit ist umso größer, je differenzierter, komplexer und pluralistischer ein Sozialsystem angelegt ist und desto weniger Möglichkeiten es für 
abgeschlossene Gemeinschaftsformen offen lässt. Gemäß dieser zweiten psychologischen Defizit-Hypothese ist die Eröffnung neuer Handlungsalternativen durch eine erhöhte individuelle Freiheit und soziale Mobilität in offenen Gesellschaftsformen mit einem Defizit im Hinblick auf Sinn, Orientierung, Sicherheit, Vertrauen und Geborgenheit verbunden. ${ }^{29}$

Fanden die Menschen in Traditionen, Religionen und dem Leben in Gemeinschaften zu allen Zeiten zumindest ein gewisses Maß an Sicherheit, indem diese Vorbilder lieferten und Wege aufzeigten, ein anerkanntes Mitglied der Gesellschaft zu werden und zu bleiben, sowie ein Gefühl der Sinnhaftigkeit im Leben vermittelten, so hat sich seit der Neuzeit der individuelle Handlungsspielraum sukzessive vergrößert und im 19. und 20. Jahrhundert revolutionär verändert. Nicht alle Menschen sind bereit oder fähig, den Preis für die Vergrößerung der individuellen Freiheit zu bezahlen. ${ }^{30}$ Die Veränderungen erfüllen viele Menschen mit Angst und Unbehagen und führen zum Wunsch nach Rückkehr in mehr oder weniger geschlossene Sozialgebilde. ${ }^{31}$ Aufgrund der Erfahrung der Beschleunigung des sozialen Wandels und massiver Strukturbrüche findet sich somit auch in modernen Gesellschaften ein individuelles Wiedereingliederungsbedürfnis. Neben den zuvor genannten Bedürfnissen kommen hier jene nach Berechenbarkeit, Einfachheit und Unkompliziertheit der Weltorientierung und der Wunsch nach einer Befreiung von Entscheidungsdruck und Entscheidungsängsten zum Tragen. ${ }^{32}$ Es besteht die Gefahr der Rückorientierung zu geschlossenen Entitäten im Sinne einer Monokollektivierung. Auf individueller Ebene zeigt sich diese Gefahr im Bedürfnis nach konkreten Bindungen und der Bindungsbereitschaft an Ranghöhere und Führer sowie den Verzicht auf Selbstverantwortung; auf der kollektiven Ebene in der Reduktion gesellschaftlicher Komplexität durch die Reintegration aufgrund von einfachen und oft auch direkt wahrnehmbaren Merkmalen, wie Hautfarbe, Abstammung oder Religion. Verbunden sind beide durch einen geringen Grad der Anpassung an die neuen komplexen Rahmenbedingungen sowie den Wunsch nach einfachen Lösungen. ${ }^{33}$

30 Vgl. Magee (1982), 92; Rapport (2005), 10.

31 Vgl. Popper (2008), 235.

32 Vgl. Salamun (1993), 106.

33 Vgl. Tiefel (2003), 135 f. 
Zwar erscheint der Versuch der Rückkehr zu geschlossenen Gemeinschaften, der Wunsch nach einfachen Lösungen, nach einer Reduktion von Komplexität aufgrund der Psychostruktur des Menschen als durchaus verständlich. ${ }^{34}$ Jedoch sind diese Versuche der Rückkehr zum Scheitern verurteilt. Hier lässt sich aus Poppers Ausführungen eine weitere Hypothese ableiten. Gemäß dieser soziologischen Unumkehrbarkeits-Hypothese führen Versuche der Rückkehr zu den Strukturen geschlossener Gemeinschaftssysteme nicht in das Paradies, sondern zu Gewalt, Unterdrückung und Terror. Denn die verlorene Unschuld der geschlossenen Stammesgesellschaft lässt sich nicht wiedergewinnen. ${ }^{35} \mathrm{Je}$ mehr wir die Rückkehr in den cosy social womb versuchen, desto sicherer landen wir bei einem neuen Typus der geschlossenen Gesellschaft, der zwangsgeschlossenen Massengesellschaft. ${ }^{36}$ Auch von liberaler Seite wird dieser Verlust der Unschuld betont, sowie auf den Umstand verwiesen, dass der Individualismus und Rationalismus zu unserer zweiten Natur geworden sind. ${ }^{37}$ Die Auflösung und Relativierung der kulturellen Traditionen und Gemeinschaftsformen wird als der Preis der Moderne verstanden, den zu bezahlen für niemanden mehr zur Wahl steht. ${ }^{38}$ In einer Welt, wo Aufklärung und Individualismus zu einer Unterminierung von traditionellen Gemeinschaften geführt haben, erscheint die kommunitaristische Forderung nach einer Revitalisierung der Gemeinschaften entweder als hoffnungslos romantisch oder als autoritär, als ein unmöglicher Traum oder als eine gefährliche Ideologie. ${ }^{39}$ Zwar wird im Kommunitarismus durch die Betonung des Gleichgewichts von sozialer Ordnung und individueller Autonomie eine Abgrenzung gegenüber traditionalistischen Ordnungskonzepten sozialkonservativer Strömungen versucht. ${ }^{40}$ Zugleich weist die kommunitaristische Forderungen nach einer Revitalisierung der Gemeinschaften und nach der Reintegration der Individuen jedoch jene Merkmale auf, die

34 Dabei streicht Popper die Ähnlichkeit zwischen der von ihm beschriebenen Last der Zivilisation und dem Phänomen, welches Siegmund Freud vorschwebte, als dieser Das Unbehagen in der Kultur schrieb, hervor. Vgl. Popper (1992a), 378. Ernst Topitsch spricht im Anschluss an Freud vom Druck der Realität. Vgl. Topitsch (1979), 52 f.

35 Vgl. Popper (1992a), 238.

36 Vgl. Spinner (1978), 423.

37 Vgl. Kautz (1995), 106.

38 Vgl. Wellmer (1993), 195.

39 Vgl. Kautz (1995), 28; Doering (1993), 28.

40 Vgl. Etzioni (1997), 29 f. 
Popper als kennzeichnend für die totalitäre Tradition ansieht. ${ }^{41}$ Bei diesen Merkmalen handelt es sich um a) den Kollektivismus, als Vorstellung einer organischen Einheit der Gemeinschaft sowie einer Überordnung des Kollektivs gegenüber dem Individuum, und b) den utopischen Romantizismus, in Form eines irrationalen Traums eines ultimativen und unwandelbaren paradiesischen sozialen Zustandes der Glückseeligkeit auf Erden. ${ }^{42}$

\section{Die Gefahr des Kollektivismus im Kommunitarismus}

Popper greift den Kollektivismus auf zwei Ebenen an. Einerseits kritisiert er auf Grundlage seines methodologischen Individualismus alle holistischen Vorstellungen sozialer organischer Ganzheiten und verlangt, soziale Gebilde als Produkte individueller Handlungen zu verstehen. Andererseits richtet er sich gegen einen Kollektivismus im sozial-politischen Bereich, der das Individuum dem Kollektiv unterstellt. Nach solchen kollektivistischen Vorstellungen ist das Kollektiv dem Individuum nicht nur vorgelagert, sondern der Einzelne ist für die Allgemeinheit da und hat ihr zu dienen. ${ }^{43}$ Die Ausrichtung des Sozialsystems erfolgt hier in Hinblick auf den kollektiven Nutzen und das Individuum wird vom Kollektiv her bestimmt. ${ }^{44}$ Das Individuum verwirklicht sich gemäß der kollektivistischen Auffassung in einer Teil-Ganzes-Relation in funktionaler Zuordnung und Unterordnung unter das Kollektiv.

Zwar handelt es sich beim Kommunitarismus nicht um eine strikt kollektivistische Strömung, da durchaus Grenzen der Unterordnung des Individuums unter die Gemeinschaft anerkannt werden. Dies ändert jedoch nichts an der grundsätzlichen kollektivistischen Ausrichtung, die sich etwa in der Bestimmung der Identität des Individuums von der Gemeinschaft her zeigt. So lässt sich im Kommunitarismus die Ansicht finden, dass der Mensch durch seine Herkunft und Zugehörigkeit zu konstitutiven Gemeinschaften sozial

41 Poppers Verwendung des Totalitarismusbegriffs ist sehr weit gefasst. Er geht von einer totalitären Tradition aus, unter die er nicht nur die bekannten Formen des Totalitarismus im 20. Jahrhundert subsumiert, sondern alle retrogressiven Bewegungen, die eine Rückkehr zu geschlossenen Gesellschaftsformen anstreben. Vgl. Stelzer (2004), 34-55.

42 Vgl. Popper (2008), 136.

43 Vgl. Gewirth (1996), 125.

44 Vgl. Popper (1992a), 242. 
determiniert ist. Er sei weder fähig, deren Überzeugungen, moralische Standards oder Praktiken in Frage zu stellen, noch sich von diesen ausreichend zu distanzieren. ${ }^{45}$ Die kollektivistische Ausrichtung wird auch in der geforderten Unterordnung der Individualinteressen unter das Gemeinwohl deutlich. Als Gemeinwohl gilt im Kommunitarismus, was der Gesamtgesellschaft zum Vorteil gereicht und was dazu geeignet ist, das öffentliche Glück zu fördern. ${ }^{46}$ Das Gemeinwohl gehe im Sinne eines gemeinsamen Guten, eines common good, der Summe der individuellen Wünsche und Interessen voraus und ist unabhängig von ihnen charakterisierbar. ${ }^{47}$ Von dieser Vorstellung des gemeinsamen Guten werden die Präferenzen der Menschen evaluiert. 48

Da der Mensch als ein von Natur aus soziales Wesen verstanden wird, stelle für ihn nur ein mit anderen geteiltes Leben ein gutes Leben dar, weshalb das Gemeinwohl nicht in Opposition zu den eigentlichen individuellen Interessen stehen könne. Das individuell wabre Gute liege nicht in der Verfolgung individualistischer Interessen, sondern in der Teilnahme an einer erstrebenswerten Form des gemeinsamen Lebens. ${ }^{49}$ Auf diese Weise wird im Kommunitarismus der Unterschied zwischen den eigenen Interessen und jenen der Gemeinschaft aufgehoben. Wenn sich die Mitglieder einer Gemeinschaft stark mit dieser identifizieren, nehme das Individuum die Interessen der Gemeinschaft als seine eigenen wahr. ${ }^{50}$ Dort wo die eigenen privaten Interessen nicht mit den Interessen der Gemeinschaft in Übereinstimmung stünden, sei es die Pflicht des Individuums, dem Gemeinwohl den Vorzug zu geben. So versteht etwa Sandel die Bereitschaft, das Gemeinwohl höher als die privaten Ziele

45 Vgl. Sandel (1982), 179; Bell (1993), $100 \mathrm{f}$.

46 Vgl. Bellah et al. (1987), 369.

47 Vgl. MacIntyre (1997), 314.

48 Vgl. Kymlicka (1989), 76-77.

49 Vgl. Sullivan (1994), 193 f; Barber (1994), 213. Gemäß MacIntyre ist aus traditioneller Sicht das Gute, nach dem der Mensch strebt, das gleiche wie das Gut jener anderen, mit denen er eine Gemeinschaft bildet. Der Egoist ist aus dieser Perspektive jemand, der darin grundlegend irrt, wo sein eigenes Gut liegt. Er schließt sich dadurch aus der Gemeinschaft aus. Vgl. MacIntyre (1997), 305.

50 An diesem Punkt verbindet sich die kommunitaristische Gemeinwohlvorstellung mit der Partizipation. Durch die Partizipation an den Angelegenheiten der Gemeinschaft komme es zu einer Identifizierung mit den anderen, so dass sich das Individuum als Teil des Ganzen fühle. Vgl. Sandel (1994), 65. 
und Interessen zu stellen, als die Bürgertugend schlechthin. ${ }^{51}$ Auch MacIntyre verweist darauf, dass die Tugend des Individuums aus Sicht des Republikanismus in nichts anderem besteht, „als zuzulassen, dass das öffentliche Gut den Maßstab für das individuelle Verhalten liefert. Die Tugenden sind jene Dispositionen, die diese vorrangige Treuepflicht aufrechterhalten. "52 Dies führt im Kommunitarismus ganz ähnlich wie im Kollektivismus zu einer Gleichsetzung von Individualismus und Egoismus. Wenn man nicht die Eigeninteressen den Kollektivinteressen unterordnet, so die kollektivistische Argumentation, dann ist man eine selbstsüchtige Person. ${ }^{53}$ Dabei beraube sich das egoistisch handelnde Individuum selbst seines eigenen Guten, welches mit dem Guten jener anderen verbunden sei, mit denen es eine Gemeinschaft bilde. Individualistische Interessen stellen sich so als Irrtum über das eigene Gute heraus. ${ }^{54}$

Der Kollektivismus ist jedoch weder als Gegensatz zum Egoismus zu sehen, noch ist er mit dem Altruismus oder der Selbstlosigkeit identisch. Wie auf der einen Seite ein Gruppenegoismus möglich ist, so ist auch ein altruistischer Individualismus möglich. ${ }^{55}$ Es erfordert eine grundlegende Unterscheidung zwischen einem exzessiven, atomistischen und materialistischen Individualismus und jener Tradition des Individualismus, welche auf dem Respekt vor der menschlichen Person basiert, die als einzigartiges und unaustauschbares Selbst aufgefasst wird. ${ }^{56}$ Ein richtig verstandener Individualismus, der auf der moralischen Autonomie des Individuums beruht, führt, wie Popper betont, nicht von der Verantwortung weg, sondern zu ihr hin. ${ }^{57}$

Zugleich ist es nicht weit von einer gemeinschaftlich bestimmten Definition des Guten und der Gleichsetzung von Individualismus und Egoismus zur gewaltsamen Unterordnung des Individuums und zu einem aufgezwungenen Konformismus. Trotz der gegenteiligen Versicherung von kommunitaristischer Seite ist die Befürchtung, dass die Versuche der Revitalisierung der Gemeinschaften eine Ge-

51 Vgl. Sandel (1994), 55.

52 Vgl. MacIntyre (1997), 314.

53 Vgl. Popper (2008), 65.

54 Vgl. MacIntyre (1997), 305.

55 Vgl. Popper (1992a), $121 \mathrm{f}$.

56 Vgl. Elshtain (1995), 82.

57 Vgl. Stelzer (2004), 272 f. 
fahr für die individuelle Freiheit darstellen könnten, nicht unbegründet. Der Kommunitarismus gefährdet wertvolle Errungenschaften des modernen Verfassungsstaates, indem er in seiner Konsequenz durch die Berufung auf Gemeinschaftswerte den Kern einer säkularisierten und neutralen Politik aufgibt. ${ }^{58}$ Die Stärkung der sozialen Ordnung auf Grundlage von geteilten Werten sowie die Förderung bestimmter Vorstellungen des Guten unterläuft die liberale Forderung nach der Neutralität des Staates. Angesichts der in modernen Gesellschaften bestehenden Pluralität von miteinander rivalisierenden Vorstellungen des Guten kann das Eintreten des Staates für die eine oder andere Konzeption des guten Lebens, auch dann wenn sie von der Mehrheit geteilt wird, zur Diskriminierung von Randgruppen und von einzelnen Individuen führen. Die Gesellschaft sollte daher von Gerechtigkeitsprinzipien regiert werden, die weitgehend unabhängig von jeder besonderen Konzeption des Guten sind. ${ }^{59}$ Gerade deshalb wird dem Staat die Aufgabe zuerkannt, einen neutralen Rahmen zu schaffen, der es jedem Individuum erlaubt, seine eigene Konzeption des guten Lebens zu verfolgen. ${ }^{60}$ Jede dieser Ansicht widersprechende Konzeption würde das universell unbegründbare Privileg implizieren, dass manche zur Erkenntnis der menschlichen Zielsetzungen mehr prädestiniert oder befähigt seien als andere. ${ }^{61}$

\section{Kritik am Romantizismus des Kommunitarismus}

Mögliche negative Konsequenzen einer stärkeren Gemeinschaftsausrichtung werden im Kommunitarismus jedoch weitgehend ausgeklammert. Schon die zugrunde liegende Vorstellung der Gemeinschaft trägt Züge der politischen und sozialen Romantik, indem sie zu einem irreführenden Bild der Gemeinschaften führt. ${ }^{62}$ Der undifferenzierte Umgang mit den verwendeten historischen Beispielen, wie den antiken griechischen demokratischen Republiken, mittelalterlichen jüdischen Ghettos, oder den puritanischen Siedlungen im

58 Vgl. Waltermann (1997), 67.

59 Vgl. Rawls (1998), 487 f.

60 Vgl. Popper (1992a), 197; Kymlicka (1992), 165.

61 Vgl. Doering (1997), 35; Koller (1993), 79.

62 Vgl. Reese-Schäfer (1994), 161; Kymlicka (1993), 210; Phillips (1993), 194; Zahlmann (1992), 13. 
Neuengland des 18. Jahrhunderts trägt zu einer Idealisierung und Verklärung der Vergangenheit bei. ${ }^{63}$ Gemeinschaften waren und sind keine einheitlichen Gebilde, sondern zumeist hierarchisch strukturiert. „Statt vorrangig durch Gemeinsinn, Teilnahme und Solidarität ausgezeichnet zu sein, waren sie mindestens ebenso durch die Gegensätze, Repression und Konflikte charakterisiert, die zu hierarchischen Machtgebilden gehören, handle es sich nun um eine patriarchale Familie, einen kastenartig strukturierten Stamm, ein feudales Gemeinwesen oder um eine durch Klassenspaltungen zerrissene Nation." "64

Unberücksichtigt bleibt im Kommunitarismus etwa die Tatsache, dass die Legitimität der Verfolgung gemeinsamer Ziele, eines gemeinsamen Guten viele Teile der Bevölkerung ausschließt, die vom rassistischen und sexistischen Gemeinwohl nicht überzeugt wären. Dabei ist die Exklusion bestimmter Gruppen nicht willkürlich, sondern durch die Definition des Gemeinwohls bestimmt. D.h. die Ziele selbst sind meist sexistisch oder rassistisch geprägt. Sie werden von bestimmten Bevölkerungsteilen definiert, um deren Interessen zu dienen. ${ }^{65}$ Weiters wird übersehen, dass Zugehörigkeit nicht immer positiv sein muss und der Wunsch der Mitglieder, einer Gemeinschaft verbunden zu bleiben oder dieser zu entkommen, von der jeweiligen politischen, sozialen und ökonomischen Situation der Gruppe abhängt. ${ }^{66}$

Eine weitere Kehrseite des Bezugs auf Gemeinschaften liegt darin, dass sich diese durch Grenzen bestimmen und damit eine Abgrenzung und Differenz, eine Unterschiedlichkeit schaffen, die auch Ausschluss bedeuten kann. Durch die Verbindung zwischen der Partikularität der kontingenten Güterordnung von Gemeinschaften und dem universellen Geltungsanspruch, mit dem sie aufzutreten pflegen, besteht die Gefahr eines militanten Ethnozentrismus, dem alles Andere und Fremde minderwertig erscheint. ${ }^{67}$ Neben der Isolierung von der Außenwelt finden sich dabei auch eine Immunisierung gegenüber Kritik und damit die Dogmatisierung gewisser Glaubensbestände, Traditionen, Normen, Werte oder Praktiken. 
Gerade enge Gemeinschaftsformen besitzen die Tendenz, sich nach außen hin abzuschließen und so kleine geschlossene Inseln in einer ansonst offenen Gesellschaft zu bilden, in denen sich dogmatische und irrationale Restbestände erhalten können. ${ }^{68}$

Zwar sollte die kommunitaristische Revitalisierung der Gemeinschaften nicht als Aufruf zur Rückkehr zu einem hierarchisch organisierten und bedrückenden Provinzialismus traditioneller Gemeinschaften missverstanden werden, die durch autoritäre Machtstrukturen, Schichtungen und einen diskriminierenden Umgang mit Minderheiten und Frauen gekennzeichnet waren. ${ }^{69}$ Es lässt sich durchaus einräumen, dass im Kommunitarismus bestimmte Gruppen nicht zur Sicherung der Legitimität und des gemeinschaftlichen Zusammenhalts ausgeschlossen werden sollen. Vielmehr wird von der Möglichkeit ausgegangen, gemeinschaftliche Praktiken, Ziele und Werte zu finden, die von allen als Grundlage für eine Politik des Gemeinwohls unterstützt werden können. Jedoch bleiben die kommunitaristischen Ausführungen konkrete Beispiele schuldig, die über die in liberalen Gesellschaften gegebene Absicherung der individuellen Freiheit und der sozialen Sicherheit, sowie die zur Verfügung gestellten öffentlichen Gütern hinausgehen würden. Dies sieht Will Kymlicka im Umstand begründet, dass es diese einfach nicht gibt. ${ }^{70}$

Zusammenfassend lässt sich feststellen, dass die Stärkung traditioneller und gemeinschaftlicher Praktiken und Vorurteile nicht die Lösung für das Problem des Ausschlusses bisher marginalisierter Gruppen sein kann, sondern vielmehr selbst damit verbunden ist. ${ }^{71}$ Durch sie würden den marginalisierten Gruppen eine von anderen entworfene Identität und damit eine fremdbestimmte Rolle aufgezwungen. ${ }^{72}$ Die Einflussnahme des Staates auf bestimmte Gemeinschaften und Werte würde dieses Problem der marginalisierten Gruppen noch verstärken, weil gerade jene Konzeptionen des guten Lebens unterstützt würden, die von einer Mehrheit geteilt werden. Trotz aller versuchter Abgrenzung vom Konservativismus scheint die kommunitaristische Gemeinschaftskonzeption reaktionär-

$68 \mathrm{Vgl}$. Hacohen (2000), $426 \mathrm{f}$.

69 Vgl. Bell (1993), 114, Fußnote 7; Etzioni (1997), 178; Tam (1998), 33 f.

70 Vgl. Kymlicka (1997), 194 f.; Phillips (1993), 149.

71 Vgl. Benhabib (1993), 97.

72 Vgl. Kymlicka (1989), 90; Kymlicka (1997), 194 f. 
utopische Konsequenzen zu implizieren. ${ }^{73}$ Demgegenüber gibt die Neutralität des Staates den benachteiligten Gruppen eine größere Chance, ihre Werte durchzusetzen, indem sie diese nicht den in der Gesellschaft vorherrschenden Lebensformen unterwirft. ${ }^{74}$

Des Weiteren scheint der Kommunitarismus den modernen Denk- und Lebensverhältnissen nicht angemessen und der Realität moderner pluralistischer Gesellschaften und deren rapidem sozialen Wandel nicht gerecht werden zu können. ${ }^{75}$ Angesichts der Pluralität von Wertvorstellungen in modernen Gesellschaften ist die Berufung auf gemeinschaftlich geteilte moralische Standards und Ziele wenig realistisch. Moderne Gesellschaften beinhalten eine Vielzahl unterschiedlicher Lebensweisen und -formen, sowie unterschiedliche Gemeinschaften und Kulturen. Sie lassen sich als dynamische Gebilde verstehen, die sich nicht nur ständig in Veränderung befinden, sondern denen auch ein gehöriges $\mathrm{Ma}$ an Komplexität, Inhomogenität und Disharmonie inhärent ist. ${ }^{76}$ Die Individuen stimmen, wie Paul Drechsel in seiner Theorie der cross-cutting cleavages herausgearbeitet hat, in Bezug auf einen Teil ihrer Identität überein, während sie in Bezug auf einen anderen Teil eine gegensätzliche Position einnehmen. Zwei Individuen können etwa ein und derselben Religionsgemeinschaft angehören und doch zu vollkommen unterschiedlichen politischen Parteien gehören. Es bildet sich ein dicht verschlungenes, verwebtes und verknotetes Beziehungsnetz von Identitäten und Diversitäten. ${ }^{77}$ Auf der gesellschaftlichen Mikroebene kommt es in Beziehungen zwischen den zahllosen Kollektiven, wie den Familien, den Religionsgemeinschaften, den Vereinen, den Ortsgemeinden, zu Konflikten aufgrund divergierender Werte und Interessen. ${ }^{78}$ Die Menschen sehen sich mit heterogenen Traditionen, Gemeinschaften und sozialen Praktiken konfrontiert. Sie sind Mitglieder verschiedener Gemeinschaften, die teilweise unvereinbare Ansprüche stellen, so dass die Verpflichtungen gegenüber diesen Ansprüchen in Konflikt miteinander geraten können. Die Individuen finden sich nicht selten in der Situation, zwischen verschiedenen

73 Vgl. Steinfath (1992), 91.

74 Vgl. Kymlicka (1992), 179-182; Kymlicka (1997), 196.

75 Vgl. Koller (1993), 80.

76 Vgl. Holenstein (2006), 180.

77 Vgl. Drechsel, (1999), 200.

78 Vgl. Obendörfer (1997), 54 f. 
Verpflichtungen wählen zu müssen. Dabei bleibt es letztlich ihnen selbst überlassen, welchem Wert- und Sinnangebot sie folgen wollen, welchen Interessen sie Vorrang einräumen. ${ }^{79}$

Es ist daher mehr als fraglich, ob eine umfassende gemeinsame Basis von Werten und geteilten Überzeugungen, wie sie im Kommunitarismus vorausgesetzt wird, überhaupt noch existiert. ${ }^{80}$ Schließlich wird auch von kommunitaristischer Seite zugestanden, dass die heutigen Gemeinschaftsformen im Gegensatz zu den traditionellen, totalen Gemeinschaften, die geographisch gebunden waren und eine monopolistische Macht über ihre Mitglieder ausübten, begrenzt sind, und zwar sowohl was ihre Ausdehnung als auch ihren Einflussbereich angeht. ${ }^{81}$ Keine kommunitaristische Position kann daher auf der Basis einer einzigen Gemeinschaft aufgebaut werden, die exklusiv die Angelegenheiten ihrer Mitglieder bestimmt. ${ }^{82}$ Vielmehr muss auch hier von einer Pluralität von Gemeinschaften ausgegangen werden, denen der Mensch angehört, in deren Schnittpunkt er steht. ${ }^{83}$ Wie es innerhalb der empirisch vorfindbaren unterschiedlichen und häufig mit einander in Konflikt stehenden Werte, Normen und Zielen dieser Kollektive möglich sein soll, verbindliche Gemeinschaftswerte, -normen und -ziele für moderne Gesellschaften zu bestimmt und zu legitimieren, bleibt offen. ${ }^{84}$ Der kommunitaristische Versuch, aus dem romantisch verzerrten Bild von prämodernen integrierten Gemeinschaften aus der Vergangenheit ein Modell für heutige Gesellschaften zu schaffen, ist daher nicht nur anachronistisch, sondern zum Scheitern verurteilt. ${ }^{85}$

\section{Schlusswort}

Ohne den Kommunitarismus als konservative, autoritäre oder gar totalitäre Ideologie einzustufen, legen die bisherigen Ausführungen gegenüber dieser Denkströmung eine skeptische Haltung nahe. Die kritische Distanz liegt nicht so sehr in der Differenz bezüglich der

79 Vgl. Fink-Eitel (1993), 308.

80 Vgl. Phillips (1993), 151-153.

81 Vgl. Etzioni (1997), 175.

82 Vgl. Tam (1998), 226.

83 Vgl. Bell (1993), 91.

84 Vgl. Obendörfer (1997), 54 f.

85 Vgl. Gewirth (1996), 82. 
Problemlagen liberaler Gesellschaften begründet, sondern in den Konsequenzen und der mangelnden Realitätsnähe der kommunitaristischen Sichtweise. Der Versuch die negativ erlebten Folgen von modernen, liberalen Sozialbeziehungen aufzuheben, indem wir zu einem status quo ante zurückkehren, sei dieser nun real oder imaginiert, scheint ebenso wenig akzeptabel, wie die vom Kommunitarismus geforderten Umkehrungen „der Zerrissenheit und Gleichgültigkeit abstrakter, gesellschaftlicher Beziehungen in die innige Einheit leibhaft konkreter Gemeinschaft; des Vorrangs des universellen, gesellschaftlichen Gerechten in den Vorrang des partikularen, gemeinschaftlichen Guten; des Vorrangs des isolierten Individuums vor der Gemeinschaft in den Vorrang des gemeinschaftlichen Ganzen vor dem Individuum. " 86

Eine ähnlich skeptische Position lässt sich auch gegenüber der Forderung nach einer Stärkung der Religion in modernen liberalen Gesellschaften einnehmen. Dabei kann die Kritik daran in manchen Punkten mit jener am Kommunitarismus parallel laufen. Einerseits kann auch dieser Forderung entgegen gehalten werden, dass sie nur allzu leicht die möglicherweise damit verbundenen negativen Folgen außer Acht lässt. Diese können in der Erhöhung des Konfliktpotentials durch die Stärkung religiöser Gruppen, deren Absolutheitsansprüche einander letztlich ausschließen, ebenso liegen, wie in der Unterdrückung von Individuen und Randgruppen aufgrund religiöser Vorstellungen und Normen. Gerade religiös bestimmte moralische Standards und Praktiken werden durch den damit verbundenen Anspruch auf Absolutheit und Gewissheit oft ohne hinreichende Berücksichtung der sich daraus ergebenden Konsequenzen durchgesetzt. Andererseits kann gegenüber den universalistischen Ansprüchen von Religionen auf die Pluralität von modernen Gesellschaften verwiesen werden. Bei diesen handelt es sich um hochgradig differenzierte, komplexe und pluralistisch verfasste Sozialsysteme, in denen eine Vielzahl von Religionsgemeinschaften, Wertordnungen, Lebensausrichtungen und Überzeugungen im ständigen Wettbewerb miteinander stehen. Aus diesem Grund lässt sich nicht nur die Möglichkeit der Integration offener Gesellschaftsformen durch die Religion bezweifeln. ${ }^{87}$ Vielmehr ist die Auszeichnung und Durchsetzung 
einer bestimmten religiösen Ausrichtung mit der Pluralität sowie mit der individuellen Autonomie nicht vereinbar und daher abzulehnen. Dies spricht dafür, die Religion als Privatangelegenheit zu betrachten. Sie ist nicht nur aufgrund säkularer Verfassungen und der geforderten Neutralität in Wertfragen soweit als möglich aus dem staatlichen Bereich herauszuhalten, sondern auch in der Gesellschaft sollte ihr keine allzu dominante Rolle zukommen. Zwar ist den religiösen Gemeinschaften innerhalb einer liberalen Gesellschaft eine relative Autonomie zuzugestehen, solange sich diese innerhalb des gesetzlichen Rahmens bewegen. Zugleich muss sich der Staat das Recht zur Intervention vorbehalten, wenn die Gemeinschaften ihre Mitglieder davon abhalten, voll an der Gesellschaft zu partizipieren. Dies ist auch dort der Fall, wo interne religiöse Praktiken geschlechtliche oder rassistische Diskriminierung hervorbringen bzw. verstärken. Die Frage, wann eine solche Intervention notwendig wird, ist in der jeweiligen Situation und aufgrund der Erfahrungen einer Gesellschaft zu entscheiden.

Den Hoffnungen auf eine Entsäkularisierung moderner, liberaler Gesellschaften ist damit ebenso eine Absage zu erteilen wie allzu engen Gemeinschaftsbildungen. Beide Konzepte scheinen modernen liberalen Gesellschaften nicht gerecht zu werden, sondern ein Schritt zurück zu sein in eine Vergangenheit, die unwiderruflich verloren ist. Wo sich die traditionalen Zusammenhänge aufgelöst haben, muss die Gesellschaft neu erfunden werden. Die Integration erfolgt hier nicht durch den Versuch, den Aufbruch der Individuen zurückzudrängen, sondern über die Akzeptanz der durch die Moderne geschaffenen Situation. Im Sinne einer Flucht nach vorne wird damit bewusst an die bestehende Problemlage moderner Gesellschaften angeknüpft und angesichts der drängendsten Zukunftsfragen versucht, neue, politisch offene Bindungs- und Bündnisformen zu schmieden, in denen in offenen Prozessen nach den besten Problemlösungen gesucht wird. Nachtraditionale Gesellschaften können, wie Ulrich Beck und Elisabeth Beck-Gernsheim betonen, nur im Experiment ihrer Selbstdeutung, Selbstbeobachtung, Selbstöffnung, Selbstfindung, ja Selbsterfindung integriert werden. ${ }^{88^{*}}$

88 Vgl. Beck/Beck-Gernsheim (1994), 35 f.

* Die Arbeit an diesem Beitrag wurde möglich durch die finanzielle Unterstützung des Fonds zur Förderung der wissenschaftlichen Forschung (FWF) im Rahmen des Projektes P 18884-G15. 


\section{Literatur}

Alt, Jürgen A. (1992): Karl R. Popper. Frankfurt am Main: Campus. Albert Hans (51991): Traktat über kritische Vernunft. Tübingen: Mohr. Barber, Benjamin R. (1994): „Strong Democracy“, in: Daly, Markate, Hg.: Communitarianism. A New Public Ethics. Belmont: Wadsworth, 213-224.

Beck, Ulrich/Beck-Gernsheim, Elisabeth (1994): „Individualisierung in modernen Gesellschaften. Perspektiven und Kontroversen einer subjektorientierten Soziologie“, in: Beck, Ulrich/Beck-Gernsheim, Elisabeth, Hg.: Riskante Freiheiten. Frankfurt am Main: Suhrkamp, 10-39.

Beck, Ulrich (1996): „Was hält moderne, individualisierte Gesellschaften zusammen?", in: Voss, Günter/Pongratz, Hans J./Bolte, Karl Martin/Beck, Ulrich: Subjektorientierte Soziologie. Karl Martin Bolte zum 70. Geburtstag. Opladen: Leske \& Budrich, 223-241.

Bell, Daniel (1993): Communitarianism and its Critics. Oxford: Clarendon Press. Bellah, Robert/Madsen, Richard/Sullivan, William/Swidler, Ann/Tipton, Stephen (1987): Gewohnheiten des Herzens. Köln: Bund-Verlag.

Bellah, Robert/Madsen, Richard/Sullivan, William/Swidler, Ann/Tipton, Stephen (1992): „Gegen die Tyrannei des Marktes“, in: Zahlmann, Christel, Hg.: Kommunitarismus in der Diskussion. Eine streitbare Einführung. Berlin: Rotbuch Verlag, 57-73.

Benhabib, Seyla (1993): „Demokratie und Differenz. Betrachtungen über Rationalität, Demokratie und Postmoderne“, in: Brumlick, Micha/Brunkhorst, Hauke, Hg.: und Gerechtigkeit. Frankfurt am Main: Fischer, 97-116.

Der Standard (2009): „Zahl der Kirchenaustritte steigt weiter“, in: Der Standard, 13. Jänner 2009, online unter: http://derstandard.at/? id=1231151695806\&sap=2\&_pid=11729769 (Zugriff am 8.4.2009).

Drechsel, Paul (1999): „Paradoxien interkultureller Beziehungen“, in: Cesana, Andreas, Hg.: Interkulturalität. Grundprobleme der Kulturbegegnung. Mainz: Universität Mainz, 173-212.

Doering, Detmar (1997): „Alte Gefahr in neuem Gewande? Liberalismus, Kommunitarismus und kein Ende der Geschichte..." in: Chatzimarkakis, Georgios/Hinte, Holger, Hg.: Freibeit und Gemeinsinn - Vertragen sich Liberalismus und Kommunitarismus?. Bonn: Lemmens, 24-46.

Elshtain, Jean (1995): „In Common Together: Unity, Diversity, and Civic Virtue", in: Walzer, Michael, Hg.: Toward a Global Civil Society. Oxford/Providence: Berghahn Books, 77-98.

Etzioni, Amitai (1995): Die Entdeckung des Gemeinwesens. Ansprüche, Verantwortlichkeiten und Programm des Kommunitarismus. Frankfurt am Main: Fischer.

Etzioni, Amitai (1997): Die Verantwortungsgesellschaft: Individualismus und Moral in der heutigen Demokratie. Berlin: Ullstein.

Fach, Wolfgang (1992): „Der zeuge Tocqueville“, in: Zahlmann, Christel, Hg.: Kommunitarismus in der Diskussion. Eine streitbare Einfübrung. Berlin: Rotbuch Verlag, 42-47. 
154 Offene Gesellschaft und geschlossene Gemeinschaft

Fink-Eitel, Hinrich (1993): „Gemeinschaft als Macht. Zur Kritik des Kommunitarismus", in: Brumlick, Micha/Brunkhorst, Hauke, Hg.: Gemeinschaft und Gerechtigkeit. Frankfurt am Main: Fischer, 306-322.

Gewirth, Alan (1996): The Community of Rights. Chicago: University of Chicago Press.

Hacohen, Malachi Haim (2000): Karl Popper. The Formative Years 1902-1945. Politics and Philosopby in Interwar Vienna. Cambridge: Cambridge University Press.

Holenstein, Elmar (2006): „Komplexe Kulturen“, in: Yousefi, Hamid Reza/Fischer, Klaus/Braun, Ina, Hg.: Wege zur Philosophie. Grundlagen der Interkulturalität. Nordhausen: Traugott Bautz, 175-196.

Honneth, Axel (1993): „Einleitung“, in: Honneth, Axel, Hg.: Kommunitarismus. Eine Debatte über die moralischen Grundlagen moderner Gesellschaften. Frankfurt am Main: Campus, 7-17.

Joas, Hans (1993): „Gemeinschaft und Demokratie in den USA - Die vergessene Vorgeschichte der Kommunitarismus-Dikussion“, in: Brumlick, Micha/Brunkhorst, Hauke, Hg.: Gemeinschaft und Gerechtigkeit. Frankfurt am Main: Fischer, 49-62.

Kallscheuer, Otto (1992): „Gemeinsinn und Demokratie. Hinter dem Etikett »Kommunitarismus « verbirgt sich eine Debatte um das Selbstverständnis der USA“, in: Zahlmann, Christel, Hg.: Kommunitarismus in der Diskussion. Eine streitbare Einfübrung. Berlin: Rotbuch Verlag, 109-117.

Kallscheuer, Otto (1995): „On Labels and Reasons: The Communitarian Approach - Some European Comments", in: Walzer, Michael, Hg.: Toward a Global Civil Society. Oxford/Providence: Berghahn Books, 133-145.

Kautz, Steven (1995): Liberalism and Community. Ithaca, NY: Cornell University Press.

Koller, Peter (1993): „Gemeinschaft und Gerechtigkeit im Disput zwischen Liberalismus und Kommunitarismus", in: Balog, Andrea/Schülein, Johann A., Hg.: Soziologie und Gesellschaftskritik. Beiträge zum Verbältnis von Normativität und sozialwissenschaftlicher Analyse. Wien: VWGÖ-Verlag, 75109.

Kymlicka, Will (1989): Liberalism, Community and Culture. Oxford: Clarendon Press.

Kymlicka, Will (1992): „Liberal Individualism and Liberal Neutrality”, in: Avineri, Shlomo/de-Shalit, Avner: Communitarianism and Individualism. Oxford: Oxford University Press, 165-185.

Kymlicka , Will (1993): „Appendix 1: Some Questions about Justice and Community", in: Bell, Daniel: Communitarianism and its Critics. Oxford: Clarendon Press, 208-221.

Kymlicka, Will (1997): Politische Philosophie heute. Eine Einführung. Frankfurt am Main: Campus. 
Lasch, Christopher (1995): Die blinde Elite: Macht obne Verantwortung. Hamburg: Hoffmann und Campe.

MacIntyre, Alasdair (1993): „Ist Patriotismus eine Tugend?“, in: Honneth, Axel, Hg.: Kommunitarismus. Eine Debatte über die moralischen Grundlagen moderner Gesellschaften. Frankfurt am Main: Campus, 84-102.

MacIntyre, Alasdair (21997): Der Verlust der Tugend. Frankfurt am Main: Suhrkamp.

Magee, Bryan (1982): Philosophy and the real world. An Introduction to Karl Popper. La Salle, Illinois: Open Court.

Obendörfer, Dieter (1997): ,Zwischen ,political correctness“ und kommunitaristischer ,Gemeinschaft ${ }^{\star}$ - Der Fall Amerika“, in: Chatzimarkakis, Georgios/Hinte, Holger, Hg.: Freiheit und Gemeinsinn - Vertragen sich Liberalismus und Kommunitarismus?. Bonn: Lemmens, 47-64.

Phillips, Derek L. (1993): Looking Backward. A Critical Appraisal of Communitarian Thought. Princeton: Princeton University Press.

Popper, Karl Raimund (71992a): Die offene Gesellschaft und ibre Feinde Bd. I, Der Zauber Platons. Tübingen: Mohr.

Popper, Karl Raimund (71992b): Die offene Gesellschaft und ibre Feinde Bd. II, Falsche Propheten: Hegel, Marx und die Folgen. Tübingen: Mohr.

Popper, Karl Raimund (2008.): After The Open Society. Selected Social and Political Writings (Shearmur, Jeremy/Turner, Piers Norris, ed.). London: Routledge.

Rapport, Nigel (2005): „Introduction: The Moral Implications of Science“, in: Rapport, Nigel, Hg.: Anthropological Journal on European Cultures. Democracy, Science and the ,Open Society'. A European Legacy?. Münster: Lit Verlag, 1-32.

Raulet, Gérard (1993): „Die Modernität der ,Gemeinschaft““, in: Brumlick, Micha/Brunkhorst, Hauke, Hg.: Gemeinschaft und Gerecbtigkeit. Frankfurt am Main: Fischer, 72-93.

Rawls, John (101998): Eine Theorie der Gerechtigkeit. Frankfurt am Main: Suhrkamp.

Reese-Schäfer, Walter (1994): Was ist Kommunitarismus? Frankfurt am Main: Campus.

Reese-Schäfer, Walter (1997): Grenægötter der Moral. Der neuere europäischamerikanische Diskurs zur politischen Ethik. Frankfurt am Main: Suhrkamp.

Riedel, Manfred (1975): „Gesellschaft, Gemeinschaft“, In: Brunner, Otto/Konze, Werner/ Kosellek, Reinhart, Hg.: Geschichtliche Grundbegriffe. Historisches Lexikon zur politisch-sozialen Sprache in Deutschland Bd. 2. Stuttgart: Klett-Cotta, 801-862.

Rosenblum, Nancy (1989): „Pluralism and Self-Defence”, in: Rosenblum, Nancy, Hg.: Liberalism and the Moral Life. Cambridge: Havard University Press, 207-226.

Salamun, Kurt (1993): „Befriedetes Dasein und Offene Gesellschaft. Gesellschaftliche Zielvorstellungen in Kritischer Theorie und Kritischem Ra- 
tionalismus“, in: Albert, Hans/Salamun, Kurt, Hg.: Mensch und Gesellschaft aus Sicht des kritischen Rationalismus. Amsterdam/Atlanta: Rodopi, 90-120.

Sandel, Michael (1982): Liberalism and the Limits of Justice. Cambridge: Cambridge University Press.

Sandel, Michael (1984): Liberalism and Its Critics. Oxford: Blackwell.

Sandel, Michael (1994): Liberalismus oder Republikanismus. Von der Notwendigkeit der Bürgertugenden. Wien: Passagen Verlag.

Soosten, Joachim von (1992): „Sünde und Gnade und Tugend und Moral. Die Erbschaft der religiösen Tradition“, in: Zahlmann, Christel, Hg.: Kommunitarismus in der Diskussion. Eine streitbare Einfübrung. Berlin: Rotbuch Verlag, 48-56.

Spinner, Helmut F. (1978): Popper und die Politik. Rekonstruktion und Kritik der Sozial-, Polit- und Geschichtsphilosophie des kritischen Rationalismus, Bd. I. Berlin/Bonn: Dietz.

Statistik (2009): Statistik Kirchenaustritte in Deutschland, online unter: http://www.kirchenaustritt.de/statistik/ (Zugriff am 8.4.2009).

Stelzer, Harald (2004), Karl Poppers Sozialphilosophie. Politische und ethische Implikationen. Wien: Lit-Verlag.

Sullivan, William M. (1994): „A Renewal of Civic Philosophy”, in: Daly, Markate, Hg.: Communitarianism. A New Public Ethics. Belmont: Wadsworth, 190-202.

Steinfath, Holmer (1992): „Der Verlust der Identität“ in: Zahlmann, Christel, Hg: Kommunitarismus in der Diskussion. Eine streitbare Einfübrung. Berlin: Rotbuch Verlag, 86-93.

Tam, Henry (1998): Communitarianism. New York/London: New York University Press.

Tiefel, Thomas (2003): Von der Offenen in die Abstrakte Gesellschaft. Ein interdisriplinärer Entwurf. Berlin: Duncker \& Humblot.

Tönnies, Ferdinand (81937): Gemeinschaft und Gesellschaft. Grundbegriffe der reinen Soziologie. Darmstadt: Wissenschaftliche Buchgesellschaft.

Topitsch, Ernst (1979): Erkenntnis und Illusion. Grundstrukturen unserer Weltauffassung. Hamburg: Hoffmann und Campe.

Waltermann, Jens (1997): „Warnung vor aufgedrängter Gemeinschaft - Ein Zuruf auf der neuen Welt (des Kommunitarismus)“, in: Chatzimarkakis, Georgios/Hinte, Holger, Hg.: Freiheit und Gemeinsinn - Vertragen sich Liberalismus und Kommunitarismus?. Bonn: Lemmens, 65-76.

Wellmer, Albrecht (1993): „Bedingungen einer demokratischen Kultur. Zur Debatte zwischen Liberalen und Kommunitaristen“, in: Brumlick, Micha/Brunkhorst, Hauke, Hg.: Gemeinschaft und Gerechtigkeit. Frankfurt am Main: Fischer, 173-196.

Zahlmann, Christel (1992): „Einleitung“, in: Zahlmann, Christel, Hg.: Kommunitarismus in der Diskussion. Eine streitbare Einführung. Berlin: Rotbuch Verlag, 7-15. 


\title{
Gemeinschaft nach der Gemeinschaft
}

\author{
Evert van der Zweerde
}

\author{
„We live in a political world, \\ Love don't have any place." \\ Bob Dylan, Political World (1989) ${ }^{1}$
}

\begin{abstract}
„Zwar ist das Wir empirisch immer begrenzt: Jedem Wir [...] steht etwas anderes, nicht zu ihm Geböriges gegenüber - irgendwelche Ihr oder Sie."

Semën Frank, Die geistigen Grundlagen der Gesellschaft (1930)²
\end{abstract}

\section{Zur Einleitung ${ }^{3}$}

Das offensichtliche Bedürfnis nach Gemeinschaft, oft einhergehend mit einer gewissen Nostalgie und gleichzeitigen Furcht vor der Idee einer geschlossenen ,traditionellen“ Gemeinschaft und mit noch größerer Abscheu vor jenen totalitären Ideologien, die in Vergangenheit (Khmer Rouge in Kambodscha) und Gegenwart (Taliban in Afghanistan) für sich beansprucht haben, die gute und gerechte Gemeinschaft zu vergegenwärtigen, nötigt zum neuen Überdenken des Begriffs. Dieser Aufsatz ist einem solchen Überdenken gewidmet: er versucht einen offenen Begriff von Gemeinschaft zu entwickeln, der an bestehende Diskussionen anschließt und sich gleichzeitig auf alltägliche Erfahrung stützt und diese philosophisch reflektiert.

Die erste Fassung dieses Aufsatzes entstand während einer langen Zugfahrt. Wie bei langen Zugfahrten üblich, kamen Reisende ins Abteil, teilten den Raum mit mir und gingen dann wieder. Einige versuchten mit mir ins Gespräch zu kommen, während ich mir Mühe gab mich auf meine Arbeit zu konzentrieren. Das gelang mir nur teilweise, was zu einer ersten Intuition bezüglich meines Themas

1 Bob Dylan, 'Political World', Album No Mery (1989), track 1.

2 Frank (2002), 136.

3 Bei dieser Gelegenheit möchte ich meinen Kollegen Inigo Bocken, Tim Houwen, Machiel Karskens, Josephien van Kessel, Marin Terpstra und Paul van Tongeren für ihre Anregungen zum vorliegenden Aufsatz danken. 
Gemeinschaft führte: wir Menschen sind keine abgeschlossenen, sondern „offene" Wesen.

Meine Fahrt führte mich durch Länder, deren Sprache ich zwar verstehe, die aber nicht meine eigene, nicht meine Muttersprache, ist, und ich traf im Zug auch auf Menschen, mit denen ich mich nur unterhalten konnte, indem wir uns auf eine dritte, für beide fremde Sprache einigten. Zweite Intuition: für die Kommunikation zwischen Menschen ist nicht ausschlaggebend, dass wir dieselbe eigene Sprache sprechen, sondern dass wir sprachliche Mittel finden, mit denen wir uns verständigen können.

Gegen Ende der Fahrt war ich Zeuge eines Gesprächs zwischen zwei Frauen, die eine wohl eine Österreicherin, die andere ,,ausländisch“, die einander offensichtlich zum ersten Mal begegneten. Sie gingen schnell zu persönlichen Themen über (Arbeitsverhältnisse, Beziehung, Kinder) und waren sehr in das Gespräch vertieft. Als die eine das Abteil verließ, fragte sie: „Wie heißen Sie?“ „Sonja. Und Sie?" „Alba“. Mit einem kurzen Lächeln verabschiedeten sie sich, vermutlich um sich nie wieder zu sehen. Dritte Intuition: elementare Formen von Gemeinschaft bilden sich an jedem Ort und zu jeder Zeit, und ihr Zweck ist nicht unbedingt die Herstellung einer dauerhaften Verbindung.

Was bedeuten diese alltäglichen Erfahrungen für die sozialphilosophische Diskussion zum Thema Gemeinschaft? Also für eine Diskussion, in welcher die Idee der Gemeinschaft üblicher Weise dem Begriff der Gesellschaft gegenübergestellt wird, wobei die zwei mit Gegensätzen wie klein/groß, natürlich/künstlich, innerlich/äußerlich, organisch/mechanisch, traditionell/modern, Dorf/Stadt, oder sogar Heimat/Globalisierung, verbunden werden, mit der Folge, dass Gemeinschaftsdenken, etwa in Form des Kommunitarismus, meistens konservativ oder sogar reaktionär anmutet (oder die Gegenwart überspringt in Richtung einer utopischen Zukunft)? Die Frage nach Gemeinschaft wird mit Vorstellungen einer traditionellen, übersichtlichen, relativ kleinen und homogenen sozialen Umgebung verbunden (ein wesentlicher Teil der Tourismus-Industrie lebt von dieser Nostalgie). Gemeinschaft und Gemeinschaftssinn sind dann ein Zustand und eine Haltung, die eher der Vergangenheit angehören als der Gegenwart, oder die in entlegenen Winkeln vor einer sich ausdehnenden Weltgesellschaft und -wirtschaft geschützt werden müssen. Oder sie werden von bestimmten Gruppen in der modernen Gesell- 
schaft angestrebt und können dann zu neuen Formen der AusschlieBung führen: „The ideal of community validates and reinforces the fear and aversion some social groups exhibit toward others." ${ }^{\text {Wie }}$ kann Gemeinschaft gedacht werden obne in solchen reaktionären bzw. utopischen Gemeinschaftsphantasien zu enden? Das ist die zentrale Frage dieses Aufsatzes.

Die Ausgangspunkte dieses Aufsatzes sind, erstens, dass die Identifizierung von Gemeinschaft (im unbestimmten Singular) mit vergangenen, bestehenden oder künftigen Gemeinschaften (im bestimmten Plural) unbegründet ist. Es geht vielmehr darum, Gemeinschaft in einer konkreten Allgemeinheit zu denken, d.h. als eine Form des menschlichen Zusammenlebens, die weder notwendigerweise zur ,bestimmten Gemeinschaft“ führen muss, noch von ihr erschöpft wird. Weiters wird davon ausgegangen, dass ein Trugschluss vorliegt, wenn Gemeinschaft - in einer auf Ferdinand Tönnies zurückgehenden Tradition - im Gegensatz zu einer sich ausdehnenden Gesellschaft gedacht wird, besonders dann, wenn sie als „Insel des guten Lebens" in einer sonst unheimlichen Welt erscheint. Es geht vielmehr darum, Gemeinschaftlichkeit und Gesellschaftlichkeit als zwei Dimensionen des menschlichen Zusammenlebens zu denken, die einander nur dann ausschließen, wenn sie jeweils zur „einzig wahren" verabsolutiert werden. Dritter Ausgangspunkt ist, dass es eine weitere Dimension des menschlichen Zusammenlebens gibt, die man als die Dimension des Politischen, d.h. des immer möglichen Konflikts, deuten kann und die nicht von Gemeinschaft oder Gesellschaft endgültig aufgehoben oder pazifiziert werden kann. In der zurückkehrenden Opposition von Gesellschaft und Gemeinschaft zeigt sich gerade diese dritte Dimension: die Fragen des menschlichen Zusammenlebens sind wesentlich umstritten. Die bekannte Debatte zwischen Liberalen und Kommunitaristen ist beispielhaft für die „ewige" Kontroverse zwischen diesen drei Dimensionen. Es ist keineswegs zufällig, dass die Liberalismus-Kommunitarismus-Debatte allmählich von einer Debatte über die Rückkehr der Religion abgelöst worden ist: die Gegenüberstellung von säkularisierter Gesellschaft und Prozessen der Entsäkularisierung spiegelt die Differenz zwischen Gesellschaft, verstanden als Individualisierung, Säkularisierung und Veräußerlichung der menschlichen Beziehungen, und 
Gemeinschaft, identifiziert mit der Bindung innerhalb einer religiösen Gemeinschaft. ${ }^{5}$

Die allgemeine Hypothese dieses Aufsatzes lautet daher nicht nur, dass die drei erwähnten Dimensionen für ein vollständiges Begreifen der sozialen Realität erforderlich sind, sondern auch, dass jede der drei nur unter Berücksichtigung ihres Verhältnisses zu den anderen zwei verstanden werden kann. ${ }^{6}$ Die Begriffe „Gemeinschaftlichkeit“ (sobornost') und „Gesellschaftlichkeit“ (obschtschestvennost') sind Semën Frank entlehnt worden, für die Dimension des Politischen verwende ich einen Begriff von Jacques Derrida: Politizität (politicité). ${ }^{7}$ Mit diesen drei Begriffe, die alle zur Kategorie der -tät, -keit, -ity, -nost' und -ité Begriffe gehören, sind also Qualitäten oder Dimensionen gemeint, keine Dinge oder Substanzen.

In einem Kommentar zur Liberalismus-KommunitarismusDebatte meint David Miller, dass jede politische Theorie zwei analytisch voneinander zu unterscheidende Elemente enthält: „, [...] on the one hand a philosophical anthropology, a general account of the human person, of the conditions of moral agency, of the nature of human relationships, and so forth. On the other hand, [...] a set of prescriptive principles, principles specifying how social relationships are to be ordered, how the state is to be constituted and so on." Der vorliegende Aufsatz folgt diesem Muster. Im ersten Teil werde ich mein Augenmerk auf eine Anthropologie richten, die meines Erachtens für ein Denken von Gemeinschaft am ehesten angemessen ist: eine Anthropologie, die den Menschen statt als substantielle Einheit primär als Energie begreift. Im zweiten Teil werde ich, auf der Grundlage dieser Anthropologie, eine normative Konzeption der drei angedeuteten Dimensionen des menschlichen sozialen Seins ausarbeiten: Gemeinschaftlichkeit, Gesellschaftlichkeit, Politizität.

\footnotetext{
5 Zum Verstehen dieser Diskussionslage ist die Arbeit von Kristina Stöckl äußerst hilfreich gewesen; Stöckl (2008).

6 Ich führe damit einen Gedanken weiter, den ich in einem Aufsatz zu Semën Frank entwickelt habe: van der Zweerde (2008), 131-136.

7 Frank (1992), 54 [Deutsch: Frank (2002), 140], Derrida (1994), 137.

8 Miller (2000), 99.
} 


\section{Die energische Grundlage des sozialen Seins ${ }^{9}$}

Ein Mensch ist eine sich selbst behauptende, erhaltende und organisierende, relativ geschlossene Menge Energie, welche verschiedene Formen annimmt: körperliche Kraft und Wärme, erotische Erregung, intellektuelle Begeisterung, spirituelle Inspiration usw. Die energische Selbsterhaltung ist durch ein dynamisches Wechselverhältnis mit der Umgebung verbunden, von ihr abhängig, und von einer Dynamik von Offenheit und Geschlossenheit gekennzeichnet. Die Haut, als Membran der Interaktion mit der Umgebung (auch Lungen und Magen-Darm Trakt sind Haut), aber auch als Metapher der Verletzlichkeit („unter die Haut gehen“) bzw. des Schutzes („eine dicke Haut haben“), drückt diese fragile Dynamik vielleicht am deutlichsten aus. Das trifft nicht nur auf den natürlichen Stoffwechsel mit der Natur zu, sondern auch auf geistige Aktivität, bei der ich bestimmte Ideen aufnehmen kann (dafür also offen sein muss), für andere geschlossen bleibe und wieder andere nicht los werden kann. In allen Fällen habe ich es mit einem spezifischen, nie ganz geklärten Verhältnis des „für mich (Un)möglichen“ mit dem „,von mir Gewollten" zu tun, und in beiden Fallen stellt sich die Überschreitung als eine Möglichkeit dar, die ich sowohl ersehnen als auch fürchten kann: sich in etwas zu verlieren ist ultimatives Verlangen und ultimativer Schrecken zugleich (die Unterhaltungsindustrie lebt von dieser Spannung).

Diese Menge Energie organisiert sich um einen relativ stabilen, verletzlichen Kern, der sich als Ich andeutet und als Person zu begreifen ist. ${ }^{10}$ Es folgt aus dem Energie-Begriff, dass dieser Kern nicht Ursprung, sondern Resultat der Energiekonzentration ist. Die Tatsache, dass der Mensch dasjenige Lebewesen ist, das von sich selbst "Ich" sagt, heißt nicht, dass dieses Ich bereits anwesend ist - etwa als Seele - oder dass es sich selbst quasi vorfindet. Vielmehr entsteht dieses Ich in und durch die Schaffung (die Produktion und Repro-

9 Der Begriff energisch wird hier im Sinne der Definition von Sergej Khoruzhy verwendet. Dieser unterscheidet zwischen den Begriffen energetisch [russ. energeticheskij] im physikalischen Sinne und energisch [russ. energijnyj] im theologischen oder philosophischen Sinne. Der Begriff energisch leitet sich vom Konzept der Energie/energeia ab, und seine Bedeutung ist vom alltäglichen Gebrauch des Wortes „energisch“ zu unterscheiden. Auf dieselbe Art und Weise trifft Khoruzhy auch eine Unterscheidung zwischen synergetisch [russ. sinergeticheskij] und synergisch [russ. sinergijny]].

10 DeLanda (2006), 47. 
duktion) einer Beziehung, in der es sich als einen der beiden Pole selbst setzt, gegenüber einer alles andere umfassenden Wirklichkeit, zu der es sich verhält. Das, was jetzt von sich selbst sagt „Ich sitze am Schreibtisch“, ist nicht identisch mit dem Ich, das in diesem Satz beschrieben wird, denn mit Sätzen der Form „Ich bin...“, „Ich will...“, „Ich denke...“, aber auch der Form „Ich habe...“. „Ich gehe..." oder „Ich sitze..." wird jeweils zugleich etwas beschrieben und etwas gesetzt, das aus dieser Setzung erst hervorgeht: „Ich“ sagen heißt sich als Ich setzen. Eine Ich-Aussage, wie eine Wir-Aussage, ist zugleich konstativ und performativ. ${ }^{11}$ Dabei hat dieses Setzen nur dann einen Sinn, wenn es etwas gibt, z.B. einen anderen Menschen, zu dem ich mich in ein Verhältnis setze: die Bildung des Kerns ist mit dem Verhältnis zum Anderen also ko-originär. Das bedeutet, dass der substantiell verstandene Mensch, im Gegensatz zum energischen Menschen, ${ }^{12}$ Ergebnis und (Selbst-)Erzeugnis ist, nicht absoluter Ursprung: es gibt Freiheit, und es gibt Subjektivität, und die beiden sind die Bedingungen des autonomen Subjekts, nicht die Eigenschaften einer Substanz. Individuum zu sein heißt dann: nicht weiter aufteilbar zu sein ohne aufzuhören zu sein. Es heißt allerdings nicht, separat und in sich geschlossen zu existieren.

Diese relativ selbständige und sich erhaltende Menge Energie, die sich um einen Kern organisiert und sich als Ich setzt, kann sich auf viele verschiedene Weisen zu seiner Umgebung und zu anderen, ähnlichen Mengen verhalten. Für Menschen sind andere Menschen diejenigen Energie-Mengen, auf sie sich in einer Vielfalt von Formen am leichtesten (und am liebsten) beziehen. Einige dieser Formen, wie zum Beispiel Liebe oder Zusammenarbeit, werden positiv bewertet, andere, wie Hass oder Streit, negativ. Es ist aber wichtig zu betonen, dass jede dieser Formen ihre eigene Positivität hat, die der Bewertung vorangeht. Es geht darum, den Menschen als ein nach Außen offenstehendes Ganzes physischer und mentaler Energie zu denken, offen für Erfahrung, Wahrnehmung und Handeln, und offen für Beziehung auf und Verbindung mit anderen offenen Gebilden.

Ich denke, dass ein energisches Paradigma die beste begriffliche Grundlage bietet für eine Philosophie des sozialen Seins der Men- 
schen. Der Unterschied zwischen körperlicher und geistiger Energie ist dabei nicht ausschlaggebend - das Energie-Paradigma hat gerade den Vorteil, diesen Unterschied als einen relativen deuten zu können. Es denkt beide Formen von Energie zusammen und behauptet, dass im spezifisch menschlichen Dasein immer beide involviert sind (das gilt auch für spirituelle Praktiken: gerade Mystik oder Meditation haben eine körperliche Dimension). Die „ewige“ Frage nach dem Verhältnis zwischen dem Körperlichen und dem Geistigen lässt sich leichter lösen, wenn wir beide als Energie denken und, in beiden Fällen, einen Unterschied zwischen innerlicher und äußerlicher Wirkung machen: Körper und Geist sind beide sowohl nach Innen wie nach Außen gerichtet und lassen sich dadurch nicht als Innenwelt und Außenwelt voneinander trennen. Schreiben, was man denkt, zum Beispiel, ist Anwendung sowohl körperlicher wie geistiger Energie und wirkt sowohl nach Innen als auch nach Außen.

Die Selbständigkeit des Individuums ist reell, aber relativ: wir reden nicht nur von mehr und von weniger selbständigen Individuen, sondern wir erfahren auch uns selbst im einen Moment als mehr, im anderen Moment als weniger selbständig. Auch wenn es keinen Sinn hat, von einer Autonomie im absoluten Sinne zu sprechen (wovon etwa die Rede wäre, wenn die Vernunft alleine den menschlichen Willen bestimmen würde), so ist doch nicht zu verneinen, dass wir, in Bezug auf uns selbst und auf andere, den Unterschied zwischen größerer und geringerer Autonomie sinnvoll anwenden. Wer sagt "Ich wurde von meiner Angst geleitet, jetzt aber stehe ich dieser Entscheidung frei gegenüber", der mag sich zwar darin irren, dass er jetzt vollkommen frei von jeder hemmenden Emotion sei, nicht aber darin, dass er vorher stärker vom Gefühl der Angst bestimmt wurde als es jetzt der Fall ist. Die Selbständigkeit des Individuums ist nicht nur zeitlich und räumlich, sondern auch in sich begrenzt. So autonom zum Beispiel der freie Wille sein mag, er ist immer relativ in Bezug auf das, was gewollt wird - und es muss notwendig etwas gewollt werden. Es gibt im Menschlichen keine creatio ex nibilo, auch nicht im Denken, das sich immer solcher Begriffe bedient, die es nicht selber geschaffen hat. Weder dass ich denke, noch was ich denke, wird nur von mir bestimmt.

Ein weiterer Vorteil des energischen Paradigmas ist, dass es uns ermöglicht, Menschlichkeit in einem nicht a priori normativen Sinne zu verstehen. Menschen sind die, von mir als solche erkannte Entitäten, mit denen ich eine spezifische energische Ähnlichkeit habe, die 
sowohl ein synergisches wie ein ,antergisches"Verhältnis möglich macht. Das schließt keineswegs aus, dass ich mit anderen Entitäten, zum Beispiel mit Tieren, auch synergische oder antergische Verhältnisse haben kann, oder sogar mit Tieren menschliche Verhältnisse nachahmen kann. Es kann zwischen einem Menschen und einem Hund ein profundes Verhältnis der gegenseitigen Liebe und Treue geben, es scheint mir aber unmöglich, ein solches Verhältnis als gleichartig zu empfinden: der Hund erscheint für einen bestimmten Menschen eben als der bessere Freund, der nie enttäuschen wird, insofern man sich von den enttäuschenden Menschen abwendet. Aber wohl kein Mensch würde menschliche und tierische Freunde auf gleiche Art und Weise zu seinem Geburtstag einladen.

Schließlich macht das energische Paradigma es auch leichter, das spezifisch menschliche Phänomen der Religion zu verstehen. Die radikale Offenheit der menschlichen Person ist auch eine transzendentale, wobei jede Form von Religiosität und von „positiver“ Religion als Form des Umgangs mit dieser Offenheit gedeutet werden kann. Spiritualität, die in allen Religionen zu finden ist, ist dabei genauso eine Antwort auf diese Offenheit wie traditionelles Ritual oder religiöse Dogmatik.

Die Inspiration für dieses energische Paradigma, das ich ohne Anspruch auf Originalität vorschlage, kommt von zwei ganz unterschiedlichen Denkern, Sergei Khoruzhy und Manuel DeLanda. Khoruzhy hat, in einer Reihe von Arbeiten, den Versuch einer „synergischen Anthropologie (sinergiynaya antropologiya)" unternommen. ${ }^{13}$ Dabei ist er stark von der sogenannten palamitischen Strömung in der orthodox-christlichen Theologie beeinflusst worden und von der Idee der synergeia. Diese steht für das Mit-Wirken der menschlichen Energie mit der göttlichen, eine Idee, die sowohl in der politischen Theologie als auch in der hesychastischen Mystik der Ostkirche Anwendung fand. ${ }^{14}$ Ich möchte von dieser synergischen Anthropologie die Grundidee übernehmen, dass es von größter Bedeutung ist, das essentialistische Paradigma, das nach wie vor das philosophische Denken beherrscht, durch ein energisches Paradigma zu ersetzen. Khoruzhy konzentriert sich dabei auf solche Fälle, die man im existentia- 
len Sinne eher Grenzfälle bezeichnen muss und worin der Mensch auf eine anthropologische Schranke stößt.

Es geht Khoruzhy nicht um das gewöhnliche menschliche Dasein, sondern um eine Alternative für die heutige Situation der Welt und der Menschheit, die von ihm als krisenhaft und katastrophal gedeutet und mit einer „Erfahrung fundamentalen Unglücks" verbunden wird, allerdings ohne dass ihn das zu einer pessimistischen Prognostik führen würde. ${ }^{15}$ Dabei betont er, dass der Mensch frei und ein „polyphones Wesen“ ist. Aus der Kombination dieser Bestimmungen ergibt sich, dass die Zukunft prinzipiell offen ist. ${ }^{16} \mathrm{Im}$ Kontrast zu Khoruzhy werde ich versuchen, das energische Paradigma auf „die ausgedehnte Welt der Strategien der alltäglichen Existenz" anzuwenden, ${ }^{17}$ also auf Normalfälle des menschlichen Daseins. Die Idee der Synergie verliert dann die besondere Bedeutung eines Mit-Wirkens der menschlichen mit der ontologisch verschiedenen Energie des göttlichen Andersseins (Inobytie), ${ }^{18}$ die es in der hesychastischen Tradition hat, und wird zum Zusammen-Wirken menschlicher Energie mit der ontisch anderen, ontologisch aber gleichartigen Energie anderer Menschen.

Man könnte sich fragen, warum es wichtig ist, hier bei Khoruzhy stehen zu bleiben, statt sofort zu einer ,gewöhnlichen“ Anthropologie überzugehen und zu versuchen, die Idee der co-existence eines Jean-Luc Nancy mit der Idee der assemblage des Manuel DeLanda $\mathrm{zu}$ verbinden. ${ }^{19}$ Viele menschliche Phänomene, darunter sämtliche soziale, lassen sich im Rahmen eines energischen, statt substantialistischen Paradigmas überzeugend darstellen. Die Leidenschaften, darunter Hass und Liebe, aber auch Handlungen, Erfahrungen und Beziehungen, lassen sich mit Energie auf den Nenner bringen. Allerdings haben die drei Grenzfälle, die Khoruzhy erörtert, den großen Vorteil zu zeigen, was die eigentümlichen Grenzen des Menschlichen sind, innerhalb derer sich die Normalfälle aufhalten und entwickeln. ${ }^{20} \mathrm{Im}$ Extremen ist etwas Wahres zu finden, auch wenn es nicht „die Wahrheit“ ist. Diese Extreme sind konstitutiv, wenn auch

15 Khoruzhy (2005), 13, 58, 119, 121.

16 Khoruzhy (2005), 116.

17 Khoruzhy (2005), 104.

18 Khoruzhy (2005), 115.

19 DeLanda (2006), 26-46; Nancy (1996), 61-67, 117-122.

20 Khoruzhy (2005), 104. 
nicht unmittelbar für den Menschen selbst, der auch ohne sie existiert, so doch für unseren Begriff vom Menschen.

Die drei Fälle, in denen der Mensch laut Khoruzhy seinem $A n$ deren begegnet, sind, erstens die ontologische Grenze des Menschen, die in spirituellen Praktiken und mystischen Erfahrungen entdeckt wird und jenseits derer sich radikal anderes Sein befindet; zweitens die ontische Grenze, die in psychoanalytischen Praktiken erforscht wird und jenseits derer sich das Unbewusste aufhält; drittens die Grenze des Virtuellen, d.h. „des nicht völlig aktualisierten Seienden“.21 Diese drei Grenzen machen klar, und zwar ihm selbst, dass der Mensch sich zwischen zwei Polen befindet, von Khoruzhy mit Plastizität (plastitschnost') und Identität (identitschnost') beschrieben, die miteinander konkurrieren, einander aber nicht ausschließen: auch an der absoluten Grenze seiner Plastizität (in der mystischen Vereinigung mit der göttlichen Energie, in den Tiefen der Analyse, in den Weiten der Internet-Games), bleibt der Mensch er selbst. ${ }^{22}$

Diesen Beispielen möchte ich ein viertes hinzufügen, das man besonders in der Lager-Literatur ausgearbeitet findet: Verfahren, deren Ziel es ist, einen Menschen seiner Menschlichkeit zu berauben. Solche Verfahren können ihr nihilistisches Ziel nicht erreichen, denn man kann einen anderen Menschen zwar als einen „Untermenschen“ betrachten oder ihn als „Vieh“ behandeln, es ist aber unmöglich, ihn zu einem Nicht-Menschen zu machen. Ganz klar wird das in Robert Antelmes L'espèce bumaine ausgedrückt: „,...] il n'y a pas d'ambiguïté, nous restons des hommes, nous ne finirons qu'en hommes. [...] C'est parce que nous sommes des hommes comme eux que les SS seront en définitive impuissants devant nous. (...) Eh bien,... nous ne pouvons devenir ni la bête ni l'arbre. Nous ne pouvons pas et les SS ne peuvent pas nous y faire aboutir." 23 Auch wenn Antelmes Mitgefangene Schokoladenpulver vom Fußboden leckten, wurden sie doch nicht zu Tieren. ${ }^{24}$ Neben dem Anderssein, dem Unbewusstsein und dem virtuellen Sein gibt es also das Un-Sein, das ebenfalls eine absolute Grenze des Menschlichen darstellt, innerhalb derer der Mensch unhintergehbar er selbst bleibt. 
Für den Begriff „Gemeinschaft“ lässt sich aus dieser Darstellung schließen, dass der Mensch, als Energie verstanden, maximale Flexibilität und Offenheit mit maximaler Freiheit und Identität vereinen kann. In der täglichen Erfahrung kommt das darin zum Ausdruck, dass man sich kaum mehr als „sich“ und zugleich mehr als Mensch fühlt, als wenn man einen anderen Menschen innig liebt oder zutiefst hasst. Es folgt aber auch, dass alle „Normalfälle“ sich innerhalb der Grenzen einer geteilten Menschlichkeit ergeben. In den erwähnten Fällen ist zwar mittels Handlungen und Praktiken irgendein „Kontakt" möglich, aber gerade in der Interaktion mit dem (radikal) Anderen zeigt sich der Unterschied zur Interaktion mit gleichartigen Anderen. Die synergische Interaktion mit gleichartiger, menschlicher Energie findet durchaus in der Form von mehr oder weniger gefestigten Praktiken und Strategien, Formaten und Repertoires statt. Anders als etwa Mystik oder Psychoanalyse (die Grenzfälle), bedürfen diese keiner besonderen Anstrengung und keiner spequiellen Übung.

Die elementaren Formen des menschlichen Zusammenlebens sind als Möglichkeiten im Zusammenleben selbst anwesend und müssen nicht entdeckt, sondern nur aktualisiert und artikuliert werden. Der Umgang mit einem Fremden kann voller Gefahr und Unsicherheit sein, ist aber vom Umgang mit dem radikal Anderen zu unterscheiden. Diesen Unterschied nicht zu machen, führt zur Xenophobie, die auf einer Verwechslung des Quantitativen mit dem Qualitativen beruht: die vielen Anderen verwandeln sich in das eine wesentlich Andere, z.B. „den Ausländer“ oder „den Islam“. Das Problem ist hier nicht, dass Menschen zu wenig offen sind, sondern vielmehr, dass sie Angst bekommen vor ihrer eigenen Offenheit: um sich erbalten zu können, meinen sie sich schließen zu müssen, und dieser SchlieBung unterliegt der Fehlschluss, der andere sei ein radikal anderer. Ich möchte hier die Hypothese vertreten, dass ein Mensch anderen Menschen gegenüber wesentlich offen ist, und ich möchte diese Hypothese verbinden mit einem Begriff, den ich als „HintergrundWir" beschreiben und im Folgenden, in Anlehnung an Udo Tietz, als wir- 0 bezeichnen werde. Ich nenne es wir-0, weil wir es sind, die unsere Menschlichkeit gegenseitig nicht verkennen können und weil wir dies voneinander wissen; wir-o existiert, weil es unbestimmt und schlicht allgemein ist.

Es gibt eine unverkennbare Erfahrung der Gemeinschaftlichkeit mit anderen Menschen: wer in den Bergen spaziert und dabei in der Ferne etwas erblickt, das sich bewegt und sich bei näherem He- 
rangehen als etwas Lebendes dartut, der macht die momentane Erfahrung des Erkennens, dass es sich hier um einen anderen Menschen und nicht etwa um einem Steinbock handelt. Man kann sich da irren und man kann die Erfahrung auch verneinen - aber um sie verneinen zu können, muss sie dagewesen sein. Es handelt sich hier nicht um ein induktives Erkennen. Man sagt nicht: dieses Lebewesen trägt einen Rucksack, es muss sich also um einen Menschen handeln: das zu sagen würde komisch wirken. Im Erkennen tut sich bei einem Menschen sofort die Palette von möglichen Beziehungen auf: der andere Mensch kann freundlich oder feindlich sein, kommunizieren wollen oder nicht, usw. Ein Steinbock kann Gefahr oder Beute sein, aber weder Feind noch Freund. Es handelt sich um so etwas wie Artgenossenschaft: es geht darum, dass Menschen andere Menschen als „ebenfalls Menschen” erkennen. Wenn diese Erfahrung auf der ontischen Ebene feststellbar ist, dann bedarf es, auf der ontologischen Ebene, eines entsprechenden Begriffes. Dieses wir-o ist ein solcher Begriff, und es kann als ein wichtiger Bestandteil der condition bumaine gelten.

Es bildet zugleich die Grundlage für die unterschiedlichen Formen der Beziehung, in der ein Mensch sich zu anderen Menschen stellen kann. Hass und Liebe, Feindschaft und Freundschaft, Abneigung und Anziehung finden vor dem Hintergrund eines an sich neutralen wir statt. Das bedeutet einerseits, dass die ontologische Grundlage des menschlichen Zusammenlebens normativ-neutral ist. Andererseits bedeutet es, dass wir Menschen uns diesem wir-o nicht entziehen können. Wir können nicht umhin, andere Menschen als Menschen zu erkennen, ein Erkennen das einer Anerkennung eines anderen Menschen als Menschen - z.B. als Träger von bestimmten Rechten - vorangeht. Jemanden als einen Nicht-Menschen zu behandeln, als ein Tier oder als ein Stück Fleisch, setzt voraus, dass dieser Mensch als Nicht-Mensch (dis)qualifiziert wird. Man kann sich einem Anderen gegenüber so benehmen als ob sie oder er kein Mensch sei, aber darin liegt trotzdem ein Tun, dieses „als ob“ muss aktiv hergestellt werden.

Die Annahme eines wir-0, also einer ursprünglichen Gemeinschaftlichkeit eines jeden Menschen mit seiner menschlichen Umgebung, ist sicher problematisch - oder eben Annabme -, jedoch nicht problematischer als die dem entgegengesetzte Annahme einer geschlossenen Substanz oder eines in sich geschlossenen Bewusstseins. Wenigstens auf der Ebene der natürlichen Erfahrung, d.h. in-der- 
Welt-seiend, scheint mir die Tatsache der Offenheit und des Ausstehens unverkennbar zu sein. Man kann von seiner Umgebung abgeschlossen sein, aber nur indem man sich selbst abschließt, die Umgebung bleibt dabei jeweils die eigene. ${ }^{25}$ Die Annahme, dass Menschen offene Wesen sind, die sich zur Selbstbehauptung und Selbsterhaltung im Sein gewissermaßen entschließen müssen, darin mehr oder weniger erfolgreich sein können und dabei zu einem unterschiedlichen Grade die Idee einer „Innenwelt“ entwickeln, scheint mir darum die realistischere zu sein. Man sollte sich dabei auch die Frage stellen, was in der Art und Weise, in der man theoretische Praxis ausübt - spricht, schreibt, diskutiert - bereits unterstellt ist, nämlich gerade die angedeutete Gemeinschaftlichkeit und Offenheit. Jemand der sagt oder schreibt, dass der Mensch ein in sich geschlossenes Individuum, ein isoliertes Bewusstsein, oder ein gesellschaftliches Atom ist, vollzieht einen performativen Widerspruch, denn er wendet sich implizit einem Zuhörer oder Leser zu. Das wir-o ist in jeder Form von Kommunikation, Feindschaft oder Gemeinschaft unterstellt. In diesem Sinne ist der Mensch ontologisch ein soziales Tier.

\section{Gemeinschaftlichkeit und Gemeinschaft: wir, sie, ihr}

Man kann den Menschen als ein soziales Tier definieren, muss dann aber hinzufügen, dass dieses Tier sich zum eigenen Sozialsein aktiv verhält, sowohl praktisch (bestimmend), als theoretisch (erkennend). Es liegt auf der Hand, dass ein Mensch notwendig in Gemeinschaft lebt. Allerdings existiert reale Gemeinschaft nur insofern, als sie von Menschen (re)produziert wird, wenn auch nicht immer bewusst oder absichtlich. Dieser Umstand nötigt zu einem Unterschied zwischen den Formen von sozialem Sein, die unumgänglich sind, und jenen, die bestehen, aber auch nicht bestehen können. Die unentrinnbare Form von Gemeinschaftlichkeit (wir-0) bildet die ontologische Grundlage der drei Dimensionen des menschlichen Zusammenlebens: Gemeinschaftlichkeit, Gesellschaftlichkeit und Politizität. Mit diesen Dimensionen sind kontingente Formen des Zusammenlebens verbunden: Gemeinschaft, basierend auf innerer Bindung; Gesellschaft, basierend auf äußeren Beziehungen; und Politik, bezogen auf 
die Möglichkeit des Konflikts. Diese drei Formen können vermischt sein, sind im Grunde aber verschieden.

„Wir" ist der ständig wiederkehrende Begriff im Gemeinschaftsdenken. Es kann aufgefasst werden als notwendig einem „Sie“ gegenüberstehend, wie etwa im schmittianischen Paradigma, es kann auch, wie bei Frank oder Nancy, gesetzt werden als potentiell alle umfassend, und es kann zum lokalen, nationalen oder kosmopolitischen Ideal werden. Es kann als eine Kollektivität aufgefasst werden, die ein constitutive outside braucht, um sich aktiv davon abzugrenzen und sich als „wir“ setzen zu können. ${ }^{26}$ Der Begriff ,,wir“ hat, wie der Begriff ,ich“, sowohl eine deskriptive als auch eine performative Seite, und darüber hinaus eine normative, die nicht immer klar zu unterscheiden ist: wenn ich zu meinen streitenden Freunden sage „Kommt, gehen wir ein Bier trinken!“, dann ist dieses wir-Sprechen als eine Form von wishful speaking zu verstehen: ein „wir“, das ich im Prinzip unterstelle, soll sich jetzt aktualisieren. Mit Ausnahme des wir0 , das einfach da ist, ist jedes ,wir“ für sein Dasein von irgendeiner Form der Zustimmung oder der Gegenseitigkeit abhängig. Ein „wir" ist also nie selbstredend oder unanfechtbar - mit Ausnahme des neutralen wir-0, das auch in der Möglichkeit des Anfechtens, des Sich-nicht-Einreihens usw. unterstellt ist. Das bedeutet, dass jede Form von Gemeinschaft eine untilgbare Dimension der Politizität hat, weil sie die Möglichkeit eines Konflikts beinhaltet.

„Wir“ kann allgemein als eine mehr oder weniger bewusste Form des gegenseitigen Energieaustausches bestimmt werden. Wir wissen alle, dass mit dem Zustandekommen jeder wir-Beziehung, von der Liebesbeziehung zwischen zwei Menschen und dem ElternKind Verhältnis bis zum ,wir“ einer Kirche oder eines Nationalstaats, mit dem angenehmen Gefühl der Verbindung auch die Angst des Verlustes entsteht, weil ein neues Individuum entstanden ist, das als „wir ${ }^{\text {“ }}$ verschwindet, wenn es aufgeteilt wird. ${ }^{27}$ Diese Sachlage lässt sich mit Hilfe eines energischen Paradigmas leichter erklären als im Rahmen des substantialistischen Paradigmas. Die existentielle Angst eines Menschen, sowohl in Bezug auf sich selbst als auch in Bezug auf ein jedes ,wir“, liegt in der nie zu Ende kommenden Abwechs-

26 Staten (1985), 23.

27 DeLanda (2006), 28; Frank (1992), 47 [Deutsch: Frank (2002), 131] - der Unterschied zwischen ihren Positionen besteht darin, dass dieses Individuum entweder ein singuläres oder ein partikulares ist. 
lung von Öffnung und Schließung, die immer auch Aufgabe ist: Öffnung und Schließung sind für die Selbsterhaltung notwendig und müssen darum balanciert werden. Diese Angst kann teilweise behoben werden durch eine Form von Gemeinschaft - von der Liebesbeziehung bis zum Nationalstaat -, aber die Aufgabe wiederholt sich: jeder weiß, dass eine sich total abschließende Liebesbeziehung zur folie à deux führt und ein sich abschließender Nationalstaat zu Nationalismus und Aggression, jeder weiß aber auch, dass Offenheit die Gefahr des Auflösens mit sich bringt.

Das Thema des „Wir“ wurde von Udo Tietz in Die Grenzen des Wir angesprochen. Ich werde versuchen, den von Tietz gemachten Unterschied mit dem Begriff des Hintergrund-Wir kritisch zu ergänzen. Tietz schreibt: ,[...] das ,wir', auf das sich die präsupponierte Vernünftigkeit bezieht, ist nicht identisch mit dem, wir ${ }^{6}$, das auf die Mitglieder einer in der historischen Zeit und im sozialen Raum situierten Gemeinschaft bezogen ist." 28 Das erste nennt Tietz wir-1, das zweite wir-2. Das von mir unterschiedene wir-o bildet die reale, ontologische Grundlage der Möglichkeit jedes konkreten „Wir“ (wir-2 in der Unterscheidung von Udo Tietz), während die „sich anerkennende Menschheit" (wir-1 bei Tietz) dessen normativ qualifizierte Vor-

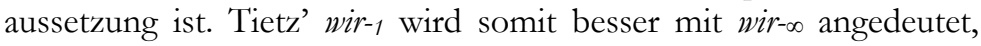
während wir-2 sich faktisch in eine Vielzahl von wir-x, wir-y, wir-z aufteilt. Wenn, zum Beispiel, Tietz in einem „Exkurs“ eine Polemik mit Arnold Gehlen und Carl Schmitt führt, wobei er sie als Vertreter eines „Ethnonationalismus“ oder „Partikularismus“, deutet, die den Begriff der universalen Menschheit (wir-1) verneinen, und ihre Position mit der Position des liberalen Kommunitaristen Michael Walzer kontrastiert, dann bildet wir-o die gemeinsame Grundlage, welche in der Polemik zwischen Universalisten wie Tietz und Partikularisten wie Schmitt real unterstellt ist. ${ }^{29}$

Diese Polemik wird von Tietz auf folgende Formel gebracht: „Die These [von Gehlen und Schmitt, EvdZ] ist also nicht: Sie sind wie ,wir-1', aber sie sind keiner von ,uns-2 ${ }^{6}$ [das war die These des Michael Walzer, EvdZ]. Die These ist: Sie sind keiner von ,uns-2", weil sie nicht wie ,wir-2 ${ }^{6}$ sind. “ ${ }^{30}$ In meine Terminologie übersetzt 
stehen hier zwei Modelle einander gegenüber: Im ersten (Walzer, Tietz) steht jedem wir-x ein sie-y gegenüber, beide gehören aber zum

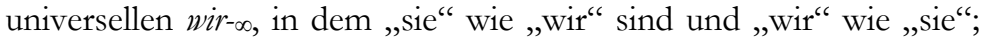
im zweiten Modell (Schmitt, Gehlen) steht jedem wir-x ein sie-y ge-

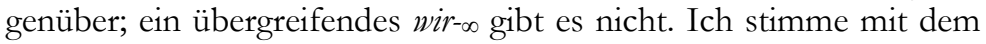

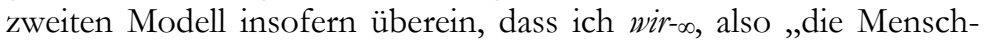
heit", als ein projiziertes Ideal betrachte, das religiös oder naturrechtlich untermauert sein kann, aber keine Realität ist, während die reale Grundlage jedes wir-x und damit auch jedes „wir"-,,sie“-Verhältnis, vom neutralen wir-o gebildet wird. Es ist sicher möglich, Menschen

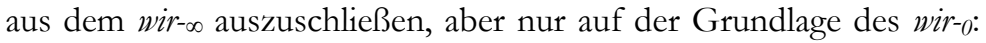

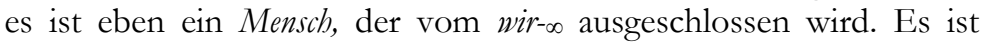

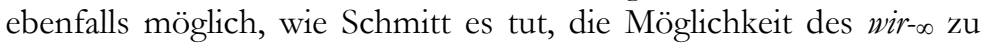
verneinen. Es muss aber etwas Gemeinschaftliches geben, damit überhaupt möglich ist zu behaupten, zu bezweifeln oder zu verneinen, dass irgendein „sie“ zu irgendeinem „wir“ gehört: auch für Schmitt ist der Feind der Andere, also jemand, der zur selben Kategorie gehört wie ich, was auch der Grund ist, dass er vom Feind zum Freund werden kann und umgekehrt. ${ }^{31}$

Wir-o schließt den skythischen Sklaven ein, von dem jeder Grieche wusste, dass er kein Mitglied des wir-HL der Hellenen noch des wir-AT der Athener oder des wir-SP der Spartaner war: die griechische Gemeinschaft unterstellte die Ausschließung der nicht-Griechen. Wir-o hingegen schließt die Aborigines, Terroristen und sans-papiers, mit denen ich nicht ins Gespräch komme, ebenso ein wie die homines

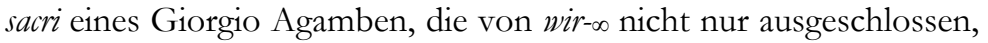
sondern als „,constitutive other“ hervorgebracht werden. ${ }^{32}$ Man muss

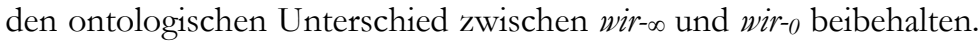
Die beiden miteinander zu identifizieren hätte verheerende Folgen, wie von William Rasch dargestellt wurde: die faktische Ausgrenzung bestimmter Menschen erschiene als selbstverschuldetes Ausgeschlossensein. Die Etablierung einer potentiell alle umfassenden Menschheit (wir-o), ob stoisch, christlich, islamisch oder liberalhumanistisch definiert, wirkt normativ insofern alle diejenigen, die sich diesem wir-o anschließen könnten - und auf Grund ihrer ontologischen Zugehörigkeit zum wir-o sind das alle Menschen -, es aber 
trotzdem nicht tun, folglich selbst für ihr Ausgeschlossensein ver-

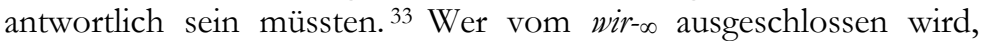
gehört nicht zu einem sie- $x$, also zu einer sich positiv und symmetrisch „uns“ gegenübersetzenden Gruppe, sondern zu einem „unwir" (Heiden, Primitive, Terroristen, usw.). Sobald wir-o, das allgemein den universalen Philosophien und Religionen entstammt, als Realität gesetzt wird, etwa in der Form der, internationalen Gesellschaft" (gegenüber denjenigen, die sich diesem Bonum zuwider setzen) oder in der gemilderten Form einer „Society of Peoples“,34 fängt es an, normativ und auschließend zu wirken.

Die Grundformen des „Wir“ sind also in meiner Hypothese folgende:

- wir-o: das neutrale Hintergrund-Wir;

- $\quad$ wir-x,y, z: die Vielheit der konkreten „Wir“;

- wir-o: der normative Begriff der Menschheit.

Ein konkretes wir-x kann mehr oder weniger geschlossen und mehr oder weniger klar begrenzt sein, steht aber immer anderen „wir“ als

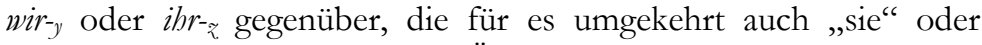
„ihr" sind. Auf der Basis dieser Überlegungen können wir zwischen den folgenden drei Erscheinungsformen von Gemeinschaft unterscheiden:

- unbestimmte Gemeinschaft: ein offenes, aber innerlich verbundenes „Wir“, das sich zu jeder Zeit bilden, aber auch wieder auseinanderfallen kann;

- eine Gemeinschaft: ein relativ geschlossenes „Wir“, z.B. eine Familie, eine Kirche, eine Nation, für welche es mehrere Formen von ,ihr" und „sie“ geben kann;

- die Gemeinschaft: ein „Wir“ das nur ein als Einziges „Wir“ bestehen kann.

Wir-o lässt eine bunte, im Prinzip unbegrenzte Vielfalt unbestimmter Formen von Gemeinschaft zu, vom Publikum bei einem Vortrag bis zur kurzfristigen Verständnisgemeinschaft im Zugabteil. Im Falle 
einer Gemeinschaft (unter mehreren) hängt die Vielfalt der Formen von der Kapazität der Menschen zur Gemeinschaftsbildung ab. Im Falle der (einen und einzigen) Gemeinschaft ist ausgeschlossen, dass ein Mensch zugleich zu mehreren „wir“ gehören kann.

Wie Hegel mit der „Dialektik von Herrschaft und Knechtschaft" gezeigt hat, ist in der Anerkennung des anderen als Mitmenschen dessen Anerkennung als Mensch (wir-o) sowie die Anerkennung einer bestimmten Form von Gesellschaft - eben das Verhältnis von Herr und Knecht - unterstellt. Für das menschliche Zusammenleben ist kennzeichnend, dass immer auch die Dimension der Gesellschaftlichkeit sich in Formen von Gesellschaft - Eigentumsverhältnissen, Rechtsbeziehungen, Bürgertum - realisiert. Die Hegelsche Dialektik wird aber idealisiert, wenn, wie etwa von Charles Taylor oder Axel Honneth, ${ }^{35}$ die Anerkennung als eine wechselseitige Anerkennung unter Gleichen dargestellt wird: zwar will „,ich“ von jemanden anerkannt werden, den ich als mich anerkennenden anerkennen kann, und zwar gilt dasselbe auch für den anderen, damit ist aber das Verhältnis noch nicht ein symmetrisches, sondern vielmehr ein verdoppelt asymmetrisches. Gerade deshalb bildet es nicht nur die Grundlage für eine sittliche Gemeinschaft, sondern auch für die bürgerliche Gesellschaft und für die Möglichkeit von Krieg und Bürgerkrieg, in dem ich den Anderen als menschlichen Feind anerkenne. Anerkennung des Andern als Andern bedeutet Anerkennung dieses Andern als genauso anders wie ich oder wir. Die Frage ist, ob das ohne Hypokrisie bzw. Ideologie möglich ist. Meine These lautet, dass eine solche Anerkennung auf der Realität des wir-o statt auf der Idealität eines wir-o beruhen soll. Jedes Denken von Gemeinschaft muss die reale Möglichkeit der Abwesenheit von konkreten Formen von Gesellschaft, sowie auch die Möglichkeit des Konfliktes mitdenken, sonst wird es zur humanistischen Ideologie. ${ }^{36}$

Es könnte die Gemeinschaft nur geben, wenn die ontologische Differenz zwischen der allgemeinen Dimension der Gemeinschaftlichkeit (wir-0) und der ontischen Gemeinschaft, sei es in der Form der

\section{Taylor (1994), 50; Fraser/Honneth (2003), 170-171.}

36 Bei Hegel ist die Anerkennungsdialektik Grundlage sowohl für Gemeinschaft als auch Gesellschaft - das Problem verschiebt sich bei ihm aber dahingehend, dass die politische Gemeinschaft als eine rein sittliche gedacht wird, der die Dimension des Gesellschaftlichen als bürgerliche Gesellschaft untergeordnet wird und die Dimension des Politischen in die äußeren Verhältnisse zu anderen politischen Gemeinschaften exportiert wird. 
einen „Menschheit“ (wir-o) oder in der Form vieler konkreter Gemeinschaften (wir-x), aufgehoben würde. Weil das unmöglich ist, wird diese Aufhebung zur Verneinung, und diese Verneinung hat zur Folge, dass es die Gemeinschaft nur retrospektiv gibt, und sie darum, wenn sie als wirklich behauptet wird, nur ideologisch existieren

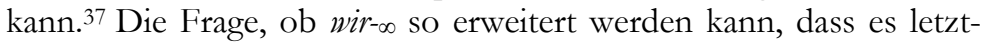
lich alle Menschen einschließt, ist eine andere Frage als die, ob die zwei Kategorien, wir-o und wir-o, zusammenfallen können. Die ontologische Differenz besteht auch dann, wenn es ontische Identität gibt, was darin zum Ausdruck kommt, dass wir-o - wie jedes positives wir-n (außer wir-o) - jedes Mal erneut gebildet, performativ gestiftet, aktiv (re)produziert werden muss. ${ }^{38}$ Das gilt sowohl dann, wenn „wir“ alle einschließt, als auch dann, wenn es ein ,sie“ gegenüber hat. Man muss also nicht, wie Tietz sagt, „Mitglied der wir-1-

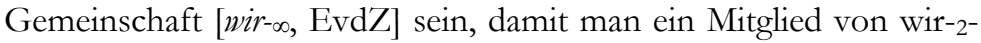
Gemeinschaften [wir-x, EvdZ] sein kann,"39 sondern man muss zum wir-o gehören, um überhaupt als Mitglied eines „wir“, „sie“ oder ,ihr“" gelten zu können.

Wenn die Grenzen eines „wir“ laut Tietz mit gemeinsamen Werten und mit einer gemeinsamen Sprache verbunden werden, ${ }^{40}$ so muss es etwas geben, das die Möglichkeitsbedingung einer solchen Gemeinsamkeit bzw. deren Abwesenheit bildet - und das kann nicht wir-s sein, weil darin schon eine gewisse Gemeinsamkeit wirksam ist. Dabei sei weiter bemerkt, dass eine oder die Gemeinschaft eine gemeinsame Sprache vielleicht unterstellt, dies aber nicht für offene Formen von Gemeinschaft gilt: dort genügt geteilte Sprache, sie muss aber nicht gemeinsame eigene Sprache sein. Und dasselbe gilt für die Werte offener Gemeinschaften: die Teilhaber einer Form von Gemeinschaft müssen ihre Werte kommunizieren können, brauchen sie aber nicht unbedingt in allen Einzelheiten zu teilen, mit Ausnahme eines Minimums, das Kommunikation und Auseinandersetzung ermöglicht. Diese Konzeption kommt dem von Young propagierten Ideal des „City Life“ nah, von ihr in polemischem Kontrast mit der

37 Devisch (2003), 82-83. Peter Osborne hat in seinem Buch Politics of Time die interessante These vertreten, dass der politische Konservatismus immer auf eine Gemeinschaft verweist, die es als solche nie gegeben hat; siehe: Osborne (1995).

38 Honig (1993), 105.

39 Tietz (2002), 55.

40 Tietz (2002), 12-13. 
kommunitaristischen Idee der einen Gemeinschaft entwickelt. In der von mir vorgeschlagenen Terminologie könnte man dieses Ideal als offene Situation der endlosen Gemeinschaftsbildung bezeichnen, deren Schlagworte Freiheit und Differenz sind. ${ }^{41}$ Diese Offenheit, die sich auf eine Anerkennung des wir-o stützt, existiert aber nicht automatisch, sondern sie muss erzeugt bzw. erkämpft werden. Eine ähnliche Position wird mit geringerem politischem Bewusstsein von Jean-Luc Nancy vertreten, der den Begriff der communauté durch den des „Mitsein“ [être-avec] ersetzt. ${ }^{42}$ Gemeinschaft muss also nicht mit der nostalgisch gefärbten Gemeinschaft der Kommunitaristen identifiziert werden. Statt von einer, geschweige denn von der Gemeinschaft zu reden, kann man von „Gemeinschaft“ reden als spontane Konkretisierung der Gemeinschaftlichkeit. Dabei sind allerdings, im Gegensatz zur einen Gemeinschaft, die Dimension der Gesellschaftlichkeit - rechtliche Verhältnisse, Eigentum, usw. - und die Dimension der Politizität notwendig mitgedacht. Weil etwa im Markt die gesellschaftlichen Verhältnisse überwiegen und in der Kirche die gemeinschaftlichen, sind doch beide auch im anderen anwesend und bestehen beide nur gegen den Hintergrund einer anerkannten Politizität als mögliche Konfliktualität und somit prinzipielle Umstreitbarkeit (wenn auch nicht notwendig tatsächliche Umstrittenheit).

Die letzte Frage lautet dann, wie sich vor diesem Hintergrund so etwas wie die politische Gemeinschaft denken lässt, etwa die österreichische (wir-ö), die amerikanische (wir-USA) usw. Traditionell wird der Staat, bei Hegel, aber auch bei Tietz oder Rawls, als die eine Gemeinschaft aufgefasst, zu der Menschen als Untertanen, unter republikanischen oder demokratischen Umständen auch als Bürger gehören. ${ }^{43}$ Wenn man dabei mit Niklas Luhmann oder Anthony Giddens anerkennt, dass es faktisch so etwas wie eine Weltgesellschaft - im Sinne einer globalen indirekten Kommunikation aller mit allen - schon längst gibt, dann führt das fast unausweichlich zur Idee einer weltweiten politischen Gemeinschaft. ${ }^{44}$ Eine solche Sichtweise ist aber nur möglich, wenn man den Begriff Gemeinschaft auf die Bestimmtheit ihrer Formen reduziert und die dritte Dimension, die politische, 
ausklammert bzw. in die internationalen Verhältnisse „exportiert“. Dabei wird übersehen, dass wir es mit Gemeinschaftlichkeit, Gesellschaftlichkeit und Politizität zu tun haben. Umgekehrt kann es die Gesellschaft nur geben, wenn die Dimension der Gemeinschaftlichkeit effektiv oder symbolisch ausgeklammert bzw. privatisiert wird, und die Dimension der Politizität auf „die Politik“ eingegrenzt wird. Und schließlich kann es reine Politik nur dann geben, wenn die beiden anderen Dimensionen reduziert oder ausgeschlossen werden, wie das z.B. im totalitären sowjetischen System der Fall war, wo die Dimension der Gesellschaftlichkeit als „bürgerlich“ ausgeschlossen und die Dimension der Gemeinschaftlichkeit mit der des Politischen identifiziert wurde (Klassenkampf gab es nur noch im internationalen Bereich, die sozialistische Gesellschaft war auf dem depolitisierten Wege zur kommunistischen Gemeinschaft). Ob solche Reduzierungen auf die Dauer lebensfähig sind, ist eine andere Frage, und vielleicht hat ihre reale Unmöglichkeit gerade zum Untergang eines Systems geführt, das notwendig zur Lüge über sich selbst wurde.

Klar ist auf jeden Fall, dass sich nach dem Ende des Totalitarismus wenigstens in Europa, die Frage nach der Gemeinschaft nicht mehr stellen lässt - es kann nur noch Gemeinschaft oder Gemeinschaften geben, d.h. im unbestimmten Singular oder im ebenfalls unbestimmten Plural: eine Vielheit von „Wir“, die einander einschließen und überschneiden können, die aber nie mit sich selbst identisch sind. Das zeigt sich am deutlichsten im Falle von Krieg, also wenn die Dimension der Politizität zum realen Konflikt führt. Die Berichterstattung über einen bestimmten Krieg, etwa im Irak, muss so gestaltet und manipuliert werden, dass die Folgen für sie-IR nicht sichtbar werden und der Krieg als ein „sauberer" [clean war] erscheint: im Namen des wir-o der Freiheit und Demokratie wird, wie der niederländische Journalist Joris Luyendijk hervorragend gezeigt hat, die Information so manipuliert, dass die spontane Wirkung der Gemeinschaftlichkeit - wir-0 - blockiert wird. ${ }^{45}$ Wer Menschen konkret leiden sieht, muss nicht auf das Ideal der „universalen Menschheit" zurückgreifen, um dem Leiden ein Ende zu setzen. Die argumentative Verbindung mit der Religion, die Menschen als „Fundamentalisten" festlegt, also zu radikal anderen macht, zeigt sich hier als ein effektiver Ausschließungsgrund. 
Konkrete, als offene verstandene politische Gemeinschaft ermöglicht es Menschen, Konflikte als Gegensatz zwischen „wir“ und „,ihr“ aufzufassen, statt im Gegensatz von „wir“ und „sie“ das Ende der politischen Gemeinschaft zu sehen. Eine konkrete politische Gemeinschaft, z.B. die amerikanische, spaltet sich in wir-USA-und wirUSA+, wobei die zwei Gruppen im ,wir-ihr“ Verhältnis stehen, also als politische Gegner, nicht als Feinde: alle gehören zur selben politischen Gemeinschaft. Eine solche Spaltung tritt bei Wahlen, Referenden, öffentlichen Debatten usw. auf und gehört zum normalen Leben einer politischen Gemeinschaft. Diese Spaltung auszuhalten ist aber nur dann möglich, wenn die Dimension des möglichen Konflikts als eine reale Dimension jedes menschlichen Zusammenlebens angesehen und die Einheit der politischen Gemeinschaft nicht so aufgefasst wird, dass jeder Antagonismus zum „wir-sie“ Verhältnis führt, also zum „Bürgerkrieg““. Das Modell, das diese Überlegungen am besten zusammenfasst, ist meines Erachtens das Modell agonistischer Politik, das auf unterschiedliche Weise von Denkern wie Iris Marion Young, Bonnie Honig, Chantal Mouffe und William Connolly entwickelt wurde. Was ihre Theorieansätze gemein haben, ist die Anerkennung der Dimension des Antagonismus in jeder Gesellschaft, auch der ,gut geordneten“ [well-ordered society] eines John Rawls, und die Anerkennung der Notwendigkeit, solche Antagonismen in Richtung politischer, agonistischer Gegensätze zu transformieren. Die Welt der wir-x, in der jedes ,wir“ zum „sie“ eines anderen „wir“, jedes „sie“ aber im Prinzip zu einem „ihr" werden kann, also vom Feind [enemy] zum Gegner [adversary], mit dem man sich streitet unter Akzeptanz bestimmter Spielregeln, ${ }^{46}$ ist an sich eine Welt der positiven „wir“, in der jedes „,sie“ oder ,,ihr“ für sich ein „,wir“ ist.

Während Gemeinschaftlichkeit, Gesellschaftlichkeit und Politizität notwendig da sind als Dimensionen des wir-0, sind alle konkreten Formen von Gemeinschaft, Gesellschaft und Politik kontingent. Obwohl schwer vorstellbar, sind Situationen denkbar, in denen eine, vielleicht sogar zwei, dieser Formen abwesend sind. Eine atomisierte Gesellschaft, in der es keinerlei Form von Gemeinschaft mehr gibt, in der alle Verhältnisse äußerlich und mechanisch sind und aus der Politik verschwunden zu sein scheint, kann literarisch vorgestellt 
werden, etwa in Michel Houellebecq's La possibilité d'une île, gleichermaßen wie eine Situation, in der Gesellschaft und Politik aufgehoben sind im Namen einer „totalen Gemeinschaft“ - George Orwells 1984 oder Evgenii Zamyatins My [Wir]. Aber abgesehen davon, dass wir es bei diesen literarischen Beispielen tatsächlich mit Schreckbildern $\mathrm{zu}$ tun haben, die als solche auch bereits eine korrigierende Rolle erfüllen können (und die mit ihrem impliziten Begriff einer Leserschaft ihrer eigenen „Realität" widersprechen), zeigen sie im Grunde, dass Gemeinschaftlichkeit, Gesellschaftlichkeit und Politizität die ontologisch verankerten Dimensionen des sozial Möglichen sind.

\section{Zum Schluss}

Jeder Mensch muss sich zu diesen drei Dimensionen des menschlichen Zusammenlebens verhalten - darin ist er nicht frei. Ein Mensch ist aber frei im Investieren oder Nicht-Investieren der eigenen Energie in Formen von Gemeinschaft, Gesellschaft und Politik, und im Reagieren oder Nicht-Reagieren auf die eingesetzte oder nicht-eingesetzte Energie anderer Menschen. Man kann sich von der Politik fern halten, muss sich dann aber fern halten. Wenn jemand ein Fußballstadion betritt, in dem ein wichtiges Spiel stattfindet, dann ist es ihm unmöglich, sich der Dynamik und Synergie der dortigen Gemeinschaftlichkeit zu entziehen. Man kann sich zwar in einem Fußballstadion aufhalten und alle anderen darin befindlichen Menschen zutiefst verachten, anstatt sich mit dem Flow mitführen zu lassen, es ist aber unmöglich, sich zum Prozess der Gemeinschafts(re)produktion nicht zu verhalten: auch wer sich etwa stoisch verhält, tut dies eben aktiv. Dabei bin ich auch frei, ins Stadion zu gehen oder nicht zu gehen; ich muss eine Eintrittskarte erwerben, es müssen freie Plätze verfügbar sein - all dies sind Elemente der Gesellschaftlichkeit. Es ist allerdings auch eine Gesellschaft denkbar, in der ich faktisch genötigt bin, ins Stadion zu gehen: die An- oder Abwesenheit gesellschaftlicher Freiheit, die in politischen Entscheidungen und Institutionen verankert ist, bedeutet, dass auch die Dimension des Politischen unausweichlich ist. So sind im Grunde alle drei Dimensionen immer im Spiel, wenn auch nicht immer alle gleich sichtbar.

Ebenso wenig wie eine Person ins Fußballstadion gehen muss, muss sie oder er sich politisch betätigen, obschon auch hier Um- 
stände denkbar sind, die mich zur Betätigung zwingen, wie etwa im Bürgerkrieg, wo ich eine Seite wählen muss, wenn ich nicht erschossen werden will, oder in einem autoritären System, wo ich meinen Job verlieren kann, wenn ich mich nicht an Wahlen beteilige, deren Ausgang bereits vor der Stimmabgabe feststeht. Sich nicht auf Politik einzulassen heißt nicht, nichts mit der Dimension des Politischen zu tun zu haben, sondern es heißt, die aktive Beschäftigung anderen überlassen zu haben - das kann man positiv, negativ oder neutral bewerten, es ist aber ein aktives Verbältnis - auch Unterlassen ist Handeln. Politisch neutral zu sein heißt nicht, dem Politischen gegenüber neutral zu sein. Nicht in einer Form von Gemeinschaft aufgenommen zu sein, heißt Außenseiter und eben nicht neutral zu sein. Nicht an Formen von Gesellschaft zu partizipieren, heißt marginal oder vielleicht illegal zu sein, und das ist die negative, nicht neutrale Stellung des Ausgeschlossenen.

Menschen sind also nicht darin frei, ob sie sich zu den drei Dimensionen verhalten, sondern nur darin, wie sie das tun: wie viel Energie sie darin investieren und von welcher Art diese Energie ist (konstruktiv, subversiv, destruktiv, dekonstruktiv, usw.). Weil andere auf ähnliche Weise vorgehen, aber auf der Basis anderer Intentionen und Erwartungen, und auch mit weniger oder mit mehr Energie, und weil Synergie sich nicht automatisch bildet oder weniger leicht wie im Fußballstadion, wo dieselbe Gerichtetheit die Energie vieler bestimmt, ist es möglich, sogar wahrscheinlich, dass das Ergebnis den Intentionen von keinem entspricht. Dieser Effekt verstärkt sich in dem Maße, in dem die soziale Situation frei differenziert ist und alle an sozialen Prozessen teilhaben - was erklärt, warum in einer pluralen Gesellschaft alle Grund zur Unzufriedenheit haben und keiner bekommt, was er will. Der Ausweg ist dann die positive Umarmung der Pluralität, also der Pluralismus, wie etwa bei William Connolly, in dem Vielfalt und Differenzierung selbst als bona angesehen werden. ${ }^{47}$

In diesem Aufsatz habe ich den Versuch unternommen, das Khoruzhy entliehene energische Paradigma auf das normale menschliche Zusammenleben anzuwenden. Dabei habe ich die These entwickelt, dass menschliche Energie sich vor dem Hintergrund eines neutralen wir-o zu unterschiedlichen Formen entwickeln kann, die mit drei konstanten Dimensionen verbunden sind: Gemeinschaft- 
lichkeit, Gesellschaftlichkeit und Politizität. Dabei deutet „wir“ immer die Dimension der Gemeinschaftlichkeit an, welche insofern grundlegend ist, dass jedes wir-x eben ein unverneinbares wir ist, kein Es oder Man. Ein Mensch kann zwar einen anderen Menschen hassen, verfolgen oder vernichten, lieben, als Freund betrachten oder vergöttern, er kann aber nicht seine Menschlichkeit aufheben. Wenn die drei erwähnten Dimensionen alle zur Menschlichkeit gehören und alle drei anwesend sind, dann bedeutet das, dass sämtliche Versuche, die oder eine Gemeinschaft oder Gesellschaft zu stiften, zu festigen oder zu schützen nur unter gleichzeitiger Ausklammerung der anderen Dimension, und in beiden Fällen auch der dritten Dimension möglich ist.

Die Frage lautet immer, ob diese Ausklammerung eine absolute oder eine relative ist: im zweiten Falle gibt es nie die oder eine Gemeinschaft bzw. Gesellschaft, sondern immer nur Formen von Gemeinschaft und Formen von Gesellschaft und wird auch politische Gesellschaft möglich. Der normative Standpunkt, den ich hier vertrete, befürwortet eine nur relative Ausklammerung. Der Preis, der dafür bezahlt wird, ist, dass jede Form von Gesellschaft und Gemeinschaft, auch politische Gemeinschaft, grundsätzlich offen ist, weil sie sich nicht auf eine ,nationale“ politische Gemeinschaft (wir-ö wir-NL oder wir-EU)

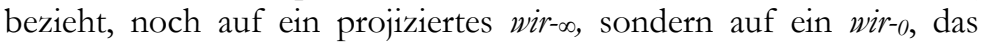
ontologisch die Möglichkeit der verschiedenen Formen enthält. Es gibt also in der Tat wir-Ö, wir-NL und wir-EU, aber immer nur im offenen Sinne, was erklärt, warum manche meinen können, man sollte diese Offenheit positiv anerkennen, während andere versuchen, die politischen Gemeinschaften zu schließen. Ob sie tatsächlich geschlossen werden, ist immer eine politische Entscheidung, philosophisch wichtig ist, dass es diese Wabl gibt. Die Offenheit der Gemeinschaft und der Gesellschaft, die ontologisch auf der Realität des wir-o beruht, kann verneint werden, aber nicht ohne es zu wissen.

\section{Literatur}

Agamben, Giorgio (1998): Homo Sacer. Sovereign Power and Bare Life. Stanford: Stanford University Press.

Antelme, Robert (2005): L'espèce humaine. Paris: Gallimard.

Connolly, William E. (2005): Pluralism. Durham/London: Duke University Press. 
182 Gemeinschaft nach der Gemeinschaft

DeLanda, Manuel (2006): A New Pbilosophy of Society. London/New York: Continuum.

Derrida, Jacques (1994): Politiques de l'amitié. Paris: Galilée.

Devisch, Ignaas (2003): Wij. Jean-Luc Nancy en het vraagstuk van de gemeenschap in de hedendaagse wijsbegeerte. Leuven: Peeters.

Dragomir, Alexandru (2004): „Utter Metaphysical Banalities”, in: Studia Phaenomenologica 4, 171-181.

Frank, Semën L. (1992): Dukhovnye osnovy obshchestva. Moskva: Respublika / Paris: YMCA Press. Deutsche Übersetzung: Simon L. Frank (2002): Die geistigen Grundlagen der Gesellschaft. Freiburg/München: Alber.

Fraser, Nancy/Honneth, Axel (2003): Umverteilung oder Anerkennung? Eine politisch-philosophische Kontroverse. Frankfurt am Main: Suhrkamp Verlag.

Honig, Bonnie (1993): Political Theory and the Displacement of Politics. Ithaca/London: Cornell University Press.

Kostjuk, Konstantin (2005): Der Begriff des Politischen in der russischorthodoxen Tradition. Paderborn: Schöningh.

Khoruzhy, Sergei S. (2005): Ocherki sinergiinoi antropologii. Moskva: Institut filosofii, teologii i istorii sv. Fomy.

Luyendijk, Joris (2007): Wie im echten Leben: von Bildern und Lügen in Zeiten des Krieges. Stuttgart: Tropen Verlag. Original: Joris Luyendijk (2006): Het zijn net mensen. Amsterdam: Podium.

Miller, David (2000): Citizenship and National Identity. Cambridge: Polity Press. Mouffe, Chantal (1993): The Return of the Political. London/New York: Verso. Nancy, Jean Luc (1996): Etre singulier pluriel. Paris: Galilée.

Nancy, Jean Luc (2001): La Communauté affrontée. Paris: Galilée.

Osborne, Peter (1995): Politics of Time. London: Verso.

Papagiannopoulos, Ilias (2006): „Re-appraising the Subject and the Social in

Western Philosophy and in Contemporary Orthodox Thought", in: Studies in East European Thought 58, 299-330.

Rasch, William (2003): „Human Rights as Geopolitics: Carl Schmitt and the Legal Form of American Supremacy", in: Cultural Critique 54 (University of Minnesota Press), 120-147.

Rawls, John (1993): Political Liberalism. New York: Columbia University Press.

Rawls, John (2002): The Law of Peoples. Cambridge Mass.: Harvard University Press.

Schmitt, Carl (1987): Der Begriff des Politischen. Berlin: Duncker \& Humblot. Staten, Henry (1985): Wittgenstein and Derrida. Oxford: Basil Blackwell. Stöckl, Kristina (2006): „Modernity and its Critique in 20th Century Russian Orthodox Thought", in: Studies in East European Thought 58, 243-269.

Stöckl, Kristina (2008): Community after Totalitarianism. The Russian Orthodox Intellectual Tradition and the Philosophical Discourse of Political Modernity. Frankfurt am Main: Peter Lang. 
Taylor, Charles (1994): „The Politics of Recognition”, in: Amy Gutmann, Hg.: Multiculturalism. Princeton: Princeton University Press.

Terpstra, Marin (2008): „Another Reference: Rome. A Comment on Nancy's Deconstruction of Christianity and His Thesis on the Impossibility of Civil Religion", in: Bijdragen 69 (3), 264-284.

Tietz, Udo (2002): Die Grenzen des Wir. Frankfurt am Main: Suhrkamp Verlag.

Walzer, Michael (1983): Spheres of Justice. New York: Basic Books.

Young, Iris M. (1990): Justice and the Politics of Difference. Princeton: Princeton University Press.

Young, Iris M. (2000): Inclusive Democracy. Oxford: Oxford University Press. Zweerde, Evert van der (2004): „...But Where is the State?”, in: Steunebrink, Gerrit/ Zweerde, Evert van der, Hg.: Civil Society, Religion, and the Nation. Amsterdam: Rodopi, 273-291.

Zweerde, Evert van der (2007): „Friendship and the Political”, in: Critical Review of International Social and Political Philosophy 10, 147-165.

Zweerde, Evert van der (2008): „Gesellschaft, Gemeinschaft, Politik: zur Aktualität der Sozialphilosophie Semen Franks“, in: Kuße, Holger, Hg.: Kultur als Dialog und Meinung. München: Otto Sagner Verlag, 113-139. 



\section{Konkrete Problemfelder}





\section{Die politische Diskussion um eine „Leitkultur“ als Kritik an Moderne und Säkularisierung}

Emil Brix

Der Begriff „Leitkultur“ wurde von dem Politikwissenschaftler Bassam Tibi vor zehn Jahren in Deutschland in die Debatte gebracht, um einen säkular bestimmten europäischen Wertekonsens als Reaktion auf die wachsende intellektuelle und politische Kritik an der Säkularisierungsthese einzufordern. ${ }^{1}$ Die Folge war allerdings eine kulturell bestimmte deutsche Diskussion um „nationale“ und „europäische“ Werte, die liberale Grundprinzipien der Moderne und der Säkularisierung in Frage stellte. Im Jahr 2000 nutzten Politiker der $\mathrm{CDU} / \mathrm{CSU}$, so der Fraktionsvorsitzende Friedrich Merz und Lothar Beckstein, diese Diskussion für eine Debatte um die angestrebte Assimilation von Zuwanderern und argumentierten gegen das Konzept eines multikulturellen Zusammenlebens („Parallelgesellschaften“). Wenig überraschend löste dies als Angriff auf den liberalen Grundkonsens seit 1945 heftigen Widerspruch aus. Die in der Folge wieder rasch beendete politische Debatte in Deutschland um eine „deutsche Leitkultur" hat aber die Problematik der Säkularisierungsthese für Europa insgesamt verdeutlicht.

Der moderne säkulare Nationalstaat als europäisches Modell des Zwanzigsten Jahrhunderts hat nach den Erfahrungen mit totalitären Regimen politische Ordnungsvorstellungen auf Grundlage kultureller Gemeinschaftsbildungen als anachronistisch und nicht 
188 Die politische Diskussion um eine „Leitkultur“

sachrational entmachtet. An die Stelle von kulturellen Wertegemeinschaften trat als politisches Ideal der liberale Rechtsstaat, der emotionale Verbundenheit nur mittels abstrakter Begriffe wie Toleranz oder in der deutschen Diskussion „Verfassungspatriotismus“2 kennt. Vergleichbar mit der Zeit der Aufklärung werden dabei abweichende komplementäre Bindungsangebote als fortschrittsfeindlich interpretiert, die modernisiert oder überwunden werden müssen. Die Reduzierung von gesellschaftlichen Bindungsoptionen erhöhte das Potential für individuelle Freiheiten. Sie schwächte aber gleichzeitig Institutionen und Haltungen, die wesentliche Anreize für solidarisches Verhalten darstellen und stärkte damit indirekt einen Kulturbegriff, der Bekenntnis und Abgrenzung einfordert. ${ }^{3}$

Eine kulturelle Wertediskussion entwickelte sich politisch in Europa nach dem Ende der ideologischen Ost-West-Teilung, weil die europäische Integration nach Ende des Kalten Krieges kein europäisches Gemeinschaftsgefühl schaffen konnte und seit 1989 durch Migration und Erweiterung der Europäischen Union der Anteil der Bevölkerung mit unterschiedlichen kulturellen Haltungen und Einstellungen deutlich zunimmt. Vor diesem Hintergrund werden heute in Europa Identitätsfragen aktualisiert. Das Schlagwort einer „Leitkultur" wurde in der Integrationsdebatte zu einem politischen Kampfbegriff, weil dieser Begriff

- gegen Pluralität und für Anpassung argumentiert (Integration als Vorgabe, Assimilation als Ziel),

- die Bedeutung von symbolischer Politik in den Vordergrund stellt (z.B. Kopftuchstreit, Moscheenbau),

- $\quad$ auf Abgrenzung von Fremden abzielt (in-out, Exklusivität).

Der Begriff Leitkultur geht davon aus, dass Gesellschaften weitgehend homogen sein müssen, um als Gemeinschaft erfolgreich agieren zu können (hohes Maß an gemeinsamen Wertvorstellungen und Verhalten). Um dies sicherzustellen, wird eine Anpassung an Mehrheitsüberzeugungen verlangt, die sich kaum von Assimilationsdiskussionen des 19. Jahrhunderts unterscheidet. Damit verbunden ist eine Modernekritik. Der Moderne wird vorgeworfen, dass sie mit der Ausschaltung von kulturellen Gruppenkonflikten gleichzeitig für 
eine zu starke Individualisierung (Darstellung des modernen Menschen als „Bürger von nirgendwo“ bei Alasdair MacIntyre) ${ }^{4}$ und eine Uniformierung der Gesellschaft (Darstellung der Moderne als „stahlhartes Gehäuse“ bei Leszek Kolakowski) verantwortlich sei. Kultur - auch Religion - lasse sich aber nicht ohne Verlust für soziale Bindungen und Ordnungen zur Privatsache machen. In den letzten Jahrzehnten wurden als Reaktion auf diese Entwicklungen Konzepte der Zivilgesellschaft entwickelt. Sie sollen den notwendigen „sozialen Kitt" sichern. Aber auch in den gängigen Zivilgesellschaftsmodellen wie sie Amitai Etzioni, Benjamin Barber, Robert Putnam oder John Keane entworfen haben (kommunitaristisch, individualistisch, deliberativ) besteht kein Einvernehmen über das Maß der Berücksichtigung kultureller Bindungen in politischen Prozessen.

Eine Analyse über den gegenwärtigen Stand der Demokratie in Europa kann mit guten Argumenten aus zwei ganz unterschiedlichen Richtungen beginnen, die aber beide auf eine Krise liberalen Denkens verweisen. Seit 1989 sind die Prinzipien Demokratie, Rechtstaatlichkeit und Marketwirtschaft die unbestrittenen Grundlagen der politischen Ordnung in Europa. Die Zahl der demokratisch regierten Gesellschaften war in Europa und weltweit noch nie so hoch wie heute. Die Europäische Union möchte - ob mit oder ohne neuen Verfassungsvertrag - die demokratische Legitimierung ihrer politischen Ordnung nachhaltig stärken. Aber man könnte auch mit dem Befund beginnen, dass Europa sich in einer tiefen, fundamentalen Krise befindet: Die EU hat ein deutliches Demokratiedefizit, kennt kaum transnationale Partizipationsmöglichkeiten für Bürger, in den Mitgliedsstaaten scheint die demokratische Legitimität zu sinken, weil immer weniger Bürger sich an Wahlen beteiligen und Meinungsumfragen verdeutlichen, dass wenig Vertrauen in die Politik und ihre Institutionen besteht.

Seit mit dem Ende der ideologischen Teilung Europas rechtsstaatliche und liberale Demokratien das unbestrittene Ideal der politischen Organisation in Europa darstellen, wächst gleichzeitig in den meisten demokratischen Staaten Europas die Kritik an einem liberalen Grundkonsens, der als zu individualistisch, als zu sehr an Institutionen und als zu sehr an Nationalstaaten orientiert gesehen wird. Es scheinen vor allem überzeugende liberale Antworten auf die zuneh- 
190 Die politische Diskussion um eine „Leitkultur“

mende „Abwanderung“ der Entscheidungsmacht von den nationalen Demokratien im Zuge der Globalisierung und auf neue moralische Versprechungen („Re-Theologisierung der Politik“5) zu fehlen. Es taucht wieder die Vermutung auf, dass eine liberale Ordnung letzten Endes die Voraussetzungen ihres eigenen Bestandes nicht garantieren kann, wenn Gesellschaften nicht weitgehend homogen sind: „Der freiheitliche, säkularisierte Staat lebt von Voraussetzungen, die er selbst nicht garantieren kann." ${ }^{\text {"6 }}$

Diese Kritik wird von unterschiedlichen Positionen aus geäuBert und enthält meist keine grundsätzlich-theoretischen Vorschläge für neue Perspektiven:

1. Politik besitze in Europa zu wenige überzeugende sozialethische und sozialpolitische Komponenten. Dies führe entweder wie in Frankreich und der Türkei - zu einer Ideologisierung der Säkularisierung (kulturelle Gruppenbindungen, so auch die Religionszugehörigkeit, werden zur Privatsache erklärt) oder zu einer multikulturellen Toleranzvorstellung, die letztlich zu sozialer Segregation und zu „Parallelgesellschaften“ beitrage. Die Herstellung von Gemeinschaft (emotionale Bindungen) wird nur auf symbolischen Ebenen (z.B. gemeinsames Logo für 50 Jahre Römische Verträge) und durch die ökonomische Phantasie des Binnenmarktes (innere Mobilität) gefördert.

2. Die demokratischen Institutionen in den europäischen Staaten lassen wenig neue Interessensformulierungen und Interessensvertretungen (Zivilgesellschaft) zu und verhalten sich gegenüber Herausforderungen wie Mobilität und Migration zumeist defensiv. Sie besitzen auch nicht die Voraussetzungen, um für eine europäische Solidarität - d.h. für ein Gemeinwohl jenseits ihrer eigenen Zuständigkeiten - eintreten zu können.

3. Es gibt zwar auf europäischer Ebene Gewaltenteilung, aber nicht im klassischen Sinne, weil die EU nur in einzelnen Bereichen über Instrumente wie ein Staat verfüge (z.B. starke Verwaltung, Europäischer Gerichtshof).

4. Die liberalen Prinzipien und Instrumente der Demokratie als Regierungsform wurden für die nationalstaatliche Organisation entwickelt und lassen sich nicht auf die europäische Ebene 
übertragen, weil es zumindest bisher keinen „europäischen de$\operatorname{mos}^{67}$ gibt.

Tatsächlich sind die Folgen für Europa eine zunehmende Entlegitimierung demokratischer Einrichtungen und Prozesse (Institutionenkritik) und vielleicht noch wichtiger, dass sowohl Politik als auch Bürger die europäische Integration nur mehr als rationales Projekt von Technokraten verstehen.

Beispielhaft wird die Krise liberalen Denkens in Europa anhand der Positionen von zwei sehr gegensätzlichen liberalen Intellektuellen deutlich, deren Einschätzungen von einer starken Skepsis bezüglich der Chancen europäischer liberaler Konstruktionen geprägt sind. Die klassische liberale Position wird von Ralf Dahrendorf vertreten. Eine der Kernthesen von Dahrendorf lautet, Demokratie sei derzeit nur im Nationalstaat möglich, weil nur er über die notwendigen Institutionen und Traditionen verfüge. ${ }^{8}$ Grundsätzlicher ist die Kritik des Philosophen Rudolf Burger („Politik muss verhandlungsfähig bleiben"), der die These aufstellt, dass es seit dem 11. September 2001 nicht mehr vernünftig sei, wenn ,einem in einer solchen Gesellschaft niemand verbindlich sagt, was richtig und gut ist ${ }^{\text {" }}{ }^{9}$ Die New Yorker Septembermorde hätten der Aufklärung wieder scharfe Konturen verschafft, die dadurch verteidigt werden müssten, dass man die „kulturelle Hierarchie von Zivilisationen“ unter Missachtung politischer Korrektheit benennt. Dahrendorf und Burger rufen zur Verteidigung der Aufklärung auf. Aber während der eine auf eine Stärkung des nationalstaatlichen Parlamentarismus vertraut, spricht der andere vom „plebejischen Hang zur Demokratie“, vom „religiösen Glutkern“ aller Kulturen und davon, dass es mit „dem sentimentalen Lob der Differenz und idyllischer Vielfalt" ${ }^{\text {“ }}$ auf absehbare Zeit vorbei sei. ${ }^{10}$

Für die Frage: „Wie religiös sind noch die Bürgergesellschaften Europas?" bedeutet dies, dass Religionen gerade in liberalen Demokratien auch Erinnerungen an (sozial)ethische Aufgaben bedeuten, die eine wiederentdeckte Aufklärung mit scharfen Konturen nicht leisten kann und will. Die fortschreitende Säkularisierung Europas ist

7 Dahrendorf (2004), 312.

8 Vgl. Dahrendorf (2002) und Ders. (2003).

9 Burger (2004), 15.

10 Burger (2004), 16. 
192 Die politische Diskussion um eine „Leitkultur“

eine soziale Tatsache. Manches spricht aber für die These: Je säkularer Demokratien auftreten, desto stärker scheint sich Politik zu theologisieren. Wenn Religiöses diskriminiert wird, entstehen Anreize für eine Ideologisierung der Politik gerade auf Grund einer Politik, die Ideologiefreiheit vertritt.

Jede Gesellschaft beruht auf Differenz und auf Vertrauen. Wer innerhalb der Rechtsordnung nicht die Rechte derer verteidigt, die anders sind als man selbst, verhält sich nicht demokratisch. Wie sehr dies zu einem ethischen Dilemma werden kann, zeigt als Beispiel die Stellungnahme einer jungen Istanbuler Filmemacherin, die in einem Artikel Die Zeit auf ihre paradoxe Lage hinwies: „Ethisch bin ich verpflichtet, für die Rechte der Religiösen einzutreten. Obwohl ich weiß, Sie werden mir irgendwann meine Rechte nehmen. "11

Politisch geht es bei der Berücksichtigung von Religion in sozialen Ordnungen um zwei Grundfragen: Welcher Stellenwert wird Religionsgemeinschaften im Rechts- und Politiksystem eingeräumt (Rechte als Gemeinschaft), und schließt die Freiheit des individuellen Religionsbekenntnisses auch Rechte im öffentlichen Bereich ein (z.B. Kreuze in Klassenzimmern, Tragen des muslimischen Kopftuches in öffentlichen Schulen in Europa, Errichtung christlicher Kirchen in arabischen Staaten, Konflikt um Errichtung einer ersten Moschee in Athen seit 1830)? Steht hinter all diesen Entwicklungen ein internationaler Trend zur Re-Theologisierung der Politik, wie dies Rudolf Burger in seinen Analysen darstellt, und wenn ja, was bedeutet dies für die Politik in Europa? Tatsächlich spielen moralische Fragen in der Politik wieder eine größere Rolle und die großen Religionen verbinden ihre Aufgaben wieder stärker mit der Politik.

Papst Benedikt hat noch in seiner Funktion als Vorsitzender der Glaubenskongregation darauf hingewiesen, dass dieses Thema zwei grundlegende Aspekte enthält. Er sagte, dass Politik nicht dem Glauben, sondern der Vernunft entnommen wird und daher die Unterscheidung zwischen Politik und Glauben wichtig ist. Die Vernunft dürfe aber nicht blind sein für moralische Fragen, sie dürfe in der Demokratie nicht zunehmend moralische Entscheidungen ablehnen, weil sonst die Politik selbst den Boden der Vernunft verlasse. ${ }^{12}$ Beide Aspekte scheinen mir wichtig. 
Wo ich Rudolf Burgers Einschätzung nicht teile, ist seine Ablehnung Europas als kulturelles Projekt, weil ein kulturell gedachtes Europa angeblich notwendigerweise zu einer Theologisierung der Politik führen müsse. Natürlich war und ist es das Grundprinzip der europäischen Integration ökonomisch und politisch zu kooperieren und kulturelle Fragen weitgehend den Nationalstaaten zu überlassen. Aber ohne das gemeinsame politische Bemühen um emotionalkulturelle Bindungen der Europäer hat das Projekt Europa längerfristig keine Chance, von der Mehrheit der Menschen in allen Mitgliedsstaaten akzeptiert und mitgetragen zu werden. Wir sehen dies bei der aktuellen Diskussion um einen Verfassungsvertrag, und auch jedes weitere Projekt der Vertiefung und Erweiterung muss sich dieser Frage stellen.

Burger weist zu Recht immer wieder darauf hin, dass in gewissem Maße Säkularisierung und Modernisierung auseinander laufen. Aber die Konsequenz für die Europäische Union kann nicht sein, sich deshalb vor kulturellen und wertebezogenen Diskussionen über Europa zu fürchten. Wir sollten eher überlegen, ob nicht die auffallende Theologisierung der Politik in so unterschiedlichen Staaten wie den USA und dem Iran gemeinsame Wurzeln hat und ob es nicht gerade ein Ergebnis europäischer Erfahrungen bis in die jüngste Zeit ist, der Reflexion über derartige Prozesse Platz zu geben, also den schwierigen Weg des Dialogs zu gehen.

Europäisch scheint mir zu sein, Kultur als Infragestellung von Entwicklungen zu verstehen, die wir beobachten können:

- Ist es ein theologisches Erbe, dass religiöse Berufung zu einem weltlichen Anspruch werden kann, die Welt zu verbessern und dies mit der Überzeugung, dass die Welt im Argen liegt und erneuert werden muss?

- Muss Politik auf einem teleologischen Weltbild beruhen? Sogar der sehr pragmatisch argumentierende Alexis de Tocqueville hat vom unaufhaltsamen Vormarsch der Demokratie gesprochen. Die Welt sei am Weg zur Demokratie; dies sei ein Auftrag universal und dauerhaft - wie eine göttliche Vorsehung.

- Entsteht daraus ein „Kampf der Kulturen“ wie Samuel Huntington behauptet hat, weil in einer globalisierten Welt dieser Anspruch quasireligiöse Züge annimmt und damit unterstützt, dass die religiösen und kulturellen Grenzen wieder auftauchen müssen? 
194 Die politische Diskussion um eine „Leitkultur“

Ich denke, diese kulturellen Diskussionen müssen in Europa geführt werden können ohne sofort unter den Verdacht einer ReTheologisierung der Politik gestellt zu werden. So haben etwa die Erweiterung der Europäischen Union 2004 und 2007 weniger säkulare Gesellschaften zu einem Teil der EU gemacht. Werden diese Gesellschaften nun einfach mit Verspätung säkularisiert? Länder wie Polen stellen in Frage, dass Säkularisierung ein notwendigerweise mit Modernisierung verknüpfter, teleologischer Prozess ist, vielmehr erscheint sie als Resultat einer historischen Entscheidung der Europäer.

Der Religionssoziologe José Casanova stellt dazu fragend fest: „Ein modernes religiöses Polen könnte vielleicht die säkularen Europäer zwingen, ihre säkularistischen Grundannahmen zu überdenken und zu erkennen, dass es nicht so sehr Polen an Gleichzeitigkeit mit Europa, sondern dem säkularen Europa an Gleichzeitigkeit mit dem Rest der Welt und mit globalen Tendenzen mangelt.“13

Diese Fragen weisen darauf hin, dass für die Zukunft Europas heute die Stärkung von republikanischen Prinzipien (Konstitutionalismus, Beratung, Repräsentation) wichtiger sein könnte als die notwendigen Anpassungen des Konzepts der Demokratie an die spezifische Form der europäischen politischen Ordnung.

Die europäischen Gesellschaften besitzen tatsächlich einen ,religiösen Glutkern“, der bei Werteentscheidungen unterschiedlich stark mitbedacht wird und heute teilweise durch die Zuwanderung muslimischer Bevölkerung sowie die Erweiterung der Europäischen Union politisch wieder relevanter wird. Politik wird auch unter diesen geänderten Voraussetzungen verhandlungsfähig bleiben. Aber sie muss zusätzliche Ressourcen für Gemeinschaftsbildungen stärker berücksichtigen, von der rechtlichen und gesellschaftlichen Verankerung der Religionsgemeinschaften und der friktionsfreien oder zumindest mehrheitsfähigen Zulassung des Religiösen im öffentlichen Raum bis zur Tatsache, dass Integrationsfragen nicht ausschließlich als sicherheitspolitisches Problem interpretiert und behandelt werden können. 


\section{Literatur}

Böckenförde, Ernst-Wolfgang (1976): Staat, Gesellschaft, Freiheit. Frankfurt a.M.: Suhrkamp.

Burger, Rudolf (2004): „Retheologisierung der Politik und weltpolitische Konfliktkonstellationen", in: Studien und Berichte zur Sicherbeitspolitik. Schriftenreibe der Landesverteidigungsakademie Wien 1/2004, 10-24: http://www.bmlv.gv.at/pdf_pool/publikationen/08_kwd_burger.pdf (Zugriff am 29.4.2009).

Burger, Rudolf (2005): Re-Theologisierung der Politik? Wertedebatten und Mahnreden. Springe: Verlag zu Klampen.

Casanova, Jose (2003): „Das katholische Polen im nachchristlichen Europa”, in: Transit Nr. 25, 50-65.

Dahrendorf, Ralf (2002): Die Krisen der Demokratie. Ein Gespräch mit Antonio Polito. München: Beck.

Dahrendorf, Ralf (2003): Auf der Suche nach einer neuen Ordnung. Eine Politik der Freibeit für das 21. Jabrbundert. München: Beck.

Dahrendorf, Ralf (2004): „Alltags-Europa, Sonntags-Europa. Wer schliesst die Kluft?", in: Ders.: Der Wiederbeginn der Geschichte. Vom Fall der Mauer zum Krieg im Irak. Reden und Aufsätze: München: Beck, 304-313.

Habermas, Jürgen (1992): „Staatsbürgerschaft und nationale Identität”, in: Ders.: Faktiqität und Geltung. Beiträge zur Diskurstheorie des Rechts und des demokratischen Rechtsstaats. Frankfurt a.M: Suhrkamp, 632-659.

Habermas, Jürgen/Ratzinger, Josef (2005): Dialektik der Säkularisierung. Über Vernunft und Religion. Mit einem Vorwort herausgegeben von Florian Schuller. Freiburg i.Br.: Herder.

Huntington, Samuel P. (1996): Kampf der Kulturen. Die Neugestaltung der Weltpolitik im 21. Jabrbundert. München/Wien: Europaverlag.

MacIntyre, Alasdair: „Ist Patriotismus eine Tugend?”, In: Honneth, Axel, Hg.: Kommunitarismus. Eine Debatte über die moralischen Grundlagen moderner Gesellschaften, Frankfurt a. M./New York: Campus Verlag, 84-102.

Tibi, Bassam (1998): Europa obne Identität? Die Krise der multikulturellen Gesellschaft. München : Bertelsmann.

Wiedemann, Charlotte (2006): „Republik contra Religion. Ein selbstbewusster neuer Islam bedrängt die alten kemalistischen Eliten", in: Die Zeit Nr. 33, 10. August. 



\section{Freier Markt statt freie Bürger. Über die Tendenzen einer transzendenzvergessenen Gesellschaft zum Wirtschaftsliberalismus}

Wilhelm Guggenberger

In diesem Beitrag soll das Zweigespann Politik und Religion noch um einen dritten Bezugspunkt erweitert werden: um Ökonomie bzw. Markt. Der politisch-philosophische Diskurs der Moderne ist unter anderem durch - einen im weitesten Sinn des Wortes verstandenen - Liberalismus geprägt, der immer wieder mit religiösen Diskursen in Konflikt gerät oder zumindest zu geraten scheint. Liberalismus ist nun aber nicht nur eine gesellschaftspolitische Signatur, sondern auch eine ökonomische. In der Gegenwart wird mit dem Terminus liberal vermutlich sogar in erster Linie eine spezifische Gestalt von Wirtschaft assoziiert. Diese steht wiederum in einem Spannungsverhältnis zu Politik, sofern diese eine steuernde und gestaltende Funktion in der Gesamtgesellschaft für sich beansprucht. ${ }^{1}$ Ich werde im Folgenden den Blick auf das Verhältnis zwischen MarktÖkonomie und Religion fokussieren, um zu sehen, ob sich daraus auch etwas für die Analyse des politisch-philosophischen Diskurses, gerade im Hinblick auf dessen Auseinandersetzung mit Religion, lernen lässt. Meine zu prüfende Ausgangsvermutung dabei ist, dass

1 Charles Taylor sieht eine unauflösbare Spannung zwischen dem Konzept des sich selbst regierenden Volkes und jenem des durch eine unsichtbare Hand geleiteten Marktes. Das erste Konzept geht von der Vorstellung eines kollektiven Handlungssubjektes aus, während sich in zweiterem das eigentliche Geschehen hinter dem Rücken der Akteure quasi automatisch herausbildet. Vgl. Taylor (2005), 76-77. 
die (neuzeitliche) Entwicklung der Verhältnisse Religion-Politik und Religion-Ökonomie weitgehend parallel verläuft, dass sich daraus aber keine Harmonisierung des Verhältnisses Politik-Ökonomie ergibt, sondern im Gegenteil eine Verschärfung der Spannungen in diesem Verhältnis. So dürfte im Gegenzug eine verstärkte Berücksichtigung religiöser Realitäten dem politisch-philosophischen Diskurs und dem gesellschaftspolitischen Handeln im Hinblick auf eine politische Hegung des freien Marktes durchaus hilfreich, wenn nicht gar unverzichtbar sein.

\section{Zwei Konzepte des freien Bürgers}

Ich möchte zur Entfaltung dieser Gedanken meinen Ausgang bei der etwas aus der Mode geratenen Unterscheidung zwischen Citoyen und Bourgeois nehmen. Im Deutschen werden beide Begriffe mit dem Wort Bürger wiedergegeben. Sprachgeschichtlich bezeichnet das eine den Bewohner einer Stadt - wohl auch im Sinne der Polis -, das andere den Bewohner einer befestigten, von einer Schutzmauer umgebenen Ansiedlung; im Wesentlichen also dasselbe Faktum. Spätestens seit Rousseau ist mit Citoyen aber der republikanische Bürger gemeint, der den Gemeinwillen der Gesellschaft mit trägt und sich vom Staat, der Polis und seinen/ihren Angelegenheiten in die Pflicht nehmen lässt. Bourgeois hingegen bezeichnet den Besitzbürger, der seine Identität vor allem aus dem Eigentum gewinnt, um das er - gemäß Rousseau - einen Zaun gezogen und damit eine Bruchlinie der Ungleichheit in die menschliche Gesellschaft gebracht hat.

Durch Karl Marx wurde der Bourgeois endgültig zum Inbegriff jener Klasse, die durch selbstsüchtige Ausbeutung vor allem des Proletariats gekennzeichnet ist und keinerlei Sinn für Schaffung und Pflege des Gemeinwohls hat. Worin die Problematik des bourgeoisen Bürgers, der seine Rechte, nicht aber seine Pflichten ernst zu nehmen bereit ist, auch jenseits Marxscher Klassenkampfrhetorik besteht, beschreibt folgendes Zitat aus der Deutschen Ideologie meines Erachtens sehr deutlich. Dabei muss man allerdings über die ungu- 
ten antisemitischen Töne hinwegsehen, die hier auch angeschlagen werden. ${ }^{2}$

„Der Bourgeois verhält sich zu den Institutionen seines Regimes wie der Jude zum Gesetz; er umgeht sie, sooft es tunlich ist, in jedem einzelnen Fall, aber er will, dass alle Andern sie halten sollen. Wenn sämtliche Bourgeois in Masse und auf Einmal die Institutionen der Bourgeoisie umgingen, so würden sie aufhören, Bourgeois zu sein - ein Verhalten, das ihnen natürlich nicht einfällt und keineswegs von ihrem Wollen oder Laufen abhängt. Der liederliche Bourgeois umgeht die Ehe und begeht heimlichen Ehebruch; der Kaufmann umgeht die Institution des Eigentums, indem er andre durch Spekulation, Bankerott pp. um ihr Eigentum bringt - der junge Bourgeois macht sich von seiner eignen Familie unabhängig, wenn er kann, löst für sich die Familie praktisch auf; aber die Ehe, das Eigentum, die Familie bleiben theoretisch unangetastet, weil sie praktisch die Grundlagen sind, auf denen die Bourgeoisie ihre Herrschaft errichtet hat, weil sie in ihrer Bourgeoisform die Bedingungen sind, die den Bourgeois zum Bourgeois machen [...]."3

Dieser Text schildert jenen Sachverhalt, den die soziologische Spieltheorie in ihrer Diktion als Free-Rider-Phänomen (Trittbrettfahrertum) oder auch als moral hazard bezeichnet. Es handelt sich dabei um ein Phänomen, das insbesondere dort auftritt, wo die Einhaltung normativer Interaktionsstrukturen nicht oder nur geringfügig überwacht und ihre Verletzung nicht entsprechend sanktioniert wird. Unter marktwirtschaftlichen Bedingungen wird das Free-RiderPhänomen daher umso mehr zum Problem, je weniger Regulierung gegeben ist. Zwar gelten in einer deregulierten Ökonomie sehr wohl Verhaltenserwartungen - als deren Möglichkeitsbedingung und Voraussetzung -, diese sind aber nicht festgeschrieben, noch weniger sanktionsbewehrt und daher individuell relativ leicht zu umgehen. Damit besteht die Tendenz, das öffentliche Gut des Wohlverhaltens anderer zu nutzen, selbst aber nicht zu dessen Bereitstellung oder Erhaltung beizutragen. Salopp könnte man also formulieren: Je liberaler Ökonomie gestaltet ist, desto mehr Raum hat die Bourgeoisie im Sinn von Karl Marx.

2 Marx spielt hier auf der Klaviatur von Vorurteilen, die die moralisch fragwürdige Position der Bourgeoisie illustrieren sollen. Auch wenn diese Vorurteile unhaltbar sind, muss das eigentlich im Zentrum stehende Urteil nicht ebenso falsch sein.

3 Marx/Engels (1969), 163f. 
Nun ist Wirtschaftsliberalismus freilich keineswegs identisch mit gesellschaftspolitischem Liberalismus. Der St. Gallener Wirtschaftsethiker Peter Ulrich, der sein Denken ganz in die Tradition von Kant, Apel und Habermas stellt, sieht den politischen Liberalismus geradezu als Gegenpol zur Logik des freien Marktes. Während auf dem Markt der freie Vorteilstausch auf der Grundlage zweckrationaler, instrumenteller Vernunft dominiert, ist der politische Liberalismus eine Gesellschaftsform, der es um die Legitimierung der gesellschaftlichen Strukturen auf der Grundlage wechselseitiger Anerkennung von Individuen geht. Diese sprechen einander gleiche und unantastbare Persönlichkeits- und Bürgerrechte zu, so Ulrich. Wörtlich schreibt er über die neoliberale Metaphysik des Marktes: „Sie dient im Kern exakt der Abwehr des [...] postulierten Primats der politischen Ethik vor dem Markt - als Voraussetzung zur Durchsetzung einer marktradikalen Politik, die sich als liberal ausgibt, damit aber nur den, freien Markt', nicht etwa das politischliberale Ideal einer Gesellschaft freier und gleichberechtigter Bürger meint."4 Der dieserart entstehenden Situation, in der ökonomische Strukturen sich der Gestaltung durch die freien und gleichberechtigten Bürger, das heißt der Gestaltung durch den Souverän einer politisch-liberalen Ordnung, mehr und mehr entziehen, entspricht eine bestimmte Haltung der Gesellschaftssubjekte. Benjamin Barber hat diese vor einiger Zeit in einem Interview zu seinem jüngsten Buch Consumed so charakterisiert: „Die Gefahr liegt darin, dass man glaubt, es reiche, ein guter Verbraucher zu sein, um ein engagierter Bürger zu sein. Der Verbraucher trifft eine private Wahl. Er fragt: Was will ich? Der Bürger hingegen trifft eine öffentliche Wahl. Er fragt: Was braucht die Gemeinde? Was die Gesellschaft? Was unsere Kinder? Das können sehr unterschiedliche Dinge sein."5

Wie kommt es aber zum nicht nur von Barber beklagten Verlust von Bürgersinn? Wie kommt es dazu, dass die Citoyens mehr und mehr zu Bourgeois werden, indem sie sich letztlich damit zufrieden geben, dass Freiheit auf Konsumfreiheit reduziert wird?

Meine These, die ich hier als Antwortversuch auf diese Frage vorlege, lautet: Es gibt in der Aufklärungstradition eine Drift vom politischen Liberalismus des Citoyen hin zum wirtschaftlichen Libe- 
ralismus des Bourgeois. Diese Drift ergibt sich nicht aus den Aufklärungsimpulsen im Allgemeinen, sondern aus dem durch Aufklärung ermöglichten, vielleicht auch ermunterten Versuch einer Gesellschaftsgestaltung unabhängig von jeder Bezugnahme auf gesellschaftstranszendente Fixpunkte oder Autoritäten.

Ich versuche diese These innerhalb des Theoriecorpus des schottischen Aufklärers Adam Smith unter Bezugnahme auf David Hume zu verifizieren. Ein derartiges methodisches Vorgehen ermöglicht freilich nicht die Erarbeitung von so etwas wie einem allgemeinen gesellschaftlichen Entwicklungsgesetz. Darum geht es auch gar nicht. Mein Interesse zielt vielmehr darauf, einem bestimmten Denkansatz nachzugehen und wahrzunehmen, wohin dieser Ansatz konsequent und kohärent ausgezogen letztlich führen kann, auch wenn der so erreichte Endpunkt mit den Ursprungsintentionen seines Urhebers längst nichts mehr zu tun haben mag.

Bevor ich mich also Adam Smith zuwende, sei noch in knappen Worten begründet, weshalb gerade er als Referenzautor gewählt wurde. Smith ist gemeinhin als Urheber der modernen Volkswirtschaftslehre bekannt, ja man könnte ihn geradezu „Kirchenvater” aller wirtschaftsliberalen Denkkonzepte bezeichnen. Zugleich lebt er aber nicht nur zur Kernzeit der Aufklärungsbewegung, sondern ist auch selbst Denker der (schottischen) Aufklärung. Damit vereinigt dieser Autor in seiner Person sowohl den umfassenden Freiheitsimpuls der Aufklärung als auch die Forcierung der Marktfreiheit. Beides steht aber nicht einfach unvermittelt nebeneinander, wie ich meine, vielmehr findet sich im Werk Adam Smiths genau jene Verschiebung, um die es mir hier geht: die Verschiebung - wie man es wohl auch formulieren könnte - vom aufgeklärten Subjekt, das Sittlichkeit am Kriterium der Universalisierbarkeit von Verhaltensmaximen bemisst, hin zum Marktteilnehmer, der sein Verhalten am eigenen Vorteil orientiert. Dieser vorteilsorientierte Marktteilnehmer mag durch die Konsequenzen seines Handelns zwar vielfach dem Gemeinwohl dienen - so zumindest die ökonomische Theorie -, er tut dies aber obwohl oder gerade weil er es nicht beabsichtigt. Dass diese merkwürdige Verschiebung sich tatsächlich innerhalb des Werkes von Adam Smith beobachten lässt, hat bei seinen Interpreten immer wieder für Verwirrung und Staunen gesorgt und ist in die Literatur als das Adam-Smith-Problem eingegangen. Ich meine jedoch, dass darin letztlich ein konsequenter Gedankengang zum Ausdruck 
kommt. Das heißt, dass die Drift vom Citoyen zum Bourgeois in Smiths Werk nicht bloß eine nachträgliche Verzerrung ursprünglicher Gedanken oder eine Dekadenz in der Rezeptionsgeschichte darstellt, sondern vielmehr von allem Anfang an in der Theoriearchitektur des Autors angelegt ist.

Als weiteres Argument für eine Beschäftigung mit Smith in diesem Kontext möchte ich anführen, dass er wohl ohne jeden Zweifel als ausgezeichneter und hellsichtiger Beobachter menschlicher Empfindungen und zwischenmenschlicher Beziehungen gelten darf. Es kann also davon ausgegangen werden, dass seine Schlussfolgerungen ein anthropologisches fundamentum in re haben und nicht nur Denkgespinste eines Theoretikers sind. Die akribische Beobachtung menschlichen Verhaltens ist es letztlich auch, die es Smith versagt, alle Brüche und Ungereimtheiten aus seinem Konzept zu tilgen. Sofern ich mich also besonders an diesen Brüchen orientiere, geschieht das nicht im Interesse der Kritik an einer großen Gestalt der Geistesgeschichte, sondern gerade in Anerkennung deren „empirischer" Feinfühligkeit und wissenschaftlichen Aufrichtigkeit.

\section{Die Moralphilosophie Adam Smiths}

Was damit gemeint ist, wenn ich vom Freiheitsimpuls der Aufklärung im Hinblick auf Smith spreche, lässt sich an der Moralphilosophie dieses Autors verdeutlichen. ${ }^{6}$ In der Theorie der ethischen Gefübleerstmals veröffentlicht 1759 - unternimmt Smith den Versuch, die Grundlage ethischer Normen zu bestimmen, indem er die Frage beantwortet, wie Menschen zu sittlichen Urteilen über Charakter und Verhalten der eigenen, sowie anderer Personen, als auch zu Entscheidungen über das richtige Verhalten kommen. Die Antworten, die er vorlegt, sind jenen seines Freundes David Hume sehr ähnlich. Für beide ist die Grundlage von Ethik die Fähigkeit der Einfühlung in andere, die Fähigkeit der sympathy, wie sie es nennen. Die Begründung sittlicher Normen aus religiösen Vorstellungen oder ihre Rückführung auf religiöse Gebote tritt im Gegenzug bei beiden Denkern radikal in den Hintergrund. Für Hume gilt dies zweifellos noch mehr als für Smith. Hume bezeichnet Moral als rein menschli- 
che, natürliche Angelegenheit. Von diesem Standpunkt aus äußert er sein Erstaunen darüber, wie etwa Francis Hutcheson einerseits eine moral-sense-Theorie vertreten und dennoch von einer göttlich begründeten Moral sprechen konnte. ${ }^{7}$ Es wäre sicherlich verfehlt, Smith oder Hume aufgrund dessen zu unterstellen, sie seien areligiöse Menschen oder auch nur säkulare, gottlose Denker gewesen. Beide waren aber, was zu ihrer Zeit und in ihrem sozialen Milieu eher die Regel denn die Ausnahme darstellte, Deisten.

Der Deismus des 18. Jahrhunderts erwuchs wohl auch aus der Tatsache, dass der Gedanke einer zugegebenermaßen oft recht einfältig präsentierten speziellen Vorsehung Gottes vor dem Forum einer kritischen Vernunft nicht mehr zu bestehen vermochte. Hume etwa hatte hinsichtlich der Diskussion um Wunder gemeint, man müsse diese wohl oder übel als nachträgliche Korrekturmaßnahmen Gottes an seiner Schöpfung verstehen, was doch eine merkwürdige Vorstellung sei und den allmächtigen und allwissenden Schöpfer in ein recht unvorteilhaftes Licht rücke. Eher denn als fehlerhaftes, nachbesserungsbedürftiges Machwerk sei die Schöpfung doch als weitgehend perfekter Mechanismus zu denken, dessen Qualität gerade darin besteht, dass sein Urheber sich nicht mehr um ihn zu kümmern braucht, wenn er erst einmal in Gang gesetzt ist. Smith schreibt in diesem Zusammenhang recht ausführlich über das Bild von Uhrwerk und Uhrmacher. Auch Dummheit und Laster der Menschen sieht er übrigens als eingeplante Rädchen in diesem Werk, so dass es ihm nicht schwer fällt anzuerkennen, dass Dummheit und Laster vielfach eher Gutes bewirken, als Weisheit und Tugend.

Auch wenn der Gottesgedanke in der schottischen Aufklärung also keineswegs geleugnet wird, finden wir dennoch sowohl bei Hume, als auch bei Smith so etwas wie einen sozietal-lebensweltlichen Säkularismus. Denn der Gottesgedanke spielt keinerlei substanzielle Rolle in der Gestaltung menschlichen Entscheidens und Handelns ${ }^{8}$ er wird damit auch reichlich überflüssig im Hinblick

7 Vgl. Brandt (1973), XLIIf. „Moral sense“ meint einen gleichsam naturgegebenen Sinn, der die Dimension des Ethischen ebenso wahrzunehmen und in seinen Schattierungen zu unterscheiden in der Lage ist, wie der Gesichtssinn das Licht.

8 Gott taugt noch zum „Kinderschreck” und als Garant einer vergeltenden Gerechtigkeit im Jenseits. Smith gesteht ihm Motivationskraft, aber keine Begründungs- oder Orientierungskraft im Bereich der Ethik zu. Dies ist eine allgemeine Tendenz in der schottischen Aufklärung. Vgl. Beck (2007), 66. 
auf die Formung gesellschaftlichen Lebens. ${ }^{9}$ Gott wirkt nicht innerhalb der Geschichte; er bewirkt demgemäß auch (fast) nichts in der Ethik des Adam Smith.

Auf diese Weise wird Ethik aus der vernunftlosen Unterwerfung unter eine göttliche Autorität gelöst. Einer theonomen Normenbegründung wird bestenfalls als Aberglaube der breiten Masse eine gewisse gesellschaftsstabilisierende Wirkung zugestanden, obwohl Hume auch daran seine Zweifel hegt. ${ }^{10}$ Doch die Handlungsorientierung der Menschen soll nicht nur aus der Unmündigkeit gegenüber religiösen Geboten, sondern auch aus der Unmündigkeit gegenüber der Willkür politischer Macht befreit werden. Das, so Smith, ist das Anliegen der Vernunftethik, deren Ursprünge er im britischen Bereich vor allem in einer Zurückweisung des Dezisionismus im Stile Thomas Hobbes' sieht. „Es wurde deshalb zu dieser Zeit allgemein herrschende Lehre, dass das Wesen von Tugend und Laster nicht in der Übereinstimmung der Handlungen mit dem Gesetz eines Höheren liegen, sondern in der Übereinstimmung oder Nichtübereinstimmung mit der Vernunft, die so als die ursprüngliche Quelle und als das ursprüngliche Prinzip der Billigung und Missbilligung angesehen wurde." 11

Im Unterschied vor allem zur deutschen Aufklärung finden wir bei den Schotten aber eine deutlich größere Vernunftskepsis. Smith meint, die Vernunft könne als Grundlage sittlicher Urteile betrachtet werden, wenn man damit meint, dass wir auf der Basis einer Vielzahl von Erfahrungen induktiv zu begründeten Urteilen kommen. Eine deduktive Ableitung sittlicher Urteile aus allgemeinen Vernunftprinzipien weist er aber als ganz und gar unverständlich zurück. ${ }^{12}$ Für

9 In der gesamten Theorie der ethischen Gefüble findet sich denn auch keine einzige Referenz auf Jesus Christus oder andere biblische Gestalten. Binswanger hat nachgewiesen, dass solche Referenzen, die in der ersten Auflage des Werkes noch vorhanden waren, von Smith im Zuge späterer Überarbeitung konsequent getilgt wurden. Vgl. Binswanger (1998), 55.

10 Vgl. Hume (1968), 112-113. Smith dürfte in dieser Hinsicht etwas optimistischer gewesen sein. Vgl. Smith (1994), 248. Religiöses Pflichtgefühl kann Menschen aber auch in die Irre leiten. Vgl. Smith (1994), 269-271.

11 Smith (1994), 532. Smith spielt mit dem Ausdruck ,zu dieser Zeit” wohl auch auf seinen Lehrer und Vorgänger Hutcheson an.

12 Vgl. Smith (1994), 532-533. 
Smith liegt die unmittelbare Empfindung der Vernunft voraus. ${ }^{13}$ Auch darin stimmt er mit Hume überein, der feststellt: „Sittlichkeit wird also viel mehr gefühlt als beurteilt." 14 Sie ist nicht so sehr ein Ergebnis von ideas, als vielmehr von impressions. Allerdings will Smith auch keinen unmittelbaren moralischen Sinn in Analogie zu den physischen Sinnen annehmen. ${ }^{15}$ Billigung bzw. Missbilligung - darin bestehen für ihn sittliche Urteile - gründen seiner Ansicht nach vielmehr allein in der bereits erwähnten Fähigkeit der Sympathie. Darunter darf nun aber nicht emphatisches Wohlwollen verstanden werden, sondern schlicht Resonanzfähigkeit. Hume bedient sich zur Beschreibung dieses Phänomens des Bildes von Saiten an Musikinstrumenten. Menschen verhalten sich wie gleichgestimmte Saiten: Schwingt eine von ihnen, können die anderen nicht anders, als mit $\mathrm{zu}$ vibrieren. ${ }^{16}$ Wenn wir also andere Menschen wahrnehmen, teilt sich uns ihre Gefühlslage gleichsam unausweichlich, wenn auch meist abgeschwächt mit. Diese Darstellung entspricht interessanter Weise neuesten neurowissenschaftlichen Erkenntnissen, die nachgewiesen haben, dass so genannte Spiegelneuronen im menschlichen Gehirn unwillkürliche emotionale Resonanzen in uns wachrufen, sobald wir das Verhalten und die wie auch immer geäußerten Emotionen anderer Menschen beobachten. ${ }^{17}$

Wenngleich Sympathie die formale Voraussetzung für das Entstehen sittlicher Normen darstellt, so beinhaltet sie selbst doch keine wertenden Urteile über Verhaltensweisen oder Charaktereigenschaften. Solche Urteile ergeben sich erst aus wechselseitiger Beobachtung von Akteuren. ${ }^{18}$ Jeder Beobachter legt dabei seine eigenen Empfindungen als Maßstab an das an, was er beim anderen sieht. Auf diese Weise bildet er sich ein Urteil über sittliche Angemessen-

13 Ein Verständnis von Tugend, das auf eine Austilgung der Affekte zielt, führt als Gegenbewegung letztlich sogar zu Theorien, die alle sittliche Bindung aufheben. So sieht es Smith in Auseinandersetzung mit Mandeville. Vgl. Smith (1994), 521.

14 Hume (1973), II/III 212.

15 Vgl. Smith (1994), 536-538.

16 Hume (1973), 329.

17 Vgl. etwa die Übersichtliche Einführung von Bauer (2006). Dort heißt es u.a.: „Die Beobachtung einer durch einen anderen vollzogenen Handlung aktiviert im Beobachter [...] ein eigenes neurobiologisches Programm, und zwar genau das Programm, das die beobachtete Handlung bei ihm selbst zur Ausführung bringen könnte.” Bauer (2006), 23.

18 Vgl. Luhmann (1997), 1022. In Luhmann (1993), 411 wird der Sympathiebegriff von Smith als Fähigkeit des Beobachtens der Beobachtungen anderer reformuliert. Vgl. Smith (1994), 15. 
heit oder Unangemessenheit. Dieser vom Beobachter herangezogene Vergleichsmaßstab besteht nun aber gerade nicht aus unverrückbaren, gleichsam naturgegebenen Normen, die das Subjekt in sich vorfinden würde. Die angelegte Richtschnur entsteht vielmehr ihrerseits daraus, dass das Subjekt an sich selbst die (imaginierten) Maßstäbe der anderen anlegt. Wir können hier geradezu von einer Beobachtung zweiter Ordnung sprechen, da ich nicht nur das Verhalten anderer wahrnehme, sondern auch und besonders deren urteilende Reaktion auf mein eigenes Verhalten. So ist es für Smith ganz zentral, dass wir in der Lage sind, unser Verhalten ,,mit den Augen anderer Leute zu betrachten, das heißt, so, wie andere Leute sie wahrscheinlich betrachten würden. “19

Auf diese Weise bringen menschliche Individuen füreinander in einem zyklischen Prozess wechselseitiger Beurteilung das zum Ausdruck, was Smith als propriety bezeichnet (Angemessenheit und Schicklichkeit des Verhaltens). Da wir uns nach Anerkennung und Billigung durch andere sehnen und darum bemühen - das ist eine anthropologische Konstante für Smith - wird unser Streben dahin gehen, diesem Angemessenheitsurteil zu entsprechen, so dass nach und nach ein kultureller Verhaltenskodex entsteht; letztlich ein Ethos.

Meines Erachtens haben wir es hier mit einer Moralbegründung zu tun, die deutlich moderner als die kantische Vernunftethik ist, da sie wirklich weitestgehend ohne heteronome Norm auszukommen vermag, indem sie letztlich auch auf einen objektivierbaren Wahrheitsbegriff verzichtet. Überdies ist diese Moralbegründung realistischer, als die Habermas'sche Diskursethik, weil sie für die sittlichen Subjekte nicht anspruchsvolle Argumentationsfähigkeit voraussetzt, sondern lediglich die Potenz zu gleichsam spontan-unwillkürlichem Empfinden und Reagieren.

\section{Orientierung ohne Abschlussgedanken}

Im Grunde ist damit ein geniales Konzept entwickelt, das nicht auf die Letztbegründung sittlicher Normen, sei es durch Religion, sei es durch Vernunftargumente, sei es durch Bezugnahme auf eine gege-

19 Smith (1994), 172. Auf diese Weise bildet sich im Individuum die Instanz des unparteiischen Beobachters, der im Denken Smiths ein Äquivalent zum Gewissensbegriff darstellt. 
bene Naturordnung angewiesen ist. Smith könnte sich damit zufrieden geben, wäre er nicht ein so präziser und aufrichtiger Beobachter der menschlichen Realität. Denn - so muss er feststellen - derselbe Mechanismus, den er als Ursprung und Grundlage ethischer Urteile beschreibt, kann auch in einem gesellschaftlich problematischen und konfliktträchtigen Jahrmarkt der Eitelkeiten enden.

Das Problem, das sich Smith stellt, liegt im Grunde auf der Hand; denn was sich als schicklich und passend durchsetzt, ist inhaltlich völlig unbestimmt. Smith müsste konsequenter Weise wohl einem reinen Evolutionismus sittlicher Normen zustimmen. Er vermeidet dies allerdings dadurch, dass er auf einen prästabilierten Plan Gottes setzt, auf den Konstruktionsplan des kosmischen Uhrmachers, der das Geschick der Menschheit letztlich zu einem guten Ende führen wird, auch wenn unserem Verstehen verborgen bleiben mag, auf welche Weise dies geschieht. Spätere Denker, die Smith positiv rezipieren, wie F. A. von Hayek, lassen diesen Gedanken ihres Gewährsmanns stillschweigend unter den Tisch fallen und setzen gänzlich auf eine selbstemergente Ordnung der Gesellschaft. ${ }^{20}$ Man kann ihnen zugute halten, dass sie sich damit keiner signifikanten Abweichung von den Gedanken Smiths schuldig machen, ist dessen deistische Religiosität doch im Grunde nicht mehr als eine besänftigende Hoffnung auf einen guten Ausgang der Geschichte jenseits des Bereichs, der unserer eigenen Verantwortung zugänglich ist. Inhaltliche Impulse wurden dadurch ohnedies nicht in die Gesellschaftsgestaltung eingebracht.

Allerdings lässt sich feststellen, dass der schottische Moralphilosoph offensichtlich einen Wertefundus mit sich trug, der dem, was sich aus dem Wechselspiel der Beobachtungen als angemessen ergibt, voraus liegt und dieses diskriminierend bewertet. Smith will bestimmte Werte und Normen aufrechterhalten, obwohl sich deren Geltung aus seiner Theorie der Moralbegründung genau genommen nicht ableiten lässt. Nach Alasdair McIntyre trifft das auch auf Hume, Kant, Diderot, Kierkegaard und andere zu. ${ }^{21}$ Ich möchte diese Behauptung für Smith anhand jenes Kapitels aus der Theorie der ethischen Gefüble belegen, das von der Verfälschung der ethischen Gefühle 
durch die Bewunderung für Reichtum und gesellschaftlichen Status handelt.

Sich im eigenen Verhalten an wechselseitiger Billigung zu orientieren, bedeutet zugleich eine Ausrichtung auf Anerkennung und Ansehen. Um zu Anerkennung zu gelangen gibt es gemäß Smith aber zwei unterschiedliche Wege. Der eine besteht im Erwerb von Reichtum und Vornehmheit, in stolzem Ehrgeiz und prahlerischer Habgier, der andere besteht im Streben nach Weisheit und Tugend mit den Mitteln der Gerechtigkeit und der demütigen Bescheidenheit. Dementsprechend bieten sich uns zwei Musterbilder zur Orientierung, wie zwei Gemälde, die uns ein erstrebenswertes Lebensmodell vor Augen führen. Das eine ,schimmernder und glänzender in seiner Färbung, das andere richtiger und von erlesenerer Schönheit in seinen Umrissen; das eine drängt sich der Beachtung eines jeden planlos umherschweifenden Auges auf, das andere zieht kaum die Aufmerksamkeit irgend eines anderen Menschen auf sich, als die eines besonders eifrigen und sorgsamen Betrachters." 22 Für Smith besteht nicht der geringste Zweifel daran, an welchem der beiden Bilder wir uns orientieren sollten, ja er präsentiert das schimmerndere, glänzendere und auffälligere unumwunden als Trugbild. Weshalb wir uns in Smiths Sinne entscheiden sollten, was das eine gegenüber dem anderen Bild richtiger und wahrer macht, vermag er letztlich aber nicht zu begründen, stellt den Prüfstein des angemessenen Handelns doch eben jenes Urteil dar, das sich aus wechselseitiger Beachtung und Bewertung ergibt. So muss der Moralphilosoph denn auch einräumen, dass das auffälligere, aber falsche Bild das gewissermaßen natürliche Objekt der Betrachtung sein wird und damit auch das prägende Muster erwartbaren menschlichen Handelns. ${ }^{23}$ Wobei er völlig klar sieht und auch ohne Umschweife zum Ausdruck bringt, dass gesellschaftlicher Vorrang ein entzweiender Zankapfel ist. Ja, er meint, soziales Ansehen sei „,der Endzweck der Hälfte aller Mühe und Arbeit des menschlichen Lebens und ist die Ursache all des Treibens und Lärmens, all der räuberischen Gewalttätigkeit und

22 Smith (1994), 87-88.

23 Auch in dieser Hinsicht besteht weitgehend Einigkeit zwischen Smith und David Hume. So schreibt Hume: „Unser Ruf, unser Rang, unser Name, das sind schwerwiegende und bedeutsame Gründe für den Stolz; ja die anderen Ursachen des Stolzes, Tugend, Schönheit und Reichtum, haben wenig Wirkung, wenn die Meinung und Anschauung anderer ihnen nicht Vorschub leistet.” Hume (1973), II/III 47-48. 
Ungerechtigkeit, welche die Habsucht und der Ehrgeiz in die Welt gebracht haben." 24

Nun scheint diese wenig optimistische Einschätzung der durchschnittlichen sittlichen Qualität menschlichen Verhaltens Smith nur mäßig zu beunruhigen, sofern er auf das Ganze der Gesellschaft blickt. Dies liegt wohl daran, dass er stolzen Ehrgeiz und prahlerische Habgier offenbar vor allem als Angelegenheit der Höfe und des Adels sieht. Da sich nur dort der Raum bietet, um diese auszuleben, hält sich der daraus entstehende Schaden für die Gesamtgesellschaft in Grenzen. Ja, die eitel glänzenden Gestalten der Höfe vermögen sogar eine gesellschaftsintegrierende und damit gemeinwohlfördernde Wirkung zu entfalten.

Allerdings kommt Smith nicht umhin, selbst zu konstatieren, dass die ständische Adelsgesellschaft, die er offenbar als gegeben voraussetzt, sich im Umbruch befindet, da die Dominanz des Adels oder gar absolutistischer Herrscher einer zunehmenden Gleichheit der Bürger weicht. Soziale Differenzierung ist in abnehmendem Maße durch das Faktum der Geburt gegeben; an dessen Stelle treten Leistung und Qualifikation. So beschreibt Smith etwa die Gestalt Ludwigs des XIV. als ,vollkommenstes Muster eines großen Fürsten" 25 , der sich allerdings durch keinerlei besondere Talente oder Fähigkeiten ausgezeichnet habe. Die Bewunderung heischende Ausstrahlung dieses glanzvollen Königs scheint dennoch selbst vier Jahrzehnte nach seinem Tod noch ihre Wirkung entfaltet zu haben. ${ }^{26}$ Andererseits beobachtet Smith aber, dass Menschen niederer Stände sich nicht durch äußeren Glanz, sondern nur durch eigene Leistung, durch Tugenden und Fähigkeiten auszeichnen können, was dazu führt, dass sie hinsichtlich praktischer Aufgaben wesentlich mehr Engagement und Einsatzfreude zeigen werden als Mitglieder der Aristokratie. „Demgemäß liegen in allen Staaten, selbst in Monarchien, die höchsten Ämter und die Leitung der ganzen Einzelheiten der Verwaltung zumeist in den Händen von Männern, die in mittleren oder niederen Gesellschaftsständen aufgewachsen sind, und die durch ihren Fleiß und ihre Fähigkeiten emporgetragen wurden,

26 Smith wurde 1723 geboren, acht Jahre nach Ludwigs Tod. Die Theorie der ethischen Gefühle wurde 1759 erstmals veröffentlicht. 
trotzdem sich ihnen die Eifersucht und der Vergeltungstrieb aller derer entgegenstellte, die den höheren Geburtsständen angehörten; in den Händen von Männern, welche von den Großen erst mit Verachtung und später mit Neid angesehen wurden, bis sich die letzteren schließlich damit abfanden, sich vor ihnen mit derselben erbärmlichen Unterwürfigkeit zu beugen, die - wie sie wünschen - die übrigen Menschen ihnen gegenüber an den Tag legen sollten." 27 Was Smith hier beschreibt erinnert an die späteren geschichtsphilosophischen Ausführungen Hegels zur Herr-Knecht-Dialektik. ${ }^{28}$ Wie in diesen kommt auch hier eine zwiespältige Haltung gegenüber der gesellschaftlichen Führungsschicht, ja generell gegenüber hierarchischen Strukturen zum Ausdruck. Besonders deutlich wird diese, wo Smith meint, es entspreche wohl der Vernunft und sei daher auch eine Lehre der Philosophie, dass Könige Diener ihrer Völker sein müssten und von diesen im Falle eines Versagens auch abgesetzt werden sollten. Diese Lehre der Vernunft decke sich aber eben nicht mit der Lehre der Natur, die sich in den faktischen Gegebenheiten niederschlägt. ${ }^{29}$

Der Zwiespalt in Smiths Haltung offenbart wohl eine Unsicherheit im Umgang mit einer Situation zunehmender Gleichheit, die ihre Wurzeln unter anderem in einer breiteren Verfügbarkeit von Wissen und den daran anknüpfenden Fertigkeiten und Fähigkeiten hat. ${ }^{30}$ Breitenbildung und die damit verbundene Befähigung weiter Bevölkerungskreise, am gesellschaftlichen Diskurs und an der sozialen Gestaltung mitzuwirken, entsprechen zweifellos den Idealen der Aufklärungsbewegung. Eine egalisierende Entwicklung führt zugleich aber auch zu einer Zunahme sozialer Dichte oder, um es im Anschluss an René Girard zu formulieren, zur Abnahme jener differenzierenden Mechanismen, die gesellschaftliche Rivalität im Zaum zu halten vermögen. ${ }^{31}$ Die Bewunderung einfacher Leute für Anse-

27 Smith (1994), 80-81.

28 Vgl. Kojève (1975), 63-65.

29 Smith (1994), 75.

30 „Wissen egalisiert tendenziell jene, die es besitzen, es führt zu Formen des Austausches, zum Diskurs.” Metz (2006), 79.

31 „Die Menschliche Kultur besteht zu einem wesentlichen Teil aus dem Bemühen, den Ausbruch von Gewalt zu verhindern, indem sie alle Aspekte des öffentlichen und privaten Lebens trennt und ,differenziert'; wenn man diese nämlich ihren natürlichen Wechselbeziehungen überlässt, drohen sie einer heillosen Gewalt anheimzufallen." Girard (2002), 446. 
hen und gesellschaftliche Stellung bessergestellter Personen und Gruppen in streng hierarchisch gegliederten Gesellschaften bezeichnet Girard als externe Vermittlung von Vorbildern, die nicht zum Konflikt um Positionen und Güter führen kann, weil jedem Akteur seine kaum verschiebbare Rolle im Gesellschaftsgefüge zugewiesen ist. ${ }^{32}$ Beginnen sich hierarchische Strukturen und Barrieren vertikaler sozialer Mobilität zu lösen, gehen Bewunderung und Anerkennung zusehends in Neid und Missgunst über, die nun nicht mehr nur innerhalb der sozialen Stände, sondern auch zwischen den Ständen, die sich gegeneinander zu verschieben beginnen, spürbar werden. Neid und Rivalität, die der Eitelkeit und dem Bedürfnis nach Wertschätzung und Anerkennung durch andere entspringen, schildert Smith aber als Gefühle, die die Bande der menschlichen Gesellschaft zu zerbrechen in der Lage sind. ${ }^{33}$

Welche Auswirkungen ein Ringen um Vorrang, das primär durch Ehrgeiz und Habsucht motiviert ist, unter Bedingungen zunehmender Gleichheit haben kann, lässt sich unschwer nachvollziehen. Smith geht darauf nicht näher ein. Wir dürfen aber wohl annehmen, dass er ihnen überaus kritisch gegenübersteht, auch wenn er festhält, dass kein Mensch eines gesunden Empfindens für Status und Würde und auch der Bereitschaft, diese zu verteidigen, ermangeln sollte. Dieses Empfinden verliert dort sein berechtigtes Maß, wo sich eine umfassende, destruktive Rivalität im Sinne Hobbes’ zu etablieren beginnt, die weder im Interesse von Individuen, noch von Gemeinwesen liegen kann und daher auf jeden Fall zu vermeiden ist.

In den Dienst des Anliegens der Vermeidung von Auswüchsen des menschlichen Geltungsstrebens stellt Smith denn auch den bescheidenen Restbestand religiöser Inhalte, der sich in seinen Ausführungen finden lässt. Ich habe bereits darauf verwiesen, dass dem nie in Frage gestellten Bekenntnis zur Existenz Gottes keine materialethisch begründende Funktion in der Theorie der ethischen Gefüble zukommt. Was allerdings bleibt, ist eine Motivationsfunktion, die Smith an die Vorstellung vom Jüngsten Gericht knüpft. Belohnung bzw. Strafe für die Einhaltung oder Überschreitung gesellschaftlich gültiger Wertvorstellungen durch ein göttliches Gericht scheinen als

32 Vgl. Palaver (2008), 89-91; zur Begrifflichkeit interne bzw. externe Vermittlung vgl. Girard (1999), 18.

33 Smith (1994), 411. 
quasi pädagogisches Instrumentarium durchaus nützlich, wenn nicht unverzichtbar zu sein. Smith spricht davon, wie bedeutsam es sei, dass die Schrecken der Religion das natürliche Pflichtgefühl der Menschen verstärken. ${ }^{34}$ Gerade dieses noch verbliebene Band zwischen Ethos und Religion vermag aufgeklärtem Denken gegenüber aber wohl kaum auf Dauer zu bestehen, zeigt sich darin doch die Neigung zu einer überaus schroffen Form austeilender Gerechtigkeit nach dem Prinzip des jus talionis. „Wie jedermann tut, so soll ihm wieder getan werden und die Wiedervergeltung des Gleichen mit Gleichem scheint das große Gesetz zu sein, das uns von der Natur selbst vorgeschrieben worden ist." 35 Wo dies innerweltlich nicht der Fall ist, weil ein Unrecht nicht an die Öffentlichkeit gelangt oder ein Übeltäter sich etwa durch seine gesellschaftliche Stellung der gerechten Strafe zu entziehen vermag, springt gleichsam Gott ein; als der große Rächer allen Unrechts. ${ }^{36}$ Dabei scheint bei Smith das Motiv der Furcht deutlich vor jenem einer allgemeinen Gerechtigkeitssehnsucht zu rangieren, welches ja auch Kant (um der Vermeidung logischer Antinomien willen) dazu veranlassen sollte, Gott zu einem Postulat der praktischen Vernunft zu erheben. ${ }^{37}$ Handeln aus Furcht entspricht nun aber gerade nicht dem Ideal einer autonom und selbstverantwortlich gefällten Entscheidung, sondern trägt vielmehr den zunehmend als Makel empfundenen Stempel der Heteronomie, des Legalismus und der Abhängigkeit. ${ }^{38}$

\section{Der Markt kommt uns zu Hilfe}

Dass Smith einer Situation entgrenzter Rivalität um Ansehen und Status, Rang und Anerkennung nur mit großer Skepsis hätte gegenüberstehen können - und soweit er sie bereits beobachten konnte auch stand - ist offenkundig. Smith ist aber auch Realist genug, um

34 Smith (1994), 248. Deutlich wird hier erkennbar, dass Religion nicht als Quelle moralischer Erkenntnis wahrgenommen wird, sondern lediglich als Mittel zum Zweck der Umsetzung auf anderem Weg begründeter Normen.

35 Smith (1994), 121.

36 Vgl. Smith (1994), 258.

37 Vgl. Kant (1977a), 223-226.

38 Vgl. hierzu etwa Kant (1977a), 261: „Auch hier bleibt daher alles uneigennützig und bloß auf Pflicht gegründet; ohne dass Furcht oder Hoffnung als Triebfedern zum Grunde gelegt werden dürften, die, wenn sie zu Prinzipien werden, den ganzen moralischen Wert der Handlung vernichten." 
deren Faktizität nicht einfach zu leugnen. ${ }^{39}$ Stattdessen geht er weitgehend stillschweigend über sie hinweg und führt uns in seinem zweiten großen Werk einen Gesellschaftsbereich vor Augen, in dem das Streben nach Ruhm und Reichtum keine negativen Folgen zeitigt - im Gegenteil. Damit weist der Autor des Woblstands der Nationen implizit einen Weg aus dem Dilemma, in dem seine Theorie der ethischen Gefüble enden musste: Er weist uns den Weg in die Ökonomie.

In den ersten Kapiteln des Woblstands der Nationen entfaltet Adam Smith was für ihn die Grundlagen einer erfolgreichen und gemeinwohldienlichen Ökonomie darstellt. Als conditio sine qua non von Wachstum und Wohlstand nennt er Arbeitsteilung, die ihrerseits aus einer allgemeinmenschlichen Neigung zum Tausch hervorgeht.

Arbeitsteilung wird anhand des bekannten Stecknadelbeispiels als effizienzsteigernde Form der Produktionsorganisation dargestellt. Sie ist aber freilich mehr als eine in dieser Ausprägung neue Form der Gestaltung von Produktionsabläufen. Arbeitsteilung ist selbst Teil eines gesamtgesellschaftlichen Differenzierungsprozesses, oder besser gesagt: Teil einer Umstellung von einer Leitform gesellschaftlicher Differenzierung auf eine andere. Emile Durkheim gilt als einer der bekanntesten Theoretiker dieser Transformation. Er sieht in Arbeitsteilung unter Anderem einen konflikteindämmenden Mechanismus, der auf zunehmende soziale Dichte, samt den sich daraus ergebenden Konkurrenzsituationen reagiert. So heißt es bei ihm: „Wenn sich die Arbeit in dem Maß mehr teilt, in dem die Gesellschaften umfangreicher und dichter werden, dann ... weil der Kampf um das Leben heißer ist." 40 In einer Stadt etwa können trotz der enormen Verdichtung der Beziehungen und der damit zugleich verschärften Wettbewerbssituation die verschiedensten Berufe friedlich

39 Mit Girard ist es wichtig zu betonen, dass zunehmende Rivalitätsverhältnisse sich nicht aus einer sittlichen Dekadenz der Menschen, sondern aus einer Veränderung der gesellschaftlichen Strukturen ergeben. „Nicht weil die Zahl der ,neidvollen Charaktere‘ oder der ,eifersüchtigen Temperamente ' auf unselige und geheimnisvolle Weise überhandgenommen hätte, haben die modernen Empfindungen Hochkonjunktur, sondern weil die interne Vermittlung in einer Welt obsiegt, in der die Unterschiede zwischen den Menschen sich allmählich verwischen." Girard (1999), 23-24. Auch diese Strukturveränderungen sollen keineswegs als negativ dargestellt werden, sehr wohl aber als Herausforderungen, die nicht leicht zu bewältigen sind und durchaus in gesellschaftliche Schieflagen führen können.

40 Durkheim (1977), 108; vgl. dazu Tyrell (1985), 210. 
koexistieren, weil ihre Ziele sich voneinander unterscheiden, meint Durkheim. Diese Logik lässt sich relativ problemlos sowohl auf den einzelnen Produktionsbetrieb, als auch auf die Gesamtgesellschaft übertragen. Es wäre erstaunlich, sollte Smith diesen Effekt nicht auch wahrgenommen haben, ist er sich doch völlig darüber im Klaren, dass die von ihm wenig geschätzten Impulse von Ehrgeiz und Habsucht zentrale Quelle gerade des ökonomischen Handelns der Menschen sind. Immerhin betont er, dass es nicht die natürlichen (Subsistenz-)Bedürfnisse sind, auch nicht das Streben nach Bequemlichkeit und Wohlergehen, die uns nach einer Verbesserung unserer materiellen Verhältnisse streben lassen, sondern schlicht die Eitelkeit, das Bedürfnis, Anerkennung zu finden. ${ }^{41}$ Es liegt auf der Hand, dass spezialisierte, häufig auf wenige gleichbleibende Handgriffe reduzierte Tätigkeiten im Sinn einer frühen Fabrikarbeit, wie Smith sie beschreibt, an sich kaum dazu taugen, das Anerkennungsbedürfnis von Menschen zu befriedigen. Diese Funktion muss dann eben vom Arbeitsertrag in Form von steigendem Lohn und steigendem Lebensstandard übernommen werden.

Erstaunlicherweise geht Smith im Woblstand der Nationen jedoch kaum auf das Thema der Eitelkeit ein, die in der Theorie der ethischen Gefüble doch als Quelle der verächtlichsten Laster dargestellt wurde. Ebenso wie ihn an Arbeitsteilung nur der Einfluss auf Produktivitätssteigerung, nicht aber menschliches Anerkennungsstreben interessiert, blendet er auch in der Behandlung des Tausches jegliches Interesse der Menschen aneinander aus und konzentriert sich ganz auf die Gegenstände des Tausches, also auf die Welt der Objekte. Arbeitsteilung ergebe sich gleichsam von selbst aus einer ,natürlichen Neigung des Menschen, zu handeln und Dinge gegeneinander auszutauschen." ${ }^{42}$ Anders als bei Tieren finde sich nämlich beim Menschen ein Kooperationsstreben oder auch eine Kooperationsnotwendigkeit, die jedoch allein der je individuellen Bedürfnisbefriedigung dienten. Die daraus abgeleitete These, dass Handel ursprünglich aus Akten eines Vorteilstausches in beiderseitigem Interesse entstanden sei, ist ethnologisch zumindest umstritten. ${ }^{43}$ Sie spiegelt wohl mehr die Rationalität eines neuzeitlichen Kaufmanns wieder, denn Lebensumstände und Weltbild prähistorischer Gesellschaften.

41 Vgl. Smith (1994), 71.

42 Smith (1996), 16.

43 Vgl. etwa Heinsohn/Steiger (1996), 290-301. 
Möglicherweise kommen wir der Realität hier durch die Ergebnisse anthropologisch-ethnologischer Forschung näher, die im „Tauschgeschäft" einen überaus voraussetzungsreichen Vorgang erkennt, der das konfliktträchtige Begehren gleicher Objekte durch eine Mehrzahl von Subjekten in geordnete Bahnen lenkt. Der so einfach erscheinende Tausch wäre demnach eine durchaus komplexe gesellschaftliche Institution, die von ihrer Genese her wesentlich mehr mit besänftigenden Gaben und religiösen Opfern zu tun hat als mit kühl kalkulierender, reziproker Kosten-Nutzen-Rechnung. ${ }^{44}$ Eine solche Interpretation entspräche letztlich auch wesentlich besser dem, was wir bisher von Smith über die Strukturen menschlichen Verhaltens erfahren haben. Dennoch werden uns nun Ökonomie und vor allem Handel als unschuldige Tätigkeiten präsentiert, die neben materiellen Annehmlichkeiten auch zu einem gesitteten, friedlichen Umgehen der Menschen miteinander führen. Diese Haltung ist durchaus nicht selbstverständlich und stellt eine Neupositionierung im 17. und 18. Jahrhundert dar. Sie löste jene Vorstellung ab, der gemäß Handel als wenig ehrbare, ja moralisch zweifelhafte Tätigkeit verstanden wurde, der sich der Adel etwa stets enthielt. ${ }^{45}$ Ein Nachhall dieser älteren Vorstellung findet sich immerhin auch noch in Goethes Faust II, wo ein unlösbarer Zusammenhang zwischen Handel, Krieg und Piraterie festgestellt wird. ${ }^{46}$

Wenngleich Smith nun auch die konfliktive Seite von Handel und Markt weitgehend ausblendet, kann er sich seiner eigenen anthropologischen Grundeinsicht doch nicht ganz entziehen. Diese nötigen ihn, auch innerhalb ökonomischer Überlegungen das Phänomen des Neides zu thematisieren. Allerdings betrachtet er diesen als im Grunde wirtschaftsfremden Irrläufer im Rahmen geschäftlicher Beziehungen. So schreibt er, dass die Nationen mit Neid auf den Wohlstand ihrer Nachbarn blicken und deren Gewinn als eigenen Verlust sehen. „Der Handel, der seiner Natur nach unter Völkern wie unter einzelnen Menschen eigentlich ein Band der Eintracht und Freundschaft knüpfen sollte, wurde so zu einer höchst starken Quelle für Uneinigkeit und Feindschaft. Der unberechenbare Ehrgeiz von

44 Laum (2006), sieht demgemäß den Ursprung des Geldes nicht als Tauschmittel im zwischenmenschlichen Handel, sondern als Wertmaßstab, der sich aus dem sakralen Opfer ergab.

45 Vgl. Hirschman (1984), 67-71; Taylor (2005), 74-81.

46 Vgl. Goethe (1986), Vers 11185. 
Königen und Ministern im Laufe unseres und des vergangenen Jahrhunderts ist für den Frieden in Europa nicht so verhängnisvoll gewesen wie die unverschämte Eifersucht von Kaufleuten und Unternehmern." 47 Diese bedrohliche Einstellung - so ist seiner weiteren Argumentation zu entnehmen - stammt aber eigentlich aus einem politischen und militärischen Denken, das die Stärke des Nachbarn als Gefahr sehen muss, dem ökonomischen Denken jedoch wesensfremd ist. Denn wirtschaftlich ist es zu begrüßen, Nachbarn zu haben, die potente Kunden sind und über einen florierenden Markt verfügen. Der Reichtum der einen befördert den Reichtum der anderen und sollte daher niemanden zu einem missgünstigen Blick auf seinen Nachbarn veranlassen.

Hume prangert aufgrund analoger Überzeugungen Neid im Bereich des internationalen Handels massiv als politisch unvernünftige Entgleisung an, da es in der Ökonomie keinen sachlichen Grund zur Eifersucht unter den Nationen gebe. Er kommt zum Schluss, man müsse als britischer Bürger auf die ökonomische Prosperität aller europäischen Nationen, sogar jene des Erbfeindes Frankreichs hoffen; dies durchaus im wirtschaftlichen Interesse der eigenen Nation. ${ }^{48}$ Es sei daran erinnert, dass derselbe Autor an anderer Stelle Eigeninteresse als die gefährlichste menschliche Regung qualifiziert: „Nur die Begierde, Güter und Besitz für uns und unsere nächsten Freunde zu erlangen, ist unersättlich, andauernd, allgemein verbreitet und unmittelbar zerstörend für die Gesellschaft. Es gibt kaum jemand, der nicht von ihr getrieben wird, und niemand, der nicht Ursache hätte, sie zu fürchten, wenn sie ohne Einschränkung sich betätigt und ihren ersten und natürlichsten Regungen folgt." ${ }^{49}$ Dass die eigeninteressierte Begierde nach Gütern offenbar an Bedrohlichkeit verliert, sobald sie in einen ökonomischen Betrachtungsrahmen gerückt wird, sollte unsere Aufmerksamkeit wecken.

47 Smith (1996), 406-407.

48 Hume (1882), 348.

49 Hume (1973), II/III 235. Eitelkeit hält Hume hingegen für einen geselligen Affekt. Er hat damit wohl insofern recht, als Eitelkeit ohne Betrachter nicht befriedigt werden kann, den inneren Zusammenhang zwischen Gier nach Gütern und Eitelkeit schätzt er aber wohl falsch ein. Smith sieht hier klarer, da er weniger introspektiv ansetzt, als vielmehr die Beobachtung zwischenmenschlicher Beziehungen ins Zentrum stellt. 
Smith und auch Hume entwickeln hier eine Idee, die uns in ethischen wie sozialwissenschaftlichen Debatten seither immer wieder begegnet: Eine Gesellschaft ohne Liebe und wechselseitige Verpflichtung ihrer Mitglieder kann Bestand haben, sofern es sich dabei um eine Gesellschaft von Kaufleuten oder moderner formuliert: um eine Gesellschaft von homini oeconomici handelt. ${ }^{50}$ Dieser Gedanke entspricht dem friedenschaffenden Handelsgeist bei Kant ${ }^{51}$ und nimmt die Überzeugung Webers vorweg, dass Ökonomie die einzige Vergesellschaftungsform sei, die keine Verbrüderung voraussetzt und auch unter Ungenossen und Feinden entstehen kann. ${ }^{52}$ Der Schlüssel für das Funktionieren eines solchen Modells besteht offenbar im Faktum des Wachstums, darin also, dass die Palette und die Quantität der umstrittenen Güter laufend ausgeweitet werden kann. So ist die Möglichkeit einer Hebung des Lebensstandards der unteren Bevölkerungsschichten auch für Smith nicht an den absoluten Wohlstand eines Gemeinwesens gebunden, sondern an dessen relative Vermehrung. ${ }^{53}$ Das nicht als (vor allem ökologisches) Problem erkannt zu haben, kann Menschen des 18. Jahrhunderts nicht ernstlich zum Vorwurf gemacht werden. Ich möchte bei aller drängenden Bedeutsamkeit dieser Frage in der Gegenwart mein Augenmerk in unserem Kontext daher auch nicht auf sie legen. Vielmehr erscheint mir der Hinweis wesentlich, dass die Überantwortung der Gesellschaft an einen auf wechselseitigen Vergleich gegründeten Wettlauf, der wohl gewisse interne Fairnessregeln zu generieren vermag, letztlich aber keine Zielrichtung kennt, schließlich im normativen Bekenntnis zum homo oeconomicus enden muss, der uns heute nicht nur als Held des Marktes, sondern auch als Held einer ökonomisch konzipierten Demokratie begegnet. Salopp gesagt: Die Dominanz des Bourgeois passiert der modernen Gesellschaft nicht, sie wird von ihr vielmehr bewusst in Kauf genommen, wenn nicht forciert, um die destruktiven Kräfte eines universalisierten Anerkennungswettbewerbs zu zügeln. Peter Sloterdijk spricht in diesem Zusammenhang von einer Reaktortechnik der Marktökonomie, die eine enorme soziale Kraftquelle an der Explosion hindert und ihre Energie in Arbeit umwandelt, und konstatiert: „In makrohistorischer 
Perspektive bietet die moderne Welt das singuläre Schauspiel einer Kultur, die auf der Koppelung von entfesselter Masseneifersucht und entgrenzter Konsumgüterproduktion beruht. Dies ist das Geheimnis der unsichtbaren Hand, die den Dogmatikern der Marktwirtschaft zufolge für den Ausgleich der Kräfte durch freien Wettbewerb sorgt." 54 Gerade in dieser Doppelgesichtigkeit besteht der Clou des liberalen Marktes, sie ist es, die ihn im Gleichgewicht hält; freilich in einem stets prekären Gleichgewicht, das sich von Seiten politischer Steuerungsversuche bestenfalls Rettungspakete gefallen lässt, sollte einmal etwas schief gelaufen sein, nicht aber störende Eingriffe.

\section{Oder doch Religion?}

Auch wenn Adam Smith eine solche Gesellschaftsordnung nicht entwarf, sie vermutlich nicht einmal gut geheißen hätte, bahnte er ihr doch den Weg, indem er letztlich den Rückzug der Individuen auf ihren Privatbereich forcierte, in dem sie ihre eigenen Interessen verfolgen sollen, um so indirekt und absichtslos einem Gemeinwohl zu dienen, dessen inhaltliche Bestimmung letztlich leer bleibt. ${ }^{55}$ Smith hat in seinem Ansatz, so formuliert es Niklas Luhmann, auf absolut geltende Kriterien verzichtet ${ }^{56}$ und lediglich in seiner Vorstellung von einer unsichtbaren Hand noch ein Kompromissangebot für die traditionelle Religion formuliert, um nicht in aller Radikalität auf ein Konzept der „freischwebend konsolidierten Realität” umschwenken zu müssen. ${ }^{57} \mathrm{Im}$ Laufe der modernen Entwicklung ist dann der ,... Markt vom zweckgebundenen Teil einer höheren Ordnung zum Selbstzweck und selbst zur höheren Ordnung geworden [...]." 58 Es wird keine kosmische Harmonie mehr vorausgesetzt. Wenn es überhaupt noch eine Harmonie gibt, so ist sie nun als Folge des Marktgeschehens wahr- und anzunehmen. „Der Markt hat den wohlwollenden Schöpfergott ersetzt." ${ }^{59}$ Er gibt uns seine Gesetze

54 Sloterdijk (2002), 253; vgl. auch Dupuy/Dumouchel (1999), bes. 240-282.

55 Smith (1996), 371; vgl. Smith (1994), 389-390.

56 Luhmann (1997), 1022. An die Stelle solcher Kriterien tritt vielmehr die Beobachtung des Beobachtens anderer.

57 Vgl. Luhmann (1984), 173-174.

58 Büscher (1991), 135.

59 Büscher (1991), 135. 
vor, sodass der verantwortlich entscheidende Citoyen letztlich überflüssig wird. Die Verteidiger des liberalen Marktes sehen in diesem dennoch das Musterbeispiel der Demokratisierung, weil er nur auf die Freiheitsentscheidungen der Individuen reagiert, weil sich in ihm keine Macht wider den Mehrheitswillen etablieren kann. Allerdings muss auch festgehalten werden, dass dieser Markt keinen öffentlichen Diskurs kennt, keine Suche und kein Ringen um mehrheitsfähige Positionen, er ist lediglich geprägt von statistischen Kumulationen und quasi natürlichen Strömungsmustern. Die Akteure des Marktes sind eben keine republikanischen Bürger, die danach fragen, was die Gemeinde oder das Gemeinwesen braucht, sondern Bourgeois, die darauf konzentriert sind, was sie selbst wollen.

Marx hat zu Recht auf dieses Problem hingewiesen. Nur ist dafür ebenso wenig eine ausbeuterische Klasse verantwortlich $\mathrm{zu}$ machen, wie ein zum Sündenbock stilisiertes Volk. Vielmehr liegt dieses Problem im Ursprungskonzept des liberalen Marktes begründet. Es liegt grundgelegt im Versuch, Moral ökonomisch zu begründen, wie Norbert Bolz es ausdrückt, der in Das konsumistische Manifest ein flammendes Plädoyer für Konsumbürgerlichkeit hält. ${ }^{60}$ Damit meint er nun aber - im Unterschied zu Peter Ulrich - gerade nicht die Haltung eines in Mitverantwortung für das Ganze entscheidenden und agierenden Wirtschaftsbürgers, sondern die Reduzierung menschlicher Handlungsmotive auf den ökonomischen Vorteil des Konsumenten, für den the pursuit of happiness längst auf happiness of pursuit ${ }^{61}$ reduziert ist. Man könnte auch formulieren: Das Problem der Bourgeoisierung ist grundgelegt im Versuch, in der Ökonomie selbst das funktionale Äquivalent einer haltlos gewordenen Ethik zu finden.

An dieser Stelle gilt es nun wieder den Bogen zurück zum Ausgangspunkt meiner Überlegungen zu schlagen: Wenn der Verzicht auf jeglichen Transzendenzbezug in der Ethikbegründung in das eben skizzierte Fahrwasser führt oder zumindest führen kann, drängt sich dann nicht die Frage auf, ob der politische Diskurs nicht geradezu ein Interesse an der vielzitierten Rückkehr der Religion in das Feld der Öffentlichkeit haben müsste, um sich selbst vor dem Versi- 
ckern in einer bourgeoisen Konsumbürgerlichkeit zu bewahren? Kann eine Renaissance von Religion in der gesellschaftlichen Öffentlichkeit nicht gerade um einer Zivilgesellschaft Willen begrüßt werden, die von verantwortungsbereiten und vor allem verantwortungsfähigen Citoyens getragen wird und somit politisch gestaltete Gesellschaft ist, die sich nicht der Sachzwanglogik des Marktes überlassen will? Die hier angesprochene Religion muss freilich mehr sein als eine Zivilreligion im Sinne Rousseaus. ${ }^{62}$ Denn gerade das, was die Religion des Menschen (im Contrat Social die Religion des Evangeliums) für Rousseau untauglich zum Einsatz in politischen Gemeinwesen macht, ${ }^{63}$ schafft dem Menschen Freiräume gegenüber Konventionen des Marktes. „Nur eine Existenz, die sich nicht rein innerweltlich definiert, bildet eine sichere Basis dafür, die Paradigmatisierung der Gesellschaft und des eigenen Lebens durch die ökonomische Vernunft im praktischen Lebensvollzug als begrenzte Orientierung betrachten zu können." 64 In diesem Sinn vermag die Präsenz lebensprägender religiöser Weltanschauungen, die ihre Orientierung an Punkten außerhalb des Wechselspiels gesellschaftlicher Mechanismen nehmen, also durchaus die politische Gestaltung der Gesellschaft jenseits ökonomischer Gesetzmäßigkeiten zu befördern und zu unterstützen. Freilich kann nicht geleugnet werden, dass ein Revival von Religion auch eine Herausforderung für den politischen Diskurs und die politische Praxis darstellt. Die Frage etwa, wie unterschiedliche Religionen in einer pluralistischen Gesellschaft miteinander umgehen oder jene, wie sie ihr Verhältnis zum sinnvoller Weise weltanschaulich neutralen Staat konkret gestalten, wurden in meinem Beitrag gar nicht berührt. Solche Fragen sind nicht in einer Randbemerkung zu klären und die Antworten auf sie nicht unumstritten. Dies sollte aber nicht dazu führen, dass die kritischen und ethisch orientierenden Potentiale von Religionen im öffentlichen Diskurs leichtfertig ausgeblendet werden. Andernfalls könnte die Freiheit der Bürger allzu leicht der Freiheit des Marktes zum Opfer fallen. 


\section{Literatur}

Barber, Benjamin R. (2008): „Ich bin, was ich kaufe“, in: Die Furche 19, 8.5.2008, 3 .

Bauer, Joachim (2006): Warum ich füble, was du füblst. München: Heyne.

Beck, Ulrich (2007): Schöne neue Arbeitswelt. Frankfurt a.M.: Suhrkamp.

Binswanger, Hans Christoph (1998): Die Glaubensgemeinschaft der Ökonomen. München: Gerling-Akad. Verl.

Bolz, Norbert (2002): Das konsumistische Manifest. München: Fink.

Brandt, Reinhard (1973): „Einführung“, in: Hume, David.: Ein Traktat über die menschliche Natur. Hamburg: Meiner.

Büscher, Martin (1991): „Gott und Markt - Religionsgeschichtliche Wurzeln Adam Smiths und die 'Invisible Hand' in der säkularisierten Industriegesellschaft", in: Meyer-Faje, Arnold/Ulrich, Peter, Hg.: Der andere Adam Smith. Beiträge zur Neubestimmung von Ökonomie als Politischer Ökonomie. Bern: Paul Haupt, 123-144.

Dupuy, Jean-Pierre/Dumouchel, Paul (1999): Die Hölle der Dinge. René Girard und die Logik der Ökonomie. Mit einem Nachwort von René Girard. Herausgegeben von Erich Kitzmüller und Herwig Büchele. Münster: LIT Verlag.

Durkheim, Emile (1977): Über die Teilung der sozialen Arbeit. Frankfurt a.M.: Suhrkamp.

Girard, René (1999): Figuren des Begehrens. Münster: LIT Verlag.

Girard, René (2002): „Gewalt und Gegenseitigkeit“, in: Sinn und Form 54 (4), 437-454.

Goethe, Johann Wolfgang (1986): Faust. Der Tragödie zweiter Teil. Stuttgart: Philipp Reclam jun.

Hayek, Friedrich August von (1983): Die Verfassung der Freiheit. Tübingen: Mohr.

Heinsohn, Gunnar/Steiger, Otto (1996): Eigentum, Zins und Geld. Reinbek bei Hamburg: Rowohlt.

Hirschman, Albert O. (1984): Leidenschaften und Interessen. Frankfurt a.M.: Suhrkamp.

Hume, David (1882): „Of the Jeaoulosy of Trade“, in: Essays Moral, Political and Literary, Vol. I, edited by T.H. Green and T.H. Grose. London, 345-348.

Hume, David (1968): Dialog über natürliche Religion. Hamburg: Meiner.

Hume, David (1973): Ein Traktat über die menschliche Natur. Buch I und II/III. Hamburg: Meiner.

Kojève, Alexandre (1975): Hegel, eine Vergegenwärtigung seines Denkens. Frankfurt a.M.: Suhrkamp.

Kant, Immanuel (1977a): „Kritik der praktischen Vernunft“, in: Ders.: Werke in zwölf Bänden, Bd. VII, herausgegeben von Wilhelm Weischedel.. Frankfurt a.M.: Suhrkamp, 105-302. 
Kant Immanuel (1977b): „Zum Ewigen Frieden. Ein philosophischer Entwurf“, in: Ders.: Werke in zwölf Bänden, Bd. XI, herausgegeben von Wilhelm Weischedel.. Frankfurt a.M.: Suhrkamp, 195-252.

Koller, Edeltraud (2008): Gutes Leben durch die Wirtschaft? München: Hampp. Laum, Bernhard (2006): Heiliges Geld. Berlin: Semele-Verl.

Luhmann, Niklas (1984): Soziale Systeme. Grundriss einer allgemeinen Theorie. Frankfurt a.M.: Suhrkamp.

Luhmann, Niklas (1993): Gesellschaftsstruktur und Semantik. Studien zur Wissenssoziologie der modernen Gesellschaft, Band 3. Frankfurt a.M.: Suhrkamp.

Luhmann, Niklas (1997): Die Gesellschaft der Gesellschaft. Frankfurt a.M.: Suhrkamp.

MacIntyre, Alasdair (1995): Der Verlust der Tugend. Frankfurt am Main: Suhrkamp.

Marx, Karl/Engels, Friedrich (1969): „, Die deutsche Ideologie“, in: Dies.: Werke, Band 3.. Berlin: Dietz Verlag.

Metz, Karl H. (2006): Ursprünge der Zukunft. Zürich: Verl. Neue Zürcher Zeitung.

Palaver, Wolfgang (2008): René Girards mimetische Theorie. Wien: LIT Verlag, 3. erw. Aufl.

Rousseau, Jean-Jacques (1975): Der Gesellschaftsvertrag oder Die Grundsätze des Staatsrechtes. In der verbesserten Übersetzung von Hermann Denhardt. Mit einem Nachwort von H. Weinstock, Stuttgart: Philipp Reclam jun. Sloterdijk, Peter (2002): „Erwachen im Reich der Eifersucht“, in: Girard, René: Ich sab den Satan vom Himmel fallen wie einen Blit: München: Hanser, 241-254.

Smith, Adam (1994): Theorie der ethischen Gefüble. Hamburg: Meiner.

Smith, Adam (1996): Der Woblstand der Nationen. München: Dt. Taschenbuch-Verl.

Taylor, Charles (2005): Modern Social Imaginaries. Durham: Duke Univ. Press.

Tyrell, Hartmann (1985): „Emile Durkheim - Das Dilemma der organischen Solidarität", in: Luhmann, Niklas, Hg.: Soziale Differenzierung. Opladen: Westdeutscher Verlag, 181-250.

Ulrich, Peter (2004): „Sich im ethisch-politisch-ökonomischen Denken orientieren“, in: Mieth Dietmar/Schumann Olaf J./Ulrich Peter, Hg.: Reflexionsfelder integrativer Wirtschaftsethik. Tübingen: Francke Verlag, 1128.

Weber, Max (1980): Wirtschaft und Gesellschaft. Grundriss der verstehenden Soziologie. Besorgt von Johannes Winckelmann. 5. revidierte Auflage, Studienausgabe. Tübingen: Mohr. 


\title{
Über Verwurzelung: Aktuelles ökonomisches Denken und Adam Smith
}

\author{
Andreas Exenberger
}

\author{
Adam, Adam, Adam Smith \\ Listen what I charge you with! \\ Didn't you say \\ In the class one day \\ That selfishness was bound to pay? \\ Of all doctrines that was the Pith, \\ Wasn't it, wasn't it, wasn't it, Smith?'
}

William D. Grampp von der University of Chicago eröffnet einen Text über die Smithsche „unsichtbare Hand“ mit folgenden Worten: „If classical economics were ever given a musical setting - unlikely, but not unconceivable, an oratorio perhaps, subsidized by a cunning National Endowment for the Arts - the title surely would be Three First Words, and they would be 'an invisible hand."'2

Die große Bedeutung von Adam Smith für die Ökonomik als Wissenschaft spricht unzweideutig aus diesem Zitat, das nicht umsonst und keinesfalls zufällig mit religiöser Symbolik spielt. Smith gilt als der Vater der Volkswirtschaftslehre ${ }^{3}$ und ist jedenfalls der Begründer der so genannten „klassischen Schule“ der „politischen Ökonomie“, durch die dieselbe als eigenständige Wissenschaft etabliert wurde 4 (interessanterweise hat er damit auch Karl Marx sehr beeinflusst). Wie die Enzyklopädie unserer Zeit, Wikipedia, in ihrer meist aussagekräftigeren englischen Version erzählt, ist Smith ein „Pionier der politischen Ökonomie“, „,weithin zitiert“ als „Vater der modernen Ökonomik“ und sein zweites zentrales Werk Wealth of

1 Sen (1990), 21, mit Referenz auf Leacock (1936).

2 Grampp (2000), 441.

3 Was, wie etwa Gary M. Anderson anmerkt, Studierende der Theoriegeschichte als ,grobe Verzerrung“ (,gross distortion") wahrnehmen werden, weil diese Ansicht Zeitgenossen und Vorläufer von Smith ungebührlich gering schätzt. Vgl. Anderson (1988), 1086. Man beachte freilich auch den religiösen Gehalt in der weit verbreiteten Vater-Metapher.

4 Vgl. zum größeren Kontext dieser Entwicklung etwa Wallerstein et al. (1996), vor allem 919 und 24-26, oder Manstetten (2000), 37-51. 
Nations (1776) ist die „erste moderne Arbeit der Ökonomik“ oder zumindest ein „Vorläufer" (precursor). ${ }^{5}$ Das bestätigt auch ein Blick in wirtschaftswissenschaftliche Lehrbücher, in denen Smith nach John Maynard Keynes der am meisten zitierte Ökonom ist. ${ }^{6}$ Freilich - wie Michael Aßländer mit Bezug auf Walther Eckstein meint - heißt das noch nicht allzu viel, denn Smith zählt wohl außerdem zu den am seltensten gelesenen Autoren ${ }^{7}$, was breiten Raum für Missinterpretationen bietet. Smith hatte und hat aber auch sonst nicht nur Anhänger: Josef Schumpeter etwa führt seine große Bedeutung vor allem darauf zurück, dass Smith in jeder Hinsicht durchschnittlich und wenig originell in seinem Denken war und daher gut verstanden und akzeptiert wurde. ${ }^{8}$ Ein anderer großer Ökonom, Paul Samuelson, meint dazu: „Smith is admired for his eclectic wisdom about developing capitalism, and for his ideological defense of competitive laissez faire as against blundering Mercantilist interferences with the market. [...] But there you have it. As a pure theorist, Adam Smith is written down precisely because of his fuzzy eclecticism." $\mathrm{Er}$ aber würdigt Smith als analytisch auf einem Niveau mit Ricardo, Malthus und Marx, allerdings realistischer (wenngleich vielmehr intuitiv als formal korrekt), und als Vorläufer der Theorie des allgemeinen Gleichgewichts. Ein dritter, Vernon L. Smith, heute als Nobelpreisträger von 2002 selbst ein Säulenheiliger des Fachs, charakterisiert seinen Namensvetter wie folgt: „Smith, being an astute observer, could see that exchange was a positive sum game leading to specialization and wealth creation limited only by the extent of the market. He also saw that humans were capable of kindness and compassion in their ordinary daily interactions, a contrary observation that he could not just leave unattended [...]."10

Aber auch Wikipedia charakterisiert Smith zuerst als ,schottischen Moralphilosophen“ und als „Schlüsselfigur der schottischen Aufklärung“", auch wenn das für die meisten Rezipienten Smiths im

5 http://en.wikipedia.org/wiki/Adam_Smith (Zugriff am 15.01.2009, Übersetzung A.E.).

6 Vgl. Hoaas/Madigan (1999), 527. Smith verweist dabei mit 76 Zitationen in zehn der zum Zeitpunkt der Studie am meisten verbreiteten englischsprachigen Lehrbücher Milton Friedman (45), David Ricardo (37), Karl Marx (34) und Thomas Malthus (30) auf die nächsten Plätze. Keynes erreicht auch kaum mehr, nämlich 78 .

7 Vgl. Aßländer (2007), 7.

8 Vgl. Schumpeter (1986), 185.

9 Samuelson (1977), 42.

10 Smith (1998), 17. 
Feld der Wirtschaftswissenschaften nicht mehr sehr präsent zu sein scheint. ${ }^{11}$ Für diese Rolle Smiths steht vor allem sein erstes Werk, die Theory of Moral Sentiments (1759). ${ }^{12}$ Beim Vergleich desselben mit dem Wealth of Nations fällt auf, dass sich das Menschenbild in beiden Schriften zu unterscheiden scheint, es einmal primär an „Sympathie“ und ein anderes Mal primär am „Selbstinteresse“ orientiert ist. Aber wie ist mit diesem widersprüchlichen Bild umzugehen und damit letztlich mit dieser Doppelrolle Smiths als Ethiker und Ökonom, die sogar als „Adam-Smith-Problem“ bekannt geworden ist? ${ }^{13}$ Oder handelt es sich dabei gar nicht um so verschiedene Zugänge zu menschlicher Natur und menschlichem Tun?

Dieser Frage soll auf den folgenden Seiten nachgespürt werden, wobei der Schwerpunkt darauf gelegt werden soll, wie sich aktuelles ökonomisches Denken im Denken Smiths verwurzelt. Dabei werden, nach einleitenden Bemerkungen zu Smiths Leben und Werk, vor allem drei Interpretationen unterschieden: die simple, eher oberflächliche, die vor allem in der Rechtfertigung von (Nicht-) Eingriffen in die Wirtschaft und damit im alltäglichen Diskurs anzutreffen ist; die spezielle, die sich vor allem in der Wissenschaft findet; und schließlich die integrative, die wenig rezipiert wird, die aber möglicherweise die angemessenste und vor allem die zeitgemäßeste ist. Da es ganz zentral um Rezeption geht, ist dieser Beitrag sehr zitatenlastig und hoffentlich gerade dadurch informativ. Zum allgemeinen Thema des diesem Sammelband zugrunde liegenden Symposiums trägt er in mehrerlei Hinsicht bei. Zwar wird Religion nur im Sinne eines ethischen Bewusstseins und der teils von Smith verwendeten religiösen

11 Die klassische deutschsprachige Referenz dazu ist der Sammelband mit dem sprechenden Titel Der andere Adam Smith, vgl. Meyer-Faje/Ulrich (1991).

12 Bezeichnenderweise, wie Leonidas Montes anmerkt, findet sich in einem mit den Beiträgen von Nobelpreisträgern bestückten Sammelband anlässlich des 200. Todestages des Gründervaters der Disziplin keine einzige Referenz auf die Theory of Moral Sentiments. Vgl. Montes (2003), 86, mit Verweis auf Fry (1992).

13 Vgl. für einen guten Überblick Montes (2003) oder den entsprechenden Beitrag von Martin Patzen in Meyer-Faje/Ulrich (1991), 21-54, sowie neuerdings Paganelli (2008), die das Pferd von der anderen Seite her aufzäumt. Der Begriff „Adam-Smith-Problem“ geht übrigens interessanterweise auf die Deutsche Nationalökonomie im 19. Jahrhundert zurück. Es wird z.B. von Jakob Viner wie folgt charakterisiert: „The Germans, who, it seems, in their methodical manner commonly read both the Theory of Moral Sentiments and the Wealth of Nations, have coined a pretty term, Das Adam Smith Problem, to denote the failure to understand either which results from the attempt to use the one in the interpretation of the other." Viner (1927), 201. 
Symbolik angesprochen, es geht kaum um Politik (am ehesten wohl im Sinne von Regulation) und um Philosophie nur in dem Sinn, dass Smith insgesamt daran gelegen war, ein System der praktischen Philosophie zu schaffen. Es geht aber natürlich darum, wie der „Markt" im Diskurs der Moderne verstanden wird und wie man ihn im Lichte historischer Beispiele auch verstehen könnte. Da dies eine „Rückkehr“ ethischer Anfragen in die Ökonomie und die Ökonomik darstellen würde, schließt sich damit der Kreis.

\section{Adam Smith und seine Stellung}

Smith wurde wahrscheinlich 1723 geboren und in seiner Ausbildung und seinem Werk vor allem von seinem Lehrer Francis Hutchinson, seinem Freund David Hume und den französischen Physiokraten beeinflusst. Er hielt in den späten 1740er Jahren zahlreiche sehr erfolgreiche öffentliche Vorlesungen in Edinburgh und wurde so bekannt. Nach einer Tätigkeit als Professor für Logik und später Moralphilosophie an der Universität Glasgow (1751-63), im Zuge derer auch die Theory of Moral Sentiments entstand, wurde er Erzieher von Henry Scott, dem Duke of Buccleuch, und begleitete ihn auf einer dreijährigen Studienreise durch Europa, was ihm eine lebenslange Rente einbrachte. Auf besagter Reise lernte er in Frankreich Anne Robert Jacques Turgot und Francois Quesnay kennen, die Größen der Ökonomik der damaligen Zeit. 1766 kehrte er nach Schottland zurück. Dort verfasste er An Inquiry into the Nature and Causes of the Wealth of Nations, das ein großer kommerzieller Erfolg wurde. Smith wurde - neben zahlreichen akademischen Ehren - 1778 schließlich erfolgreicher schottischer Zollkommissar, ehe er 1790 starb.

Als Ökonom wurde Smith zum frühen Vertreter dessen, was später die „Klassik“ genannt werden sollte, und stand damit in einer Reihe mit Malthus, Ricardo und Say. Daraus entwickelte sich sowohl der Marxismus, als auch, ausgehend vor allem von John Stuart Mill und Jeremy Bentham, der Utilitarismus, der zur theoretischen Basis des politischen und ökonomischen Liberalismus im 19. Jahrhundert wurde. Daraus wuchs die zweite Revolution in den Wirtschaftswissenschaften in den 1870er Jahren, als sich die so genannte „Neoklassik" Bahn zu brechen begann. Ausgehend von den Arbeiten von William Jevons, Leon Walras und Carl Menger und weiter popularisiert durch Alfred Marshall kam es daran anschließend zur Entwick- 
lung der methodisch formalen und inhaltlich am Rationalismus orientierten Ökonomik, die wir heute kennen.

Smiths Werk hingegen ist eine fundierte Betrachtung der menschlichen Natur und der Organisation menschlichen Tuns (unter Einschluss der Diskussion der Arbeiten anderer) mit dem Hintergrund, die Daseinsbedingungen für die Menschen verbessern zu wollen. ${ }^{14}$ Dass Smith dabei historischen Betrachtungen breiten Raum einräumte, sei aus der Sicht eines Wirtschaftshistorikers besonders betont und ist auch sonst methodisch bemerkenswert. ${ }^{15}$ Smith ist dabei zwar grundsätzlich dem Menschen gegenüber wohlwollend, aber keinesfalls blind für negative Affekte wie Dummheit oder Laster, die er ausführlich thematisiert. Seine Kernthesen beziehen sich auf die Rolle des Menschen, des Staates und der Wirtschaft für die Gesellschaft. Er sieht den Menschen als freies Individuum und geprägt vom Eigeninteresse, das sich paradoxerweise vor allem im Streben nach Anerkennung durch seine Mitmenschen und ihrem Mitgefühl äußert, ${ }^{16}$ sich darin aber freilich nicht erschöpft. Der Staat hingegen möge sich möglichst zurückhalten und weder Gesellschaft noch Wirtschaft zu sehr gängeln, dies freilich vor allem deshalb, weil Politiker unfähig und oft geradezu dumm seien. Schließlich ist die Wirtschaft in seiner Sicht nicht produktions-, sondern tauschbasiert, also nicht vom Angebot, sondern von der Nachfrage gesteuert, woraus Smith (und vor allem seine Apologeten) die Forderung nach Freihandel ableitete.

Smith war dabei auf der Höhe seiner Zeit und vor allem in zweierlei Hinsicht modern: in seiner Betrachtung des Menschen als Individuum und in seiner Fähigkeit, kollektives Handeln aus individuellem Handeln auch in widersprüchlicher Weise abzuleiten, als

14 Vgl. für eine leicht lesbare allgemeine Einführung in Smiths Werk z.B. Aßländer (2007), sowie O’Rourke (2007) oder Winter/Rommel (1999) für den Wealth of Nations, die beide unter anderem das aufzeigen, was ich die „simple Rezeption“ nenne. Vgl. für umfassende und kritischere Einschätzungen die Einführungen der Übersetzer seiner Hauptwerke, Walther Eckstein in Theory, XI-LXXI, und Horst Claus Recktenwald in Wealth, XVLXXIX.

15 Das veranlasst Recktenwald etwa zu dem Schluss, dass „kaum ein Ökonom oder Philosoph [...] bis heute die wirkliche Natur der Phänomene so vorbildlich zu erkennen gesucht [hat] wie er". Wealth, LXXV.

16 Smith zur „Sympathie“ und ihrer Rolle für das Wohlbefinden: „, [...] sicher ist, dass nichts unser Wohlgefallen mehr erweckt, als einen Menschen zu sehen, der für alle Gemütsbewegungen unserer Brust Mitgefühl empfindet, und dass uns nichts so sehr verdrießt, als wenn wir an einem Menschen kalte Gefühllosigkeit beobachten. “ Theory, 9. 
kollektive Rationalität, die auch aus individueller Irrationalität entspringen kann. Er hat sich außerdem verdient gemacht um die Befreiung der englischen Volkswirtschaft von teils grotesker Überregulierung und damit um die tatsächliche Befreiung von Menschen aus Beschränkungen ihres Handelns, die sowohl für sie selbst als auch für die Gesellschaft schädlich waren. ${ }^{17}$ Gerne vergessen wird freilich die Beschränkung des „Strebens nach Glück“ des Menschen durch die „ethischen Gefühle“ der Menschen, die sich bei einer Betrachtung des Smith'schen Gesamtwerks zeigt. Sowohl der Wealth of Nations als auch die Theory of Moral Sentiments wurden von Smith dabei bis zum Schluss bearbeitet, ohne grundlegend revidiert zu werden, wobei er dies geplant haben dürfte (da Smith seinen Nachlass erfolgreich zur Verbrennung bestimmt hat, haben wir freilich keine genaue Kenntnis von seinem Spätwerk). ${ }^{18}$

\section{Aktuelles ökonomisches Denken und Adam Smith}

Im Folgenden soll nun gezeigt werden, wie unterschiedlich Smith auf verschiedenen Ebenen im modernen ökonomischen Denken rezipiert wird - was manchmal durchaus offensichtlich missbräuchlich geschah und geschieht. Ich möchte dabei drei Arten der Rezeption unterscheiden: zum ersten eine simple, also eher einfache und oberflächliche Rezeption, wie sie bei vielen Praktikern (freilich mehr

17 Vgl. Exenberger/Nussbaumer (2004), 27-30. Wie Jakob Viner schon 1927 anmerkte, war er allerdings kein Prophet und konnte nicht ohne weiteres voraussehen, dass seine Entfesselung des unternehmerischen Geistes zur Unterdrückung der werktätigen Massen führen würde. Schließlich starb Smith, ehe sich die Industrielle Revolution wirklich Bahn brechen konnte. Im Original: „He [Smith] helped greatly to free England from the bonds of a set of regulatory measures which had always been ill advised and based on fallacious economic notions, but he did not foresee that England would soon need a new set of regulations to protect her labouring masses against new, and to them dangerous, methods of industrial organization and industrial technique.” Viner (1927), 231.

18 Schon 1774 und also im Zusammenhang mit dem Wealth of Nations wurde eine vierte Auflage der Theory of Moral Sentiments veröffentlicht, 1781 eine fünfte und 1791 wurde die sechste Auflage, die „letzte von eigener Hand“, posthum veröffentlicht. Die deutsche Fassung nach Walther Eckstein (erstmals publiziert 1926) ist auf der Basis dieser letzten Auflage erstellt und dokumentiert die vorangegangenen Änderungen ausführlich in einem Fußnotenapparat, wobei sich Eckstein auch um das Nachvollziehen der unzitierten Querverweise von Smith verdient gemacht hat. Der Wealth of Nations erlebte zwischen 1776 und 1789 fünf Auflagen, blieb dabei aber nahezu unverändert. Auch hier ist die deutsche Fassung nach Recktenwald (erstmals publiziert 1974) auf der Basis der letzten Auflage erstellt, die (wenigen) Änderungen sind dabei aber leider nicht dokumentiert. 
der Politik und Beratung als der Wirtschaft selbst) sowie in der medialen Öffentlichkeit anzutreffen ist; zum zweiten eine spezielle, die sich auf bestimmte Elemente der Theorie konzentriert und die sich vor allem in den ökonomischen Fachdiskursen findet, freilich in erster Linie jenen theoriegeschichtlicher Natur; zum dritten schließlich eine integrative Rezeption, die versucht, den sozusagen ganzen Smith zusammen zu denken und aktuell anzuwenden, und die sich in jüngerer Vergangenheit kaum mehr entfaltet, und wenn, dann am ehesten in Debatten im Umfeld dessen, was von ,politischer Ökonomie“ heute noch übrig geblieben ist. Und das ist nicht viel.

Wie bereits an anderer Stelle geschrieben: „Derjenige Strang der Ökonomik, der sich im 20. Jahrhundert durchsetzte, begriff sich vor etwa hundert Jahren fortschrittlich als mechanistisches System von Ursache-Wirkungs-Ketten, bei denen der Mensch als ,Wirtschaftssubjekt ${ }^{6}$ auftrat [...]. Er betätigte sich in der Folge zunehmend in der Analyse von Teilmärkten, von einzelnen, isolierten Aspekten der Wirklichkeit, blendete damit eine Fülle von Interdependenzen aus und damit immer mehr auch den ethischen Gehalt aus seiner Wissenschaft. Was man durch diese engen Grenzen gewann, war Prognosefähigkeit innerhalb dieser Grenzen. Was man außerdem gewann, war die Newtonsche Mechanik, die streng wertfrei gedacht wird und damit ist die Analyse eines nach ihren Gesetzen ablaufenden Systems einem ,unparteiischen Beobachter' im Sinne Smiths in werturteilsfreier Weise möglich." 19 Was diesem Prozess insbesondere zum Opfer fiel, war das Politische in der politischen Ökonomie und was man gewann, war die Illusion, man könne Wirtschaft von Gesellschaft isolieren (also ein „Innen“ und ein „Außen“ definieren) und dadurch besser funktionsfähig machen. ${ }^{20}$

\subsection{Die ,simple“ Rezeption}

Seltsamerweise wurde Smith gerade für diese Sichtweise zum Säulenheiligen. Die simple Rezeption ist daher jene, die ihn als den $\mathrm{Va}$ ter oder zumindest Begründer der Ökonomik und insbesondere des

19 Exenberger/Nussbaumer (2004), 44-45. Das meint man zumindest. Wie Reiner Manstetten anmerkt, wäre dieser „unparteiische Beobachter" (impartial spectator) in diesem Sinne der archimedische Punkt im ökonomischen System. Vgl. Manstetten (2000), 147148.

20 Diese Interpretation steht im Gegensatz zum oft festgestellten Aristotelianismus von Smith, der in seiner Vorstellung einer Trias aus Politik, Ethik und Ökonomie besteht. 
Neoliberalismus - oder richtiger: des laissez faire - sieht. Sie ist sehr präsent, speziell in alltäglichen Debatten über Wirtschaft, kommt aber kaum je über grobe Vereinfachungen hinaus und steht daher oft sogar in krassem Widerspruch zu Smith. Mehr noch, sie geht sehr oft ahistorisch vom status quo aus und setzt voraus, dass das, was im Laufe von 200 Jahren aus der Theorie gemacht worden ist, sich mit dem deckt, was der „Begründer“ dieser Theorie gemeint hat. Um die Wissenschaft dabei nicht zu Unrecht zu sehr in Schutz zu nehmen: Da die meisten ihrer Angehörigen kaum Interesse an den ideologischen und noch weniger an den methodologischen oder anthropologischen Grundlagen ihres Tuns haben, ${ }^{21}$ stellt diese Interpretation auch das implizite Verständnis der meisten Wirtschaftswissenschaftler(innen) vom Werk Smiths dar. Dazu meint etwa John F. Henry: „It is usually held that orthodox economic theory supports a (generally) laissez faire, noninterventionist position that is traceable to Adam Smith. Perhaps the strongest argument for this view emanates from Chicago [...], but it is the prevalent position among most economists." 22 Aber es handelt sich, wie Henry weiter ausführt, oft um reine Lippenbekenntnisse, denn die theoretischen Grundlagen von Smiths Ökonomik und der frühen neoklassischen Ökonomik unterschieden sich deutlich, insbesondere hatte Smith ein sehr realistisches und keinesfalls abstrakt rationales Bild von menschlichem Verhalten. ${ }^{23}$

Zentrale Elemente dieser Sichtweise sind der Individualismus, die Eigennutzorientierung und Tauschneigung des Menschen, seine Rationalität, die Vorteile der Arbeitsteilung, eine generelle Skepsis gegenüber Regierungen ${ }^{24}$ und die Vorstellung von einem sich selbst regulierenden Markt. Sie speist sich etwa aus Zitaten wie: „Nicht vom Wohlwollen des Metzgers, Brauers oder Bäckers erwarten wir

21 Das zeigt sich etwa darin, wie wenig Aufwand in den Wirtschaftswissenschaften der angemessenen Bestimmung der verwendeten Begriffe gewidmet wird. Ein besonders warnendes Beispiel ist etwa der Begriff „Globalisierung“, der - obwohl völlig unterschiedlich verwendet - kaum definiert oder auch nur erklärt wird. Vgl. etwa Exenberger/Cian (2006), vor allem 27-29.

22 Henry (2008), 209. Die im Zitat explizit angesprochene Referenz ist Coase (1976), erschienen in einer Sondernummer des Journal of Law and Economics zum Wealth of Nations.

23 Vgl. ausführlicher etwa Henry (2008), 213.

24 Der Staat solle sich im Wesentlichen auf die Landesverteidigung, die Garantie der Rechtsstaatlichkeit (Schutz der Person und des Eigentums) und die Bereitstellung öffentlicher Güter (Infrastruktur) sowie Repräsentation beschränken. Vgl. Wealth, 587-695, oder überblicksartig bei Aßländer (2007), 128-140. 
das, was wir zum Essen brauchen, sondern davon, dass sie ihre eigenen Interessen wahrnehmen. Wir wenden uns nicht an ihre Menschen-, sondern an ihre Eigenliebe, und wir erwähnen nicht die eigenen Bedürfnisse, sondern sprechen von ihrem Vorteil." 25 Und sie kommt aus der Denkfigur der „unsichtbaren Hand“" 26 , auf die später noch ausführlicher zurückzukommen sein wird.

Behauptet wird damit, dass Smith dem Prinzip des laissez faire oder - moderner - dem Neoliberalismus den Boden bereitet hat. Diese Gleichsetzung ist freilich nicht nur unangemessen, sondern auch ganz und gar anachronistisch. ${ }^{27}$ Wie verbreitet sie jedoch ist und warum, zeigt freilich nochmals Henry: „But as an ideology, it is most useful. Many, perhaps most, of the population do not trust government - correctly so. Many, perhaps most, do believe that welfare programs are inefficient and merely reward the indolent, the corrupt, the incompetent. Many, perhaps most, see regulations as an infringement on their freedom, even when those regulations speak to matters such as preserving the environment (or at least slowing the rate of destruction). Let well-specified property rights and the workings of the free market dictate the results as this is a formula for optimal outcomes reflective of people's real interests. [...] As public

25 Wealth, 17. Das Zitat steht im Kontext von Smiths Diskussion der Tauschneigung des Menschen sowie der Vorteile der Arbeitsteilung und ist auch bemerkenswert, weil es jene paradoxe Logik des durch Egoismus erzeugten Gemeinwohls verdeutlicht. Schon der zweite Teil des Zitats wird ja oft ausgelassen, weil dieser Kontext nicht interessiert - wie leider so oft, speziell in „simplen“ Rezeptionen oder solchen, die sich Smiths nur im Dienste eigener Interessen bedienen. Daher wird auch noch seltener zitiert, wie der Text weitergeht: „Niemand möchte weitgehend vom Wohlwollen seiner Mitmenschen abhängen, außer einem Bettler, und selbst der verlässt sich nicht allein darauf. Mildtätige Menschen geben ihm zwar, was er zum Leben unbedingt benötigt, doch weder wollen noch können sie ihn mit allem unmittelbar versorgen, was er gerade braucht."

26 Wealth, 371, bzw. Theory, 316-317. Im Wealth of Nations heißt es: „Wenn er [jeder einzelne] es vorzieht, die nationale Wirtschaft anstatt die ausländische zu unterstützen, denkt er eigentlich nur an die eigene Sicherheit und wenn er dadurch die Erwerbstätigkeit so fördert, dass ihr Ertrag den höchsten Wert erzielen kann, strebt er lediglich nach eigenem Gewinn. Und er wird in diesem wie auch in vielen anderen Fällen von einer unsichtbaren Hand geleitet, um einen Zweck zu fördern, den zu erfüllen er in keiner Weise beabsichtigt hat." In der Theory of Moral Sentiments steht die unsichtbare Hand für ein den Akteuren unbewusstes trickle down, das darin besteht, dass die Reichen die Armen zumindest soweit beschäftigen, dass trotz ursprünglich sehr ungleicher Verteilung des Reichtums eine „beinahe gleiche Verteilung der zum Leben notwendigen Güter" (natürlich nicht der Luxusgüter) resultiert.

27 Wie könnte Smith, der zweifellos Wegbereiter für den Liberalismus (wenn auch nicht den orthodoxen) war, neo-liberal sein, wo sich doch der Neoliberalismus von Hayek bis Friedman als direkte Gegenposition zum „klassischen“ laissez-faire-Liberalismus verstanden hat? 
policy, laissez faire is not practiced and never will be practiced. As an ideology, it continues to serve the interests of the major property holders, though the fight is no longer against feudalism: it's now against that propertyless class that was wrought in the early stage of this social formation."28 Zentral für Henry ist dabei das Argument, dass die Ausbreitung der neoklassischen Ökonomik Ergebnis einer regelrechten Kampagne war, die in den 1930er Jahren als Reaktion auf die dirigistische Wirtschaftspolitik während und nach der GroBen Depression gestartet wurde. ${ }^{29}$

Natürlich ist die Kritik an dieser Interpretation selbst kritikwürdig, wie etwa Vivienne Brown in einer Rezension anmerkt: „From a scholarly point of view Pack's argument is demolishing a caricature of Adam Smith's writings, albeit one that became increasingly popular during the 1980s with the widespread shift to a more antistatist economic rhetoric. But given the gap that clearly exists between the scholarly output on Smith and the representations of his work in popular debate, it could be countered that this argument still needs to be put." 30 Denn was Smith letztlich vertreten hat, ist das, was Reiner Manstetten treffend wie folgt zusammenfasst: „Wenn Wirtschaftssubjekte, deren Interesse ausschließlich auf ihren privaten Vorteil gerichtet ist, durch ihr Handeln, sofern es sich innerhalb rechtlicher Grenzen hält, ohne ihr Zutun und ohne staatliche Eingriffe die wirtschaftliche Wohlfahrt der gesamten Gesellschaft fördern, dann soll der Staat die Wirtschaft sich selbst überlassen. “31 Oder wie Jakob Viner schreibt: „Adam Smith was not a doctrinaire advocate of laissez faire. He saw a wide and elastic range of activity for government, and he was prepared to extend it even farther if government, by improving its standards of competence, honesty, and public spirit, showed itself entitled to wider responsibilities." 32

28 Henry (2008), 223.

29 Henry (2008), 215-219, vgl. auch Cockett (1994). Henry unterscheidet daher auch „sanftes“ von „hartem“ laissez faire, wobei Smith für ersteres und neoklassische bzw. neoliberale Ökonomik für letzteres steht. Aber, so Henry, „[...] as a practical policy, laissez faire is only honored in the breech. This has always been the case. It is a useful ideology for providing a façade under which large corporations - that certainly violate every underlying assumption on which the free market optimizing conclusions are reached - are increasingly organizing the world in their own interests [...]" Henry (2008), 218.

30 Brown (1993), 231. Die Bemerkung bezieht sich auf das Buch Capitalism as a Moral System (1991) von Spencer J. Pack.

31 Manstetten (2000), 146.

32 Viner (1927), 231. 


\subsection{Die „sperielle“ Rezeption}

Freilich gibt es auch eine speziellere Rezeption, die besser als die doktrinäre, teils rein instrumentelle reflektiert, wie einzelne Ideen von Smith in dessen Gesamtwerk verankert sind, welchen Beitrag sie zur Theorieentwicklung geliefert haben und aus welcher Zeit heraus sie entstanden sind. In dieser Hinsicht sind sie vielleicht nicht besonders einzigartig, aber trotzdem reformatorisch, wenn nicht sogar revolutionär. Schließlich sollte man nicht vergessen, dass Smith lange vor der Französischen Revolution wirkte und daher als einer der Vordenker der Emanzipation des Individuums durch persönliche Freiheitsrechte und Kämpfer gegen die Willkür von Regierungen mit - wie man heute vielleicht sagen würde - intransparenter Legitimationsbasis gelten kann. In diesem Kontext wird Smith jedoch auch als ein letztlich weniger brillanter Zeitgenossen von Hume (in der Philosophie) und Ricardo (in der Ökonomik) dargestellt, sowie andere (vor allem Say, Marshall und Walras) als die eigentlichen Väter dessen, was heute Wirtschaftswissenschaften heißt. ${ }^{33}$

Diese Rezeption ist allerdings tatsächlich speziell, weil sie in der Regel auf bestimmte Elemente der Theorie Smiths beschränkt ist und weil der Diskurs vor allem theoriegeschichtlich ist. In ihr wird Smith als Vorläufer der allgemeinen Gleichgewichtstheorie gewürdigt (wie schon erwähnt etwa von Samuelson), in seiner Rolle als früher Bearbeiter von Verteilungsfragen (schließlich unterschied er die „Faktorentgelte“ als Löhne, Renten und Gewinne), als früher moderner Theoretiker des Außenhandels (seine Merkantilismuskritik ist geradezu sprichwörtlich ${ }^{34}$ ) oder sogar als Vordenker von so aktuellen Konzepten wie corporate social responsibility (CSR). Letzteres sieht dann z.B. wie folgt aus: „However, the CSR approach is not that new. Before Smith proposed his famous idea of the 'invisible hand' in the Wealth of Nations, he had written about the necessity of main-

33 Letzteres gilt freilich vor allem deshalb, weil sich die Wirtschaftswissenschaften heute generell in keiner Weise mehr im Sinne einer „politischen Ökonomie“ verstehen, während Smith ein vielmehr ganzheitlicher Denker war, der sich für die vielfältige Einflüsse auf die Wirtschaft (und Gesellschaft) tatsächlich interessierte und sie nicht aus einer Analyse von Märkten ausklammerte. Nicht umsonst verstand sich die neoklassische Schule als ,reine Ökonomik“, als eine Analyse der Wirtschaft, die von störenden, wesensfremden Einflüssen so weit wie möglich ,gereinigt" war.

34 Vgl. Wealth, 347-559, wo Merkantilismus nicht zuletzt als Politik im Dienste ganz bestimmter, keinesfalls allgemeiner Interessen gebrandmarkt wird. Trotzdem lassen sich mit Smith auch infant-industry-Argumente vorbringen, vgl. etwa Viner (1927), 229. 
taining an ethical behaviour in order to maximize long term growth in the Lectures on Jurisprudence. In the lectures, Smith presents the idea that 'honesty is profitable,' such as when Smith says that if a salesman makes a considerable number of commercial deals, his goal is not to obtain the maximum benefit in each deal, but to obtain a maximum of the total deal. So, to lie or cheat can make the number of future deals decrease, diminishing the total benefit. Honourable behaviour has a commercial logic." 35 Gerade im aktuellen Bezug interessant ist freilich, dass es Smith dabei durchaus um die Wirklichkeit gegangen ist, das tatsächliche Selbstverständnis, und nicht nur streng utilitaristisch den schönen Schein für andere. ${ }^{36}$

Zudem erschließen diese kontextsensitiven Betrachtungen, dass Smith im politischen Sinn nicht konsequent anti-interventionistisch argumentierte. ${ }^{37}$ Zusammenfassend: „Government activity is natural and therefore good where it promotes the general welfare, and is an interference with nature and therefore bad when it injures the general interests of society. Whether in particular circumstances it works well or ill is to be determined only by examination of the character of those circumstances, though in most cases such examination may be expected a priori to reveal that it works badly." 38

Aber Smith war nicht nur der Regierung und Verwaltung gegenüber skeptisch, wie etwa folgendes Beispiel zeigt: „Kaufleute sind immer daran interessiert, den Markt zu erweitern und den Wettbewerb einzuschränken [...]. Jedem Vorschlag zu einem neuen Gesetz

35 Carrasco (2007), 457-458 (Hervorhebung A.E.). Der erwähnte Verweis bezieht sich auf die Seiten 327-328 der Lectures. Es ist dabei durchaus bezeichnend, wie interpretativ frei auch der Umgang mit der ,unsichtbaren Hand“ im angeführten Beispiel ist. Dass diese für eine sozusagen moralische äußere Ordnung stehen könnte, ist durchaus diskutabel.

36 Siehe dazu das relevante Kapitel in Theory, 171-199.

37 Dieses Argument wird z.B. von Viner ausführlich vorgebracht, vgl. Viner (1927), was er später in einen größeren Zusammenhang stellt, vgl. Viner (1960). Smith anerkannte sogar die indirekte Verantwortung des Staates für das Aufrechterhalten eines gewissen, ortsüblichen Lebensstandards, was zeitgenössisch gut verständlich ist, gerade im Lichte aktueller Sozialstaatsdebatten aber aufschlussreich bleibt. Im Original: „Unter lebensnotwendigen Gütern verstehe ich nicht nur solche, die unerlässlich zum Erhalt des Lebens sind, sondern auch Dinge, ohne die achtbaren Leuten, selbst der untersten Schicht, ein Auskommen nach den Gewohnheiten des Landes nicht zugemutet werden kann.“ Wealth, 747. Smith argumentierte an dieser Stelle insofern indirekt für Staatsintervention, als er für niedrige Steuerlasten im Bereich dieses „Lebensnotwendigen“ eintritt, weil solche Steuern über die Preise die Löhne erhöhen müssten, um den Menschen weiter den notwendigen Lebensunterhalt zu finanzieren.

38 Viner (1927), 220. 
oder einer neuen Regelung über den Handel, der von ihnen kommt, sollte man immer mit großer Vorsicht begegnen. Man sollte ihn niemals übernehmen, ohne ihn vorher gründlich und sorgfältig, ja sogar misstrauisch und argwöhnisch geprüft zu haben, denn er stammt von einer Gruppe von Menschen, deren Interesse niemals dem öffentlichen Wohl genau entspricht, und die in der Regel vielmehr daran interessiert sind, die Allgemeinheit zu täuschen, ja sogar zu missbrauchen." 39

Bleibt da schließlich noch die recht lebendige Debatte um das Smithsche Verständnis der „unsichtbaren Hand“, eine typische theorie- und rezeptionsgeschichtliche Debatte. ${ }^{40}$ Reiner Manstetten steht in dieser Diskussion für den krypto-religiösen Gehalt der Metapher, die unsichtbare Hand als Ausdruck der natürlichen Ordnung, an die der Deist Smith glaubte ${ }^{41}$ - oder als Gottesersatz eines doch nicht restlos überzeugten Atheisten. Manstetten sieht sie als getragen von vier Überzeugungen, die Smith auf der Basis von Beobachtungen und Indizien gewonnen hat: Skepsis gegenüber sozialer Planung, Realismus bezüglich der Bedeutung von Macht und Eigeninteressen, Hoffnung (sic!), dass nicht nur ökonomische Motive im Leben wichtig sind und Glauben (sic!) an eine göttliche und damit zwingend gute „,natürliche“ Ordnung. ${ }^{42}$ Sie ist daher keineswegs neutral oder gar liberal, sondern Ergebnis des gesamtgesellschaftlichen Wirkens: „Smith's hypothesis of a strong private concern with achieving 'security' and a consequent aversion to foreign investment is as much a part of the invisible hand mechanism as the basic desire for profit. " 43 Man kommt aber in diesem Zusammenhang auch ohne Rückgriff auf Gott aus. Emma Rothschild argumentiert etwa, dass Smith die Denkfigur der „unsichtbaren Hand“ eingeführt hat, weil sie ein ästhetisch ansprechendes Bild ist, das auch gut in den Zeitgeist gepasst hat, und als einen ,ironischen, aber nützlichen Witz“"44. In der Weise,

39 Wealth, 213. Das Zitat beschließt das Kapitel über die Bodenrente und endet mit dem Satz: „Beides hat sie auch tatsächlich bei vielen Gelegenheiten erfahren müssen.“

40 Vgl. etwa Hodgson (2004) für einen relativ aktuellen Sammelband zum Thema.

41 Man kann auch noch weitergehen und den gesamten Wealth of Nations als Naturtheologie lesen, vgl. etwa Waterman (2002).

42 Manstetten (2000), 259-263, vor allem 262.

43 Persky (1989), 198.

44 Rothschild (1994), 319. Ursprünglich - in der History of Astronomy - war der Vergleich noch unmittelbar göttlich, mit der unsichtbaren Hand des Jupiter, der die Gestirne lenkt. Später drehte sich diese Beziehung sozusagen um. 
wie sie normalerweise verstanden wird (auch von Manstetten) ist sie eher un-Smithianisch. Smith war realistisch ganz im sokratischen Sinn, indem er die Begrenzungen eigener Erkenntnis sehr wohl erkannte und daher die Idee einer zwar dem Theoretiker, nicht aber dem einfachen Bürger kognitiv zugänglichen übergeordneten Instanz kaum geschätzt hätte. ${ }^{45}$

\subsection{Die ,integrative“ Rezeption}

Das kritische Potential von Smiths Arbeiten wird zwar zeitgenössisch gesehen (und auch als solches historisch analysiert), aktuell aber meist nur gestreift. Eine solche ,integrative“ Rezeption Smiths im Sinne einer Überwindung der künstlichen Trennung vom Moralphilosophen (jenem der Theory of Moral Sentiments) und dem Ökonomen (jenem des Wealth of Nations) existiert daher praktisch nicht - zumindest nicht im Mainstream der Ökonomik. ${ }^{46}$ Jenseits dieser Trennung aber gibt es einen Smith, der gerade angesichts aktueller Herausforderungen eine auch heute interessante ethisch fundierte politische Ökonomie vertritt.

Dieser Teil sei aber mit einem Namensvetter Smiths, dem bereits genannten Experimentalökonomen Vernon L. Smith begonnen. Er bemüht sich insofern um eine integrative Rezeption Smiths, als er das Adam-Smith-Problem aufgreift und eine zumindest heutzutage mainstreamtaugliche ${ }^{47}$ „Lösung“ dafür bietet, warum der Mensch zugleich eigennutzorientiert nicht-kooperativ wie auch sympathieorientiert kooperativ agiert. Der Schlüssel liegt für ihn in der Unterscheidung zwischen anonymem Tausch auf Märkten und persönlichem Tausch in Beziehungen, wo jeweils unterschiedliche Verhaltensweisen belohnt werden. ${ }^{48}$ Damit freilich erfolgt die Integration der verschiedenen „Gesichter“ Smiths unter der Voraussetzung der

45 Ähnlich argumentiert auch Evensky (2001), 514.

46 Im Feld der Wirtschaftsethik gibt es sie noch am ehesten. Neben Amartya Sen, auf den noch etwas ausführlicher einzugehen sein wird, sei z.B. auf Kurt Rothschild verwiesen, vgl. etwa Rothschild (1993), 15.

47 Die experimentelle Ökonomik war früher ein Randbereich der Wirtschaftswissenschaften, ist spätestens mit den Nobelpreisen für einige ihrer Vertreter und Wegbereiter aber in den Mainstream aufgestiegen. Sie ist zu würdigen für ihr deutlich realistischeres Verständnis menschlichen Verhaltens als es in den Modellwelten der reinen Neoklassik präsentiert wird, das auch Reziprozität und Altruismus einschließt. Damit geht sie freilich nur im Hinblick auf die methodische Fundierung über das bereits von Smith erkannte hinaus.

48 Vgl. V. Smith (1998). 
Rationalität (Erwartung der positiven und negativen Sanktionierung von Verhalten) und ist von der Absicht getragen, die „Natürlichkeit" von Eigentumsrechten nachzuweisen. Vernon Smith versteht diese in engem Zusammenhang mit Reziprozität: „Reciprocity in human nature (and prominently in our closest primate relative, the chimpanzee) is the foundation of our uniqueness as creatures of social exchange, which we extended to include trade with nonkin and nontribal members long, long before we adopted herder and farmer life styles." 49 Diese Sicht ist aber insofern zweifellos Smithianisch, dass sie von der generellen Tauschneigung des Menschen ausgeht, die auch für Smith zentral war und die auch den Austausch von Geschenken und Gefühlen, nicht nur von Gütern meint.

Während für diesen Beitrag Ethik nicht von Bedeutung ist, speist diese eine zweite, mächtigere Linie der Integration. Darauf hat bereits in den 1980er Jahren der spätere Nobelpreisträger Amartya Sen hingewiesen, als er im Rahmen der Royer Lectures an der renommierten Universität von Berkeley drei Vorträge zum Thema „Ethik und Ökonomik“ hielt. ${ }^{50}$ Zwar dominiert heute ein vielmehr technisch-logistischer Zugang zur Ökonomik, und das nicht zu ihrem Vorteil.51 Smith steht aber seiner Ansicht nach ganz in der wichtigeren Tradition der Entwicklung der Ökonomik, die aus der Ethik kommt und schon auf Aristoteles zurückgeht. Jedoch wird Smith übertrieben vereinfacht und daher missverstanden: „The misinterpretation of Smith's complex attitude to motivation and markets, and the neglect of this ethical analysis of sentiments and behaviour, fits well into the distancing of economics from ethics that has occurred with the development of modern economics." 52

Das wird von Jerry Evensky aufgegriffen, der Smith vor allem mit dem Ansatz von Gary Becker kontrastiert, den er mit einem Satz zitiert, der Smith auf den Kopf stellen würde: „I am saying that the

49 V. Smith (1998), 3.

50 Die Vorträge wurden in Sen (1990) veröffentlicht, erstmals 1987.

51 Sen beklagt nicht nur eine „Verarmung“ der Wohlfahrtsökonomik, sondern auch die damit verbundenen Nachteile für die Qualität der beschreibenden und der prognostischen Ökonomik. Vgl. Sen (1990), vor allem 7-10. Vgl. für eine aktuelle Arbeit zur Wohlfahrtsökonomik mit bezug auf Smith auch Blaug (2007). Sen kritisiert auch die zudem oft auf Smith zurückgeführte übertriebene Eigennutzorientierung und den überzogenen Stellenwert des Selbstinteresses für die Erklärung ökonomischen Verhaltens. Vgl. Sen (1990), vor allem 15-28 und 80-88, oder auch Exenberger/Nussbaumer (2004), 24-27 und 35-36.

52 Sen (1990), 27-28. 
economic approach provides a valuable unified framework for understanding all human behaviour."53 Mit dem „ökonomischen Ansatz" meint Becker dabei im Kern individualistische und rationale Nutzenmaximierung. Auch Joseph Spengler äußert sich zu diesem Verhältnis: „Smith did not treat of utility maximization within a social and economic institution a la Gary Becker. His concern was mainly to describe and seek establishment of a politicoeconomic environment within which man's desire and efforts to better his condition could work optimally for himself and society whether the sought object be the adequate supply of education both useful and not needlessly expensive, or the supply of physical commodities." 54

Smith war skeptisch gegenüber einfachen, eindimensionalen Erklärungen, wie Sen anhand seiner Bearbeitung von Epikur in der Theory of Moral Sentiments zeigt. ${ }^{55}$ Sen sieht es daher geradezu als Ironie an, dass viele Bewunderer von Smith in ihm ganz gegen dessen eigene Neigung einen exklusiven Vertreter des Selbstinteresses sehen. „The defence of self-interested behaviour comes in specific contexts, particularly related to various contemporary bureaucratic barriers and other restrictions to economic transactions which made trade difficult and hampered production." 56 Das Eigeninteresse und die Selbstliebe waren bei Smith daher immer gesellschaftlich eingebettet, wie auch Michael Aßländer ausführt: „Trotz seines Eintretens für ein System der ,natürlichen Freiheit' konstruiert Smith keinen Laissezfaire-Kapitalismus. Stets bleibt das menschliche Handeln - auch im ökonomischen Kontext - durch die Gebote der Moral begrenzt. Was der unparteiische Zuschauer nicht gutheißen kann, ist auch im ökonomischen Kontext untersagt. "57 Persky fasst das sehr treffend zusammen: ,[...] it is clear that economic freedom alone is not sufficient to guarantee the desired outcome. The relation between selfinterest and social welfare is mediated by a host of economic, political and social institutions." 58 Die Grundlage für dieses gesellschaftliche Ergebnis ist und bleibt freilich ein individueller Vorgang, der aus sich selbst heraus entsteht und keine Transzendenz braucht, und den

53 Evensky (2001), 508. Die Referenz bezieht sich auf Becker (1976), 14.

54 Spengler (1977), 36.

55 Sen (1990), 23-25, vgl. auch Theory, 491-500.

56 Sen (1990), 25.

57 Aßländer (2007), 128-129. Vgl. dazu auch Theory, 510-523.

58 Persky (1989), 201. 
daher Wilhelm Guggenberger „zyklische Immanenz“ nennt: „Die Grundstruktur des von Smith präzise dargestellten Vorgangs, in dem ich beobachte, wie andere mich beobachten und daraus schließe, was richtig, weil zustimmungsfähig ist. “59

\section{Synthese und Ausblick}

Horst Claus Recktenwald äußert sich, obzwar damit eine der Kontroversen in der Smith-Rezeption aufgreifend, recht eindeutig im Hinblick auf die Vereinbarkeit der verschiedenen Gesichter von Smith: „Es ist, unter von ihm eindeutig beschriebenen (von anderen aber später gern übergangenen) Bedingungen durchaus möglich, persönliche Freiheit und wirtschaftliche Leistung mit sozialer Koexistenz auf einem weiten Feld menschlichen Lebens auf friedliche Weise in Einklang zu bringen, ja, sie zum Wohle des Gemeinwesens miteinander $z u$ versöhnen." 60

Totale Planung ist aber für Smith angesichts der Willensfreiheit und zugleich Fehlbarkeit des Menschen völlig illusorisch. Dazu ausführlich Viner: „He had little trust in the competence or good faith of government. He knew who controlled it, and whose purposes they tried to serve [...]. He saw, nevertheless, that it was necessary, in the absence of a better instrument, to rely upon government for the performance of many tasks which individuals as such would not do, or could not do, or could do only badly. He did not believe that laissez faire was always good, or always bad. It depended on circumstances; and as best he could, Adam Smith took into account all of the circumstances he could find." 61 Trotzdem ist - wenngleich kontextspezifisch - ein Ordnungsrahmen gerade in einer liberalen Gesellschaft unbedingt nötig, wie Recktenwald an anderer Stelle ausführt: „Eine Marktwirtschaft ohne einen normal funktionierenden Staat, der seine klassischen Aufgaben effizient erfüllt, ist für Smith ebenso undenkbar wie unrealistisch. Zudem vertritt er die Ansicht, dass der Inhalt dieser Funktionen von den historischen Umständen abhängig sei."62 Smith sah die Wirtschaft nur als verwobenen Teil einer Gesellschaft, die für ihren gedeihlichen Fortbestand morali-

59 Guggenberger (2007), 271, ausführlicher 261-273.

60 Recktenwald, in: Wealth, XV.

61 Viner (1927), 232 (Hervorhebung A.E.).

62 Recktenwald, in: Wealth, LXXVI, ausführlicher LXV-LXXI. 
schen Halt braucht. Ja selbst sinnvolles wirtschaftliches Handeln kann nicht von einem Gefühl für die „Schicklichkeit“ (,propriety") dieses Tuns getrennt gedacht werden. Dazu ausführlich Evensky: „Smith's economic prescriptions were only one dimension of a larger vision of societal improvement. Pursued in isolation they cannot accomplish his goal. Markets are, like all other institutions, only instrumental. The character of any given society and the ultimate hope for the human prospect derive not from markets, but from the character of the individuals that people society. A society of unethical individuals pursuing their self interest would turn a perfectly free market system into an Hobbesian abyss - a rent-seeking society. A society of perfectly ethical individuals pursuing their self interest would interact on the basis of justice and beneficence, would realize the best for each individual on the basis of his or her talents, and in the process of bringing out the best in each would serve all by producing the greatest possible wealth for the nation. Thus, most fundamental to societal progress in Smith's view are those policies that develop an independent, educated, ethical citizenry." 63 Auch wenn diese Folgerungen wohl nur als positive oder negative Utopien zu verstehen sind - was wohl auch der Realist Smith so gesehen hätte sind sie doch konsequent zu Ende gedacht und man kann die beobachtbare Realität stets an diesen Extremzuständen messen.

Smith war aber nicht zuletzt Aufklärer und um eine Emanzipation des Einzelnen bemüht. Was man heute über ihn - zumindest unter Ökonom(inn)en - denkt, ist freilich etwas anderes, wie nochmals zusammengefasst werden soll: „What has come out of Smith's thoughts has been his idea that the market mechanism, on its own, can provide general welfare to a society. This thinking was included in the utilitarian trend. Utilitarianism gave place to economic liberalism. Liberalism has been the most relevant economic trend until some financial scandals and ecological disasters have opened other ways of thinking that recovers an essential characteristic of humans: the moral conscience. “64 Und diese Erkenntnis war Smith völlig klar, wie bereits an anderer Stelle geschrieben: „Letztlich kommt es Adam Smith darauf an, dass die empirisch unbestreitbaren positiven Resul-

63 Evensky (2001), 514-515.

64 Carrasco (2007), 458. Dazu nochmals Sen: „Indeed, it is precisely the narrowing of the broad Smithian view of human beings, in modern economies, that can be seen as one of the major deficiencies of contemporary economic theory." Sen (1990), 28. 
tate einer liberalen Marktwirtschaft (eines ,Systems der natürlichen Freiheit') im Hinblick auf den Massenwohlstand ohne größere Eingriffe zur Korrektur der empirisch unbestreitbaren negativen Resultate erreicht werden können. Ob das möglich ist, hängt auch davon ab, ob das wirtschaftliche Moment in der Gesellschaft übermächtig ist oder ob es einen wirkmächtigen öffentlichen, am Gemeinwohl orientierten Geist (einen, public spirit') gibt [...].“65

Die Rezeption und Interpretation von wissenschaftlichen Ausführungen ist letztlich immer wirkmächtiger als das Wort selbst. Smith hat darunter als einer der im Nachhinein populärsten Vertreter des Fachs zweifellos zu leiden wie kaum ein anderer. Das wiegt umso schwerer, weil er um die Gefahr der Fehlinterpretation wusste und möglicherweise gerade deshalb seinen Nachlass hat vernichten lassen. ${ }^{66}$ Doch immerhin kann man die ursprünglichen Schriften selbst stets wieder konsultieren, auch wenn der dadurch mögliche Kampf gegen den Irrtum oder die Instrumentalisierung ein nie endgültig zu gewinnender ist. Auch das Oratorium, von dem Grampp zu Beginn dieses Beitrages sprach, endet seiner Ansicht nach in der Dissonanz der vielen, oft unversöhnlichen Lehrmeinungen - nicht nur jener zu Smith. Dass innerhalb dieser Dissonanz ein Register so überdeutlich zu vernehmen ist, das Smith zudem zur Begründung einer Art Ursprungslegende vereinnahmt (wie ja ausführlich dargelegt), macht die Musik nicht anregender. Da empfiehlt es sich doch, Viner zu folgen: ,[...] how refreshing it is to return to the Wealth of Nations with its eclecticism, its good temper, its common sense, and its willingness to grant that those who saw things differently from itself were only partly wrong." 67

Als die diesem Text zugrunde liegende Konferenz stattfand (im Juni 2008) wurde in der Öffentlichkeit trotz eines - zumindest bei jenen, die einen gewissen Überblick über die globalen Finanzmärkte hatten - bereits vorhandenen mulmigen Bauchgefühls noch milde über die „linken“ Kritiker(inn)en des Kapitalismus gelächelt. Als dieser Text sich in der Endredaktion befand (im Februar 2009), wagte angesichts täglich nach unten korrigierter Wachstumsprognosen und neuer Hilfsansuchen von Banken und anderen Unterneh-

65 Exenberger/Nussbaumer (2004), 30.

66 Das ist zumindest nach Aßländer „wahrscheinlicher“, als dass er nicht mehr an eine einheitliche praktische Philosophie geglaubt hätte. Vgl. Aßländer (2007), 8.

67 Viner (1927), 232. Und dann am besten auch zur Theory of Moral Sentiments zu greifen. 
men kaum noch jemand ernsthaft, den marktfundamentalistischen Kapitalismus zu verteidigen. Im Gegenteil, selbst die Marktwirtschaft an sich gerät vor dem Hintergrund sich intensivierender Rufe nach Staatsintervention unter großen Druck und braucht einen Wladimir Putin als Verteidiger. Damit hat der Text im Laufe eines halben Jahres gehörig an Originalität verloren und entspricht heute vielmehr dem, was viele denken und die meisten publizieren. Aber die Zeiten werden sich wieder ändern. Dass dies auch für die hier zu ziehende Schlussfolgerung gilt, ist hingegen unwahrscheinlich: weniger (Neo-)Liberalismus und dafür mehr umfassend verstandener (Neo-)Smithianismus würde unserer globalisierten Wirtschaft gut tun, um im 21. Jahrhundert zu bestehen. Schließen wir daher diesen Text mit dem Beginn der Theory of Moral Sentiments: „Mag man den Menschen für noch so egoistisch halten, es liegen doch offenbar gewisse Prinzipien in seiner Natur, die ihn dazu bestimmen, an dem Schicksal anderer Anteil zu nehmen, und die ihm selbst die Glückseligkeit dieser anderen zum Bedürfnis machen, obgleich er keinen anderen Vorteil daraus zieht, als das Vergnügen, Zeuge davon zu sein."68 Halten wir uns auch diese Anteilnahme stets vor Augen, nicht nur den Egoismus, und machen wir sie uns selbst zur Pflicht. Das wird uns beim Verstehen des Wirtschaftslebens ebenso helfen, wie bei der Teilnahme daran.

\section{Literatur}

\section{Primärquellen}

Theory = Smith, Adam (21977): Theorie der ethischen Gefüble, übersetzt und herausgegeben von Walther Eckstein. Hamburg: Felix Meiner Verlag.

Wealth $=$ Smith, Adam (71996): Der Woblstand der Nationen: Eine Untersuchung seiner Natur und seiner Ursachen, übersetzt und herausgegeben von Horst Claus Recktenwald. München: dtv.

\section{Sekundärquellen}

Anderson, Gary M. (1988): „Mr. Smith and the Preachers: The Economics of Religion in the Wealth of Nations“, in: Journal of Political Economy 96 (5), 1066-1088.

Aßländer. Michael S. (2007): Adam Smith zur Einführung. Hamburg: Junius. 
Becker, Gary (1976): The Economic Approach to Human Behaviour. Chicago: University of Chicago Press.

Blaug, Marc (2007): „The Fundamental Theorems of Modern Welfare Economics, Historically Contemplated“, in: History of Political Economy 39 (2), 185-207.

Brown, Vivienne (1993): „Reviews“, in: The Economic Journal 103 (416), 230232.

Carrasco, Inmaculada (2007): „Corporate Social Responsibility, Values, and Cooperation", in: International Advances in Economic Research 13 (4), 454460.

Coase, Ronald (1976): „Adam Smith’s View of Man“, in: Journal of Law and Economics 19 (3), 529-541.

Cockett, Richard (1994): Thinking the Unthinkable: Think-Tanks and the Economic Counter-Revolution, 1931-1983. London: Harper Collins.

Evensky, Jerry (2001): „Adam Smith’s Lost Legacy“, in: Southern Economic Journal 67 (3), 497-517.

Exenberger, Andreas/Cian, Carmen (2006): Der weite Horizont. Globalisierung durch Kaufleute. Innsbruck: Studienverlag.

Exenberger, Andreas/Nussbaumer, Josef (2004): „Über praktische und theoretische Armut. Vom Vergessen wichtiger Fährten in der Ökonomik und ihrer aktuellen Relevanz", Working Papers Facing Poverty 08, Poverty Research Group, Salzburg, online unter: http://www.unisalzburg.at/ pls/portal/docs/1/479480.PDF (Zugriff am 7.4.2009).

Fry, Michael, Hg. (1992): Adam Smith's Legacy: His Place in the Development of Modern Economics. London: Routledge.

Grampp, William D. (2000): „What Did Smith Mean by the Invisible Hand?", in: Journal of Political Economy 108 (3), 441-465.

Guggenberger, Wilhelm (2007): Die List der Dinge. Sackgassen der Wirtschaftsethik in einer funktional differenzierten Gesellschaft. Münster: LIT.

Henry, John F. (2008): „The Ideology of the Laissez Faire Program“, in: Journal of Economic Issues 42 (1), 209-224.

Hoaas, David J./Madigan, Lauren J. (1999): „A Citation Analysis of Economists in Principles of Economics Textbooks", in: The Social Science Journal 36 (3), 525-532.

Hodgson, Bernard, Hg. (2004): The Invisible Hand and the Common Good. Berlin: Springer.

Leacocks, Stephen (1936): Hellements of Hickonomics in Hiccoughs in Verse Done in Our Social Planning Mill. NY: Dodd, Mead.

Manstetten, Reiner (2000): Das Menschenbild der Ökonomie. Der homo oeconomicus und die Anthropologie von Adam Smith. Freiburg/Br.: Verlag Karl Alber.

Meyer-Faje, Arnold/Ulrich, Peter, Hg. (1991): Der andere Adam Smith. Beiträge zur Neubestimmung von Ökonomie als Politischer Ökonomie. Bern: Verlag Paul Haupt. 
Montes, Leonidas (2003): „Das Adam Smith Problem‘: Its Origins, the Stages of the Current Debate, and One Implication for Our Understanding of Sympathy", in: Journal of the History of Economic Thought 25 (1), 63-90.

O’Rourke, P. J. (2007): Adam Smith: Vom Woblstand der Nationen. München: dtv.

Pack, Spencer J. (1991): Capitalism as a Moral System: Adam Smith's critique of the free market economy. Aldershot: Elgar, 1991.

Paganelli, Maria P. (2008): „The Adam Smith Problem in Reverse: SelfInterest in The Wealth of Nations and The Theory of Moral Sentiments“, in: History of Political Economy 40 (2), 365-382.

Persky, Joseph (1989): „Retrospectives: Adam Smith’s Invisible Hands“, in: Journal of Economic Perspectives 3 (4), 195-201.

Rothschild, Emma (1994): „Adam Smith and the Invisible Hand“, in: American Economic Review 84 (2), 319-322.

Rothschild, Kurt W. (1993): Ethics and Economic Theory. Ideas - Models - Dilemmas. Aldershot: Edward Elgar.

Samuelson, Paul A. (1977): „A Modern Theorist's Vindication of Adam Smith“, in: American Economic Review 67 (1), 42-49.

Schumpeter, Joseph A. (1986): History of Economic Analysis. London: Allen \& Unwin.

Sen, Amartya (1990): On Ethics and Economics. Oxford: Basil Blackwell.

Smith, Vernon L. (1998): „The Two Faces of Adam Smith“, in: Southern Economic Journal 65 (1), 2-19.

Spengler, Joseph J. (1977): „Adam Smith on Human Capital“, in: American Economic Review 67 (1), 32-36.

Viner, Jacob (1927): „Adam Smith and Laissez Faire“, in: The Journal of Political Economy 35 (2), 198-232.

Viner, Jacob (1960): „The Intellectual History of Laissez Faire“, in: Journal of Law and Economics 3, 45-69.

Wallerstein, Immanuel, et al. (1996): Die Sozialwissenschaften öffnen: Ein Bericht der Gulbenkian-Kommission zur Neustrukturierung der Sozialwissenschaften. Frankfurt/M.: Campus-Verlag.

Waterman, A. M. C. (2002): „Economics as Theology: Adam Smith's Wealth of Nations“, in: Southern Economic Journal 68 (4), 907-921.

Winter, Helen/Rommel, Thomas (1999): Adam Smith für Anfänger: Der Woblstand der Nationen. München: dtv. 


\title{
Kontinuitäten und Wandel politischer Religion. Vom Kommunismus zum Politischen Islam
}

\author{
Harald Wydra
}

\section{Religion, Moderne und Gewalt}

Es ist heutzutage sehr viel die Rede von der Rückkehr der Religion als Triebkraft für globale Konflikte. Diese Politisierung der Religion ist wohl nirgends deutlicher zu spüren als im Terror im Namen Gottes. ${ }^{1}$ Zerstörung und Gewalt werden hier mit religiöser Hingabe und dem Kampf gegen „Ungläubige“ legitimiert. Die Reaktionen auf religiös motivierte Gewalt können prinzipiell in zwei unterschiedliche Ebenen aufgeteilt werden. Zum einen mobilisieren Staaten ihre organisatorisch-bürokratischen Kapazitäten zur Terrorbekämpfung mit dem Ziel der Aufrechterhaltung von Ordnung und Sicherheit. Zum anderen sehen viele Beobachter in den irrationalen und rückständigen Aspekten des religiösen Fanatismus eine Bedrohung für die säkulare, institutionelle Ordnung des Staates.

In der stark mediatisierten und globalisierten Welt ist die Verbindung zwischen Gewalt und Religion keineswegs offensichtlich, geschweige denn direkt oder kausal. ${ }^{2}$ Während das Verhältnis zwischen Theologie und Politik lange Zeit durch Fragen nach der Natur nationaler Souveränität oder nach den verfassungsrechtlichen Bedin-

2 Siehe hierzu die Einleitung zu einem umfassenden Sammelband zum Thema Politische Theologie, de Vries/Sullivan (2006), 6. 
gungen für die Trennung zwischen Kirche und Staat bestimmt war, ist die Rolle der Religion in der post-säkularen Welt sehr viel nebulöser und unschärfer. Sie ist nicht nur schwerer lokalisierbar, sondern sowohl konzeptuell als auch empirisch nur schwer zu greifen. Die folgenden Ausführungen sind deshalb nicht dazu gedacht die Rolle der Religion als Konfliktherd im Staate zu umreißen, sondern als Versuch sich dem Spannungsfeld Religion-Politik-Gewalt unter Berücksichtigung historischer Kontingenz und anthropologischer Ansätze konzeptuell zu nähern.

Die Idee der Eindämmung religiös motivierter Gewalt gründet auf der entwicklungsgeschichtlichen Annahme, dass die Trennung religiöser von staatlichen Institutionen eine notwendige Konsequenz eines Modernisierungsprozesses gewesen ist, der das Religiöse in den Bereich des Privaten zurückgedrängt hat. Diese Modernisierungsthese arbeitet mit der Prämisse einer zunehmenden funktionalen Differenzierung und Säkularisierung des Staates. Da lediglich säkulare Institutionen Frieden und Sicherheit gewährleisten können, wird Religion eine konservative oder gar „fundamentalistische“ Tendenz zugewiesen. Deshalb wird ihr öffentlicher Einfluss als hemmend oder gar schädlich für Modernisierungsprozesse eingeschätzt.

Das Problem mit solchen Annahmen ist neben ihrem retrospektiven Determinismus ihre funktionalistische Logik. Die Kontrolle des Staates durch Herrschaft und der Seele durch Religion werden von vornherein als unterschiedliche Funktionen betrachtet, die von unterschiedlichen Strukturen versehen werden. Die geschichtliche Entwicklung wird reduziert darauf, dass sich eine Struktur von der anderen emanzipiert hat. Mein zentrales Argument postuliert hingegen nicht die Trennung, sondern die ursprüngliche Einheit des Religiösen und des Politischen. ${ }^{3}$ Bestimmte Staatsbildungsprozesse revolutionärer Natur gründen auf religiösen Faktoren als zentralem Handlungsmotiv. Politische Akteure mit weltlichen Absichten verfolgen weltimmanente Kategorien mit einer Energie und Hingabe, die sie als überzeitlich, absolut und heilig setzen. Am Beispiel der revolutionären Staatsbildungsprozesse in Russland nach 1917 und im Iran nach 1979 skizziert dieser Beitrag die Rationalität historischer Formen der Sakralisierung von Politik. 
Diese Sakralisierung weltlicher Einheiten war jedoch kein rein religiöser, sondern fundamental ein Akt politischer Spiritualität. Im Sowjetkommunismus und im politischen Islam wurde die Identität der eigenen revolutionären Bewegung nicht nur mit der ideologischen Verurteilung eines Feindes, sondern auch mit einer praktischkonkreten Politik der Vernichtung dieses Feindes verknüpft. Die Identifikation des Feindes war in erster Linie eine Praktik der Säuberung und Reinigung im Inneren: sie richtet sich gegen Elemente des alten Regimes ebenso wie Vertreter von ideologischen Irrlehren, die von der korrekten Linie der revolutionären Bewegung abweichen. Die Verteidigung der neuen Ordnung ging einher mit der Selbststilisierung zum Opfer. Der Feindbegriff wurde unterstützt von Diskursen, die die politische Religion als Opfer von Leiden, Ausgrenzung, und Hass kennzeichneten. Die Bindung der Opferlogik an Identitätsbildung ist zentral für die sakrale Natur einer politischen Religion. Während der Sowjetkommunismus staatlichen Terror und permanente Säuberung im Namen einer Partei durchführte, hat der politische Islam im Iran zum blutigen Krieg mit dem Irak sowie zu einer Fülle relativ dezentralisierter Formen von sektiererischer Gewalt innerhalb der islamischen Welt geführt.

Beide revolutionäre Bewegungen waren spezifische Produkte geschichtlicher Krisen, in denen nicht nur instrumentelle Macht und technische Rationalität, sondern geistig-religiöse Kräfte die alte Ordnung transformieren und die neue politische Ordnung gestalten. Die Herausbildung moderner Staatlichkeit beruhte nicht nur auf Modernisierung, Rationalisierung oder Säkularisierung, sondern erfüllte auch geistige Bedürfnisse der Menschen, indem sie weltliche Einrichtungen und Institutionen mit quasi-religiöser Autorität versah. ${ }^{4}$

Politische und soziale Krisen mobilisieren Kräfte, die für ein bestimmtes weltliches, kollektives Gut eine religiöse Hingabe und Devotion freimachen. Wie Norman Cohns bahnbrechende Untersuchungen zum mittelalterlichen und frühneuzeitlichen Millenarismus gezeigt haben, schöpfen Führer aus existenziellen Bedrohungsszenarien Energien, die den sozialen Kampf nicht an konkrete Ziele binden, sondern entgrenzen, mit dem Ziel die Welt komplett zu trans-

4 Eine umfangreiche Literatur in der Gesellschaftstheorie und in der politischen Anthropologie hat auf die fundamentale Bedeutung religiöser und geistiger Wurzeln in den Prozessen moderner Staatsbildung hingewiesen, siehe dazu Lefort (1986 a/b); Pizzorno (1987); Voegelin (1987); Szakolczai (2003); de Vries/Sullivan (2006). 
formieren. ${ }^{5}$ Es ist das Verdienst Eric Voegelins herausgearbeitet zu haben, dass radikale Modernisierungsprozesse und die Herausbildung säkularer Staaten auf einem ursprünglich religiösen Impetus der innerweltlichen Eschatologie beruhen. Sein Konzept der politischen Religion identifiziert die religiöse Dimension in weltlichen Projekten, wenn eine politische Bewegung einer weltlichen Einheit, Institution oder Doktrin einen ,heiligen“, sakralen Status zuerkennt. ${ }^{6}$ Weltliche Einheiten werden somit nicht nur ideologischdoktrinär als absolutes Prinzip der kollektiven Existenz postuliert. Sie werden mittels sozialer, politischer und kultureller Maßnahmen des staatlichen Herrschaftsapparates zum dominanten Prinzip des Zusammenlebens erhoben. Wie Voegelin nachgewiesen hat, beruhte die Redivinisierung von Politik auf dem Einfluss von Denktraditionen, die von der katholischen Kirche als häretisch und sektiererisch angesehen wurden. Diese ,gnostische Revolte“ verband eine jüdisch-christliche Eschatologie mit Lösungsvorschlägen für Probleme weltimmanenter Macht. ${ }^{7}$ Dabei werden die kollektive Existenz und die fanatisch propagierten Werte nicht nur zum Objekt der Verehrung und absoluten Hingabe erklärt. Revolutionäre Massenbewegungen sind gekennzeichnet durch Aufgabe des Selbstinteresses, getrieben von der Leidenschaft zu Selbstverzicht, Aufopferung und Unterordnung unter sinnstiftende kollektive Gebilde. ${ }^{8}$ Kollektive Selbstopfer und die Reinigung der Gemeinschaft von Feinden werden zu einem konstitutiven Prinzip der Organisation und der moralischen Rechtfertigung des neuen Systems gemacht. Dieses weltimmanente Heilsversprechen politischer Religionen ist keine Frage des persönlichen Schicksals, sondern eine öffentliche Angelegenheit, der fanatischen Verfolgung einer kollektiven Wahrheit mit der Absicht diese nicht nur zu predigen, sondern mit allen gesellschaftlichen und staatlichen Mitteln einen neuen Menschen zu formen.

5 Cohn (1970).

6 Siehe Voegelin (1987), (1993) und Gentile (2000); für eine informative Diskussion neuer Ansätze siehe auch Shorten (2007), 163-187.

7 Siehe dazu ausführlich Szakolczai (2003).

8 Siehe dazu ausführlich Hoffer (1964). 


\section{Das Geistige und das Politische}

Regierungen und Staatsverwaltungen folgen klar definierten institutionalisierten Prozessen, in denen Akteure klar umrissene Ziele und strategisches Kalkül verfolgen. Als rationalisierter Organisationsapparat wahrt der Staat seine Legitimität durch die Erfüllung funktionaler Aufgaben. Ebenso wird politischer Kampf in der Demokratie durch rationales Eigeninteresse, strategisches Denken und Langzeitperspektiven der Stabilität ermöglicht. Menschen werden häufig erst in Krisensituationen gewahr, dass ihr normales Leben von Umständen institutionellen Gleichgewichts von Rechtssicherheit, Voraussehbarkeit und Arbeitsteilung geprägt ist.

Die Auflösung politischer und sozialer Strukturen (wie zum Beispiel aber nicht ausschließlich in großen Revolutionen) führt nicht nur zur Unübersichtlichkeit im institutionellen Rahmen des Staates, sondern auch zum Zerfall symbolischer und sinnstiftender Gewissheiten auf individueller Ebene. ${ }^{9}$ Im Sinne der Sozialanthropologie Victor Turners finden wir hier liminale Situationen vor, in denen soziale Umbrüche nicht nur Strukturen auflösen, sondern die Beteiligten innerlich transformieren, ganz ähnlich den Initiationsriten, die eine neue Symbolkraft im Bewusstsein von Individuen verankern. ${ }^{10}$ Die politische Anthropologie Claude Leforts arbeitet ganz in diesem Sinne mit einem Begriff des Politischen, der sich auf die Bedingungen konzentriert, unter welchen konstitutive Prinzipien für politische Ordnung entstehen. ${ }^{11}$ Der Begriff der Krise bei Lefort erhält also in Anlehnung an Marcel Mauss' Begriff der totalen sozialen Tatsache einen existenziellen Charakter. Wie Mauss ausdrücklich betont hat, sind soziale Tatsachen nicht einfach auf die Gesellschaft beschränkbar, wonach religiöse, wirtschaftliche, rechtliche oder politische Sektoren, Bereiche, Klassen oder Gruppen funktional unterschieden werden können. ${ }^{12}$ Vielmehr gilt es individuelle Erfahrungen mit ihren anthropologischen Auswirkungen auf die physischen und geistigen Kräfte der Menschen und ihr Verhältnis zu Mitmenschen zu untersuchen.

Das Autoritätsvakuum ist daher nicht nur eine Ausnahmesituation, ein Zwischenraum, der eine evolutionäre und zielgerichtete 
Entwicklung unterbricht. Es ist vielmehr ein kreativer Akt, in dem neues Bewusstsein und neue symbolische Gewissheiten geschaffen werden. Ganz in diesem Sinne hat der Soziologe Heinrich Popitz neben der physischen, instrumentellen, und datensetzenden Macht die Maßstabsbedürftigkeit des Menschen als eine von vier anthropologischen Grundformen der Macht bezeichnet. ${ }^{13}$ Die schöpferische Symbolkraft historischer Ereignisse hat zum Beispiel Alexis de Tocqueville deutlich erkannt, als er die französische Revolution auch als eine religiöse Revolution charakterisierte, und zwar deshalb, weil sie den Menschen nicht nur als Staatsbürger der französischen Nation, sondern universal, als Abstraktum postulierte. ${ }^{14}$

\section{Die Rolle des Geistig-Politischen in Staatsbildungsprozessen}

Der westliche Weg der Staatsbildung erfolgte durch engagierten Kampf und Verflechtung geistiger und politischer Elemente. Vor dem 4. Jahrhundert entwickelte das Christentum in der Auseinandersetzung mit einem ihm prinzipiell feindlich gesinnten römischen Imperium Institutionen, die geistige und juristische Führung gaben. Die Kirche entwickelte eine innere hierarchische Struktur mit dem Papst an der Spitze, und die Grundlegung einer eigenen Gesetzgebung (in der Form des kanonischen Gesetzes) führte später zur Herausbildung von Gegensatzpaaren wie heilig-profan, geistigzeitlich, religiös-weltlich. Diese Gegensätze sollen nicht den Eindruck erwecken, das Religiöse wäre ein Antipode des Weltlichen gewesen. Wie der italienische Gesellschaftstheoretiker Alessandro Pizzorno anhand der Gregorianischen Reform im späten 11. Jahrhundert argumentiert hat, sind die Grundlagen staatlicher Macht in Kategorien geistiger Macht verwurzelt. Die Herausbildung des Politischen war nach Pizzorno ein absolutes Projekt, in dem geistige Impulse vier Arten von Macht unterfütterten, die entscheidend für die Expansion und Konsolidierung des Staates wurden: die Kontrolle und Organisation von Wissen, die Produktion von Normen, die Politik der Hingabe, und die Identifikation von Feinden der eigenen Gemeinschaft. ${ }^{15}$ Der entscheidende Punkt hier ist, dass vor der Territorialisierung des Staates, mit welcher die Identifikation eines Fein- 
des außerhalb des Staatsgebietes ermöglicht wurde, die entscheidende Konfliktlinie nicht zwischen der religiösen und der staatlichen, sondern zwischen der geistigen und der zeitlich-säkularen Dimension lag.

Drei weitere Zäsuren seien zur Veranschaulichung der zentralen Rolle geistig-religiöser Kräfte in Prozessen moderner Staatsbildung herangezogen: die Bekehrung des römischen Kaisers Konstantins zum Christentum und die Erhebung dieser Religion zur Staatsreligion, die Lutherische Reformation und die Französische Revolution. Wie der französische Historiker Paul Veyne jüngst gezeigt hat, war Konstantins Bekehrung im Jahre 312 keine rationale Wahl mit strategischem Kalkül (immerhin erfolgte sie im Bewusstsein, dass mehr als neunzig Prozent seiner Untertanen nicht diesem Glauben anhingen). Vielmehr ließ der Kaiser sich von der Dynamik dieses Glaubens anziehen. ${ }^{16}$ Er sah das Christentum als ein ideologisch geeintes und sozial kompaktes Gebilde, über das er seine Macht ausüben wollte. Die Christianisierung von Rom übertrug den exklusiven Charakter der Kirche auf den Staat, wo die Einheit und Wahrheit der Religion ein Zweck an sich wurden und den weltlichen Herrscher zum Interpreten der Orthodoxie, der Dogmen und der Entscheidung über Häresie werden ließen.

Die Spaltung des westlichen Christentums durch die Luthersche Reformation beförderte Weltimmanenz sowohl durch seine theologische Doktrin als auch durch die konkrete politische Durchsetzung reformatorischer Ideen und Praktiken in Allianz mit Territorialstaaten. ${ }^{17} \mathrm{Da}$ für Luther das Verhältnis zwischen den Menschen und Gott nicht durch eine Klasse von Priestern vermittelt werden könne, war auch das mönchische Leben nutzlos für die Rechtfertigung vor Gott. Deshalb bestand er auf der wachsenden Bedeutung innerweltlicher Pflichten, was seinerseits die unbedingte Unterwerfung unter die weltliche Autorität verlangte. Obwohl die Konfessionalisierung von Territorialstaaten den Partikularismus im deutschen Reich förderte, ist ein wesentliches Vermächtnis der Reformation, dass die weltimmanente Frömmigkeit letztlich großen Einfluss auf das Erreichen praktischer Ziele im Hinblick auf nationale Einigung hatte. ${ }^{18}$ 
Obwohl die Französische Revolution ein Ausbruch unkontrollierter Gewaltsamkeit war - gerichtet gegen die Vertreter der alten Ordnung, aber insbesondere gegen die katholische - etablierte sie neue Rituale, Kulte und mythische Symbolik, die die doktrinären, rituellen, und symbolischen Dimensionen des Christentums auf die weltliche Sphäre übertrugen. Während Mona Ozouf ${ }^{19}$ auf die zentrale Rolle von Festivals und öffentlichen Ritualen als Transfer des Sakralen hingewiesen hat, spricht Claude Lefort vom theologischpolitischen Fundament moderner Politik. ${ }^{20}$ Die Auflösung von institutionellen und symbolischen Strukturen in der Revolution führte zu einer Zersplitterung sozialer Bindungen, zu einer Individualisierung und Desorientierung, die ihrerseits eine Notwendigkeit von Einheit, Sinn und Richtung erforderte. Lefort argumentiert, dass geschichtliche Krisen mit ihrer Tendenz zur Weltimmanenz gleichzeitig eine Bewegung hin zur Transzendenz sind. Der Auflösung von Machtund Identitätsstrukturen in der revolutionären Krise wurde mit der Personifizierung und Sakralisierung scheinbar objektiver und unpersönlicher Institutionen wie Eigentum, Familie, Staat, Nation oder Souveränität begegnet. ${ }^{21}$

Diese kurze Skizze mag genügen um festzustellen, dass man staatliche Autorität - beruhend auf dem Gewaltmonopol innerhalb eines Territoriums und den entsprechenden rechtliche Strukturen nicht eindeutig von der Religion als sinnstiftende private Dimension in einer ansonsten hoffnungslosen Welt trennen sollte. Ganz im Gegenteil: Religion erhält die gesellschaftlich definierte Wirklichkeit aufrecht, indem sie Ausnahmesituationen im Sinne einer alles übergreifenden transzendenten Wirklichkeit legitimiert. ${ }^{22}$ Wie Voegelin darlegte, kann das Leben des Menschen in einer politischen Gemeinschaft nicht als säkularer Bereich definiert werden, in dem es lediglich rechtlichen Normen und Zwängen sowie politischen Machtstrukturen unterworfen ist. ${ }^{23}$ Vielmehr gründet menschliche Gemeinschaft auf religiöser Erfahrung, die in der Symbolik des modernen Staates in Begriffen wie Nation, Demokratie oder Gesellschaft auftreten. Schon Max Weber hat gezeigt, dass auch Staaten in die 
Rolle der sinnstiftenden Macht schlüpfen können, nämlich in dem Moment, in dem das soziale Kollektiv, die Nation, in allergrößter, existenzieller Gefahr ist. ${ }^{24}$ Kriege und nationale Formen von Erinnerungspolitik an das Selbstopfer von Bürgern für die Gemeinschaft haben die emotionalen und moralischen Grundlagen für demokratische Identität in modernen Staaten gelegt.

\section{Religion und Modernisierung im Sowjetkommunismus und politischen Islam}

Es ist also kaum strittig, dass im Verlauf der Geschichte Menschen und ihre Institutionen die Religion genauso geformt haben, wie die Religion mit ihren Ritualen, heiligen Erzählungen, und Praktiken die Menschen geformt hat. Das Potenzial geistig-religiöser Kräfte im Hinblick auf politische Ordnung ist jedoch von einer ganz besonderen Schlagkraft in zivilisatorischen Sphären, die relativ spät mit der westlichen Moderne in Kontakt kamen. Während Russland die wirtschaftliche und kulturelle Überlegenheit des Westens als Modell ansah, das es mit allen Mitteln zu imitieren und zu überwinden galt, bewirkte die Herrschaft westlicher Kolonialmächte im Nahen Osten sowohl innere Umwälzungen und Modernisierungsversuche einiger Führer als auch tiefe Ängste im Hinblick auf die Erhaltung der eigenen religiös-kulturellen Fundamente. ${ }^{25}$ Die Symbolik und die Mythen des Kalten Krieges haben das Bild des Sowjetkommunismus als Feind der freien westlichen Welt, der Moderne und der Religion verfestigt. Trotz der Tatsache, dass fundamentalistisch-islamischer Terrorismus weitaus größeren Schaden in muslimischen Ländern als in westlichen Staaten anrichtet, haben wir uns daran gewöhnt, von einem Kampf der Kulturen zwischen dem Islam und dem Westen zu sprechen. Die Prämisse hierbei ist, dass der Islam soziokulturell auf fundamental unterschiedlichen Werten, Denkweisen und Leistungen beruht. Solche Antagonismen sind allerdings problematisch, da sie eine stark wertende, unhistorische und letztlich abstrakte Opposition von „Strukturen“ suggerieren.

24 Weber (1988), 548f.

25 Siehe dazu zum Beispiel die These des Okzidentalismus, der die Bekämpfung des Westens in anderen Zivilisationen an die Erfahrungen der Menschen mit den Denkweisen und Projekten der Modernisierung bindet und die daraus folgenden negativen Auswirkungen auf Kultur und Moral der Menschen, Buruma/Margalit (2004). 


\section{Kommunismus, die Diktatur des Proletariats und der Feind im Inneren}

Es wird zum Beispiel leicht übersehen, dass der Westen für Russland nicht nur ein abstraktes Modell wirtschaftlicher und militärischer Organisation darstellte. Aufgrund seines kulturellen und geistigen Potentials entfachte der Westen in weiten Teilen der russischen Elite eine mimetische Begierde, die absolute Bewunderung mit Rivalität und Ressentiment vereinte. Der Sowjetkommunismus muss in diesem Sinne in zweierlei Hinsicht als integraler Bestandteil der westlichen Moderne begriffen werden. Zum einen führte spätestens seit Zar Peter I. die Gewissheit der eigenen Rückständigkeit zur gesteigerten Imitation westlichen Wissens und Organisationsfähigkeit mit dem Ziel, dem Westen ebenbürtig und schließlich überlegen zu werden. Nicht nur die Entwicklung der Militärtechnik, sondern auch Hofzeremonielle, die Sprache und die Lebensweise des Adels deuten klar auf die Selbstdarstellung russischer Zaren als europäische Herrscher hin. Dagegen beruhte die Macht im Inneren größtenteils auf der mystischen Verehrung des Zaren als absolutem Herrscher durch die russische Bauernschaft. Diese absolute Abhängigkeit vom gosudar und die durch die orthodoxe Religion vermittelte Mystik sollte später den Bolschewiken die Herrschaft ermöglichen. Sie gründeten auf die sakrale Dimension des Immanenten, unterstützt vom Monopolanspruch einer Parteitheokratie, dem Dogma des MarxismusLeninismus und dem Personenkult um Lenin und Stalin.

Die geistigen Wurzeln für den Erfolg einer atheistischen Doktrin in einem zutiefst religiösen Land wie Russland wurden in der Tat durch die enge Verflechtung zwischen der Staatsmacht und dem institutionalisierten Glauben der Orthodoxie befördert. Im Gegensatz zur Dynamik des Investiturstreits im Westen und der nachfolgenden Konfessionalisierung von Staaten wurde die Orthodoxie in Russland relativ früh ein Diener des imperialen Staates. ${ }^{26}$ Prinz Vladimirs Bekehrung 986/7 zum orthodoxen Christentum beruhte auf der Schilderung der Schönheit der Hagia Sophia und der rituellen Praktiken der griechischen Orthodoxie. ${ }^{27}$ Organisatorisch blieb die orthodoxe Kirche ohne Papsttum und relativ dezentralisiert. Unter dem Druck von Enteignung und drohender Glaubensspaltung im 
frühen 16. Jahrhundert stellte sich die orthodoxe Kirche unter die absolute Gewalt des Zarismus. Die Ideologie des Dritten Roms wurde von orthodoxen Klerikern ausgearbeitet, die den göttlichen Ursprung der Staatsautorität und ihre hierarchische Dominanz akzeptierten. 1721 schließlich macht Zar Peter I. die Kirche zum Teil der Staatsbürokratie. Aufgrund des strikten Verbots für Adelige, Teil des Klerus zu werden, kam es weder zu engen Bindungen zwischen Adel (dvorianstvo) und Klerus, noch vermochte es dieser, über den Status einer verarmten und isolierten Klasse hinauswachsen.

Zum anderen stand die russische Intelligenzija unter dem starken geistigen Einfluss des Westens, den sie teilweise bedingungslos imitierte. Der Bolschewismus gründete auf der marxistischen Doktrin, einer radikalen Kritik des Kapitalismus von innen heraus und war damit ein reines Produkt des Westens. Die prophetische Vision von Karl Marx war ihrerseits eine gnostische Revolte gegen die Unterdrückung durch die kapitalistische Klasse. Seine Ideologie verwandelte die Arbeiterklasse in eine Art kollektiven Erlöser, deren Sieg im historischen Konflikt mit der Bourgeoisie nicht nur deren Herrschaft, sondern auch alle Herrschaftsverhältnisse überhaupt auflösen würde. ${ }^{28}$ Lenin war entschlossen das Programm des Marxismus auf Russland anzuwenden, zutiefst bewegt von einem hypnotischen Glauben an völlige Harmonie. Wie schon Jacob Talmon unterstrich, war Lenins messianische Vision nicht nur eine Konsequenz, sondern der Ausgangspunkt seiner völligen Hingabe an die Sache der Revolution. ${ }^{29}$ Lenins lebenslange Faszination durch den revolutionären Messianismus ist unter anderem daran zu erkennen, dass er 1871 dem Revolutionären Katechismus beitrat, der unter anderem betonte, dass ein Revolutionär völlige Selbsthingabe und Verzicht auf weltliche Dinge wie Eigentum praktizieren müsse, um sein eigentliches Ziel, die Revolution, zu verwirklichen.

Ohne die Katastrophe des Ersten Weltkriegs und den moralischen Verfall des Zarismus wäre der Bolschewismus allerdings niemals an die Macht gelangt. In den Wirren des revolutionären Chaos und des Bürgerkriegs waren prophetisches Dogma und absolute Hingabe an die Revolution die entscheidenden Bedingungen für den Erfolg der bolschewistischen Sekte. Die Übertragung der Symbolik 
und Ästhetik der Orthodoxie, wie auch kirchlicher Riten der Reinigung und Konfession auf die bolschewistische Partei zeigen deutlich, wie die kommunistische Partei eine Theokratie mit dogmatischem Monopolanspruch, Führerkult und einer umfassenden politischen Mythologie errichten konnte. ${ }^{30}$

Die historische Krise des Zarismus in Russland brachte also eine revolutionäre Partei an die Macht, deren Projekt nicht nur die Modernisierung der Gesellschaft vorsah, sondern primär die menschliche Seele transformieren wollte. Für Stalin war die soziale Umstrukturierung der Sowjetunion ohne die Umstrukturierung der menschlichen Seele nutzlos. Die Revolution war gebunden an die Hoffnung einer undefinierten, aber umso radikaler propagierten besseren Welt, eines „roten Paradieses“, um in den Worten Leo Trotzkis zu sprechen. Die Utopie eines Übergangs zum Kommunismus ging einher mit der kompletten Selbstaufgabe des einzelnen, um die korrekte Linie der Partei durchzuführen. ${ }^{31}$ Die zentralen Annahmen marxistisch-leninistischer Ideologie reservierten dieses Paradies einer Schar ideologisch bestimmter Auserwählter, dem Proletariat. Von Interesse ist hier weniger die Plausibilität der soziostrukturellen Grundlage einer solchen Formation, sondern vielmehr die Implikationen für die Herrschaft der Partei, vor allem im Hinblick auf die Symbolkraft der Diktatur des Proletariats.

In Lenins Auffassung diente die Diktatur des Proletariats der Reinigung der Gesellschaft von Feinden. ${ }^{32}$ Die zentrale Idee bestand einerseits darin, die Einheit des Volkes auf der Basis der soziologischen Kategorie des Proletariats zu erklären; andererseits war es die Aufgabe dieser Diktatur, die Reste der alten Ordnung zu zerschlagen. Ohne diese reinigende Gewalt wäre das Absterben des Staates unmöglich. Während also Lenin die Trennung von Staat und Gesellschaft theoretisch verneinte, brachten die Pöbelherrschaft während der Revolution 1917 und der darauf folgende Bürgerkrieg einen gesichtslosen „Anderen“ hervor, der nicht einer ideologisch determinierten Kategorie entsprach. Vielmehr wurde jeder, der nicht den revolutionären Bolschewiken angehörte, zum Volksfeind erklärt. Wie Claude Lefort gezeigt hat, war die Definition des Volksfeinds konsti-

30 Siehe Kharkhordin (1999) und Wydra (2007), 62-78.

31 Ein beeindruckendes Zeugnis hierfür findet sich in Arthur Koestlers Version des Schauprozesses gegen Nikolai Bukharin (Koestler, 1940).

32 Siehe dazu ausführlich Wydra (2007), 78f. 
tutiv für die Identität des Volkes-als-Eines, aber gleichzeitig bedrohte dieser Volksfeind diese Einheit ständig. Auf dem Höhepunkt des großen Terrors 1937 forderte Stalin die Beschleunigung der Ausrottung der Volksfeinde mit folgendem Argument: Je mehr Feinde wir eliminieren, desto unbarmherziger und gefährlicher werden sie. ${ }^{33}$

Die sowjetische Herrschaft gründete sich nicht nur auf der Ablehnung der kapitalistischen Moderne und der gleichzeitigen Hypermodernisierung der Sowjetunion mit allen Mitteln. Die ritualisierte Identifikation des Feindes im Sowjetkommunismus führte zur starken Internalisierung der Gewalt, zu einem latenten Bürgerkrieg, der jedoch innerhalb territorialer Grenzen und mittels strategischpolitischer Überlegungen geführt wurde. Der permanente latente Bürgerkrieg hatte somit eine strategische Rechtfertigung, war geographisch lokalisierbar und, im Rahmen des Kalten Krieges, als Staatsräson auch berechenbar.

\section{Politischer Islam und Terror im Namen Gottes}

Islamischer Fundamentalismus als Motor religiösen Terrors wird als archaische Barbarei dargestellt, die mit ihrer anti-westlichen und antimodernen Stoßkraft den Kampf der Kulturen reflektiert. ${ }^{34}$ Wenn islamischer Fundamentalismus als konservativ, rückständig und unaufgeklärt dargestellt wird, wird aber nicht nur übersehen, dass „Fundamentalismus" keine eigentliche theologische Dimension hat (es gibt keine „liberale“ Theologie - im Sinne interpretativer Strömungen, die den Koran als Wort Gottes mittels philosophischen oder weltlichen Argumenten kritisieren), sondern auch, dass der Islam historisch oft toleranter gewesen ist (insbesondere gegen Juden und Christen) als Christen gegenüber Muslimen. Wie jedoch eine Reihe von Autoren gezeigt hat, liegen die Ursprünge der Revolte des Islam gerade im Zusammentreffen westlicher Moderne und islamischer Zivilisation im Nahen Osten. ${ }^{35}$ Obwohl radikale Islamisten während des 20. Jahrhunderts mehrere Arten von Feinden anvisierten (Juden, Zionisten, Christen, Missionare, Imperialisten oder Russische Kommunisten), so waren ihre Hauptfeinde doch einheimische Säkularisierer wie Muhammad Ali Pascha, Kemal Atatürk, 
die Präsidenten General Nasser und Anwar al-Sadat in Ägypten, Hafez al-Asad in Syrien, Saddam Hussein oder der iranische Schah. Die größten Erfolge der Fundamentalisten waren demnach die Entfernung des Schahs im Iran 1979 und Sadats Ermordung 1981 durch den ägyptischen Dschihad, einen Nachfolger der Muslimbruderschaft. ${ }^{36}$ Die Verbrechen Sadats und des Schahs lagen in der Preisgabe der Scharia und der Auferlegung fremder Rechtstraditionen und Gesetze, die den Islam verweltlichten. Im Wesentlichen ist politischer Islam eine Erfindung moderner Fundamentalisten, praktisch undenkbar vor dem Zerfall des Osmanischen Reiches und somit erst seit den zwanziger und dreißiger Jahren des 20. Jahrhunderts ein Begriff. ${ }^{37}$ Das eigentliche Ziel der Fundamentalisten ist die Umkehrung der traditionellen Beziehung zwischen den Sphären der Religion und der Politik. Während historisch das Religiöse dem Politischen unterworfen war, gilt es nun die politische Sphäre dem religiösen Führungsanspruch zu unterwerfen.

Vor der Iranischen Revolution war Religion im Islam in der Tat keine speziell politisierte Angelegenheit. Die Fusion der religiösen Sphäre und der Dimension weltlicher Herrschaft im klassischen Islam ließ kaum eine Unterscheidung der beiden zu. Als der Chef des iranischen Geheimdienstes 1963 Ayatollah Khomeini darlegte, dass Politik Lüge, Betrug und Gemeinheit seien, antwortete dieser: Der ganze Islam ist Politik. ${ }^{38}$ Während das zentrale Ritual des Christentums das Opfer Jesu als Akt der Liebe und seine Ablehnung der Welt in den Vordergrund stellt, rückt der Gründungsmythos des Islam den politischen Triumph des Propheten zu seinen Lebzeiten ins Zentrum. Muhammad eroberte sein gelobtes Land und herrschte als Souverän über seinen Staat. Im Gegensatz zum mittelalterlichen Europa (in welchem Kirche die Gemeinschaft der Gläubigen und den Klerus bezeichnete) und der russischen Orthodoxie (in welcher der Klerus - obwohl recht unabhängig in Glaubensfragen - institutionell dem Staat untergeordnet wurde), gab es im Islam keinen Klerus im theologischen Sinne. Der Islam ist eine Religion ohne Weihe, Sakramente oder Priester als Vermittler zwischen Gott und den Menschen. Es gab im Islam keine Unterscheidung zwischen kanoni- 
schem und weltlichem Recht des Staates, ebenso wenig wie es unter Muslimen eine Auffassung von Laientum gab.

Die Geschichte Persiens hat in der Tat eine einflussreiche Schicht von Spezialisten in Glaubenfragen entstehen lassen - die ulamā, eine einflussreiche Gruppe von Rechts- und Glaubensgelehrten - die seit dem Beginn des 20. Jahrhunderts zunehmend politischen Einfluss ausübten. Im Gegensatz zur bolschewistischen Sekte war die zukünftige herrschende Klasse der Mullahs im Iran also ein historisch integraler Bestandteil der Elite des Landes. Die Grundlage für den hohen gesellschaftlichen Einfluss der Mullahs ist das Prinzip des ijtihâd, was sich auf eine Anstrengung bezieht, mittels derer Gottes Wille auf Erden erfüllt werden kann. ${ }^{39}$ Der entscheidende Punkt ist, dass die Fähigkeit ijtihâd zu leben nicht durch Inspiration oder Offenbarung erfolgt, sondern durch Gelehrsamkeit, welche langes, intensives Studium erfordert und somit einer kleinen Gruppe von qualifizierten Spezialisten, den mujtabid vorbehalten ist. Vor dem Durchbruch des Regimes von Kemal Atatürk in der Türkei trugen die ulamā einen beträchtlichen Teil zur Abfassung der ersten persischen Verfassung im Jahre 1906 bei. Erst nachdem die türkische Revolution zu einer in den Augen weiter Teile der persischen Elite unkritischen Verwestlichung führte, unterstützten die ulamā die Etablierung der Pahlavi Monarchie. Als dieser und sein Nachfolger, Reza Pahlavi, immer klarer in wirtschaftliche und politische Abhängigkeit zuerst von den Briten und danach von den Vereinigten Staaten gerieten und eine Kommandomodernisierung betrieben, wurden die ulamā zunehmend kritischer.

Die Revolution im Iran 1979 stand unter der Führung eines einflussreichen Teils der etablierten ulamā Klasse. Ayatollah Khomeinis wichtigste Innovation war das Konzept der „Führung durch die Rechtsgelehrten" (velayat-e faqih), das er in seinem Buch Islamische Regierung formulierte und welches ein neues Modell eines schiitischen Staates unter der politischen Vorherrschaft der Rechtsgelehrten vorschlug. Die fundamentale Forderung Khomeinis nach der Herrschaft durch islamische Rechtsgelehrte war tief verankert im Charakter schiitischer Klagerituale und Visionen eines Endes der Zeiten, die messianischen Erwartungen in der jüdisch-christlichen Tradition vergleichbar sind. Die schiitische Tradition unterscheidet sich von 
der sunnitischen nicht durch theologische Doktrin, sondern aufgrund eines historischen Konflikts. Das rituelle und dramatische Zentrum des schiitischen Glaubens ist die rituelle Erinnerung an das Martyrium von Hussein, dem Schwiegersohn des Propheten, in Kerbela. Die Nachfolger Husseins, die Imame, sind in der schiitischen Tradition als rechtmäßige Nachfolger des Propheten gesehen worden. Die millenaristischen Erwartungen der Schiiten gründen im Martyrium Husseins 680 und dem Glauben, dass Gott den zwölften Imam Muhammad al-Mahdi 873 verbarg, um sein Leben zu schützen. Während für Sunniten der Mahdi die Rückkehr von Gerechtigkeit symbolisiert, glauben die Schiiten an die Rückkehr des Imams hier auf Erden. Verbunden mit der Heilserwartung einer weltimmanenten Eschatologie hat die Ritualisierung der Klage um das Martyrium Husseins eine herausragende Rolle für die Verankerung dieses Glaubens in breiten Teilen der Bevölkerung gespielt. Khomeini nutzte schiitische Symbolik und Sprache ebenso wie die Selbstdarstellung als Imam, um die politische Herrschaft der Rechtsgelehrten zu begründen. ${ }^{40}$ Er bezeichnete das Schahregime mit einer Sprache, die sich in religiösen Texten auf die Feinde des Zwölften Imams bezieht, u.a. als falscher Gott und Verderber der Erde. Im Hinblick auf den äußeren Feind, die Vereinigten Staaten, wurde die technologisch-militärische Überlegenheit als weniger gefährlich angesehen als die mögliche Infektion durch Ideen und Lebensweisen. So benutzte Khomeini zum Beispiel die letzte Sure des Korans (114,4-5), um die USA dem großen Feind Gottes und der Menschheit gleichzusetzen. Er fürchtete nicht so sehr die Macht der USA, als eher den american way of life. ${ }^{41}$

Die Elemente der Klagereligion und millenaristische Erwartungen sollen jedoch nicht darüber hinwegtäuschen, dass Khomeinis Islamische Republik maßgeblich von marxistischen Ideen beeinflusst wurde, die effektiv in das System kultureller Symbole der Schiiten eingefügt wurden. Hier kann die Rolle insbesondere des marxistischen Intellektuellen Ali Shariati nicht überbewertet werden. Shariati transformierte den Schiismus, ganz im Sinne der Sakralisierung von Politik, in einen revolutionären Glauben. Das Ritual der Klagereligion in Erinnerung an Husseins Martyrium wurde als revolutionärer 
Akt eines revolutionären Helden interpretiert, der die Befreiung von Unterdrückung jetzt und heute bringen sollte. ${ }^{42}$ Nach Shariati ist „jeder Tag Aschura ${ }^{43}$, jeder Ort ist Kerbela“. Obwohl Khomeinis Sakralisierung der Politik von vielen anderen ulamà scharf kritisiert wurde, waren gerade junge ulamā wie der derzeit höchste geistige Führer, Ayatollah Ali Khamenei, stark von Shariati beeinflusst. Während die Fusion messianischen Glaubens und ritueller Klagereligion von Khomeini also symbolisch stark ausgenutzt wurde, war die Islamische Republik in ihrer Herrschaftsausübung zentralistischautokratisch, rechtlich dogmatisch und bemüht, die rituelle Praxis der Religion herunterzuspielen.

Verstärkt durch logistische und finanzielle Unterstützung von Staaten wie Saudi-Arabien und Iran, weisen die Feindbilder und Rivalitäten zwischen den zwei religiösen Gruppen auf eine geistigpsychologische Disposition hin, die den Status als mögliches Opfer zur Rechtfertigung von Gewalt heranzieht. Der geistige Führer des ägyptischen Dschihad, Muhammad Abd al-Salam Faraj, definierte den Feind im Inneren folgendermaßen: „Der Kampf gegen den nahen Feind ist wichtiger als der Kampf gegen den fernen Feind; ein Kampf gegen den Imperialismus wäre weder glorreich noch nützlich, sondern Zeitverschwendung. Unsere Pflicht ist es, Gottes Gesetz und Wort in unserem Land durchzusetzen. Das Schlachtfeld des Dschihad ist die Ausrottung der ungläubigen Führer und ihre Ersetzung durch eine perfekte islamische Ordnung. "44 Ganz ähnlich ist die Stoßrichtung von Abu Musab al-Zarqawi, einem der sunnitischen Kriegsherren im Irak: „Unser Kampf gegen die Amerikaner ist einfach; Kreuzritter werden morgen oder übermorgen verschwinden;...Die Schiiten dagegen sind schlauer als ihre Meister und ihr Ziel ist einen Schiitenstaat vom Iran zum Libanon und hin zum Golf zu etablieren." $" 45$

\section{Die Identifikation des Feindes und die Logik des Opfers}

In der Debatte um die religiösen Motivationen von Selbstmordattentätern wird die religiöse Dimension häufig als Determinante einer

43 Der zehnte Tag des Monats Muharram, das rituelle Zentrum der Schiiten.

44 In Lewis (2002), 120 (Übers. H. W.).

45 In Nasr (2006), 205 f (Übers. H. W.). 
zivilisatorischen Essenz oder eines kulturell-genetischen Codes betrachtet. Diese These wurde vielleicht am deutlichsten von Samuel Huntington in seinem Buch Der Kampf der Kulturen vertreten. Für Huntington ist die Religion und dabei insbesondere die Radikalisierung in fundamentalistischen Strömungen das entscheidende Element, das die unversöhnliche Diskrepanz zwischen der islamischen Zivilisation und der amerikanisch-westlichen definiert. Allerdings hat auch anthropologische Forschung jüngst die scheinbare Unausweichlichkeit von Feindstrukturen als in der arabischen Kultur angelegt postuliert. ${ }^{46}$

Um die Rationalität der Gewalt im Namen der Religion zu erfassen, ist ein intellektualistischer Ansatz wenig hilfreich. Hinweise auf die Aggressivität einer theologischen Doktrin oder auf eine kulturelle Essenz einer Zivilisation sind ähnlich abstrakt und unhistorisch wie die Idee, Religion sei modernisierungsfeindlich. Statt Religion als Triebkraft für Gewalt zu sehen, argumentiert Olivier Roy von der entgegengesetzten Position. ${ }^{47}$ Für Roy handelt es sich beim islamischen Terrorismus vor allem um kulturlose Jugendliche, die religiöse Versatzstücke als Rechtfertigung für ihren Drang nach Rache und Vergeltung einsetzen. Diese These macht insofern Sinn, als sie die Radikalisierung im Namen Gottes als eine Reaktion auf fehlgeschlagene Modernisierungsversuche versteht. Statt den islamischen Fundamentalismus als Ursache religiöser Gewalt anzuprangern, solle man interne Staatskrisen im mittleren Osten zur Erklärung heranzuziehen, vor allem das Scheitern dreier Modelle, des Säkularismus, des Marxismus und des Nationalismus. In ähnlichem Sinne hat Mark Juergensmeyer darauf hingewiesen, dass das Fehlen einer starken staatlichen Zentralgewalt eine Brutalisierung für das Leben von Individuen zur Folge haben kann, eine Situation, die wiederum zu einem idealen Nährboden für religiöse Rechtfertigung werden kann. ${ }^{48}$

Die Arbeiten von Roy und Juergensmeyer postulieren, dass politische Krisen die Religion sozusagen gegen ihre eigentliche Bestimmung und Funktion für fremde Zwecke missbrauchen. In der Tat hat eine Reihe von Arbeiten in der Kulturanthropologie und Religionssoziologie die fundamental friedensstiftende und heilsorien- 
tierte Dimension von Religion postuliert. Wie Martin Riesebrodt jüngst argumentiert hat, ist allen Religionen ein liturgisch-ritueller Kern gemeinsam, der Heilserwartung und die Abwendung von Unheil in das Zentrum der Gemeinschaft stellt. ${ }^{49}$ Nach David Martin ist das Christentum eine besondere Art einer transzendenten Vision, die Frieden auf Erden und guten Willen gegenüber den Menschen propagiert. ${ }^{50}$ Jedoch wird es teilweise vom sozialen Heiligen im Sinne Durkheims absorbiert und vom widerstandsfähigen säkularen Element von Macht und Gewalt im Sinne von Machiavelli und Hobbes abgelehnt. Wie René Girard gezeigt hat, besteht die Funktion religiösen Rituals nicht darin, gewalttätig und zerstörerisch zu werden, sondern Gewalt mittels sich wiederholender Praktiken oder Liturgien zu kanalisieren und abzuwehren. Obwohl Rituale einer ursprünglichen Gewalttat entsprangen, ist der rituelle Bezug auf das Opfer versöhnend und friedensstiftend. Rituale sind auf die Förderung und das Wachstum einer Gemeinschaft ausgerichtet. Sie erreichen dies mittels des zentralen Prinzips der Imitation, mittels derer der Zeremonienmeister im Akt der Verehrung eine Identität mit einer höheren Wirklichkeit, Gott, herstellt. ${ }^{51}$ Historisch gesehen haben die abrahamitischen Religionen den friedenserhaltenden Aspekt des Opfers anerkannt. ${ }^{52}$ Die Ablehnung des Menschenopfers, als Abraham von Gott aufgefordert wird von seinem Sohn Isaak (Ismael) abzulassen, markierte einen Bruchpunkt. Die Ritualisierung des Opfers ist auch im Islam zu finden, wo eines der größten Feste (Aïd-el Kebir - das große Fest) an die Nichtopferung von Ismael erinnert. Die Ritualisierung des Opfers von Gewalt verbietet konkrete Akte der Gewalt und etabliert einen Habitus, der strukturierend wirkt, indem er Grenzen, Hierarchie und Ordnung befördert. Nach Girard ist die Aufdeckung des Sündenbockmechanismus als Ursprung der Gewalt und die Verteidigung des unschuldigen Opfers die Voraussetzung für den Zivilisierungsprozess. ${ }^{53}$ Die zivilisierende Kraft des Schutzes unschuldiger Opfer hat maßgeblich den Respekt der menschlichen Würde oder den Schutz von Minderheiten befördert. Umgekehrt haben radikale und revolutionäre Bewegungen den

49 Siehe Riesebrodt (2007).

50 Martin (2007), 1.

51 Hocart (1970), 42-50.

52 Siehe dazu ausführlich Palaver (2008), 154-158.

53 Szakolczai (2001). 
„Kult des Opfers“ benutzt, um ihre eigene Situation als Opfer der Umstände und Machtverhältnisse als Rechtfertigung für Rache, Vergeltung und Terror einzusetzen. ${ }^{54}$

Sowohl der Sowjetkommunismus als auch der politische Islam haben die Identifikation des Feindes an eine doppelte Funktion des Opfers geknüpft. Zum einen geht es um die Selbstdarstellung der revolutionären Bewegung als Opfer von Leiden und Erniedrigung. Im Falle der Bolschewiken handelte es sich um ein repressives Machtsystem, den Zarismus und eine dominierende ökonomische Logik, den Kapitalismus. Im Iran kämpfte die Revolution gegen gottlose Modernisierung als Folge des Kolonialismus und Imperialismus und den Schah als Marionette der Amerikaner. Zum anderen erfordert die revolutionäre Dynamik einer politischen Religion die kontinuierliche Produktion von Opfern.

Hier ist allerdings auf wichtige Unterschiede zwischen beiden Formen politischer Religion hinzuweisen. Die Konstruktion eines neuen Menschen in der Sowjetunion war an die Kontrolle eines Staatsterritoriums und die Institutionalisierung einer Utopie gebunden, die konkret in einer massiven Umstrukturierung der Gesellschaft umgesetzt wurde. Während Gewaltanwendung im sowjetischen Herrschaftsapparat fundamental auf die Kontrolle des Herrschaftsgebiets sowie die Aufrechterhaltung des Monopolanspruchs auf die korrekte Linie einer einzig gültigen Interpretation des Rechts, der Geschichte und der Zukunft konzentriert war, hat sich religiöse Gewalt im politischen Islam zunehmend dezentralisiert. Diese Dezentralisierung von Gewaltstrukturen im religiös motivierten Terrorismus ist nichts Neues, sondern ist spätestens seit den Partisanenbewegungen im Zweiten Weltkrieg und in den Unabhängigkeitskriegen gegen koloniale Mächte bekannt. Allerdings divergiert religiös begründeter Terrorismus, wie Herfried Münkler nachgewiesen hat, dadurch von klassischen Modellen, dass er nicht im Namen eines interessierten Dritten geführt wird. ${ }^{55}$ In der Auflösung klarer Handlungszentren und der Ent-territorialisierung von Terrorakten fällt unweigerlich das Fehlen eines strategischen Nutzens auf. Es ist wohl Roy zuzustimmen, wenn er argumentiert, der politische Islam sei kein geostrategischer Faktor mehr, sondern primär ein gesellschaftli- 
ches Phänomen. ${ }^{56}$ Allerdings darf hier die symbolische und geistige Dimension nicht unterschätzt werden. Wie der Soziologe Mark Juergensmeyer feststellt, ist der Kampf von religiös orientierten Terroristen ein kosmischer Kampf, der komplexe Sachverhalte in eine vereinfachte Dichotomie zwischen Gut und Böse bringt. ${ }^{57}$ Der Feind ist gesichtslos und kollektiv. Solch ein Kampf ist unmöglich in der realen Welt zu gewinnen und muss daher sakralisiert werden, d.h. auf eine Ebene gehoben werden, die keiner rationalen Kontrolle oder strategischem Kalkül unterliegt. Dies wird ganz besonders deutlich in der Tatsache, dass terroristische Gruppen Gewalt inszenieren, indem sie für kurze Zeit zentrale Orte innerhalb des Machtbereichs ihrer Gegner mittels dramatischer Handlungen sozusagen metaphorisch in Besitz nehmen. Die Wirkung dieser dramatischen Inszenierung von Gewalt ist nicht rational in einem strategischen Ziel wie territorialer Kontrolle begründbar, sondern sozusagen das Ziel der Gewalt selbst.

Obwohl selbstmörderische Attacken im Namen Gottes mit den Maßstäben einer konventionellen, staatsorientierten Logik nur schwer zu begreifen sind, hat diese Opferlogik eine klare Rationalität, die innerhalb eines religiösen, nicht eines politischen Zusammenhangs erfasst werden muss. ${ }^{58}$ Die Sakralisierung der Politik im politischen Islam überträgt die Opferung im anthropologischen Sinne, d.h. das Töten von Unschuldigen im Namen der kollektiven Gruppe unter Berufung auf ihren eigenen Opferstatus und mittels des von ihr staatlich kontrollierten Herrschaftsapparates, auf den säkularen Bereich gesellschaftlicher Beziehungen. Ein besonders eindringliches Beispiel ist die Selbstopferung tausender freiwilliger iranischer Soldaten im Krieg mit dem Irak. ${ }^{59}$ Als Inkarnation des zwölften Imams verkleidete Schauspieler ritten auf weißen Pferden vor der Frontlinie und segneten die Soldaten, vorwiegend Bauernjungen mit einer einfachen Frömmigkeit. Dies führte zu hoffnungslosen Attacken, bei denen die fanatisierten Jünger des Imams zu Zehntausenden dem überlegenen irakischen Feuer zum Opfer fielen.

Wenn auch der Sowjetkommunismus und der politische Islam wesentliche Differenzen im Hinblick auf ihre Organisationskapazität, 
Berechenbarkeit, und ihren geostrategischen Einfluss aufweisen, sind beide fundamental in geistig-religiösen Motivationen der Sakralisierung von Politik begründet. Der Feind ist jedoch nicht einfach eine Funktion existierender Strukturen (wie des Gegensatzes von Proletariat und Bourgeoisie, Kommunismus-Kapitalismus, ImperialismusDritte Welt) oder eines abstrakten Freund-Feind Prinzips als Essenz des Politischen; er ist überhaupt nur schwer zu fassen mit einer strukturalistischen Sprache. Die Identifikation des Feindes kann wohl eher erfasst werden als eine geistig-psychologische Disposition, die das kollektive Interesse absolut setzt und damit auch Selbstopferung als Dienst an der Sache nicht ausschließt. Die gewalttätige Reinigung der eigenen dogmatisch postulierten Gemeinschaft von Kräften des Bösen entwickelte eine Symbolik, die Feindbilder und das Töten Unschuldiger als eigentliches Lebenselixier der revolutionär begründeten Ordnung einrichten. Statt etablierten Strukturen zu folgen, strukturieren Feindbegriffe die Wirklichkeit durch Handlung.

Die Identifikation des Feindes erfolgt durch symbolische und semantische Grenzziehungen, die weder territorial noch klassenorientiert sind. Ähnlich den vormodernen Formen der Identifikation des Feindes als Anderer, sind die Grenzen als Trennwände der Tugend $^{60} \mathrm{zu}$ sehen, laut denen der Andere als Ungläubiger, als Abweichler von der Orthodoxie gesehen wird. Neben dieser soziopsychologischen Erklärung hat die Begriffsgeschichte eine tiefgründige Erklärung dafür gegeben, warum in Zeiten globaler Konflikte die Schärfe von Feindbegriffen abnimmt und zu einer Verallgemeinerung, wenn nicht Verabsolutierung führt. ${ }^{61}$ Nach Reinhart Koselleck haben semantische Gegenbegriffe seit der Antike wesentlich die Verhältnisse von Wir-Sie, von Freund und Feind, strukturiert. Ausgehend von der originalen semantischen Opposition zwischen Griechen und Barbaren sind trotz zahlreicher verschiedener historischer Erfahrungen und neuen Namen (die Normannen, die Ungarn, die Tataren, die Türken, die Indianer, die Russen, die Deutschen) die Strukturen erhalten geblieben; die Barbaren bleiben trotz unterschiedlicher Namen. Seit der Einführung des Christentums entwickelte sich jedoch ein neuer Feindbegriff, wonach der Nichtchrist der Verdammnis verfällt und nur der Christ Aussicht auf Erlösung 
habe. Der religiös ausgegrenzte Feind wird spiritualisiert und gerät damit in eine Ausweglosigkeit, die der Antike unbekannt war. „Die Aussicht auf Heil und Erlösung, nicht nur Kampf und Unterwerfung, diskriminierten den Feind als Ungläubigen weit radikaler als den nur barbarischen Feind. “62

\section{Schlussfolgerungen}

Was kann der Begriff der politischen Religion zur konzeptuellen Klärung der ambivalenten Verbindung zwischen Religion und Gewalt beitragen? Meine Ausführungen haben sich darauf beschränkt die Identifikation des Feindes als ideologische Waffe, aber auch als rituelle Praxis in revolutionären Herrschaftsordnungen herauszuarbeiten. Revolutionäre Krisen können die „reinigende“ Kraft des Opferkults als zentrales Symbol der dogmatisch durchgesetzten kollektiven Wahrheit etablieren. Der Kult des Opfers ist jedoch nicht als Essenz einer religiösen Doktrin oder als Rückkehr der archaischen Religion zu sehen, sondern erfordert eine historische Anthropologie von Feindbildern.

Aus diesen Überlegungen ergeben sich zwei Schlussfolgerungen. Zum einen gilt es die These von der „Rückkehr der Religion“ zurückzuweisen. Die revolutionären Grundlagen moderner Staatlichkeit im Sowjetkommunismus und im politischen Islam weisen das Religiöse nicht als Fremdkörper in weltlichen Prozessen, sondern als integraler Bestandteil dieser Ordnung aus. Zum anderen sollte religiös motivierte Gewalt nicht einfach als rückständig oder irrational gesehen werden. Die Rechtfertigung des kommunistischen wie auch des islamistischen Terrors durch Hinweis auf den eigenen Opferstatus und die Vergeltung erlittenen Unrechts ist nicht etwa nur Rhetorik, sondern fundamental für die Identitätsbildung für Kämpfer im Namen Gottes. Entgegen allgemeiner Auffassung sind zum Beispiel Aussagen Osama Bin-Ladens über das eigentliche Handlungsmotiv seines Kampfes gegen Ungläubige als Antwort auf erlittenes Unrecht durch Ungläubige äußerst ernst zu nehmen. Er bezog sich nicht nur auf den bitteren Verlust Andalusiens am Ende des 15. Jahrhunderts. ${ }^{63}$ Er verwies auch darauf, dass gerade die aktive Unterstützung 
der israelischen Invasion im Libanon 1982 durch die Vereinigten Staaten ausschlaggebend dafür gewesen ist, in ihm einen mächtigen Drang zur Vergeltung erlittener Erniedrigung der Muslime entstehen zu lassen, ebenso wie eine starke Entschlossenheit, die Aggressoren zu bestrafen. ${ }^{64}$

Die Frage, warum religiöse Begründungen zur Gewalt gegen Unschuldige benutzt werden, kann weder mittels einer Logik von Ursache und Zweck noch mittels eines auf Zukunft gerichteten Determinismus erfasst werden. Wenn, wie Jan Assmann festgestellt hat, politische Theologie sich auf das ständig wechselnde Verhältnis politischer Herrschaft und religiöser Ordnung, zwischen Herrschaft und Heil bezieht, dann produziert die Transzendenz des Immanenten in politischen Religionen eine Logik, die über den staatlichen Rahmen hinaus in ihrer existentiellen und symbolische Dimension begriffen werden muss. ${ }^{65}$ Die weltimmanente Heilserwartungen der bolschewistischen und der islamischen Revolution waren Antwort auf Krisen, die nicht nur politisch, sondern im Sinne von Marcel Mauss eine totale soziale Tatsache waren: sie umfassten politische, gesellschaftliche, psychologische, wirtschaftliche und religiöse Probleme und sind somit als existentiell zu betrachten; als existentielle Krise erforderten sich nicht nur politische, sondern auch geistige Antworten. Obwohl stark gemindert in ihrem Einfluss, bleibt Religion somit vielleicht gerade aufgrund ihrer unbeständigen, ungreifbaren und erratischen Natur eine Größe, die eine maximalen Effekt zeitigen kann. ${ }^{66}$ Dies ist insofern von Bedeutung, als die gängigen Strategien gegen Terror im Namen Gottes - beruhend auf der organisatorisch-militärischen Kapazität von Territorialstaaten und einer Dämonisierung des Feindes - Antworten auf falsch gestellte Fragen zu geben scheinen.

\section{Literatur}

Assmann, Jan (2000): Herrschaft und Heil: Politische Theologie in Altägypten, Israel und Europe. München: Carl Hanser.

Ayubi, Nazih (1993): Political Islam: Religion and Politics in the Arab World. London: Routledge. 
Berger, Peter L. (1967): The Sacred Canopy. Elements of a sociological Theory of Religion. New York: Random House.

Burke, Peter (1979): „Religion and Secularisation”, in Burke, Peter, Hg.: The New Cambridge Modern History, Vol. XIII Companion Volume. Cambridge: Cambridge University Press, 293-317.

Buruma, Ian/Margalit, Avishai (2004): Occidentalism. A Short History of AntiWesternism. London: Atlantic Books.

Cohn, Norman (1970): The Pursuit of the Millenium. Revolutionary Millenarians and Mystical Anarchists of the Middle Ages. London: Pimlico.

Dupuy, Jean-Pierre (2002): Avions-nous oublié le mal? Paris: Bayard.

Gentile, Emilio (2000): „The Sacralisation of Politics: Definitions, Interpretations, and Reflections on the Question of Secular Religions and Totalitarianism", in: Totalitarian Movements and Political Religions 3 (1), 18-55. Girard, René (1992): Das Heilige und die Gewalt. Frankfurt am Main: Fischer. Halm, Heinz (2008): The Shi'ites. A Short History. Princeton, NJ: Markus Wiener Publishers.

Hocart, Artur (1970): Kings and Councillors. An Essay in the Comparative Anatomy of Human Society. Edited and with an introduction by Rodney Needham. Chicago/London: The University of Chicago Press.

Hoffer, Eric (61964): The True Believer. Thoughts on the Nature of Mass Movements. New York: Mentor.

Huntington, Samuel (2006): Kampf der Kulturen: Gestaltung der Weltpolitik im 21. Jabrbundert. München: Goldmann.

Juergensmeyer, Mark (2000): Terror in the Mind of God. The Global Rise of Religious Violence. Berkeley/Los Angeles: University of California Press.

Kharkhordin, Oleg (1999) The Collective and the Individual in Russia: A Study of Practices. Berkeley: University of California Press.

Koestler, Artur (1940): Darkness at Noon. London: Vintage.

Koselleck, Reinhart (2006): Begriffsgeschichten. Frankfurt am Main: Suhrkamp. Lefort, Claude (1986a): Essais sur le politique. Paris: Seuil.

Lefort, Claude (1986b): The Political Forms of Modern Society: Bureaucracy, Democracy, Totalitarianism. Cambridge: Polity.

Lewis, Bernhard (1994): Der Atem Allabs. Die islamische Welt und der WestenKampf der Kulturen? München: dtv.

Lewis, Bernhard (2002): What Went Wrong? Western Impact and Middle Eastern Response. London: Phoenix.

Likhachev, Dmitry (1998): „Religion: Russian Orthodoxy”, in: Rzhevsky, Nicholas, Hg.: The Cambridge Companion to Modern Russia. Cambridge: Cambridge University Press, 38-56.

Malouf, Amin (1998): Les identités meurtrières. Paris: Grasset.

Marx, Karl (1971): Die Frühschriften. Hg. von Siegfried Landshut. Stuttgart: Kröner. 
270 Kontinuitäten und Wandel politischer Religion

Martin, David (2007): „The Religious and the Political”, Vortrag an der Universität Cambridge im Rahmen des Networks „Religion and Secularism“, Dezember 2007.

Mauss, Marcel (2001): Sociologie et Anthropologie. Paris: PUF.

Müller, Johann Baptist (1983): Die Deutschen und Luther. Text zur Geschichte und Wirkung. Stuttgart: Reclam.

Münkler, Herfried (32007): Die neuen Kriege. Reinbek: Rowohlt.

Nasr, Vali (2006): The Shia Revival. How Conflicts within Islam will shape the Future. New York/London: W.W. Norton.

Ozouf, Mona (1988): La fête révolutionnaire, 1789-1799. Paris: Gallimard.

Palaver, Wolfgang (2008): „Im Zeichen des Opfers. Die apokalyptische Verschärfung der Weltlage als Folge des Monotheismus", in Palaver, Wolfgang/Siebenrock, Roman/Regensburger, Dietmar, Hg., Westliche Moderne, Christentum und Islam. Gewalt als Anfrage an monotheistische Religionen. Innsbruck: Innsbruck University Press, 151-176.

Pipes, Richard (21995): Russia under the Old Regime. London: Penguin.

Pizzorno, Alessandro (1987): „Politics Unbound”, in: Maier, Charles S., Hg.: Changing Boundaries of the Political. Cambridge: Cambridge University Press, 27-52.

Popitz, Heinrich (1992): Phänomene der Macht. Tübingen: Mohr.

Riesebrodt, Martin (2007): Cultus und Heilsversprechen. Eine Theorie der Religionen. München: Beck.

Rodenbeck, Max (2006): „Their Master's Voice”, in: The New York Review of Books, 9. März, 4-8.

Roy, Olivier (1998): The Failure of Political Islam. Cambridge, Mass.: Harvard University Press.

Roy, Olivier (2006): Globalized Islam. New York: Columbia University Press.

Salzman, Philip Carl (2008) Culture and Conflict in the Middle East. Amherst: Humanity Books.

Shorten, Robert (2007): „The Status of Ideology in the Return of Political Religion Theory", in: Journal of Political Ideologies 12 (2), 163-187.

Szakolczai, Arpad (2001): „Civilization and Its Sources”, in: International Sociology 16 (3), 369-386.

Szakolczai, Arpad (2003): The Genesis of Modernity. London: Routledge

Tocqueville, Alexis de (1988): L'ancien régime et la révolution. Paris: Flammarion.

Turner, Victor (1967): The Forest of Symbols. Ithaca: Cornell University Press.

Veyne, Paul (2007): Quand notre monde est devenu chrétien (312-394). Paris: Albin Michel.

Voegelin, Eric (1987): The New Science of Politics. An Introduction. Chicago: Chicago University Press.

Voegelin, Eric (31993): Die politischen Religionen. Hg. von Peter J. Opitz. München: Wilhelm Fink. 
De Vries, Hent/Sullivan. Lawrence (2006): Political Theologies. Public Religions in a post-secular world. New York: Fordham University Press.

Weber, Max (1988): Gesammelte Aufsätze zur Religionssoziologie. Vol. 1. Tübingen: Mohr.

Wydra, Harald (2007): Communism and the Emergence of Democracy. Cambridge: Cambridge University Press.

Wydra, Harald (2008a) „Revolution and Democracy: The European Experience“, in: Foran John/Lane, David/Zivkovic, Andreja, Hg., Revolution in the Making of the Modern World. London: Routledge, 27-44.

Wydra, Harald (2008b): „The recurrence of violence”, in: Sociology Compass 2 (1), 183-194. 



\section{Die Herausgeber, Autorinnen und Autoren}

Frank Adloff, seit 2007 Professor für Soziologie am John F. Kennedy-Institut für Nordamerikastudien der FU Berlin. Forschungsschwerpunkte: Philanthropie und Zivilgesellschaft, Religionssoziologie, Wohlfahrtsstaatlichkeit, Gaben- und Reziprozitätstheorie, politische und historische Soziologie.

Emil Brix, 1975-1979 Studium der Geschichte und Anglistik in Wien; seit 1982 im Österreichischen Diplomatischen Dienst; 198689 Leiter des Ministerbüros im Bundesministerium für Wissenschaft und Forschung; 1990-95 Generalkonsul der Republik Österreich in Krakau; 1995-99 Direktor des Österreichischen Kulturinstitutes in London. Derzeit als Botschafter Leiter der Kulturpolitischen Sektion im Bundesministerium für europäische und internationale Angelegenheiten. Seit 1994 stellvertretender Vorsitzender des Instituts für den Donauraum und Mitteleuropa; seit 2000 Generalsekretär der Österreichischen Forschungsgemeinschaft. Ehrendoktorate der Universitäten Drohobytsch/Ukraine (2003) und Cluj-Napoca/Rumänien (2005).

José Casanova, Studium der Philosophie, Soziologie und Theologie in Spanien, Innsbruck und USA; von 1987 bis 2007 Lehre an der New School in New York; zahlreiche Gastprofessuren, seit 2008 Professor für Soziologie und Senior Fellow am Berkeley Center für Religion, Peace and World Affairs an der Georgetown University/Washington D.C. und derzeit Visiting Fellow am Wissenschaftskolleg in Berlin. Forschungsschwerpunkte: Globalisierung und Religion, Migration und ethno-religiöse und kulturelle Diversität, vergleichende Untersuchungen zu Katholizismus, evangelikalem Christentum und Islam. Ausgewählte Publikationen: Religion, Politics and Gender in Catbolicism and Islam (2008), Public Religions in the Modern World (1994). 
Andreas Exenberger, Wirtschaftshistoriker und als solcher wissenschaftlicher Mitarbeiter am Institut für Wirtschaftstheorie, -politik und -geschichte der Universität Innsbruck; Mitglied der Forschungsplattform „Weltordnung - Religion - Gewalt" und der ÖFGArbeitsgemeinschaft „Politik - Religion - Gewalt“. Forschungsschwerpunkte: Globalisierungsgeschichte, Armutsforschung (insbesondere Hunger), politische Ökonomie.

Wilhelm Guggenberger, Studium der Theologie, 1991-2006 Assistent am Institut für Moraltheologie und Gesellschaftslehre bzw. Institut für Systematische Theologie der Universität Innsbruck, seit 2006 Ao. Professor für Christliche Gesellschaftslehre; seit 2007 Leiter des Clusters „Anthropologie und Gewalt“ der interfakultären Forschungsplattform „Weltordnung - Religion - Gewalt" an der Universität Innsbruck. Forschungsschwerpunkte: Anthropologie und Gewalt im Kontext der mimetischen Theorie René Girards, Ethos der Ökonomie.

Gerhard Larcher, Studium der Theologie und der Philosophie in Münster und Löwen, 1978 Promotion (Theologie) in Münster; Wissenschaftlicher Assistent am Institut für Fundamentaltheologie der Universität Bochum; seit 1990 Professor für Fundamentaltheologie an der Universität Graz. Forschungsschwerpunkte: Theorien der Moderne/Modernismusforschung, Französische Religionsphilosophie des 20. Jahrhunderts (besonders Blondel und Ricoeur), Theologie - Kultur - Ästhetik.

Walter Reese-Schäfer, seit 2001 Professor für Politische Theorie und Ideengeschichte an der Universität Göttingen, außerdem Fellow am Kulturwissenschaftlichen Institut Essen. Wichtigste Veröffentlichungen: Grenzgötter der Moral. Der neuere europäisch-amerikanische Diskurs zur politischen Ethik, Frankfurt: Humanities Online, 22007; Aristoteles interkulturell gelesen, Nordhausen 2007; Das überforderte Selbst. Globalisierungsdruck und Verantwortungslast, Hamburg 2007. Forschungsschwerpunkte: Interkulturelle politische Philosophie, Politische Ethik. 
Dietmar Regensburger, Studium der Theologie, Germanistik und Politikwissenschaft; 1991-2003 Assistent am Institut für Systematische Theologie der Universität Innsbruck; seit 2003 Assistent Professor für Systematische Theologie an der Universität Innsbruck; seit 2006 Koordinator der Arbeitsgemeinschaft „Politik - Religion Gewalt" bei der Österreichischen Forschungsgemeinschaft. Forschungsschwerpunkte: Friedens- und Konfliktforschung, mimetische Theorie René Girards, Film \& Theologie.

Harald Stelzer, wissenschaftlicher Mitarbeiter und Lehrbeauftragter am Institut für Philosophie der Universität Graz. Bearbeiter des Projektes des Österreichischen Fonds zur Förderung wissenschaftlicher Forschung „Poppers praktische Philosophie im Licht des Kommunitarismus“, sowie Projektleiter des Projektes „Entwurf einer kritisch-rationalen Ethik“. Forschungsschwerpunkte: Kritischer Rationalismus, Kommunitarismus, Interkulturalität, Wirtschaftsethik.

Kristina Stöckl, Studien der Internationalen Beziehungen an der Central European University in Budapest und der Vergleichenden Literaturwissenschaft und Slawistik an der Universität Innsbruck. Doktorat in Sozial- und Politikwissenschaften am Europäischen Hochschulinstitut Florenz. Seit 2007 Koordinatorin der Forschungsplattform „Weltordnung - Religion - Gewalt“. Forschungsschwerpunkte: Politische Theorie, Sozialphilosophie, Religion und Politik, russische Orthodoxie.

Evert van der Zweerde, Studium der Philosophie und Russistik in Nijmegen, Moskau und Freiburg; 1994 Dissertation, seitdem Dozent für Politische Philosophie an der Radboud Universität in Nijmegen; Forschungskooperation mit dem dortigen Instituut voor Oosters Christendom und dem Centrum voor Ethiek. Veröffentlichungen zu Russischer Philosophie, Zivilgesellschaft, Ideologie, Globalisierung, Orthodoxie, Europäische Integration. Forschungsprojekte: „Repertoires of Democracy“, „Islam \& Democracy“, „Alte Grenzen, Neue Fronten: Die orthodoxen Kirchen und die europäische Integration“. 
Harald Wydra, seit 2003 Fellow am St. Catharine's College/University of Cambridge; seit 2007 Gründungsherausgeber der Online Zeitschrift International Political Anthropology; Publikationen u.a.: Communism and the Emergence of Democracy, Cambridge, 2007; Democracy and Myth in Russia and Eastern Europe (hg. mit Alexander Woll), London, 2008; Forschungsschwerpunkte: Vergleichende Demokratieforschung, Ost- und Mitteleuropastudien, politische Anthropologie, Gesellschaftstheorie. 